Historic, Archive Document

Do not assume content reflects current scientific knowledge, policies, or practices. 



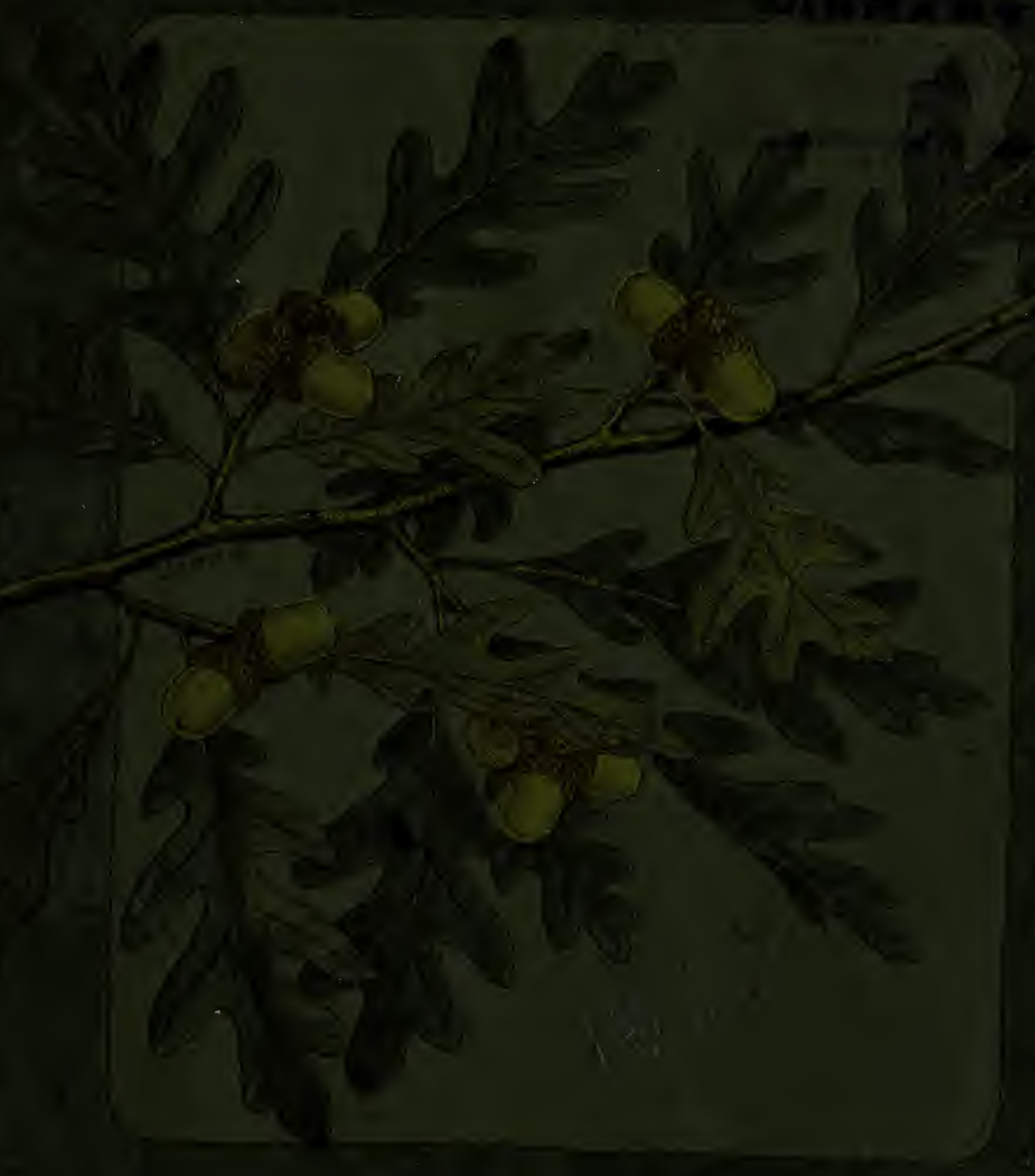

\section{TREES FOR LONG ISLAND \\ ISAAC HTEKS AND SON$$
\text { T.AREE-IAREE MOVERS }
$$

Whatibry Stubion, Nassau CaN.X. . 



\section{WESTBURY NURSERIES}

AND THE

\section{HICKS PATENT TREE-MOVERS}

\section{Isaac Hicks $\&$ Son}

WESTBURY STATION, NASSAU COUNTY, LONG ISLAND, N. Y,

TELEPHONE $76 \mathrm{~W}$

Illustrated by photographs of trees which habe been mobed, and of places most of which were planted with stock from the Westbury Nurseries

\section{PREFACE}

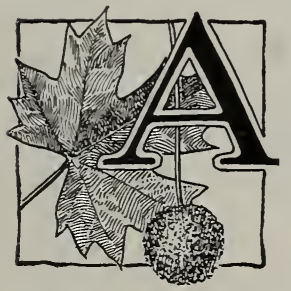

NEW and distinct type of nursery is shown in the Westbury Nurseries in the growing of large trees for immediate landscape results. No establishment in this country or Eurofe grows such a quantity or variety of large trees. The nursery was founded half a century ago, and many of the trees now available for moving were planted in the first decade of the business as specimens, and allowed to attain perfect development. More than twenty-five acres are devoted to the growing of extra-sized trees; the trees being placed 8 to 40 feet apart, permitting ample sunlight, air and soil. The object is not how cheap, but how perfect. A tree 4 inches in diameter, 20 feet high, may be in a close crowded block 2 or 3 feet away from adjoining trees. Neither good roots nor wide top can exist. Our trees are grown wide apart, and such a tree will be 2 feet from its neighbors, with wide, low-branched top and perfect root system. The latter is worth many times the former. These trees will give immediate results. They are not mere promises of future shade and beauty. The large evergreen trees are 8 to 35 feet high, Io to 50 years old, and are kept in perfect condition for transplanting. The usual sizes kept in nurseries, as trees 6 to $\mathrm{I}_{4}$ feet, and evergreens I to 5 feet, we offer of the best possible grade.

\section{Arboretum and Test Orchards.}

Our arboretum and certain nursery blocks contain hundreds of new and rare species of trees from Siberia, Japan, China, Europe and other temperate regions, that are being tested to determine their value here. Extensive test orchards established over sixty years ago by the late Isaac Hicks have proved that many varieties thriving inland are inferior to other sorts here. 
Location. Westbury Nurseries are located on the Jericho turnpike, a continuation of Fulton street, Brooklyn, one mile north of Westbury, on the main line of the Long Island railroad, having eighteen trains daily. We are three miles from Mineola, which has fifty trains per day and a trolley line to Freeport. Public hacks may be obtained at the stations. The good roads of the region add pleasure to a drive to inspect the beautiful flowers and trees. The rare evergreens make a winter visit nearly as interesting as one in spring or summer. Trees selected are reserved until the planting season.

Being centrally located, even trees of large size are quickly delivered by wagon to distant points-as Far Rockaway, Brooklyn, New York, Great Neck, Northport or Islip, and to more distant points by rail.

\section{Planting Season and Large Tree Mobing.}

The method of growing, digging, transporting and planting is more important than the time. With our improved methods we are moving trees, especially evergreens, all the year round. In spring the planting season begins about March I, when frost is out of the ground, and continues until about the middle of May. Shrubs, and some varieties of trees, may be moved the last of May, and later, if a ball of earth is kept on the roots, or if they are kept moist and planted immediately. Thus newly completed houses can have hedges and shrubberies planted about them in midsummer. August and September are favorable times for planting Pine, Spruce, Boxwood, Cedar and other evergreens. In autumn the transplanting of deciduous trees may begin three or four weeks before the leaves fall. Usually, transplanting begins at or before the middle of October, and continues until the middle of December, or later. Besides fall and spring, the moving of deciduous trees may be done any mild day in winter if the ground is not frozen deeply, or if it has been mulched to keep out the frost. In winter large evergreens may be moved to advantage, as our invention saves the feeding roots outside the balls of earth. Some deciduous trees, as Magnolia, Tulip and Liquidambar, prefer spring to autumn. Evergreens without a ball of earth on the roots require spring planting. Early orders and selections are an advantage.

Business Terms. Prices are usually quoted for trees dug and loaded at the tionate to distance and expense. Large trees on a tree-mover are priced according to labor, teams and mover used, or are priced delivered, with or without assistance in planting. Stock shipped will be carefully packed in straw bales or boxes, charged at cost. Delivery to railroad is free, where our responsibility ceases. Accounts will be subject to sight draft sixty days from date of shipment. Unknown correspondents should send satisfactory references or cash with order. Money orders may be obtained for Westbury Station, Nassau county, New York.

Notification of errors in count, etc., should be made promptly, so that they may be corrected. The living of trees depends upon so many conditions of weather and after-care beyond the nurserymen's control, that it is not possible for us to guarantee trees to live after leaving the nursery in good condition, without previous special agreement and price to that effect. We desire that all our patrons should be satisfied, and, if not, we wish to be so informed promptly. No complaints will be considered after fifteen days from delivery. While we exercise great care to keep varieties true to name, in case varieties of fruit, etc., prove not true to name, we will not be held responsible for a greater amount than the original price of the trees. Late in the season we may be out of some varieties of fruit, and we will 
substitute other sizes or varieties similar in time of ripening and quality, unless otherwise ordered. In several villages orders may be left with the florists or gardeners who act as our agents, and who may plant the trees if desired.

\section{Horticultural Questions.}

We offer to answer inquiries as to varieties for special purposes, as seaside or dry-ground planting, for names of trees, wild flowers, shrubs and fruits; for remedies for fungous diseases and insects; for preparation of soil for planting; for fertilizer for special crops and soils; for advice on pruning, grafting or culture; and can usually refer inquirers to books or bulletins on forestry, landscape gardening, botany, entomology, referring to these subjects. In cases where a special investigation is required, a moderate charge is made for reports.

\section{Gardening. Tree-surgery and Preserbation and Pruning of Trees and}

Hedges. For tree planting we furnish competent men and foremen. For pruning Hedges. trees and hedges, spraying, renovating old orchards, preserving and rejuvenating decayed or decrepit trees, repairing the damage of ice storms, or resetting trees blown over by the wind, the equipment of machinery, skilled workmen and intelligent supervision is at the disposal of our patrons.

Photographs. The illustrations in this Catalogue are, with few exceptions, of photographs showing the success of our work.

To aid in solving your landscape and horticultural problems, we can show many photographs.

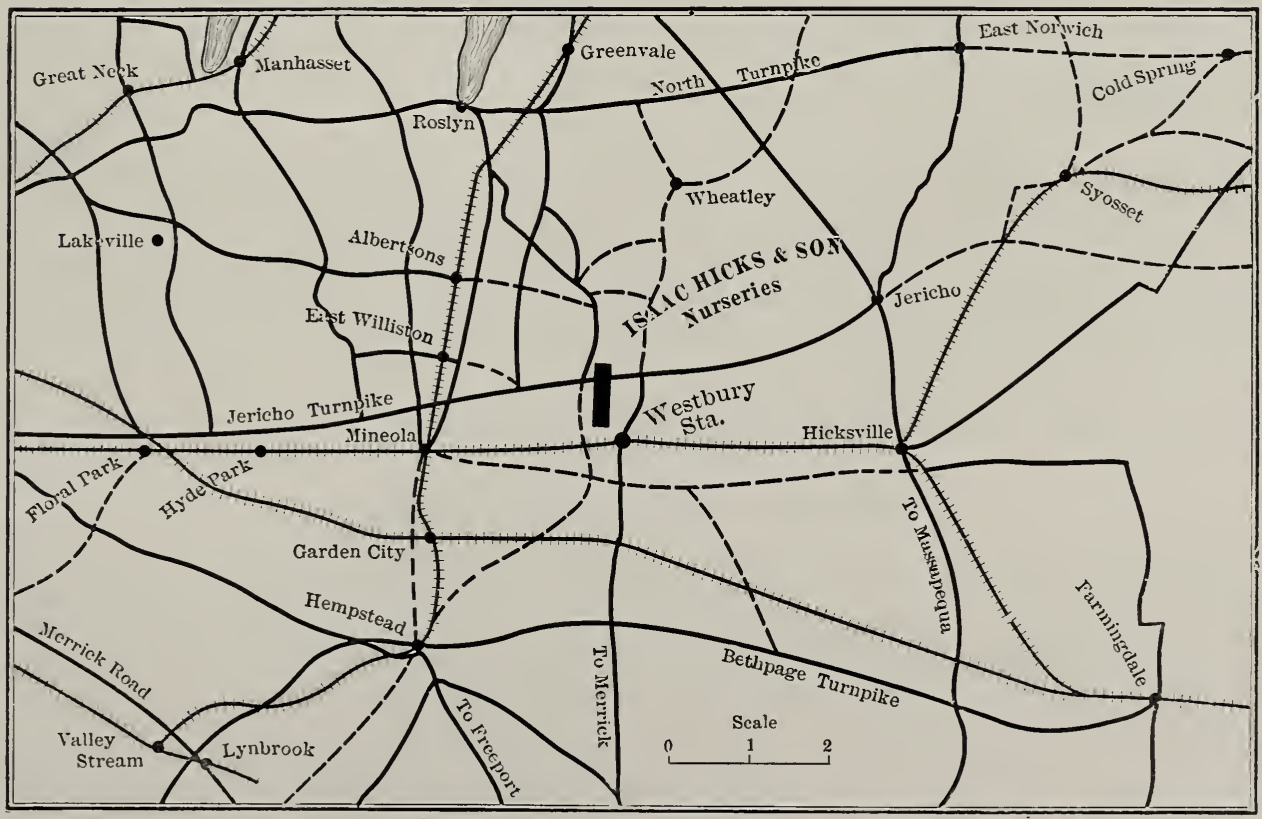

STONE ROADS

DIRT ROADS - - RAILROADS

The above Map will serve as a guide to all who visit our Nurseries. 


\section{Seaside List \\ DECIDUOUS TREES}

Red Cedar,

Austrian Pine,

Scotch Pine,

Indian Currant,
Privet,
Marsh Elder,
Rugosa Rose,
Trailing, or Memorial
Rose,
Carolina Rose,

Carolina Rose,

Virginia Creeper,

Japanese Ivy,

Sea Sand-Reed, or Am-

\begin{abstract}
Sycamore Maple,
Norway Maple,

Red Maple,

Oriental Plane,

Wild Cherry,
\end{abstract}

Japanese Honeysuckle, mophylla,

\author{
Catalpa, \\ Japanese Poplar, \\ Carolina Poplar, \\ Pin Oak, \\ Scarlet Oak,
}

Nulberry

White Birch, Canoe Birch, Euonymus, Ailanthus.

\section{EVERGREEN TREES}

Red Pine,

Mugho Pine,

Juniper,
White Spruce,

Douglas Spruce,

Colorado Spruce,
Norway Spruce, Nordmann's Fir Concolor Fir.

\section{SHRUBS}

$\begin{array}{ll}\text { Sumach, } & \text { Spirea, } \\ \text { Bayberry, } & \text { Blackberry, } \\ \text { Beach Plum, } & \text { Blackcap, } \\ \text { High-bush H u ck le - } & \text { Tamarix, } \\ \text { berry, } & \text { Barberry, } \\ \text { Upright Honeysuckle, } & \text { Elder, } \\ \text { Lilac, } & \text { Alder, }\end{array}$

\section{VINES}

Wistaria, Myrtle,

Trumpet Creeper, Bitter Sweet,

\author{
Buttonbush, \\ Viburmum dentatum, \\ Cormus paniculata, \\ Holly, \\ Inkberry, \\ Yucca, \\ Bearberry.
}

\section{HERBACEOUS PLANTS}

Couch, or Quack Grass, Swamp Rose Mallow, Cactus, etc. Beach Pea,
IVild Morning-Glory, Matrimony Vine.

\section{ACKNOWLEDGEMENTS}

In writing this Catalogue we desire to acknowledge the following authorities:

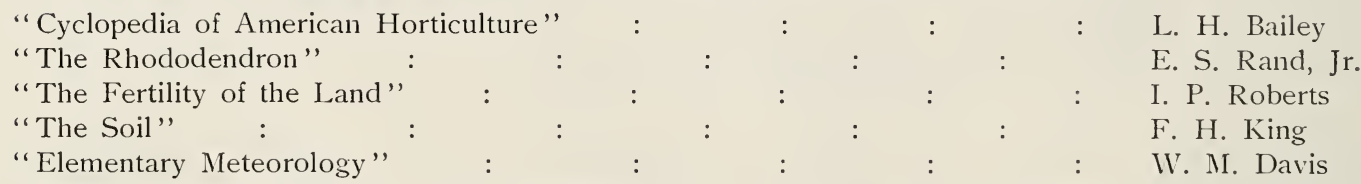

"Pleistocene Geology of portions of Nassau County and Borough of Queens"* J. B. Woodworth

Thanks are also due to Messrs. Veatch and Bowman, of the United States Geologial Survey, who are preparing a report on the geology and water supply of Long Island, in connection with the New York City Water Commissioners; and J. A. Bonsteel, of the United States Department of Agriculture, Division of Soils, who has prepared a map of the soil of Long Island.

*Obtainable of New York State Museum, Albany, N. Y. Price, 25 cents.

\section{ZONES OF PLANT LIFE}

In the distribution of trees according to zones of physical climate, Long Island is in the cold temperate zone of deciduous trees. The boundaries are not closely marked. Deciduous trees predominate in the forest, as oak, beech, birch, maple, elm, poplar, chestnut, dogwood, ash, linden, hickory and tulip tree.

The native evergreens are typical.of the two bordering zones. Holly, inkberry, laurel and rhododendron extend from the warm temperate zone of broad-leaved evergreens; white pine and hemlock extend from the sub-arctic zone of conifers - the cone-bearing trees with evergreen needle-shaped leaves. The warm temperate zone has winter, mostly without severe frost, and from Washington southward is characterized by broad-leaved evergreens, as holly, live-oak and Magnolia grandiflora. The sub-arctic zone, from the Catskill mountains and Maine northward, has winters with nearly continuous freezing, and the forests are mostly fir, spruce and pine. For Long Island, evergreens must be selected from portions of these three zones most closely resembling ours, avoiding mainly those of western coasts with an equable climate, as England and Oregon, and including those of eastern coasts, as this and Japan, and the interiors of the continents, as Colorado and the Caucasus mountains, which have a widely variable climate with extremes similar to ours. See map page 5.

Long Island is fortunate in liaving been, for two centuities, the testing ground of the beautiful trees of the world. Many evergreens need from 50 to Ioo years' test. Plant according to these tests and the scientific knowledge we have made available, and the many mistakes now made to vex the sense of beauty or economy will be avoided. 


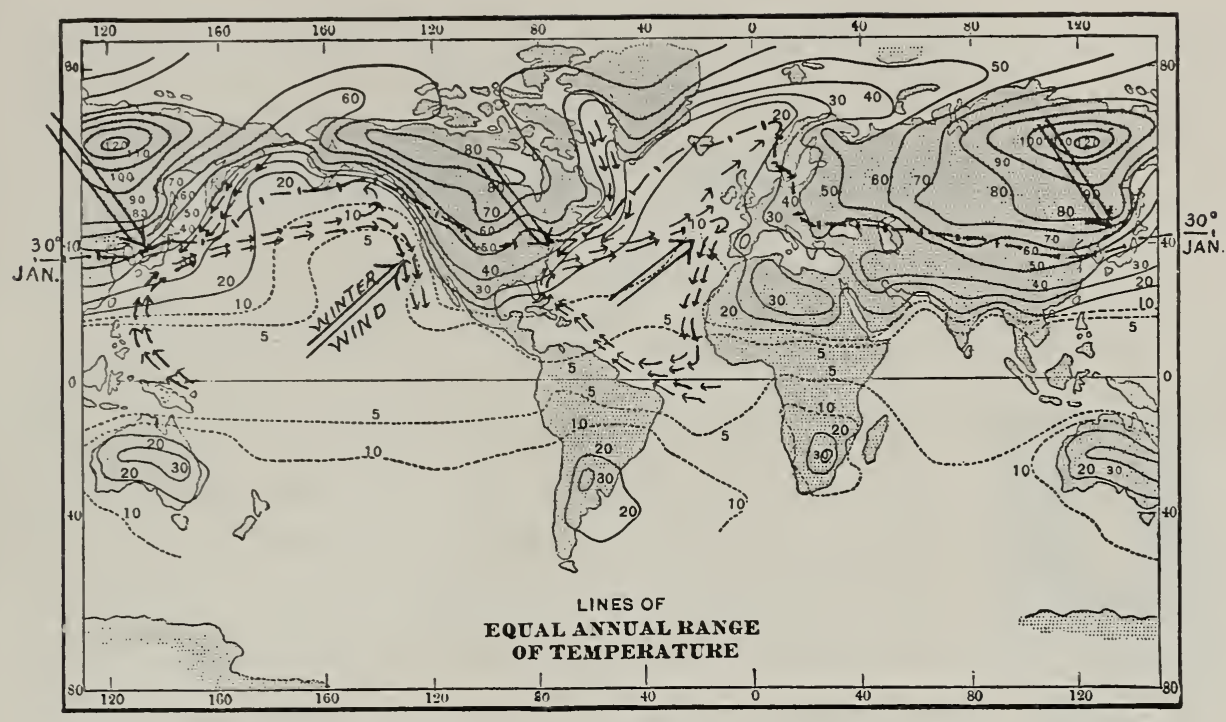

\section{EXPLANATION OF CLIMATE MAP}

Climate map adapted from Meteorology, by Prof. William M. Davis, Harvard. Numbered lines show degrees of difference or annual range between average temperatures of January and July. Line of $40^{\circ}$ goes through Lony Island, Corea, Northern Japan, Caucasus, Austria, Southern Alleghanies, Colorado. $-1,-$ line of arerage January temperature of $30^{\circ} ;$ where this line crosses $40^{\circ}$ or $50^{\circ}$ annual range, the evergreens are generally hardy on Long Island, as we have proved by numerous tests, and we are growing them largely. It means a winter climate, alternately freezing and thawing. The evergreens of western Europe and the Pacific coast of North America are largely grown in nurseries but are not reliably hardy.

Small arrows, cold and warm ocean currents. Large double arrows, prevailing winter wind from warm ocean current to coast of England and Oregon, and from dry cold interior to Long Island, Japan and coast of Manchuria. We have tested about every tree we could buy from temperate regions. Look around Long Island in August, and the European trees are sick; after a hard winter they are damaged. The East Asian species are generally healthy; therefore we are introducing them largely and encouraging plant-introduction and plant-breeding by private enterprise and government.

Long Island is different from the adjacent mainland. It is sand, gravel and hard-pan, with but little solid rock or clay. The climate is different-subject to wider extremes. The flora is different, and an understanding of the reason is essential to right planting. Millions have been lost for lack of this understanding, and, what is worse, the highest use, comfort and beauty is not attained.

The glacier brought the hills. In some parts the hills are hard-pan and hold up stagnant ponds; there the flora is more like the adjacent mainland. In other parts the hills are dry and the flora changes. The outwash plain was formed by rapid streams from the melting glacier. The finest particles were carried to sea, leaving a sieve of sand and gravel. On this the flora is more like that of the sandy coastal plain of southeastern New Jersey. The majority of stock usually grown in nurseries does not fit these dry conditions. Nurseries usually grow trees from damp ground or equable climate, or European trees, as ash, eln, Carolina poplar, willow, arborvitæ, Norway spruce, Spirca opulifolia, because they multiply cheaply, grow rapidly when young, live when carelessly transplanted with short roots, or small ball, or when dried in shipment, and supply the demand for cheap trees that make a good show the first year. We grow trees for dry ground from Long Island seed. Long Island has widely varied conditions, as the soil survey shows. Moisture conditions change in a few yards. The report of the Commission on Additional Water Supply for New York shows that the water table is a controlling factor in tree growth.

The climate of Long Island is strongly influenced by the ocean. At Southampton there are 16 parts of chlorine (salt) per million of fresh water. In the center of the island it is 3 , on the north shore 7 , at Poughkeepsie I. This shows the relative influence of the moist equable ocean winds. Near the sea, California privet thrives ; inland, it may winter-kill ; we have a hardy form from Manchuria. Near the sea, hemlock fails. We have pines and spruces that like salt air. Nany trees from southern seed are tender; from Long Island seed of the same species, they are hardy. Liquidambar, or sweet gum tree, and willowleaf oak from the latitude of Philadelphia winter-kill. It has been customary to use southern seed. We have $1,000,000$ young trees and plants from the seed of Long Island native or acclimated stock, or from regions with climate most like Long Island. Some northern trees do not like our variable winters or hot, dry summers. We are preparing a tree map of part of Long Island, based on the above, and other principles, and on the "Flora of Hempstead Plains and Vicinity," by Henry Hicks. This will show the localities in which various trees fail or thrive, and the reasons.

By using our stock and this knowledge, you can most nearly attain the following results: The least loss from winter-killing, summer drought, insect enemies, fungus, and variable climate; the least expense for watering, cultivating and fertilizing; the greatest per cent of trees living and thriving; save years of waiting ; the greatest height and breadth of thriving large trees, with the greatest amount of healthy foliage for a given expense. 


\section{Landscape Architecture}

HENRY HICKS, Cornell University, College of Agriculture.

Harold Truesdel Patterson, of Harvard School of Landscape Architecture. ARNold P. KOHLER, Civil Engineer.

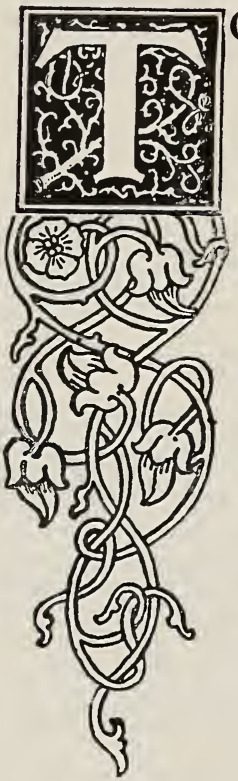

O those desiring landscape advice we offer our services for all classes of artistic work in connection with the landscape development of grounds surrounding private dwellings in city, or suburbs, or country; on new estates, or the renovation of old estates, either large or small; parks, and landscape forestry, and to make detailed reports on special problems in connection with landscape architecture.

The method of procedure necessitates a visit of examination, to determine the proper treatment of the property; as the location and orientation of the house, stable and outbuildings; subdivisions, as lawn, flower and vegetable gardens, service and laundry courts; the courses of the drives and walks; the arrangement of groves of trees and shrubbery for the beauty of form and color in the house picture, in framing distant views, and in screening objectionable features from sight. Plans, specifications, estimates and superintendence of construction are furnished in connection with this work.

It is obviously clear that the Landscape Architect should be employed from the beginning, to give the dwelling the proper relation to views, divisions of the property, necessary approaches, natural drainage and prevailing winds. The house should be placed to fit the ground, and all approaches, divisions and views should be planned for before the house is built. The ideal design makes a single unit or composi- 
tion of the house and all the parts surrounding it; the house fits the grounds; the drives and paths approach correctly; and the various other buildings are arranged to suit the peculiar needs of that particular place. Convenience and beauty are the primary qualities of a good design.

We can lay the foundation of this work for you by submitting plans and advice, for the present and future, for the working out of a definite and tangible ideal toward which all steps may progress.

Landscape forestry as applied to Long Island conditions is the slow and systematic development of the trees in the closely growing, monotonous woods into a diversified and interesting forest of wide-spreading trees, which show the characteristic beauty of their species. This development of the woodland is obtained through judicious selection of the trees to remain as the future forest, and gradually preparing them for changed conditions. These are naturally those kinds best suited to produce the picturesque results suggested by the situation. The aim is to obtain the fullest degree of forest beauty under existing conditions.

There are many excellent residential sites, now shut in and unattractive, which may be developed in three to five years by Landscape Forestry and by clearing the woods for future lawns, vistas and breezeways.

We are prepared to make reports on landscape problems, forestry, seaside planting and horticultural questions.

The fees for these services are reasonable, varying with the classes and conditions of work.

\section{ISAAC HICKS \& SON}

Westbury Station, Long Island, New York 


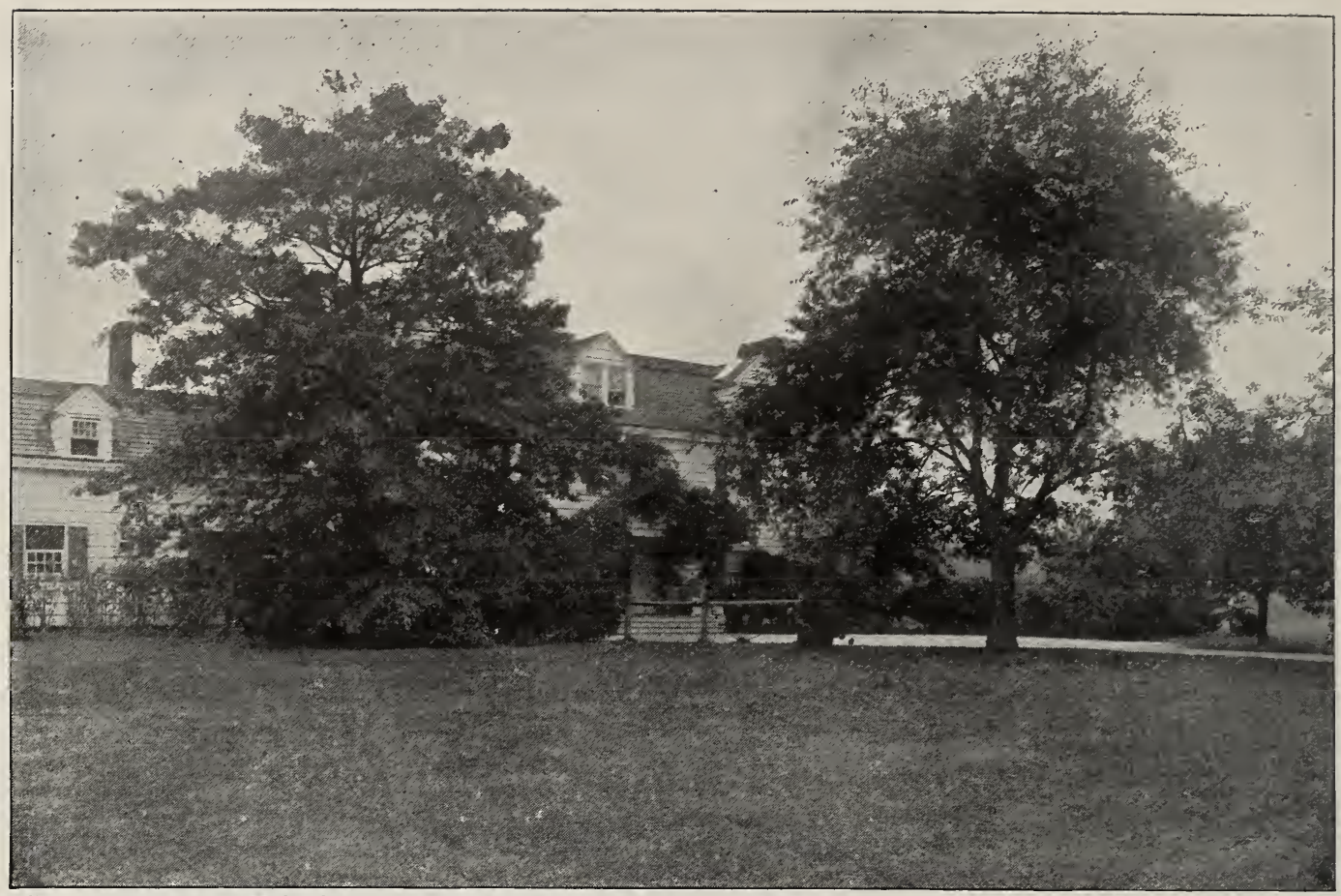

Permanent success results from moving t1ees with Hicks' Patent Tree-Movers. This Pin Oak and Wild Cherry were moved in 1897 , and photograph taken 1905 . They grow at the full normal rate. Residence of John L. Lawrence, Lawrence, L. I.

\section{The Moving of Large Deciduous Trees}

The invention of our Tree-movers in their present perfection is the result of a slow growth. Thirty-five years ago this firm moved trees of large size, some of the first being to the then new arboretum of the late Charles A. Dana, at Dosoris, and others to the village of Garden City, then

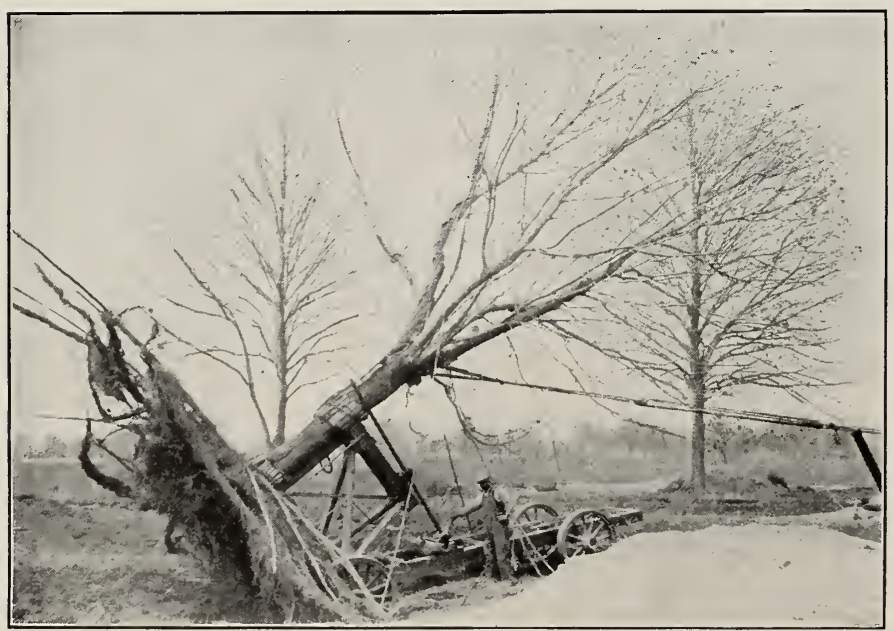

One of the Hicks' Patent Tree-Movers. - We have invented the method of digging which preserves the small feeding roots. The roots have a spread of 30 or 40 feet. After digging, the tree is grasped by the hinged cradle and swung over horizontally by a screw. In this position trees may pass under electric wires. being built on the treeless prairie of the Hempstead Plains.

We have made a vast improvement as regards the size of tree which can be moved, and in the economy and safety of the method. The far-famed stone roads of Long Island have been an important factor in the development of treemoving, aiding in transporting such heavy weights twenty to fifty miles.

The moving of a tree is a surgical operation. The small roots are its feeders; in moving they are disconnected from the original site and re-established. The moving requires expert and careful operators to pick out the small roots of the tree. From these small roots branch out the root-hairs and rootlets which gather up the food and water.

After the outer feeding-roots are freed the tree is undermined and the central ball of earth, 7 to I2 feet in diameter, cleaved from the subsoil. This central ball of earth contains mainly the large 
roots, which act as pipes to carry the sap, and as braces. This ball contains only i5 to 25 per cent of the feeding-roots, while with our method the full circle, 30 to 40 feet in diameter, is preserved. While some large trees may live a few years, or gradually recover, the method of moring with only 15 to 25 per cent of the roots is not to be recommended.

The operation of loading a large deciduous tree, as a Maple or Linden, on a HICKS PATENT TREE-MOVER, is to swing the cradle forward till it touches the trunk, which is attached so as to

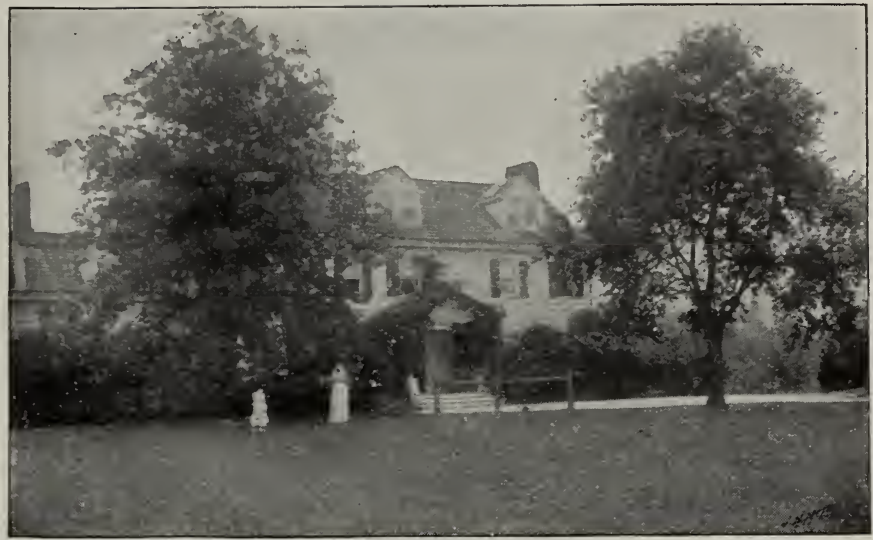

The same trees as shown on opposite page, four years after planting avoid injury to the bark. The tree is picked up and laid over on its side by the screw and tackle. The front of the cradle is inclined, to carry the weight over the front axle. The roots on the under side are tied up under the mover, there being no danger of breaking them by swinging of the axle, for the axle is stationary and the wheels are on pirots. The roots are parted for the pole and seat to be inserted, and the tree starts upon its journey.

When the roots are to be out of the ground for some time they are wrapped, to prevent drying.

In planting, the operation of loading is reversed and the roots replaced in the earth in their natural position. Great care is necessary to get the roots properly enclosed in soil and at the right depth below the surface.

While nature generally supplies food and moisture, additional amounts judiciously applied result in rapid, dense growth. An overdose of food and water may have injurious results in causing the ground to sour and the roots to decay. The ground should be moist, but not wet and sodden with

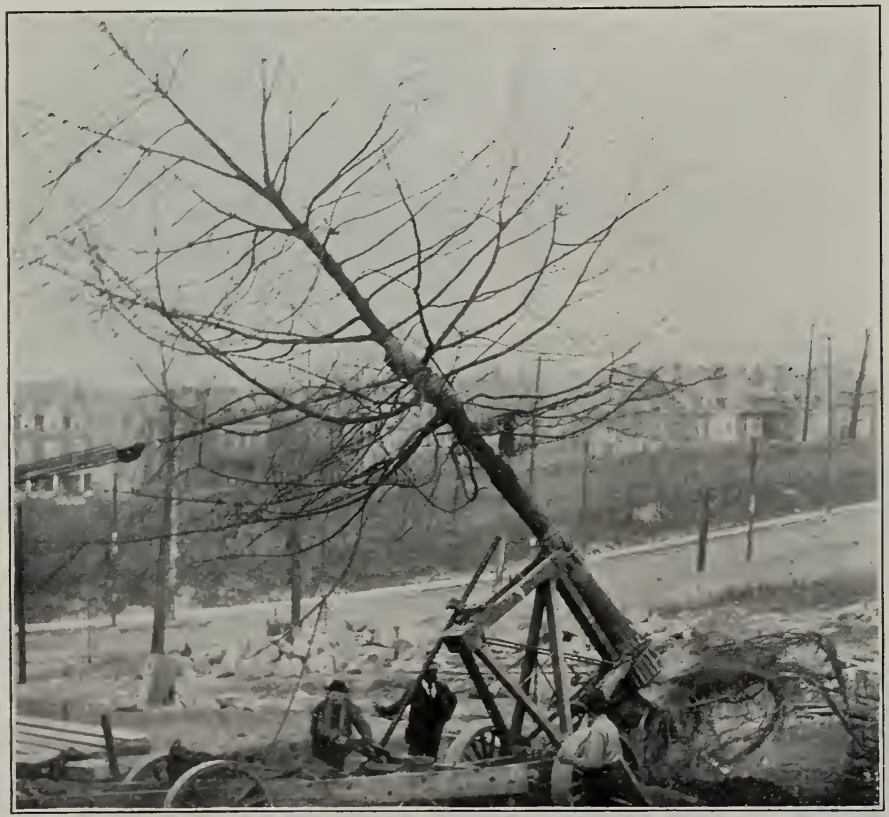

Moving large trees from the site of the new Carnegie Institute in Pittshurg to the lawn of Mr. IV. L. Mellon, in the same city. water. Air should fill the soil spaces. Under-draining in heavy soils is advisable. Watering with one inch of water once a week during a dry season, and conserving the moisture by a mulch of four inches of strawy manure, or hoeing to keep the surface soil loose, is best. After the roots get to work in summer, and in succeeding years, additional food supplies should be given. In short, the most farorable conditions are those of a successful potato field or flower bed.

We have now reduced the moving of large trees to a science, with more certain results than with small trees.

Tree-movers sent anywhere with crews of expert men and portable house. We will look up suitable trees within forty miles of any point and submit photographic report of cost of moving, and of preparing if necessary.

To demonstrate the success of our methods we offer to plan a trip and show some of the 2,000 trees moved with our twelve Treemovers of various types. 


\section{The Moving of Large Evergreen Trees}

The moving of large evergreen trees requires a somewhat different method, owing to the fact that their foliage is constantly calling on the roots for moisture, and therefore a large proportion of

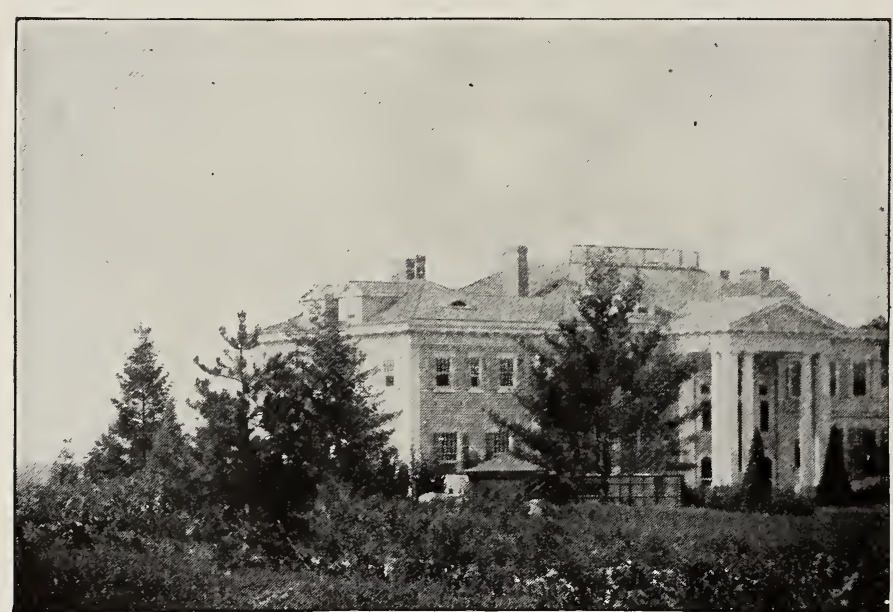

Residence of Mr. Walter G. Oakman, Roslyn, L. I. The Hicks system is the only one that preserves the fine feeding roots outside the ball of earth. the roots should be in undisturbed contact with the soil.

The resinous sap of the roots is hardened if the roots are exposed for a few hours, and does not readily circulate again. The roots of a deciduous tree are not injured nearly as quickly by exposure to the air, and it is not necessary to keep them in contact with the soil. The methods we have invented safely hold the mass of earth solid even when the soil is of gravel and easily broken. The outer feeding-roots are preserved and not exposed to the air.

While it is not possible to move an evergreen 50 feet high with as small expense as a maple, still trees 20 to 35 feet are economically and safely moved, and many hundred large evergreens we have moved demonstrate the success of our method.

The series of photographs inadequately portrays achievements in producing landscape beauty heretofore believed impossible. The painter, sculptor, architect and musician attain results on the completion of their work. The landscape architect may now do the same, instead of waiting fifteen to fifty years. One of the most difficult tasks in composing a landscape is to screen adjacent houses, stables, roads and other objectionable features. This may be done by planting large trees, and then the balance of the landscape and water views often compose themselves into most satisfactory form. This problem of screening adjacent property has thus been most happily solved in the many colonies of country residences on the shores of Long Island, avoiding the vexatious

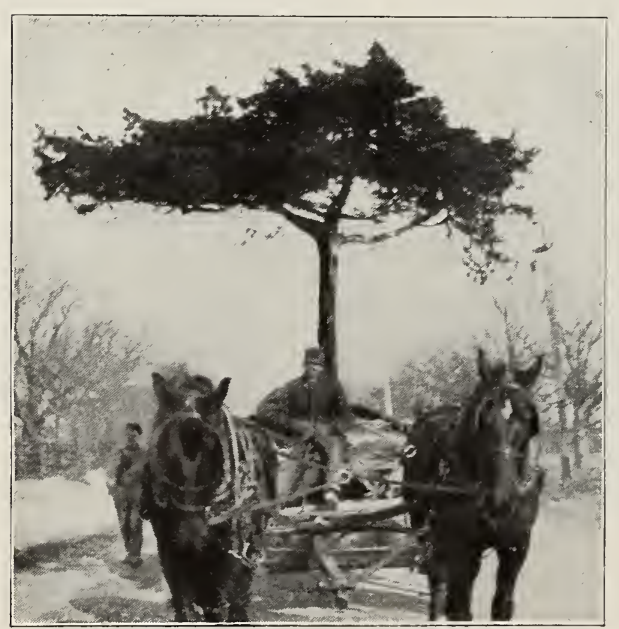

A picturesque Japanese effect. Cedar being moved for Mr. Robert L. Stevens.

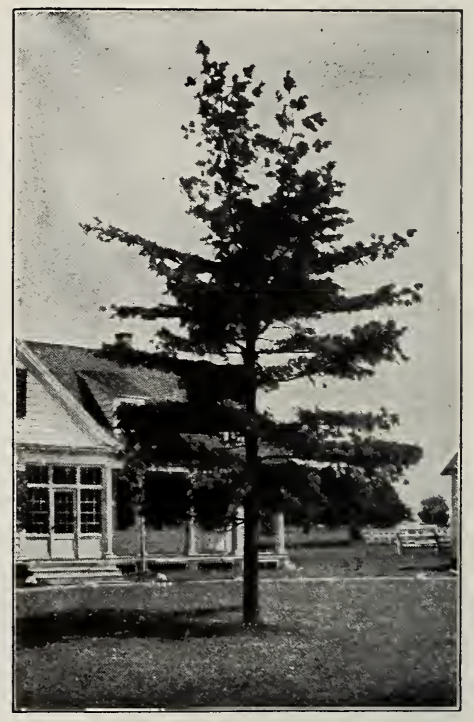

Large White Pine moved for Mr. F. Ambrose Clark. This tree has been moved three times on Hicks' Mover No. 13, without being checked in growth. home.

A windbreak of Pine, Spruce, Cedar and other evergreens on the north side of a residence, terrace, formal garden or lawn, render possible out-of-door life on bleak, cold and windy winter days.

The demand for large evergreens to embellish formal gardens and give a mature and finished appearance has led to our training them in symmetrical form for vistas, terraces and decoration of old-fashioned gardens. 


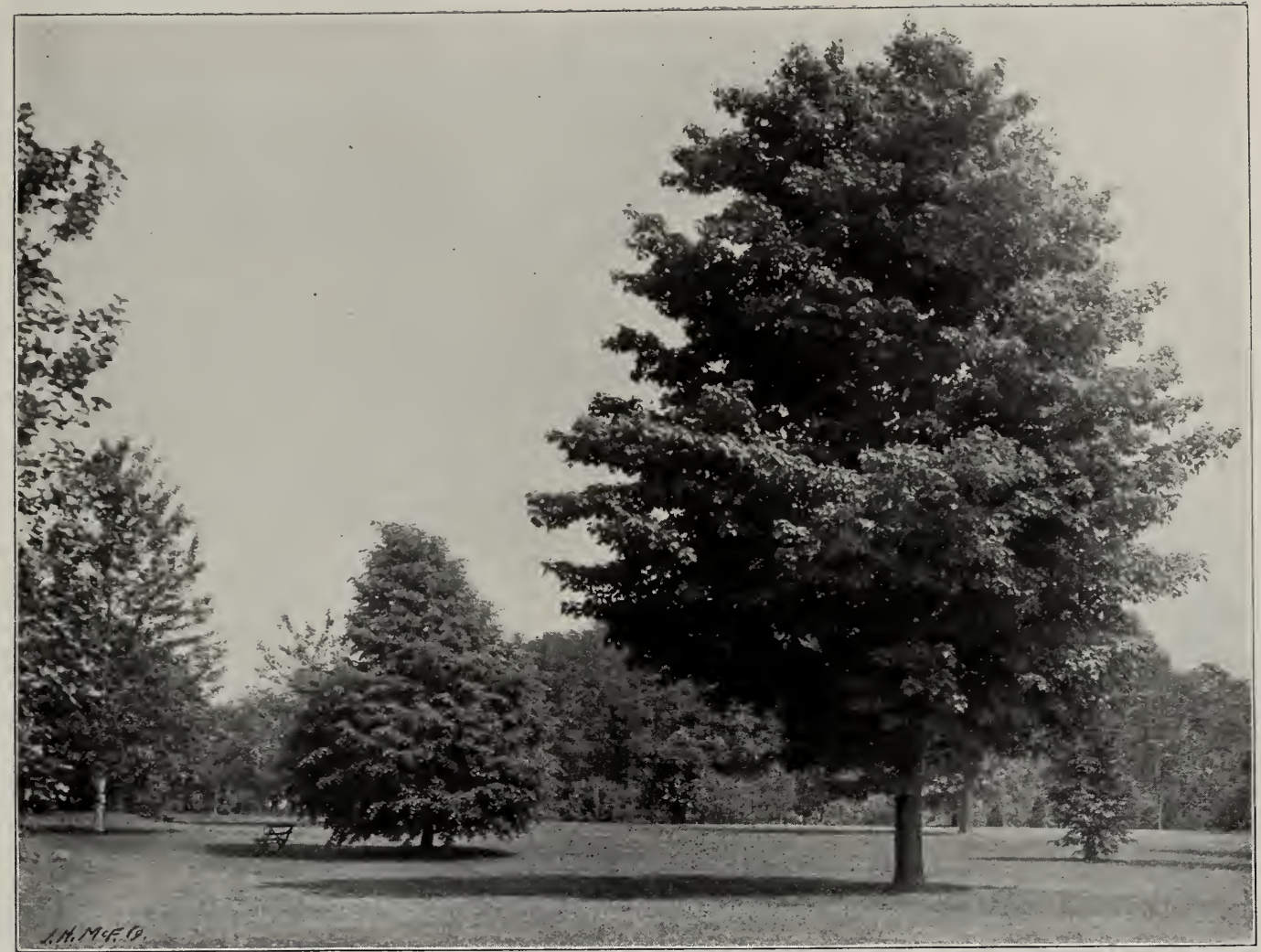

Large trees moved to the lawn of Mr. Edmund Wetmore, Glen Cove, in 1893 , demonstrating the fine growth of the trees. Sugar Maple on the right, small-leaf European Linden in the center, and Japanese Poplar on the left.

\section{Deciduous Trees}

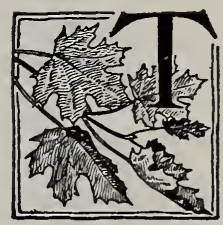

HE ornamental shade trees that we recommend for their landscape value as fine lawn specimens and avenue trees are the Beech, Catalpa, Elm, Linden, Liquidambar, Maple, Oak, Poplar and Tulip. Most of these are available to our patrons in sizes ranging from the ordinary nursery tree of 6 to 14 feet, to specimens up to 40 feet or more in height and 30 feet spread of branches.

Having the advantage of soil that causes a tree to produce a compact mass of fibrous roots and giving them special culture, the large trees we offer are in perfect condition for successful transplanting.

We invite a personal inspection of our blocks of large trees, especially during the summer, to make selections that will be reserved till the planting season.

For extensive street planting we call attention to the Norway and Silver Maples.

In the following pages it is our aim to so describe the different trees that the purchaser may readily decide upon the best trees for his purpose, considering climate, fertility and moisture of the soil, and exposure.

The system of nomenclature is to give the common or English name whenever that is best known, followed by the Latin or botanical name as given in the Cyclopedia of American Horticulture, and such botanical synonyms as have been in recent use.

We have developed a method of producing numerous fine flexible feeding-roots close to the stem, and a method of digging and carrying which preserves them. For shipment by rail we offer trees thus prepared, up to 35 feet high, loaded on open cars and boxed over.

Price, 50 cts. to $\$ 1$ each, and upward. Trees of extra size and quality, $\$ 1$ to $\$ 3$ each, and upward. Quick-growing trees, such as Silver Maple, Catalpa and Poplar, 20 to $50 \mathrm{cts}$. each. Prices are subject to change according to quality, size and quantity. 


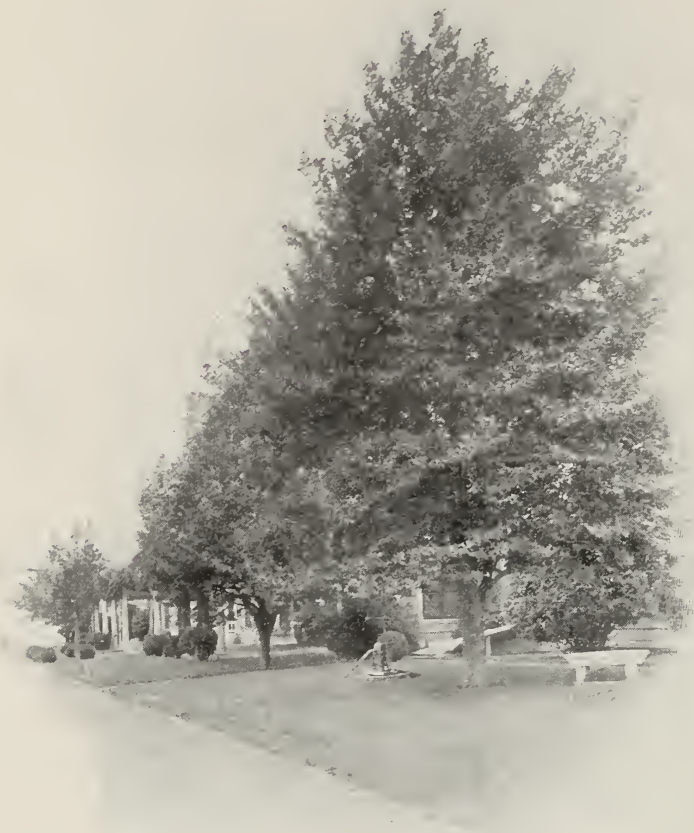

English Beech moved to terrace at "Wheatlands," the estate of Mr. E. D. Morgan, Wheatley Hills, L.I. In the distance a large Hornbeam.

\section{ANDROMEDA. Sorrel Tree}

A. arborea. A small tree, growing to the size of the Dogwood, and characteristically Japanese in its aspect. In July it has graceful outreaching sprays of flowers resembling lily-of-the-valley. During the summer many carmine leaves give hint of the glorious autumn color it is to assume.

\section{APPLE. Pyrus}

Bechtel's Double-flowering. P. Ioensis, var. Bechtel. A small bush-like tree bearing double pink flowers resembling Hermosa roses.

\section{ASH. Fraxinus}

White. F. Americana. The Ash is a tall pyramidal tree requiring heavy or moist soil. The foliage starts late and falls early.

\section{BEECH. Fagus}

The Beech is one of nature's noblemen. Strength without roughness, dignity with grace, cleanliness and delicacy are combined as in no other tree. For a lover of trees to come upon a grove of Peeches in the forest is like finding pearls on the shore. Like many trees attaining great age, it grows slowly the first two years after transplanting, establishing first a wide and deep foundation of roots. At transplanting time it needs close pruning. Beeches grow under the shade of other trees in the forest. We offer specimens of American, English and Purple Beech of large size.

English, or European. $F$. sylvatica. Is distinguished from the American by having smaller leaves of darker green color, and in winter they are russet-brown, while the American Beech's leaves in the winter fade to a straw color. It is perfectly at home in the eastern United States, growing vigcrously to old age.

Purple, or Copper. F. syliatica, var. purpurea. This variety has dark purple foliage in early summer, changing to dark green later. It is frequently called the Copper Beech.

Rivers' Purple. F. sylvatica, var. purpurea Riversii. It has larger leaves than the last and is more graceful in the curves of its branches. The color is deeper and maintained longer during the season. A large tree of this species is a most striking object in the landscape.

Weeping Purple. F. sylvatica, var. purpurea pendula. A new variety of weeping habit.
Weeping. F. sylvatica, var. pendula. A tree attaining a height and width of 40 feet or more. Its masses of foliage hang like the spray of a cataract, plunging from rock to rock in its descent.

Fern-Leaf. F. sylvatica, var. hetcrophylla. This is a gem among trees. Its delicate gracefulness may be compared to the maidenhair fern. It is harmonious with other foliage, and the spirited outline of its spray against the sky constitutes one of its principal charms. Many of the old estates of Newport cherish this variety as the prize of the lawn.

American. F. ferruginea. This species would be used, as it deserves to be, in great quantities, but for the fact that its growth, while young, is comparatively slow. This fact, however, produces an advantage over many more rapid-growing species in its longer life. It may be depended upon to grow from $\mathrm{I} / 2$ to 2 feet per year.

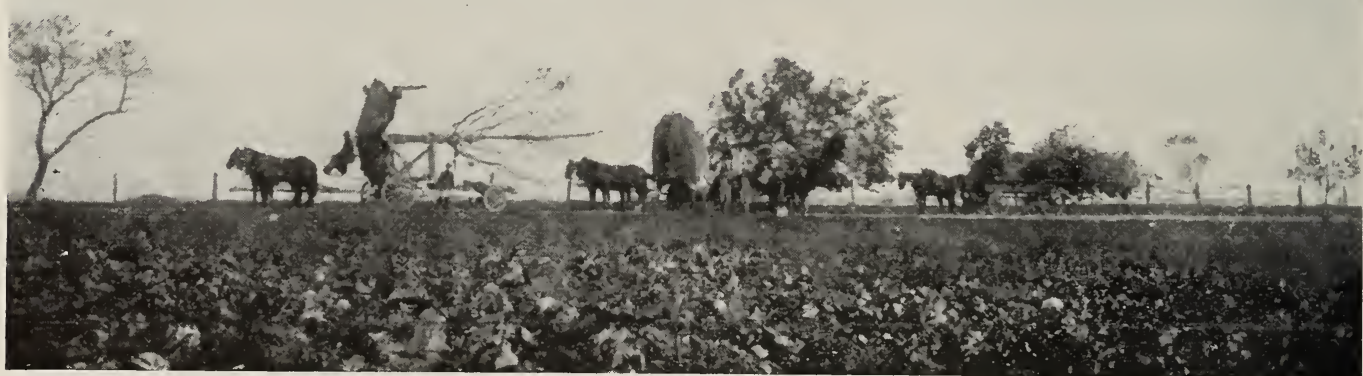

Delivering trees to Mr. William K. Vanderbilt, Jr. The second tree has the roots bent down and wrapped; the leaves are to be stripped off when planted in early October. 


\section{BIRCH. Betula}

The Birch family contains some indispensable elements of landscape decoration, among which the White and Canoe Birches stand preëminent. Gracefulness is the predominant characteristic. They transplant readily; adapt themselves to soil both wet and dry, fertile and impoverished. Members of the Birch family are nature's pioneers in establishing forests on impoverished soil. It has won the admiration of poets and artists. Scott has called it "the lady of the woods."

European White. $B$. alba. The most commonly known species and extensively planted in cultivated grounds; usually growing with a straight, slender trunk clothed with white bark. We have low-branched specimens 30 feet high.

Cut-Leaf Weeping. $\quad B$. alba, var. pendula laciniata. This is one of the most beautiful and graceful of all trees, especially in the fern-like arching sprays. Unfortunately it sometimes loses its lower branches in this region.

American White. B. populifolia. This is the species native to Long Island, growing freely in sandy and poor soil. It has one or several graceful white trunks. Large specimens can be supplied.

Canoe, or Paper. B. papyrifera. This is a large, strong tree. The pure white bark was used by the Indians for canoes. The leaves are broader than those of the other white Birches. We can recommend it for general planting.

Cherry, Sweet, or Black. B. lenta. The bark of this species is like that of a young cherry tree, of a reddish brown and smooth. It forms a tall, broad-spreading tree of vigorous health. The twigs have a pleasant aromatic flavor.

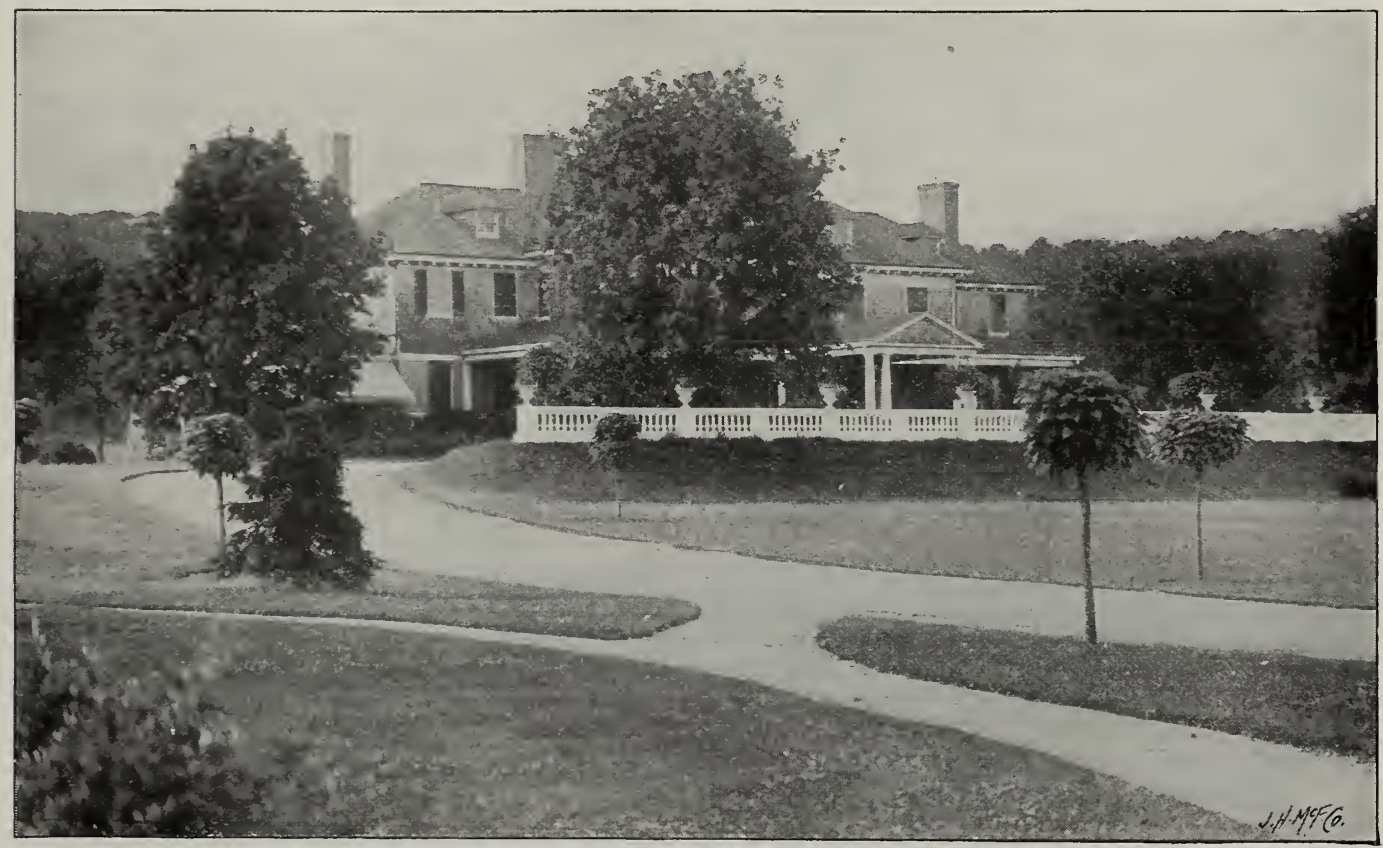

Large Norway Maples moved by Hicks Patent Tree-Mover to the residence of the late Charles Albert Stevens, Wheatley Hills; L. I. We can supply trees of this type for immediate effect. Catalpa Bungei in the foreground.

\section{CATALPA}

Western. C. speciosa. This is a rapid-growing, upright tree with very large leaves. In July it bears flowers in clusters a foot wide, more showy than the horse-chestnut. Its sturdy, healthy and handsome appearance even near the ocean has won it many friends. It has no bad habits and is superior to the Southern Catalpa formerly planted. The foliage appears late. We offer large specimens up to 30 feet high.

C. Bungei. C. bignonioides, var. nana. BAY TREE FORM. In formal gardens and on terraces the standard form combines as well with architecture as the Bay Tree. It has a compact, globular head, maintaining its form even under unfavorable conditions. It grows vigorously two feet per year. On a small lawn a pair may be appropriately placed on either side of a path or at a gate. Having devised a new system of training standards, we have the best possible quality of this and other standards, as Privet, Boxwood, Cedar, Laurel, Nillow, etc.

SHRub Form. Suitable for seaside shrubberies. Described under Shrubs.

\section{CERCIDIPHYLLUM. Kadsura Tree}

C. Japonicum. A new Japanese tree of large size, similar in form to our tulip tree. The leaves are-small, and, when starting from the bud, are a translucent pink, and as pretty as a spray of flowers. 


\section{CHERRY. Prunus}

Double-flowering Japanese. P. Pseudo-Cerasus, var. Sieboldi. The double flowers are pink and white, with fimbriated edges, and make a beautiful display in spring.

Japanese Weeping Rose-flowered. P. pendula. The single pink flowers are in such profusion on the graceful, pendent branches that they give the appearance of a pink mist or veil thrown over the tree in early spring. It is a decided acquisition to our flowering trees and produces a handsome effect on the lawn.

Wild Black. $P$. serotina. In searching for a tree which will grow upon the sand dunes and meadow edges of the south side of Long Island, this tree has been found of high value. It grows there vigorously, forming a noble broad tree with foliage glossy and healthy, rivaling the privet. The fruit is like a small bunch of grapes and is used medicinally. In the interior of the island it grows to a troublesome extent along the fences.

\section{CHESTNUT. Castanea}

American. C. Americana. In the open the Chestnut quickly develops the same appearance as the noble and wide-spreading English or white oak. It should be used not only on lawns, but for park planting and in fields and pastures. In the forest each Chestnut crown stands out distinctly in July, covered with cream-colored tassels. For the large fruiting varieties, see Nut Trees.

Spanish. C. savita. The Spanish Chestnut, some varieties of which are hardy, is a tree of similar appearance to the American. The nuts, especially of the improved varieties, are much larger.

Attempts to cultivate it here illustrate the importance of getting hardy varieties, for many either die when young, or in old age look unhappy.

\section{CHESTNUT, continued}

Japanese. C. crenata. As a lawn ornament this species takes high rank and may be considered intermediate between a tree and a shrub, for while young it branches close to the ground and forms a round-headed mass of handsome foliage. The fruit is $I$ to 2 inches in diameter and borne often the first year after planting. Not so sweet in flavor as the American Chestnut.

\section{CYPRESS. Taxodium}

Deciduous. $T$. distichum. It is a pyramidal tree of fleecy light green foliage. Its conical spiry top and the contrast in foliage to all other deciduous trees call for its occasional use. In appearance it resembles the larch, another member of the Pine family which drops its leaves.

Chinese Weeping. T. distichum, var. Imbricarium; syn., Glyptostrobus Sinensis. A narrow fastigiate form, having a landscape value similar to the Lombardy poplar.

\section{DOGWOOD. Cornus}

Flowering. C. florida. This is the most showy native flowering tree. In the shadowy recesses of the forest the flowers appear as if floating in the air. As a lawn tree it rivals the Magnolias, flowering, like them, before the leaves appear. During the summer it maintains in all situations healthful dense foliage. With the sumach and woodbine it is the first to assume brilliant autumn colors. The clusters of large coral red berries attract the robins on their southward migration. The Dogwood is a tree to be extensively planted on the lawn in the rear of shrubbery, and in groves of large trees. Its ultimate height is about 20 feet, with an equal spread.

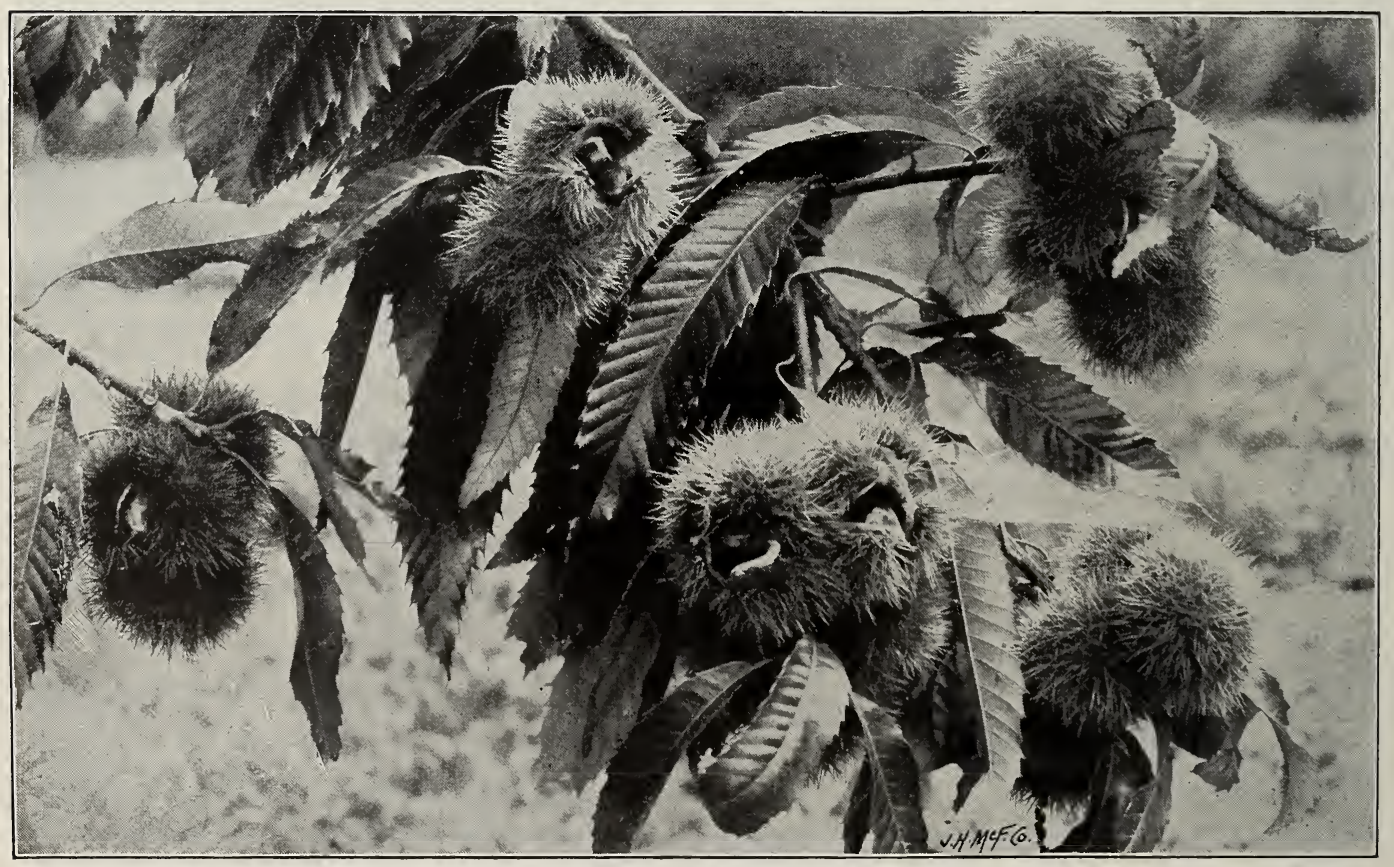

Chestnut trees are quick-growing, broad-spreading, noble trees. We have thousands of little trees from Long Island seed. There is no advantage in waiting till they are larger. Plant some now among the shrubbery and elsewhere. 


\section{DOGWOOD, continued}

Red-flowering. Cormus florida, var. rubra. This beautiful and comparatively rare variety has bright pink flowers.

Japanese. C. Kousa. This differs from the flowerir $\mathrm{g}$ Dogwood in having long-pointed petals forminy a star-shaped flower, and blooming about a month later, in June. It is a new and distinct tree worthy of planting. (See illustration.)

Variegated. C. macrophylla, var. variegata. A white-foliaged plant from Japan which maintains its color without becoming browned by the sun.

\section{ELM. Ulmus}

American. $U$. Americana. The Elm has contributed more to the landscape beauty of New England than any other tree. Its branches gracefully rise from the trunk with the lofty sweep of the gothic arch. At E st Hampton, Merrick, Glen Cove and many parts of the north shore the lofty height and wide curve of the branches attest that the soil and moisture supply make it perfectly at home. In some portions it fails to develop its fullest beauty, and should not, therefore, be extensively planted. In these regions many of the oaks and Norway maples do thrive. The destructive elm-leaf beetle has been nearly exterminated by a fungous disease, thus illustrating the balance of nature.

Weeping. U. Americana, var. pendula. This has an open crown of wide arching branches. The tracery against the sky is graceful and cheerful, recommending it for grouping with other trees. It is a more beautiful change from the monotony of round-headed trees than the Lombardy poplar, and is much planted for that purpose. We offer trees 25 feet wide.

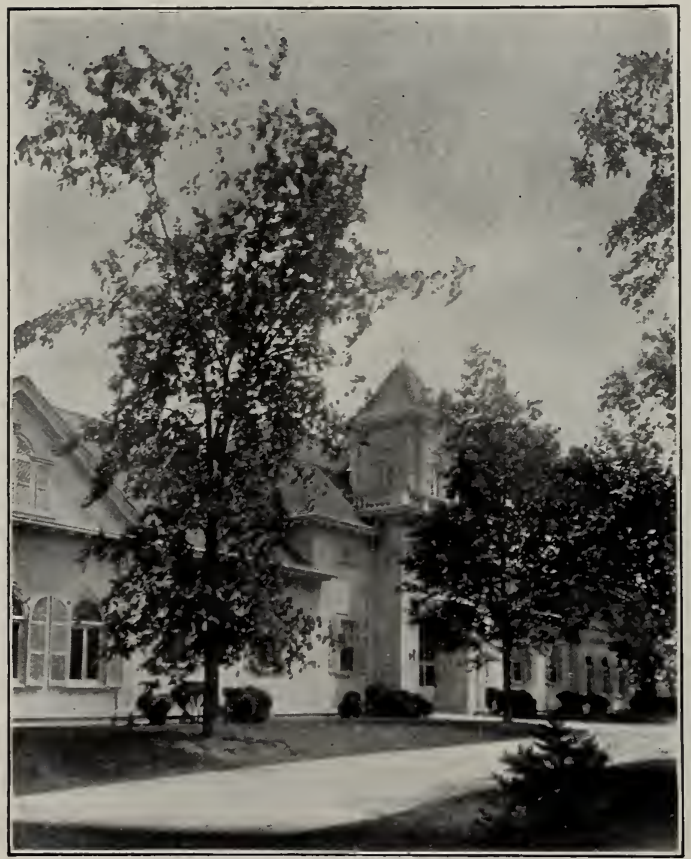

Elm and Sugar Maple by the stable at "Meudon," planted two years ago.

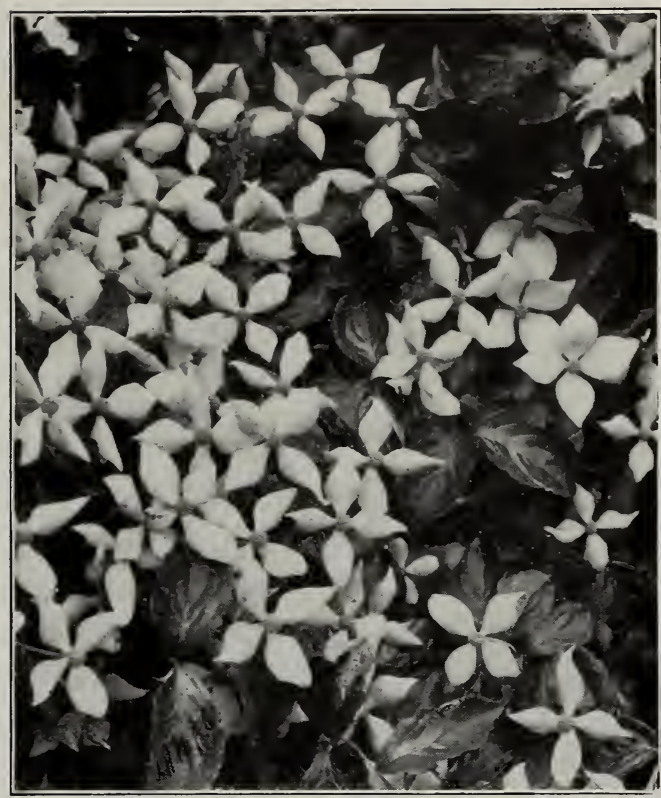

Japanese Dogwood. We offer an opportunity to get this very rare tree, and the most beautiful of its season.

\section{GINKGO}

G. biloba ; syn., Salisburia adiantifolia. Maidenhair Tree. The Ginkgo stands out distinct from all other trees. The trunk, like its relatives in the pine family, is a gracefully tapering shaft. At a uniform ascending angle the widely spaced upper branches stand out against the sky. When old, its tall, massive trunk, its limbs in graceful curves, and its golden autumn foliage, make it a splendid and impressive object. It is a tree to plant for posterity, though it is rapid in growth. The Ginkgo's nearest relatives are fossils in the coal. It would have become extinct several centuries ago except for its preservation in the Japanese temple gardens, where trees a thousand years old are growing. Its insect and fungous enemies appear to have been left behind, for it has an entirely healthy growth even in cities.

\section{HICKORY. Hicoria; syn., Carya}

In this part of Long Island the Hickory as a tree standing alone in the field takes the place of the Elm in New England. To plant a tree to be valued by future generations is a worthy aim, well filled by the Hickory, White Oak or White Pine. They should be transplanted when small, and after becoming established will grow two feet per year.

Mockernut. $H$. tomentosa. A variety thriving on the poorest soils.

Shagbark. H. ovata; syn., H. alba. The best variety for fruit.

\section{HORNBEAM. Carpinus}

European. C. Betulus. This is a close relative of the beech, resembling it in bark and foliage. In England it is used for hedges, and grows so strong and thick that a person can stand on its top. It is a healthy and handsome tree of compact rounded form. 


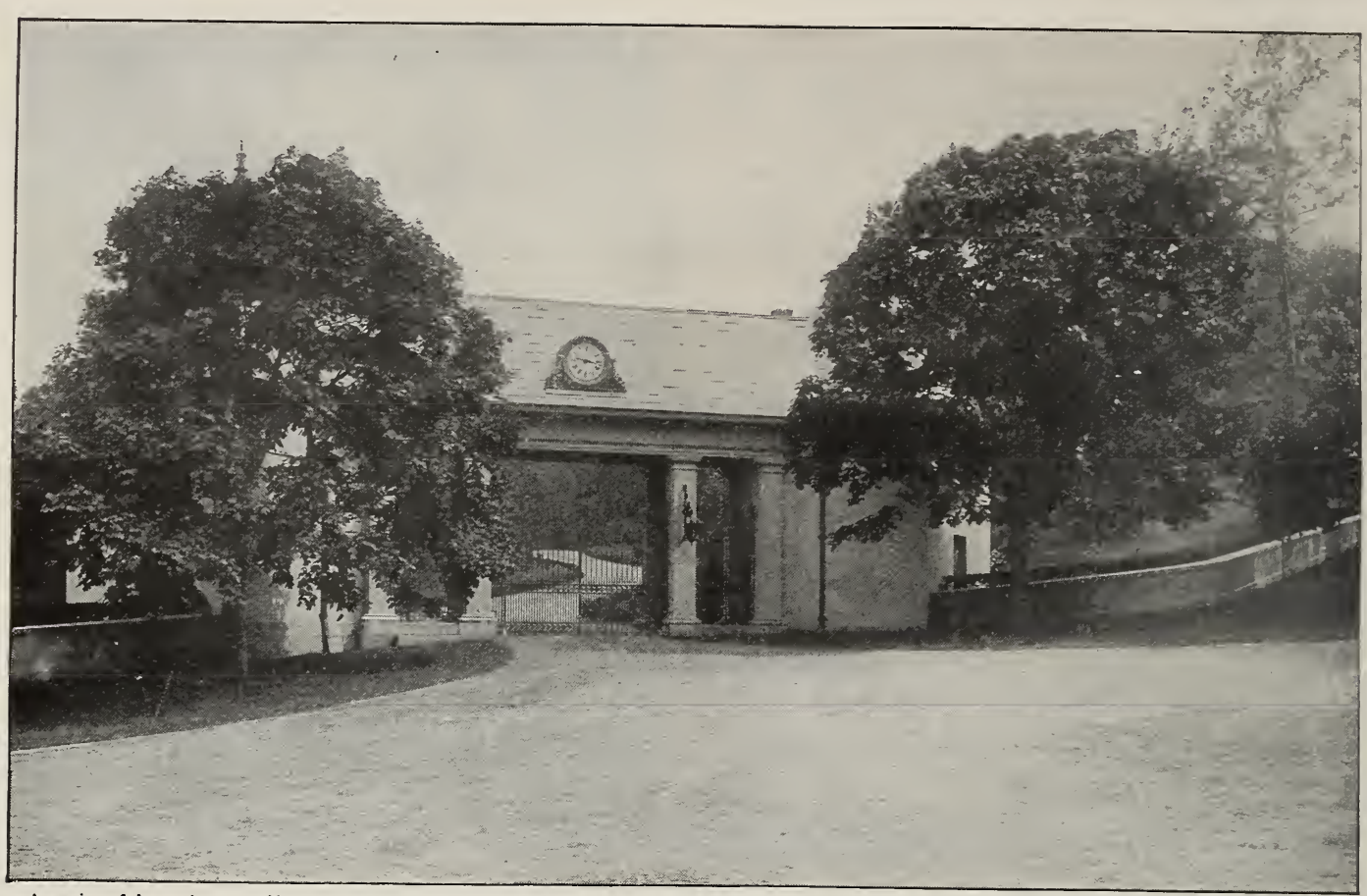

A pair of broad-spreading Maples moved to the entrance at Harbor Hill, the estate of Mr. Clarence H. Mackey. Photographed the first year after planting, they show the excellent immediate results obtained.

\section{HORSE - CHESTNUT}

\section{Esculus Hippocastanum}

The Horse-Chestnut and Buckeye are trees of medium to large size, thriving on rich and moist soil. Admiration is universally drawn to the HorseChestnut in early May, when it first bursts into flower, and the luxuriant foliage, so suddenly formed, casts a heavier shade than any other tree at the time. In favored localities it maintains good foliage, but in some parts of Long Island the leaves turn brown in late summer.

Red. E. carnea; syn., E. mibicunda. A smaller growing tree with bright red flowers.

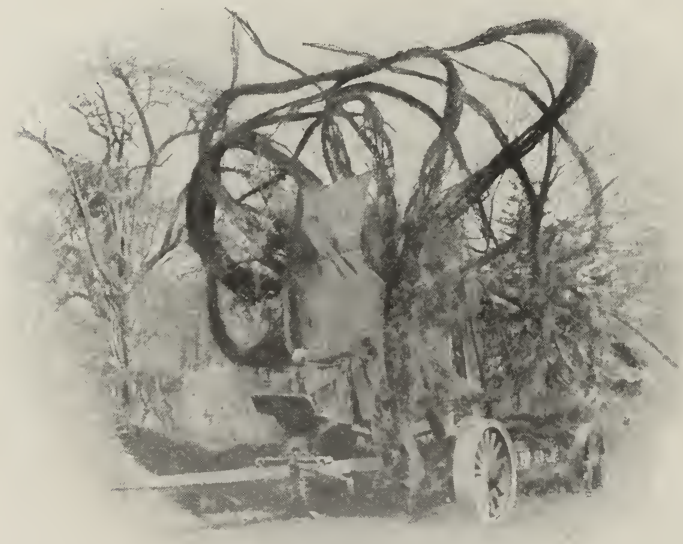

Illustrating root-system of roo avenue trees moved for Mr. Clarence H. Mackey.
HORSE-CHESTNUT, continued

Dwarf. E. parviflora; syn., A. macrostachya. A most valuable shrub, flowering in July and maintaining healthy foliage. See under Shrubs.

\section{JUDAS. Cercis}

American. C. Canadensis. Red Bud. A small tree, blooming with the Dogwood. In early May, before the leaves appear, its branches are wreathed with rosy pink pea-shaped flowers.

Japanese. C. Chinensis. Usually a shrub, but in its native country a tree with brighter pink flowers. See under Shrubs.

\section{KENTUCKY COFFEE TREE Gymnocladus}

G. Canadensis. A large tree with divided leaves 2 feet long; requires deep, rich soil.

\section{KOELREUTERIA. Varnish Tree}

K. paniculata. A rare and beautiful Japanese tree with panicles of bright yellow flowers a foot long in midsummer.

\section{LARCH. Larix}

European. L. decidua; syn., L. Europcea. It is the first tree to come forth in its summer dress of a beautiful feathery light green, interspersed with tiny red cones, and makes a pleasing contrast to its darker green relatives, the pines and firs. 


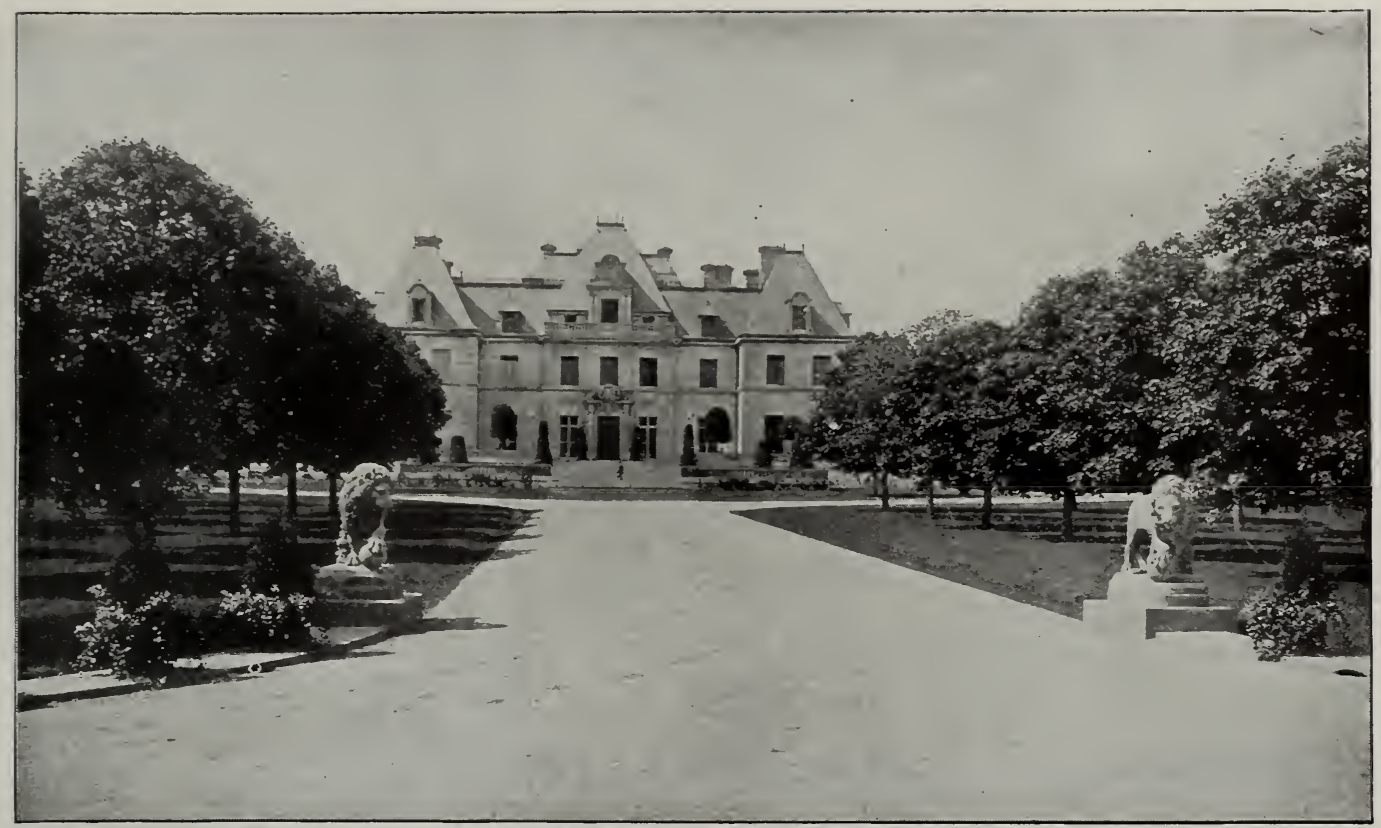

Harbor Hill, estate of Mr. Clarence H. Mackey, Roslyn, L. I., Guy Lowell, Landscape Architect. Four rows of Norway Maples trained to uniforın shape, These trees were started in our nursery over thirty years ago and planted along a road. Sinilar trees were selected, obtaining more uniform and formal effect than if small trees were planted.

\section{LINDEN. Tilia}

The Linden family comprises trees of the highest beauty, especially in the elliptical curves of their outlines, as all the species have an ovate, or egg-shaped form. The curves are so smooth and perfect as to excite general admiration. They all transplant readily and grow to a large size. For lawns and entrance drives they take first rank.

Silver. T. tomentosa; syn., T. argentea; syn., alba. White Linden. : Justly considered one of the handsomest of trees. In symmetry of form and dignity of bearing it is unsurpassed. The upper sides of the leaves are dark green. The foliage remains in healthy condition through drought and other unfavorable conditions until late in autumn. The flowers have a lemon fragrance.

Spectabilis. T. tomentosa, var. spectabilis. A noble tree, resembling the above, except that the lower sides of the leaves are green.

Weeping Silver. $T$. petiolaris; syn., $T$ argentea, var. pendula. This distinct and beautiful species is a tall tree with just the tips of the twigs gracefully turning down. The lower branches arch to the ground, making a verdant tent. The foliage has the good qualities of the Silver Linden. IVe have specimens suitable for planting where a low branched tree is needed in the landscape. It grows to a height of 60 feet and will make a noble lawn specimen.

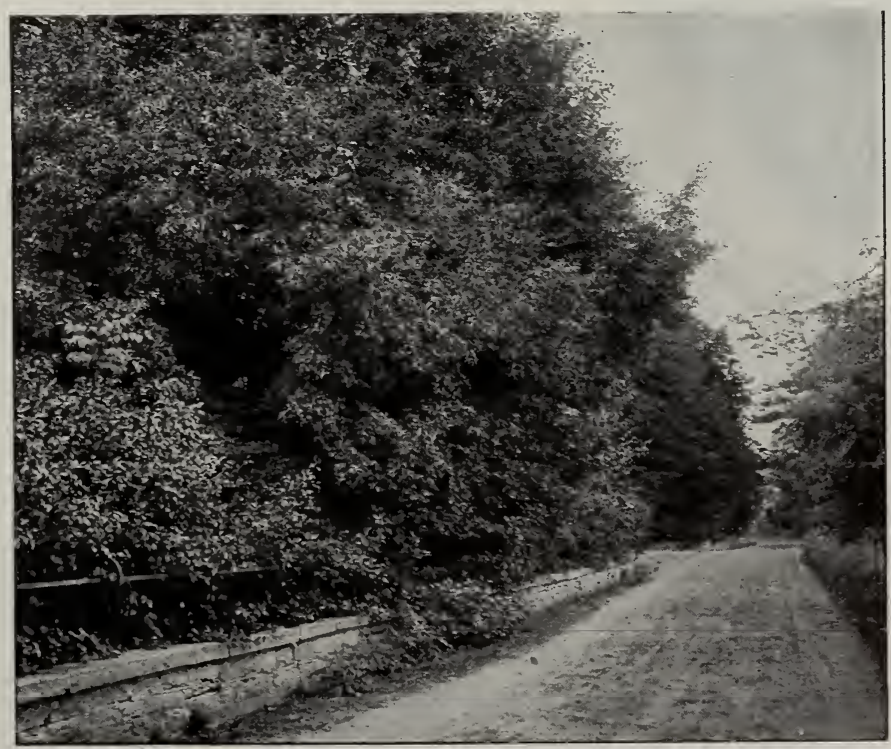

Row of Lindens moved as large trees twenty-five years ago, for the late Charles A. Dana, Dosoris Island, Glen Cove, L. I. 


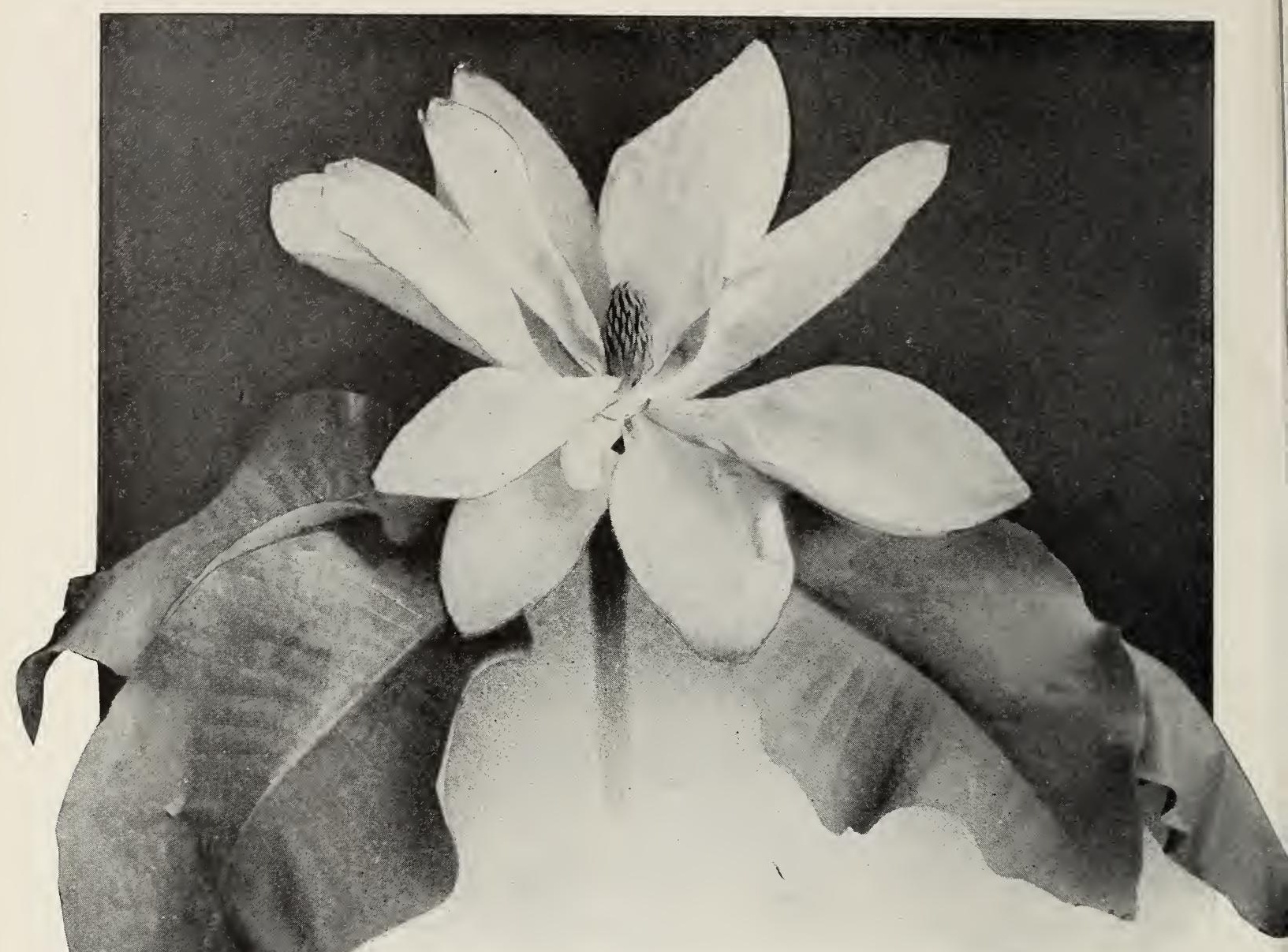

Umbrella Magnolia, less than one-half natural size. An unequaled opportunity to buy Magnolias cheaply. I I $1 / 2 \mathrm{ft}$, $25 \mathrm{cts}$.: $5 \mathrm{ft}$., $\$ \mathrm{I}$. Roots trained and delivered in a manner sure to grow.

LINDEN, continued

Small -leaved. T. ulmifolia ; syn., microphylla. This and the Silver are the best of the family. The dense foliage of small leaves forms a compact and very symmetrical top. The foliage is maintained in good condition throughout the season. We recommend the tree highly for lawns, streets and entrance drives.

American. T. Americana. Basswood. A broadleaved tree requiring fertile, moist soil. The top is more open than that of the other Lindens.

European. T. Europaca. A tall, ovate tree.

Broad-leaved. T. platyphylla. Beautiful in spring, but its foliage browns in midsummer.

\section{LIQUIDAMBAR. Slveet Gum}

L. styraciflua. Bilsted. A tall, ovate tree native to Long Island. It has glossy, star-shaped leaves, turning to scarlet, orange and bronze in autumn.

\section{LOCUST}

Yellow. Robinia Pseudacacia. Tall, narrow trees with strong, straight trunks and feathery light green foliage. Probably the first planted forest in the new world were with Locusts on Long Island. It was very profitable and still is in demand.

Honey. Gleditschia triacanthos. Three-thorned Acacia. Pleistocene Geology of Portions of Nassau County and Borough of Queens, by J. B. Woodworth, University of State of New York, Albany (price 25 cts.), defines the Far Rockaway ridge as "yellowish quartz gravel up to 3 inches." It is different from the plains to the east; more sterile and porous. A gardener said it "needs a shower of rain and a shower of manure." There is more money wasted for trees there than elsewhere on Long Island. The Honey Locust grows faster and bigger there than any other tree ; its roots go deep and wide for water ; it is feathery, graceful and healthy; insects and salt air don't hurt it. 


\section{MAGNOLIA}

We are offering the first opportunity to get all the hardy species of Magnolias. They like Long Island, and will grow with luxuriant vigor on any part that grows good farm crops Grown in quantity from seed, it is possible to plant masses and groves of Magnolia. The rich lustrous foliage is entirely healthy. The different varieties are in flower from March to August, and in autumn they bear showy scarlet fruit. Spring planting is best.

For convenience all are listed together under trees. The following should be used as shrubs: Yulan, Glauca, Soulangeana, Alba superba, Alexandria, Lenne, Soulangeana nigra, Speciosa, Parvifora, Watsoni, Obovata, Obovata gracilis, Stellata, Salicifolia.

Umbrella. $M$. tripetala. Large tropical foliage ; white flowers $S$ to Io inches across, and showy red fruit. It thrives on upland and swamp, and will make a broad tree 30 feet high. For a new effect that is good, sure and cheap, plant a hundred of this and MI. glauca on the border of wet land.

Large-leaved. M. macrophylla. The largest flower of the temperate climates, with firm creamy petals and leaves over 2 feet long. Our old tree is 20 feet wide, with strong, candelabra-like branches, and is never injured by cold, insects or fungi.

M. Fraseri. A small tree with leaves io inches long and flowers nearly as wide, white and fragrant in June.

Cucumber. 1 . acuminata. A tall, symmetrical tree of ovate form.

M. hypoleuca. In May and June this beautiful Magnolia bears fragrant, creamy white flowers 6 to 7 inches across, with brilliant scarlet filaments. The leaves are over a foot long and bluish white on the under side. The showy fruits, often 8 inches long, are a striking feature in

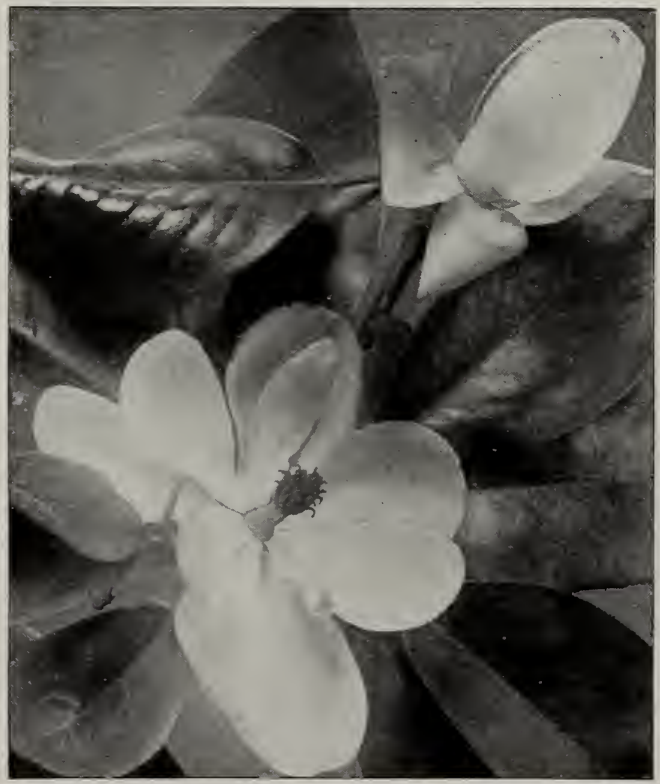

Sweet Bay. Magnolia glauca. We offer this beautiful native shrub in quantity at a low price.

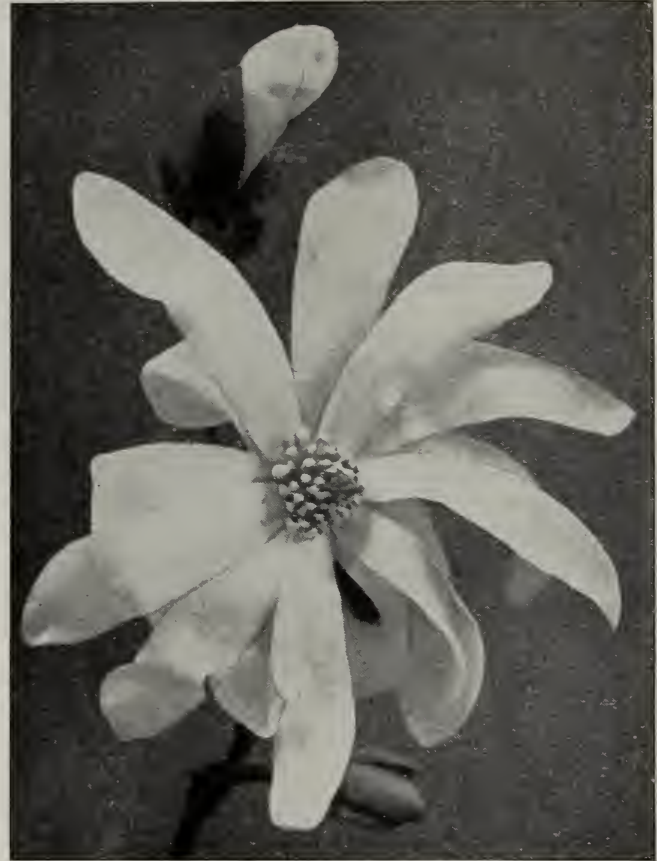

Magnolia stellata. Hall's Magnolia. No longer rare and expensive, these exquisite Magnolias are available for the small cottage garden or in quantity for the large estate. See price-list.

M. Kobus. White flowers 4 inches across in May. In New England it is the hardiest and most rapid growing Magnolia, becoming a tall, symmetrical tree.

M. Yulan; syn., conspicua. The pure white cups coming before the snow is gone, are considered in China symbols of candor and beauty. There are trees 30 feet high on Long Island.

M. Soulangeana. This is the most widely known because it is easy to propagate. It has large pink flowers in April before the leaves. With the five following it is a hybrid of two Chinese species, M. Yulan and M. obovata. They are all hardy.

M. Soulangeana nigra. Dark reddish plum color.

M. alba superba. Nearly white, slight reddish tinge.

M. Alexandria. Large white flowers, bright red shading.

M. Lenne. Deep crimson flower, cream color inside.

M. speciosa. Rose color outside, pearly pink inside.

Sweet Bay. $M$. glauca. The only Magnolia native to Long Island. It is nearly evergreen, having clear green stems and thick, shining foliage that does not wilt quickly when cut. The exquisite globular cups, 3 inches across, are cream-colored and pleasantly fragrant. They should be planted abundantly so that the leafy branches with flow- 
Sweet Bay, Magnolia glauca, con. ers or fruit may be cut for decorative purposes. Plant from 25 to Ioo for a mass in the shrubbery or the border of a swamp too wet for many upland trees.

M. parviflora. One of the rarest and daintiest flowers of June. Large creamy white flowers with crimson stamens.

M. Watsoni. Similar to above.

M. obovata. Large purple flowers, white inside ; thick, Heshy petals.

M. obovata gracilis; sin., gracilis. A broad shrub with deep red Howers; tender while young.

M. stellata; syn., Halleana. Hall's Magnolia. This compact little bush of 8 feet or less is distinct from the other Magnolias. It is the earliest showy flower, making a snowy mass in March and April. The exceptionally dainty buds open star-shaped, with numerous

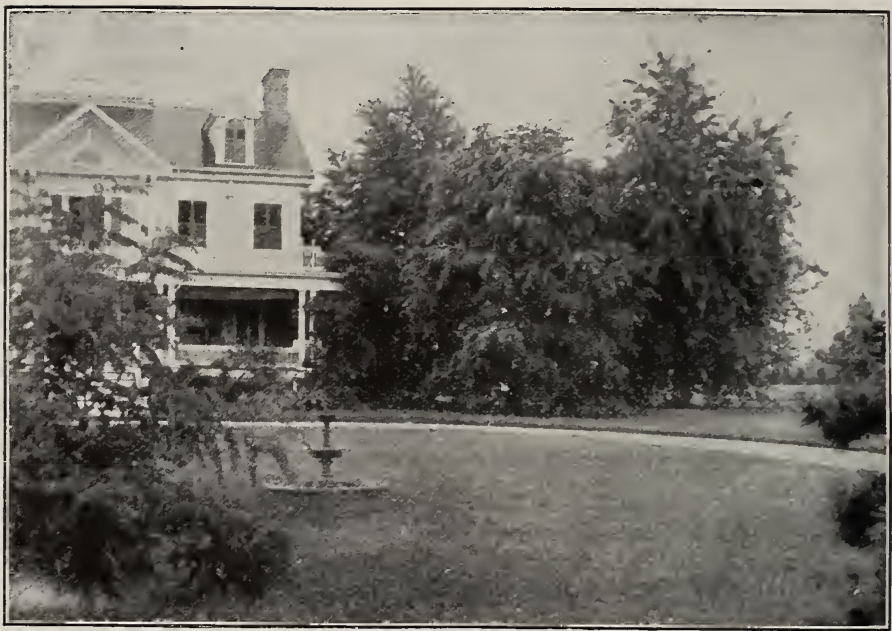

Weeping Silver Maple, Wier's Weeping Maple and Silver Maple on the lawn of Mr. Edmund Wetmore, Glen Cove, L. I., moved by our tree-mover.

narrow petals, and have a delicate fragrance. It blooms profusely when only a foot or two high.

M. salicifolia. A new species just introduced. A slender little tree with white flowers.

\section{MAPLE. Acer}

As a result of their many good qualities, the Maples are the most extensively planted of all trees. A comparison of the various species will show the wide range of their usefulness. The Sugar Maple is a native of New England and westward, but rarely of Long Island. Along the north shore and on the hills it frequently grows well, especially where there is a deep loam soil, or clay or hard-pan subsoil. On the plains region, with its subsoil of sand and gravel, the Sugar Maple, the Elm, the Kentucky Coffee Tree, and some others do not reach the perfection of old age and feel at home. Although it has had opportunity for thousands of years, the Sugar Maple has not established itself, and seedlings do not spring up around it. The foliage sometimes turns brown in summer, while the Norway Maple foliage does not. The Norway Maple does thrive vigorously in this region, reaching its highest development, and the young seedlings spring up freely under old trees.

The Red, or Scarlet, Maple is native to all parts of the island, both along the streams and on the upland. Its nearest relative, the Silver Maple, is native to rich river bottoms in the Middle States. It is so rapid in growth that its branches have not the strength of other Maples.

Norway. A. platanoides. The Norway Maple is the best all-round shade tree for Long Island. Its foliage is retained in good health until late in autumn, when it turns a clear yellow. It is a tree which may be depended upon to live when transplanted, and grow and thrive on poor and dry soil, growing faster, of course, when well fed. In form the head is a sphere, or in old trees a hemisphere, with broad spreading branches. For street planting our trees are trained with hign heads to

the dock and rustic "Brookhol," the residence of Hon. O. H. P. Belmont. To shade as the screen of large evergreens bordering the public road. Photographed three years after planting. 


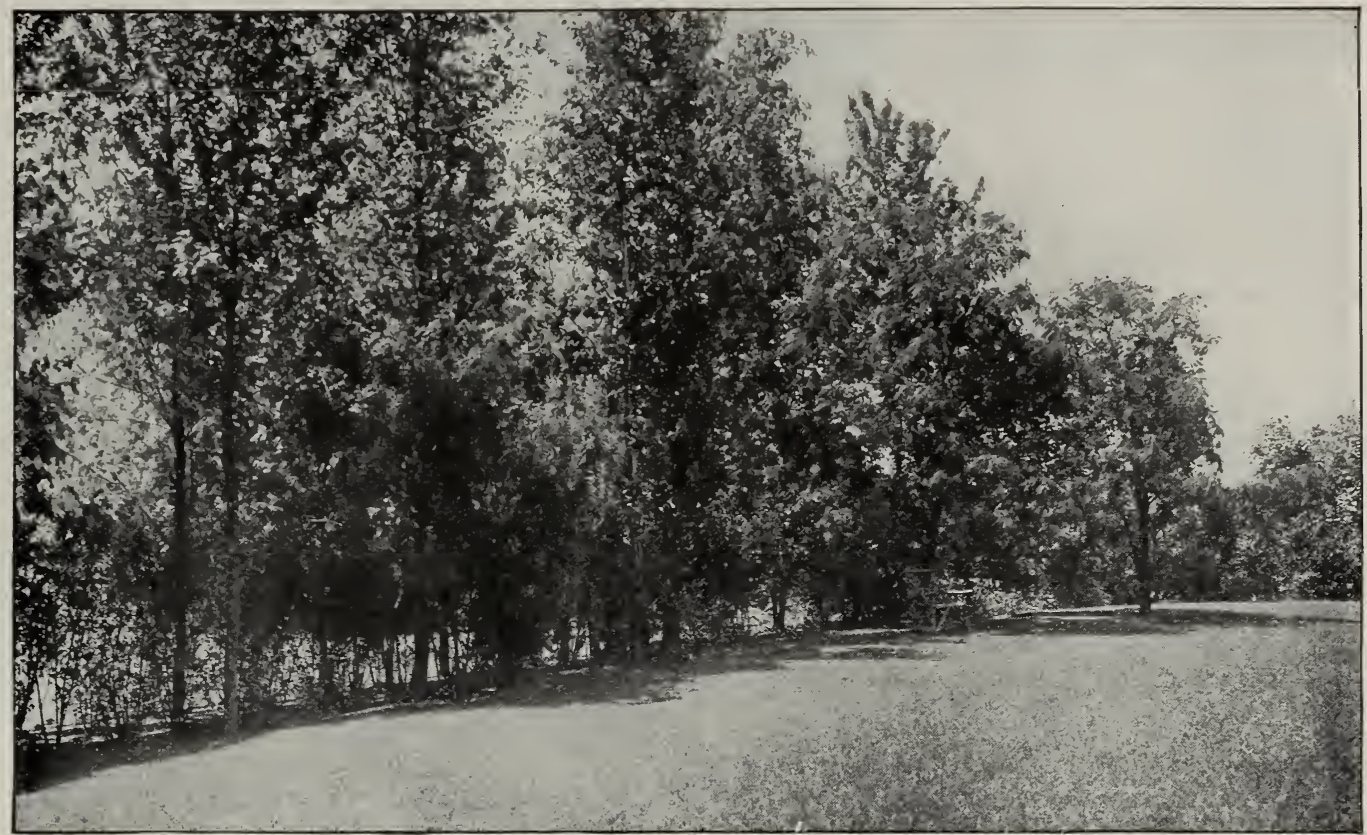

Tall screens are not expensive. We have hundreds of Norway and Silver Maples and Pin Oaks, 20 to 30 feet high, at $\$ 3$ to $\$ 15$ and upward. (See price-list at back of Catalogue.) Screen to the second story of a row of stables from the second story of a house, planted from our nursery at Red Spring, Glen Cove. Tall shrubs fill out the base. For all-the-year screen, we have evergreens in our nurserv 20 to 40 feet high.

NORWAY MAPLE, continued

clear wagon tops, the lower branches being at io or 12 feet. The leader, or trunk, is continued up through the top, so that they may be pruned still higher without disfiguring the tree or causing large wounds. Our stock is the largest in size and of the best quality in existence. T'here

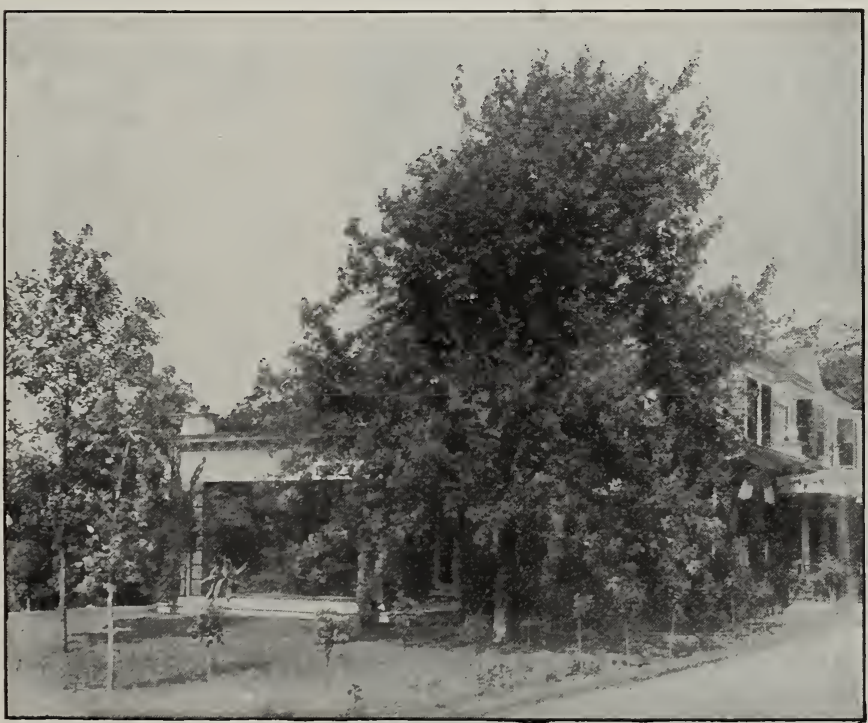

A tree like this makes the piazza cooler. It keeps off the glare of the hot afternoon sun. The breeze is cooled by passing under it. The second-story windows are cooler during the night. We have many such trees at economical prices. Can you afford to wait twenty years?
NORWAY MAPLE, continued

the problem is to furnish foliage immediately for shade, ornament or screens, these large-sized Norway Maples, I 5 to 22 feet high and 6 to I 2 feet spread of branches and roots, will give best satisfaction. In the ordinary sizes of 8 to I6 feet, and $I \frac{1}{2}$ to $2 \frac{1}{2}$ inches in diameter, our stock is in large quantity and at low prices, and worthy the attenticn of extensive planters for groves, drives, roadsides and streets. For the development of real estate for sale as building lots the Norway Maple is the best tree. A few well-established trees planted on the lots enhance the attractiveness and value of the property.

Schwedler's Purple Norway. $A$. platanoides, var. Schwedleri. IVith all the vigor of the Norway Maple, the purple variety has the foliage effect of the Purple Beech, the leaves being bright red during spring, and in early summer changing to dark green.

Reitenbach's Purple Norway. $A$. platanoides, var. Reitenbachi. Unlike the last, it is dark bloodred in late summer.

Sugar, Rock or Hard Maple. $A$. saccharum; syn., $A$. saccharinum. The form of the Sugar Maple is upright and ovate and not as broad as the other Maples. The autumn color is yellow and red. 
MAPLE, continued

Sycamore. A. Pseudo-platanus. A tree closely resembling the Norway Maple, but having darker green leaves of thicker texture, which stand the caustic action of salt spray. It thrives at the Hamptons and well repays the additional fertility it requires. On drier soil it is not so good as the Norway Maple. We offer specimens i 5 to 25 feet high.

Silver. A. saccharimum; syn., $A$. dasycarpum. The Silver, or Soft Maple, is the best quick-growing tree for general Long Island planting. Its form most closely resembles the elm with long gracefully arching branches.

Our stock is trained with a single leader, and in that form it is not liable to break by the winds. In moist, or rich soil, it will grow 4 to 6 feet per year, rapidly gaining on other trees. On average soil it thrives well. The borers which occasionally attack it are killed by a bit of cotton dipped in carbon bisulphide put in the hole and closed by putty.

The low cost at which trees of considerable height can be sold renders it valuable for tall screens, and we offer specimens 18 to 25 feet high in quantity, suited for quick results in planting screens, avenues or shading residences. Larger specimens of nursery-grown trees, 25 to 50 feet high, 6 to $\mathrm{I} 2$ inches in diameter, and $\mathrm{I} 5$ to 25 feet spread of branches, are in stock in quantity at the nursery. These have been grown especially for transplanting with the Tree-Mover, and, having been properly pruned, they form good trees for shading residences.

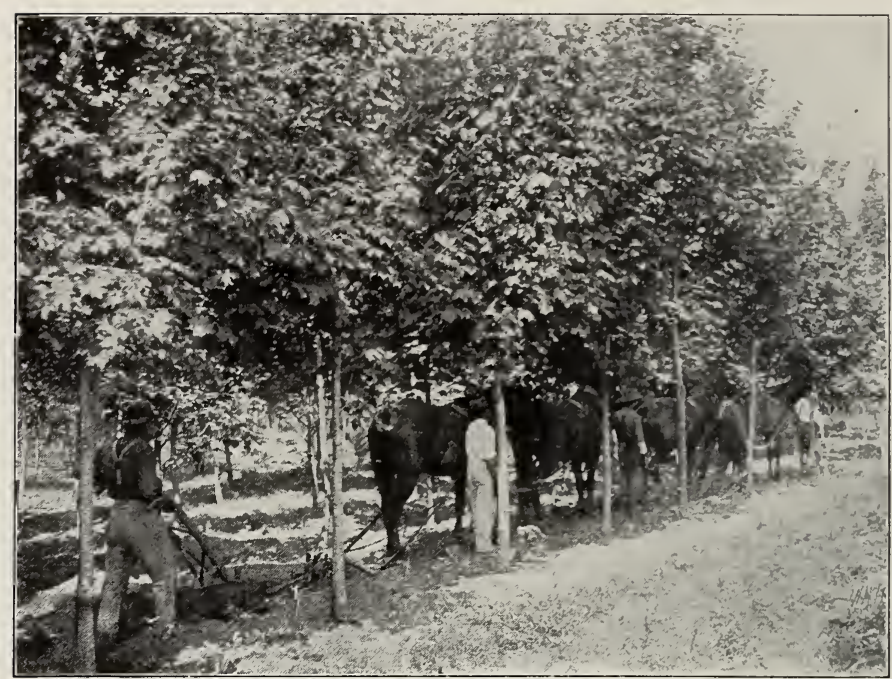

Root-pruning our specimen trees to grow fiexible roots close to the trunk We have hundreds of trees growing 8 to 30 feet apart, highly fet tilized, with tops trained to symmetrical form.

\section{MAPLE, continued}

Wier's Weeping. A. saccharimum, var. Wieri. A most beautiful tree with upright, vigorous habit, and long arching branches. It attains a mature appearance rapidly. We offer specimens up to 25 feet high and I8 feet broad. (See illustration on page 20.)

Scarlet, or Red. A. rubrum. This is thoroughly at home on all parts and soils of Long island, and should be more extensively planted. It is a round-headed tree of vigorous, healthy growth. Its autumn color is brilliant. We offer specimens up to 47 feet.

Japanese. The Japanese Maples are fern-like gems. Described under Shrubs, page 47.

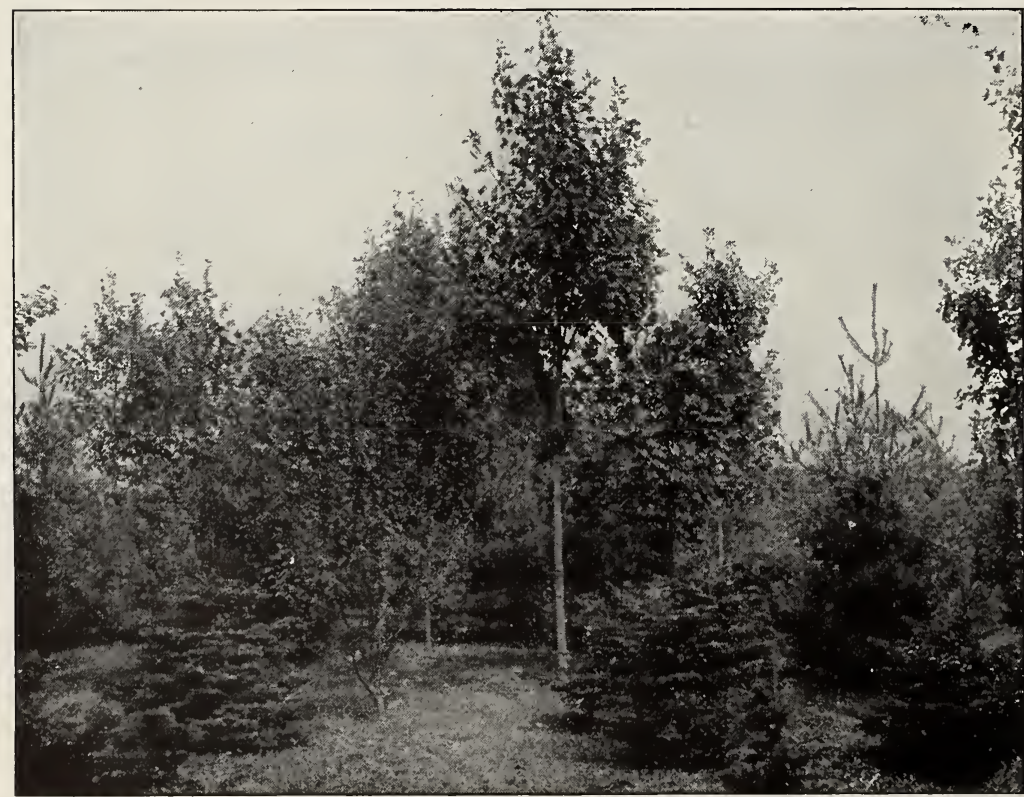

The proper way to arrange a border planting of Oak, Maple, Pine and Fir. They need the minimum amount of care.

\section{MOUNTAIN ASH. Sorbus}

S. Americana; syn., Pyrus Americana. A s mali tree highly prized for its clusters of orange berries. The foliage keeps in good condition in the interior of the continent, but here it becomes rusty.

\section{MULBERRY Morus}

The Mulberries are la rge, wide-spreading trees of vigorous and rapid growth. They are beautiful lawn trees.

New American and Downing's Everbearing. A variety cultivated for fruit, forming a handsome shade tree. 


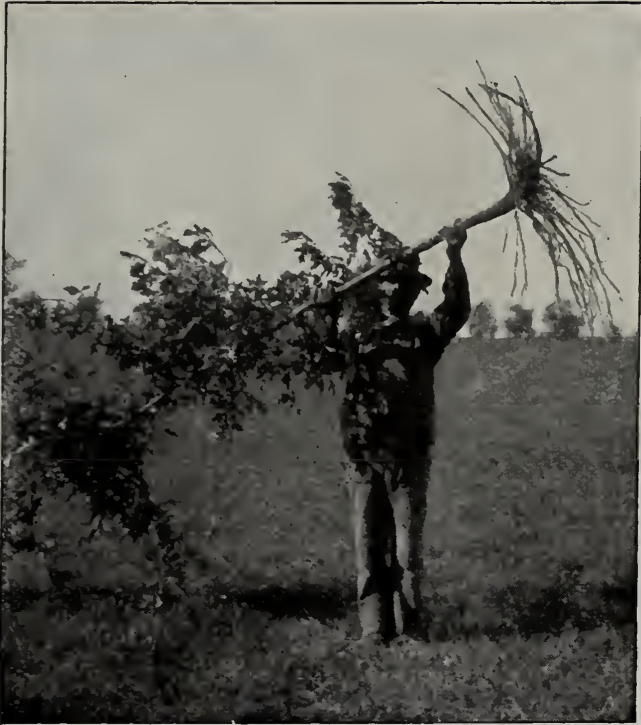
Young Oak tree ready to be stripped of its leaves and
transplanted.

MULBERRIES, continued

Russian. M. alba, var. Tatarica. This is a bushytopped small tree of dense foliage, suited to large shrubberies. It was introduced into the
RUSSIAN MULBERRY, continued

western states by Russian Mennonites, and recently the following variety was found :

Weeping. M. alba, var. Tatarica pendula. Of the several umbrella-shaped trees, as Kilmarnock Willow, Camperdown Elm, W'eeping Ash, etc., this is much the best ; far exceeding them in this climate, in vigor and healthfulness; growing 7 feet per year. The fruit is of little value. The usual form is grafted on a stem 4 feet high, when it weeps straight to the ground. IVe have devised the following new methods of training it, and offer suitable plants for the purpose :

As a verdant tent or summer-house we have them in various heights, 5 to 8 feet, ready for transplanting. A pair of trees will form a garden arch, or a row of them will make a beautiful pergola, no posts being necessary after they are established. It may also be trained on a trellis, arbor or wall, as are grape-vines or espalier fruit trees in European gardens. When trained to a stake or pipe, to a height of 15 or 2 , feet, the long and graceful sprays fall like fountain jets. As a shrub, it heaps up a mass of arching branches, perhaps 4 feet high and twice as wide, being suitable both for masses in the shrubhery and as a specimen standing on the lawn. On exposed and windy places it is especially valuable. To those wishing a new garden feature, which is quickly complete, these forms are highly recommended.

For covering steep banks it has the babit of Forsythia suspensa.

\section{OAK. Quercus}

'The Oak has long had a hold on the affections of the people through its individuality and its almost human characteristics of dignity and nobility, which are marked both in old and young trees. The opinion that they are of slow growth is due to the fact that they can patiently endure on a poor and dry soil. In our nursery, and when planted on lawns, they frequently grow 4 feet per year.

Oaks should be extensively planted along streets, entrance drives and on lawns. The Brooklyn TreePlanting Society has planted many of our Oaks on the streets and found them to thrive despite the unfavorable conditions of pavements, dust, smoke and insects.

Where a broad shade is desired quickly and Oaks cannot be procured of sufficient size, extrasized Maples, as describea on page 3I, may be planted between the Oaks and later taken out with the tree-mover.

The Oaks have a reputation of being difficult to transplant. The new roots start slower than other trees, because of the slower circulation of the sap, the crude sap having first to go up to the leaves to be digested,

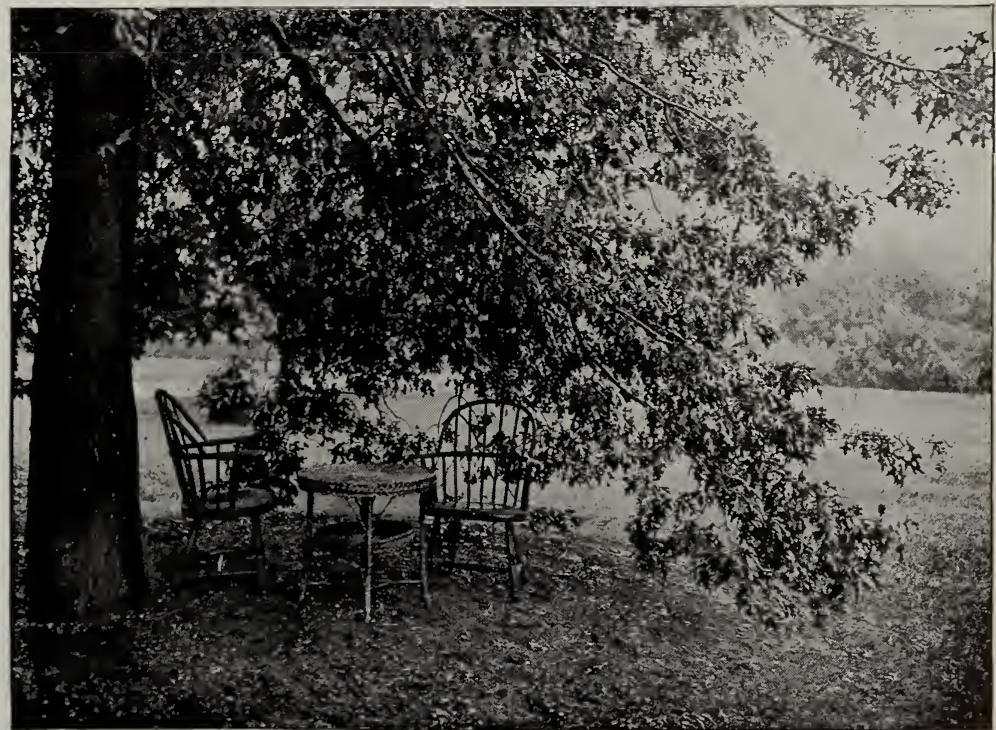

Under the shade of a large Pin Oak. moved by us to a new, bare lawn. Is it worth while to wait for a small tree to grow? 


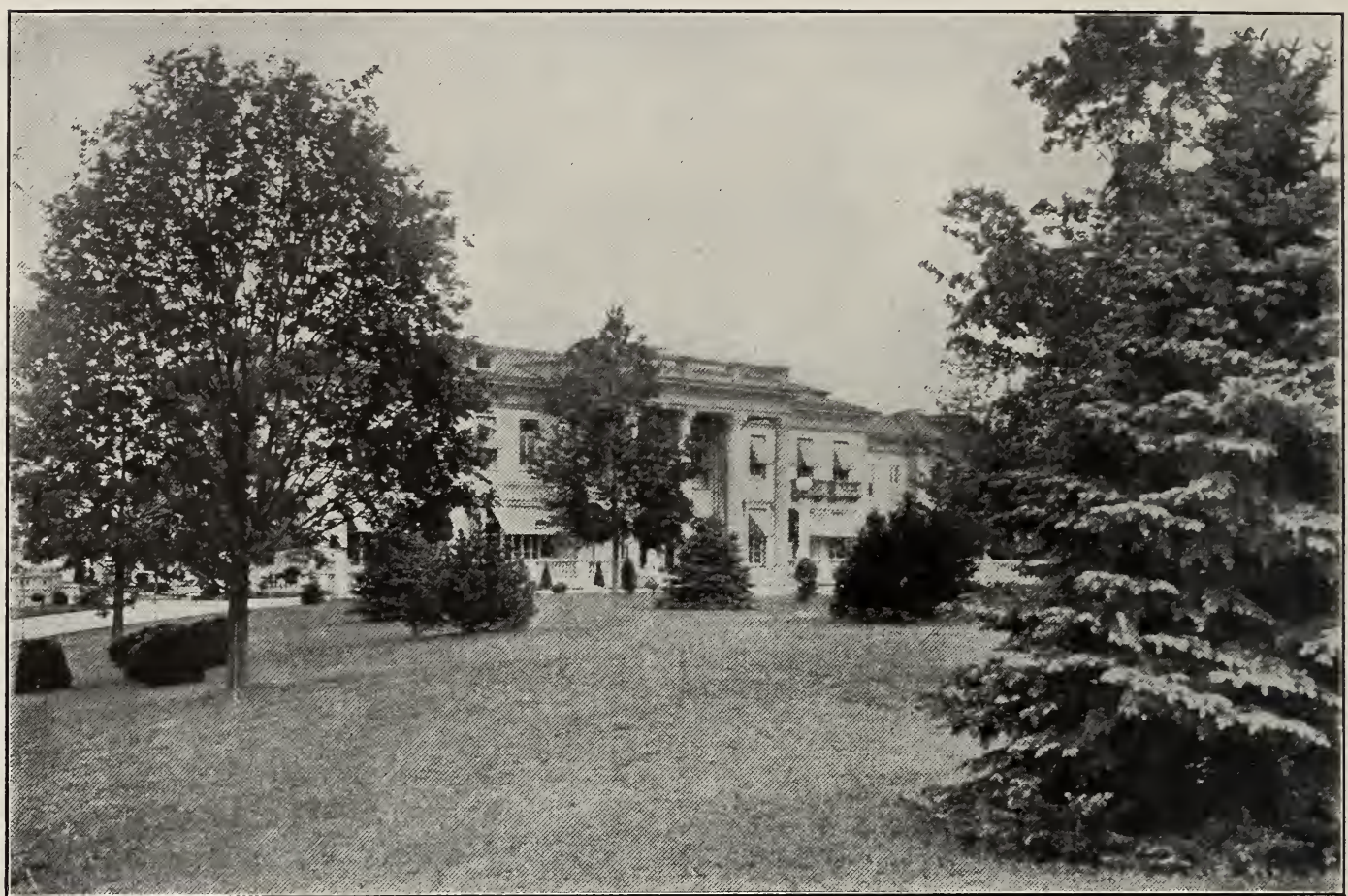

Landscape of Norway and Scarlet Maples, Colorado Blue Spruce and Boxwood. A complete planting by means of the tree-movers on a site cleared from a dense forest. "Meudon," the estate of Mr. Wm. D. Guthrie, Locust Valley, L. I. Photographed fifteen months after planting.

OAK, continued

and then return to make new roots. These new roots, just getting to work, may not supply the demand for moisture in summer, and the tree may die. Our Oaks have the roots properly trained for transplanting, and are carefully dug. The pruning should reduce the buds to 15 or 25 per cent of the original number, leaving some large buds at the end of each branch. Wrapping the trunk with straw, and mulching the ground, help to establish the tree. Understanding these principles, no more trouble need be expected with Oaks than with other trees.

Pin. : Q.palustris. The Pin Oak is a thickly branched tree of upright ovate form and graceful habit. It is the most popular and most generally planted of the Oaks. It may be 1dentified by its habit of drooping its long, slender lower branches at a uniform angle. The small glossy leaves are bright red in autumn. As an avenue or broad-spreading lawn tree it is unsurpassed. Trees $5 \circ$ feet high transplant readily and grow well. Besides the usual sizes we offer many Pin Oaks 20 to 30 feet, and 30 to 40 feet high, and strongly recommend their use. They give a dignity and completeness attainable with few other trees. Prices, including delivery, on the tree-mover and planting, on application. The roots are so trained that they may be safely shipped by rail.

Scarlet. Q. coccinea. This species is so named from its bright scarlet autumn color. The tree resembles the Pin Oak in foliage and form, except that the lower limbs are horizontal or ascend ing. We offer specimens Io to I 5 feet high.

Red. Q. rubra. The Red Oak is a large and noble tree, with strong, wide-reaching arms. The large leaves in autumn are a dull crimson. A tree that does its part well and requires no coddling.

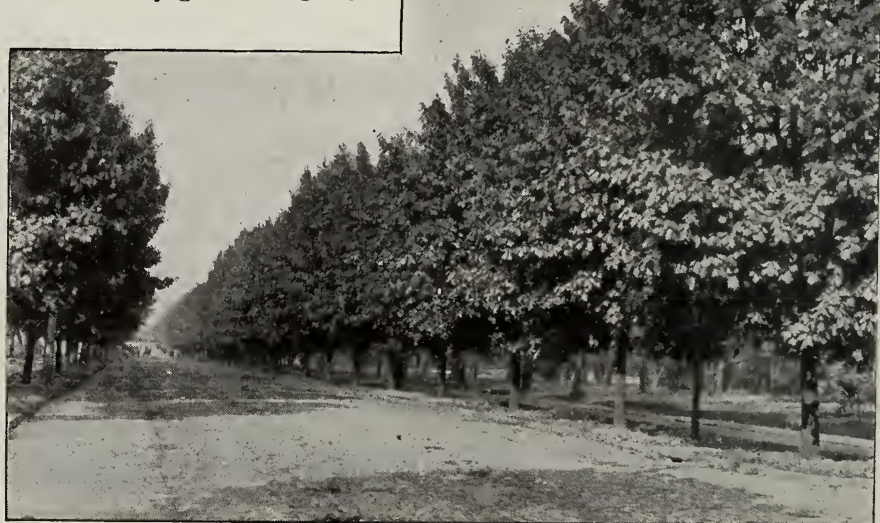

Avenue of Red Oaks. These grow as fast as Sugar Maples. We are growing them by the thousand because they are permanently good. 
OAK, continued

willow. $Q$. Phellos. The willow-like leaves are a half-inch wide. It is a close pyramid of slender gray twigs.

White. Q. alba. The White Oak is the most majestic of all native trees.

Swamp white. Q. bicolor. This forms a tall tree with light gray flaky bark.

Mossy Cup, or Burr. Q. macrocarpa. A lofty tree, rugged, rough and strong. The twigs are ridged with cork, like the liquidambar. We offier trees Io to 23 feet.

English, or Royal. Q. pedunculata; syn., $Q$. Robur. This is the Oak of the English parks. It is a noble broad-spreading tree with powerful horizontal branches, and closely resembles our White Oak. In this region it grows rapidly; sometimes 4 feet per year.

Pyramidal English. Q.pedunculata, var. fastigiata. It is a narrow columnar tree like the Lombardy Poplar.

Golden English. Q. pedunculata, var. Concordia. The foliage is bright yellow in spring.

Besides the above list, we have specimens of many rare species of Oak.

\section{PAULOWNIA. Empress Tree}

P. imperialis. In early May this tree sends out a pleasant perfume, and it is rather surprising to find the cause in flowers so nearly like the sky in color as not to be noticed at first sight. The flowers are trumpet-shaped, 3 inches long, borne in panicles a foot in length. The large tall tree resembles its relative the catalpa, but it is more open and irregular. For tropical gardening, the stem is cut to the ground, and annually shoots up Io feet with leaves 2 feet wide.

\section{PEACH. Prunus}

Double-flowering. P. Persica, var. camelliceflora plena. These are clouds of beautiful color, being masses of double rose-like flowers of white, pink or crimson. They are small, short-lived trees, benefited by close pruning and fertilizing it with wood ashes.

\section{PEPPERIDGE. Nyssa}

N. sylvatica. Sour Gum. This is a tree native to wet ground, remarkable for its horizontal branches, shining leaves and flaming scarlet autumn color. It transplants with difficulty.

\section{PERSIMMON. Diospyros}

D. Virginiana. It is not generally known that this fruit tree of the South is native here, forming a round-headed tree of healthy dark and glossy foliage.

\section{PHELLODENDRON Chinese Cork Tree}

P. Amurense. Like many plants from the Amoor Valley in China, finding the climate similar, this thrives and grows rapidly here. It resists drought and is free from insect attacks. The foliage and form resemble the black walnut.

\section{PLANE TREE. Platanus}

P. orientalis. Oriental Plane, or Sycamore. The Plane is a vigorous and rapid-growing tree of the largest size. The wide thick leaves withstand salt spray. In winter the tree is ornamental because of the light-colored bark. It has been famous and largely planted since the days of the ancient Greeks. It is a good street tree and does not suffer from the fungous disease which kills the twigs of the native Buttonball, or American Plane. An excellent city tree.

\section{PLUM. Prunus}

Purple. $P$. cerasifera. var. atropurpurea; syn., $P$. Pissardii. The Purple Plum has especially bright red foliage in midsummer and purple in the autumn.

\section{POPLAR. Populus}

The Poplars belong to the Willow family. A prominent characteristic of the family is quickness of growth, some members exceeding all other trees of temperate regions. The wood is soft and light. They are strong feeders and repay added fertility and moisture with luxuriant growth.

Carolina. P. deltoides, var. Carolinensis. This is the most commonly planted Poplar, quickly forming a tall tree. Where quick results for a few years are wanted it answers well. Many thousands have been planted on real estate subdivisions, but after a dozen years only a small proportion remain in good condition. On heavier soil in the Prairie States, and along the streams, it makes a large old tree. It is benefited by fertilizing and bi-annually cutting back, which helps it to overcome its fungous enemies.

Lombardy. P. nigra, var. Italica; syn., P. fastigiata; syn., $P$. dilatata. The Lombardy Poplar is an exclamation point in the landscape. Its vertical column of foliage strikes a new note in the tranquillity of ordinary scenery, and is a pleasing break in the sky-line of round-headed trees. It is sometimes used for vistas and screens. For immediate screens, tall trees of more permanent species, as maples, on page 29 , are preferable. In France, long avenues of them are characteristic.

Japanese. P. suaveolens. This is by far the best Poplar for this climate, as may be expected from its origin. The foliage comes out earlier in spring than other trees, and is a beautiful shade of light green, maintained throughout the season. It is free from the fungous attacks which frequently cause the Carolina Poplar to drop its foliage in late summer. It roots deeper than other Poplars, therefore resists drought better.

Prof. Sargent, director of Arnold Arboretum, Harvard, writes us: "I believe your specimen to be the northern China and northern Japan, $P$. suaveolens, which I see in this country for the first time. I met with this tree in northern Japan, where it grows to a very large size, but was unable to introduce it into cultivation." As far as we know, this is the only nursery offering it. For transplanting on tree-mover, we offer trees 30 to 40 feet high, as beautiful and symmetrical as the tulip tree. 


\section{SASSAFRAS}

S. officinale. The beauty of the Sassafras as a lawn tree is not appreciated because it is usually seen crowded in a hedgerow. It thrives on light soil and keeps good foliage.

\section{SOPHORA \\ Japan Pagoda Tree}

S. Japonicus. This is a roundheaded tree of the locust family, with cream-colored flowers in midsummer.

\section{STYRAX}

S. Japonica. Too high praise cannot be accorded the delicate and chaste beauty of this new acquisition. It is so neat and dainty in its general habit that it is worthy of planting even without the myriads of silver bells or snowdrops, gracefully suspended from its branches in early summer. When young it is a pyramidal shrub, broad at the base, with pleasing foliage. Worthy of being placed singly on the lawn, and as much honor accorded it as to the Magnolia. The flowers very much resemble those of the Silver Bell tree, illustrated on this page.

\section{SILVER BELL, or SNOWDROP TREE Halesia}

H. tetraptera; syn., Mohrodendron tetraptera. A small tree or large shrub decorated in May with hanging bells of pure white flowers.

\section{THORN (Hawthorn) Crataegus}

This family is most widely known through the hedges of

England. They are all small, thick-topped, thorny trees bearing clusters of flowers in May, and red haws or miniature apples in autumn. They group harmoniously with both trees and shrubs. The English Thorn is so variable in its success here that we do not recommend its general cultivation.

Paul's Double Scarlet. C. monogyna, var. Pauli. In May a tree of this variety looks like a mass of fire, and no plant exceeds its brilliancy of color.

Cockspur. C. Crus-galli. This is to be found on the edges of the salt meadows and on the Hempstead Plains, where it is too windy for other trees. The horizontally arranged branches of shiny foliage give a distinct element to a group of trees or shrubs.

\section{TULIP TREF Liriodendron}

L. Tulipifera. White IVood. No tree native of Long Island is more worthy of praise, as it ranks with the White Pine and White Oak, among our noblest trees. The trunk is as straight and graceful as a Grecian column. The beauty and symmetry of its ovate top i.: worthy of admiration. The flowers are yellow tulips. It rapidly becomes a large tree. It should be transplanted in spring only.

Pyramidal. L. Tulipifera, var. pyramidale. With all the healthfulness of the species, this variety promises to fill the same place in the landscape as Lombardy Poplar.

\section{YELLOW-WOOD Cladrastis}

C. tinctoria ; syn., Virgilea lutea. This neat clean tree has long racemes of white flowers like the wistaria. The smooth gray bark resembles the beeches.

\section{WILLOW. Salix}

The IVillow family is characterized by quick growth, ability to grow on upland and where too wet for many other trees, and ease of transplanting. They have generally narrow leaves. For forming shelterbelts near the sea, they should be planted thickly with poplars, privet and other species recon1mended for the purpose, in groups 15 to 50 feet wide, 5 to I2 feet apart. In the lee of such shelter-belts most other species thriving in this latitude may be grown, as well as Pines, Firs and Spruces, thus making an all-the-year-round shelter. The thickly matted roots hold streambanks and shores.

Babylonian Weeping. S. Babylonica. In old trees the wide top of gnarled branches supports a soft veil of foliage dipping to the water.

Salamon's. S. Babylonica, var. Salamonii. The most rapid-growing tree where it finds a supply of moisture and fertility. It is more upright than the Babylonian, and makes a handsome tree, with the tips of the branches droopins.

Yellow. S. vitellina. The Yellow Willow, sometimes called White Willow, is a broad-spreading tree with no weeping branches. It quickly becomes a tree 2 or 3 feet in diameter. 
WILLOW, continued

Golden. S. vitellina, var. aurea. It grows to a large tree, or may be kept as a shrub by cutting back. With the Red-twig Dogwood its golden bark forms a beautiful contrast-a cheerful and harmonious touch in the winter landscape.

Salmon-barked. S. vitellina, var. Britzensis. A unique tree with brilliant salmon-red bark in winter.

Rnyal. S. alba; syn., S. regalis. The silky down on the leaves gives the tree a white or silvery gray appearance. It is of value for contrast in groups of shrubs, especially at the seaside.

Laurel-Leaf, or Bay-Leaf. S. pentandra; syn., $S$. laurifolia. It differs markedly from other W'illows in having broad leaves which exceed all others in glossiness, and appear as if polished and varnished. It is an upright-growing, roundheaded tree, or it may be grown in the form of a slirub, in which case it closely resembles the privet. Being, however, more rapid in growth, it can be used instead of privet for tall hedges and screens, especially near the shore. We have specimens which have been trained in the form of the bay tree.

\section{WALNUT. Juglans \\ See, also, Nut Trees}

Black. J. nigra. The Black Walnut is one of the largest trees in this region, where the strength and ruggedness of its far-reaching branches render it worthy of admiration. It needs ample room for its aggressive roots, as other plants do not thrive near it. The nuts are of good quality.

White (Butternut). J. cinerea. The tree is smaller than the Black IValnut.

English J. regia. It is not generally known that Long Island contains many old specimens of the

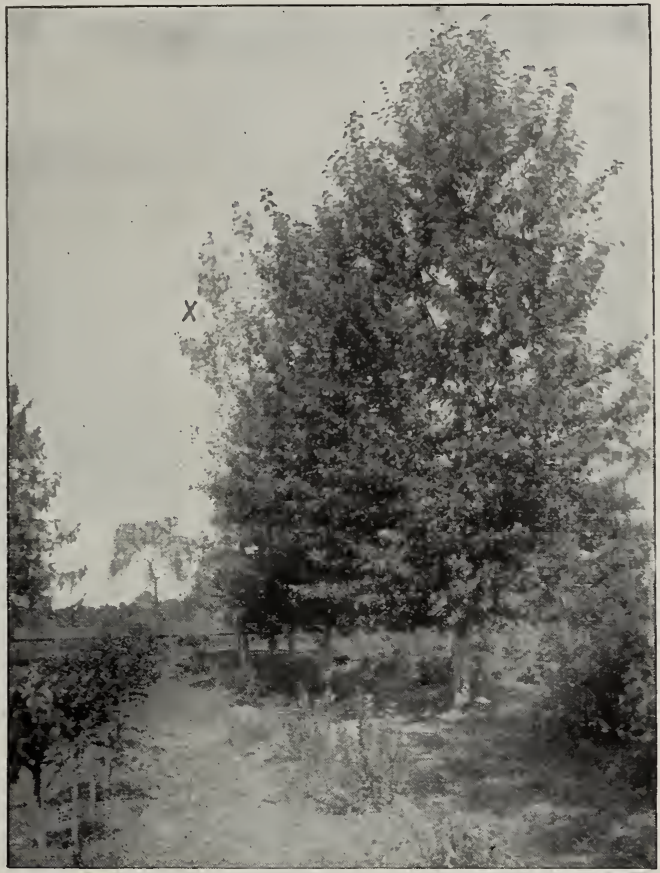

Japanese Poplar. Compare the good foliage of the Japan ese Poplar with the poor foliage of the Carolina Poplar, at $\mathbf{X}$ after midsummer when it becomes infested with a fungous rust. The foliage of the Japanese Poplar is thick, leathery, rich dark green until late autumn. Ours is the only stock on the market.

English Walnut, continued

English or Persian Walnut. Although tender while young, it may be readily established.

Japanese. $J$. cordiformis. This is a rapid-growing tree resembling the Butternut.

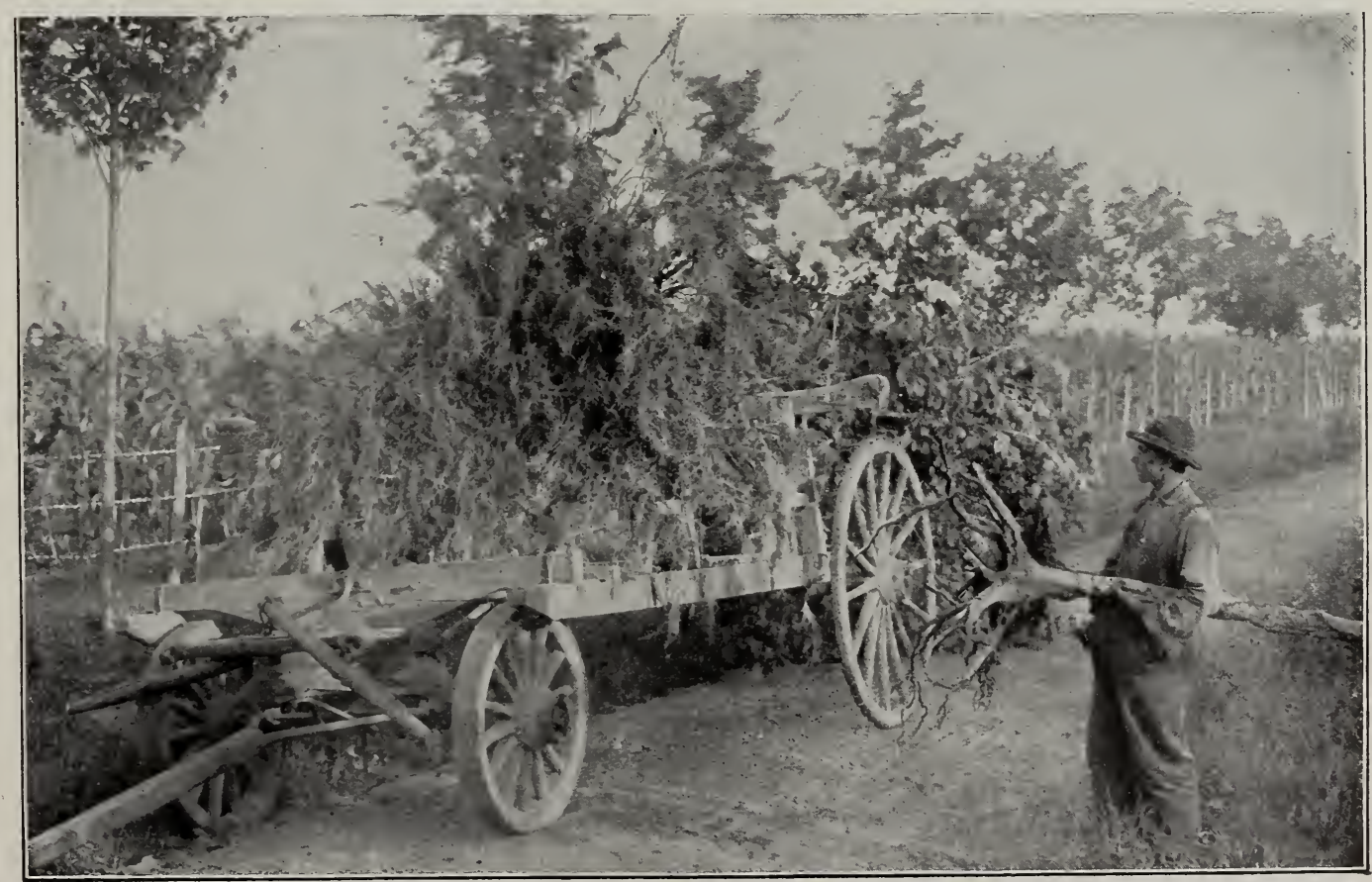

Maple showing abundant feeding-roots skilfully dug, compared with one ot the same age, as sometimes grown and dug. 


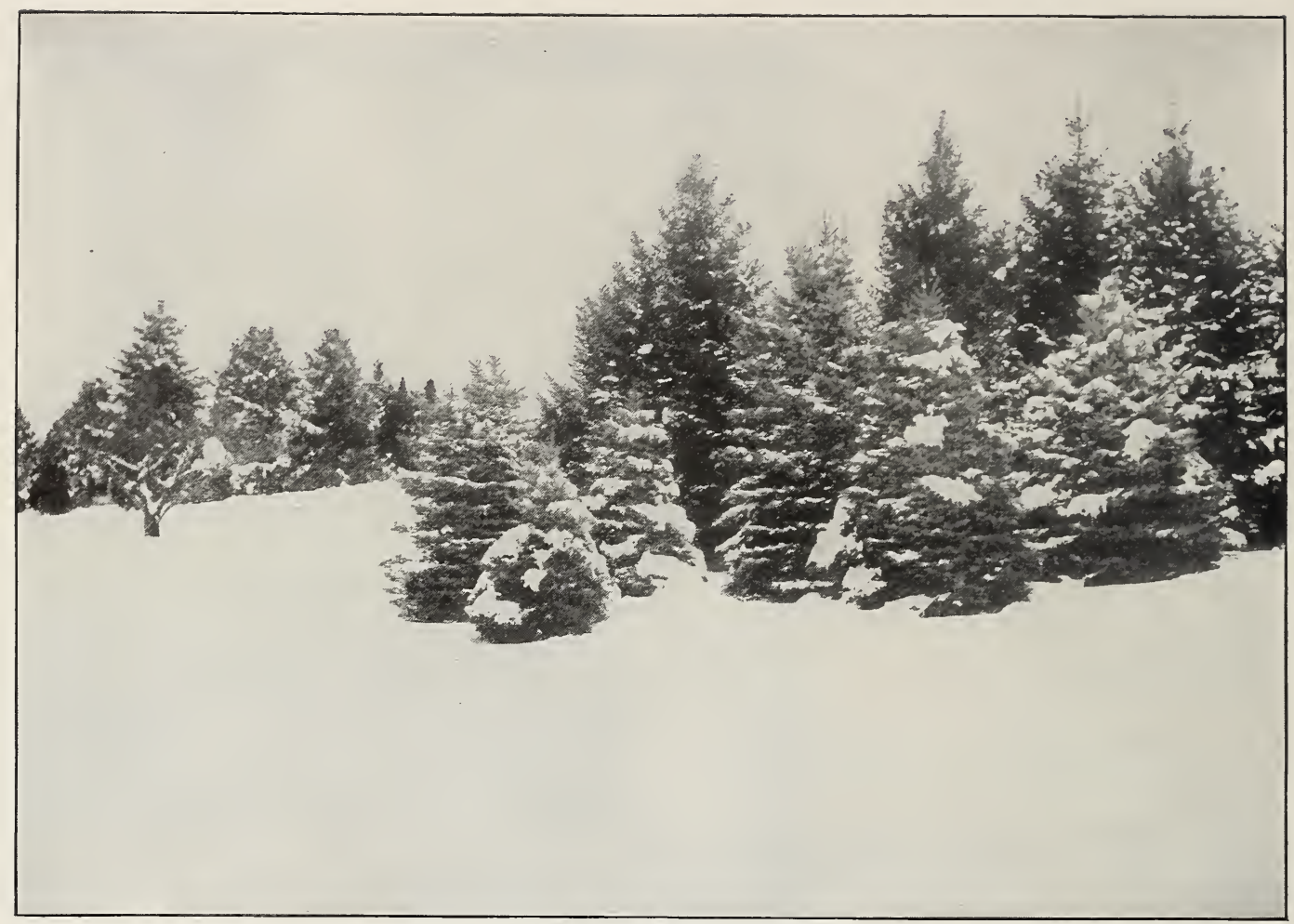

A group of White Spruce, Nordmann's Fir and Colorado Blue Spruce. They were mostly moved there by our tree-mover, and later thinned out by the same. They are at the northeast corner of a terrace, and make an excellent windbreak.

\section{Ebergreens}

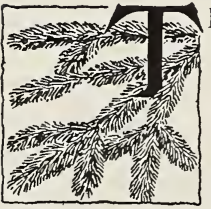

HERE always has been a demand for evergreens for landscape planting. There are several reasons why this want has never been adequately filled. First-They were not available in quantity at the nurseries. We have overcome this by growing them in hundred-thousand lots. Second-They were difficult to transplant. IVe have trained the roots for successful transplanting, have invented machinery and appliances for safely and quickly moving large evergreens, and have trained the men to do it properly. ThirdThey would not stand as long shipment as deciduous trees, which shed their foliage and are dormant. We have them right here when they are wanted, and they can be taken up with earth on their roots any time of the year and planted immediately. Good stone roads radiate from Westbury, making it practicable to deliver a thousand little pines and plant them in a day, so that they are just as certain to grow as poplars or privets. Fourth-The mental picture that some people have of evergreens is gloomy and unattractive. This is due to planting such species as the Norway Spruce, which here is often ragged and haggard in old age. We have grown and tested nearly every possible species of evergreen and their various geographical varieties, and know just about what they will do. Fifth-The evergreens love company and mutual protection. Failures have often been clue to planting them as isolated specimens. They have been too rare and too high-priced to plant in quantity. We now offer them at a low price in quantity, and big evergreens that give immediate protection.

The objections and difficulties have thus been largely overcome. The gist of it all is,-you want evergreens, we have the right stock and the men to plant it. We have the knowledge of where and how to plant them, and where not to plant the different species. One cannot expect to reproduce the evergreen effects of England, France, California, Oregon, Canada and North Carolina, by indiscriminately ordering the species from those regions. Millions are being wasted that way, and infinitely worse, the

Botanical gardens and arboretums will find here nearly every hardy species of evergreen. We shall be glad to exchange or give rare trees to test. We have many species not described in the Catalogue. 
fullest usefulness, comfort and beauty of the land is not attained. Nurserymen and their customers have both contributed to this mistake. The desire for quick results, the ease of importing, competition, and lack of the skill, foresight and botanical knowledge needed to grow hardy evergreens are responsible.

What to do.-Order a quantity of these pines and other evergreens. Plant the little seedlings, 6 inches high, in the grass of abandoned land, or in beds to grow on for planting-out later. If you want larger evergreens, we have them

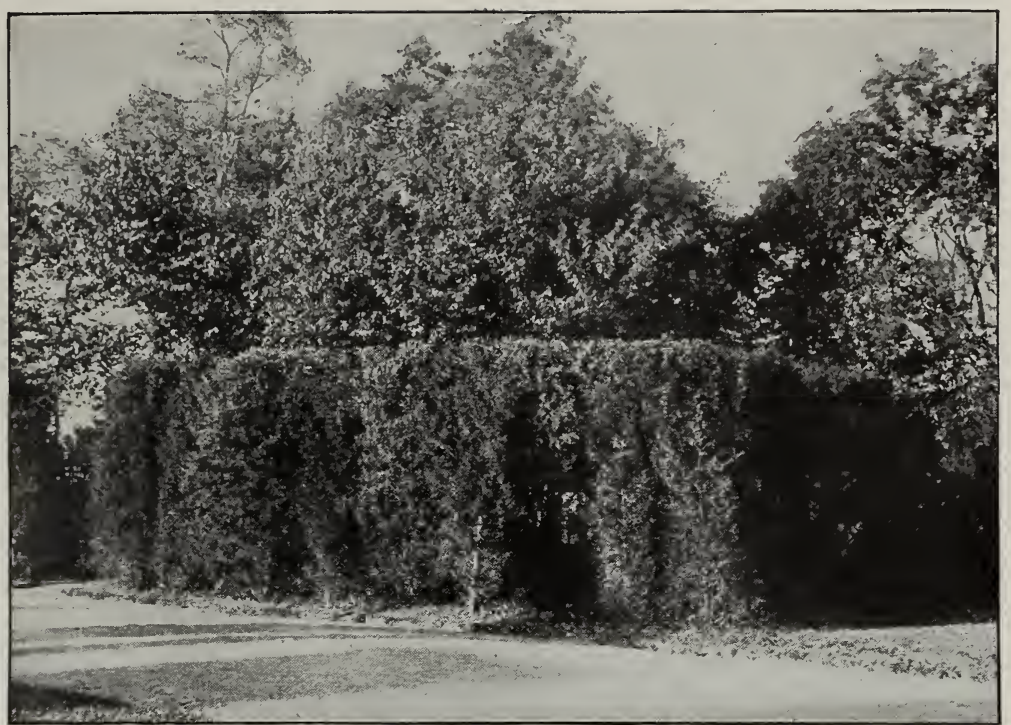

This laundry yard had to be next the entrance drive. It looks merely the thicker portion of a grove of Cedars.

from I foot to 40 feet high, and can move them in the best way by the most successful method.

Evergreens have been unjustly regarded the luxury of the wealthy. We have grown them at a price that will allow them to contribute to the comfort of every class. Our evergreens fit Long Island; therefore they are beautiful, and make utility the vehicle of beauty. Long Island is wind-swept. Thousands who cannot afford two residences desire to live in the country all the year. If transit and schools suited, and the winter bleakness were lessened, they would do so.

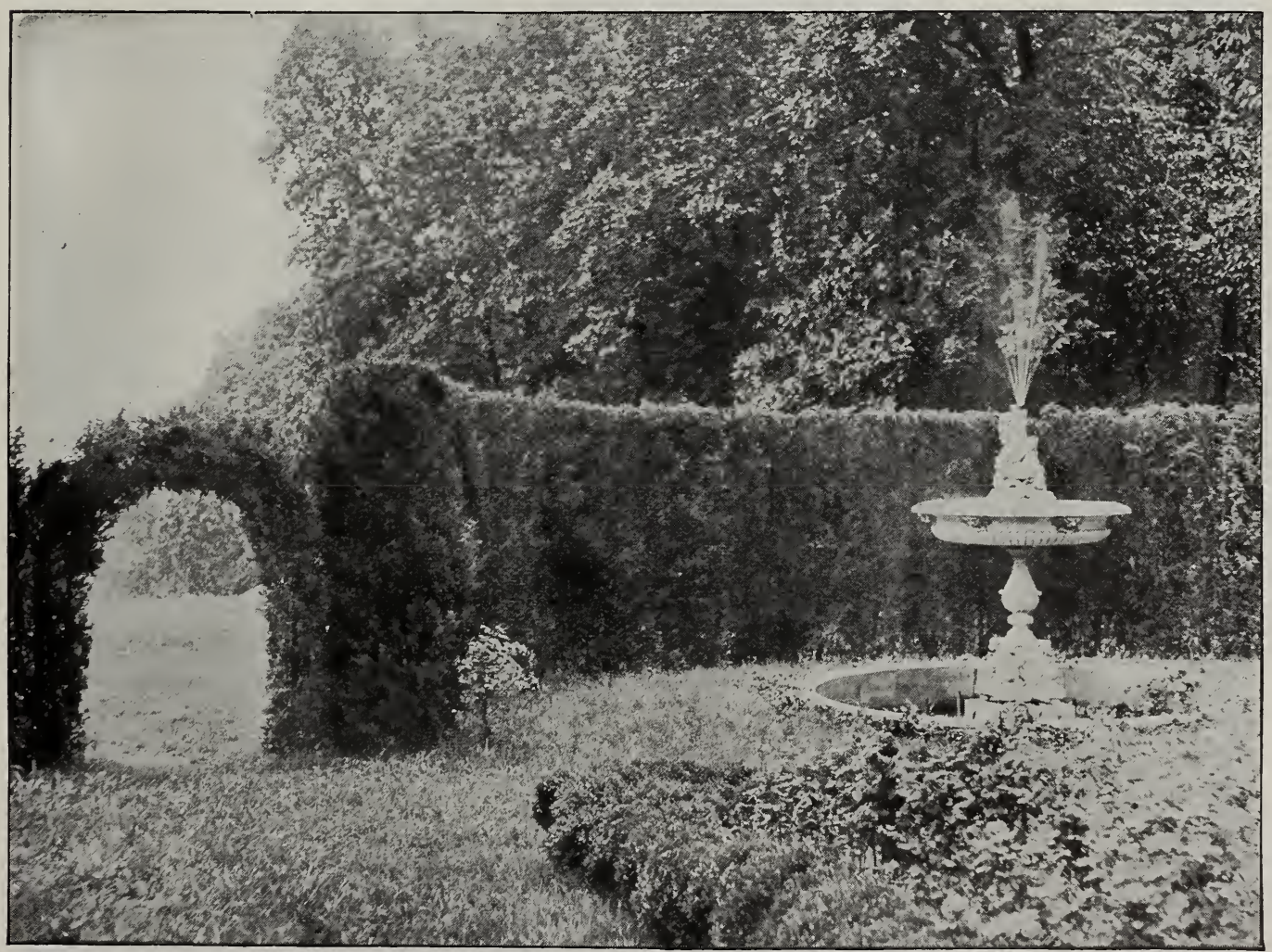

Portion of formal garden at Roslyn House, the residence of Mr. Stanley Mortimer. Hedge and arches of Cedar moved by us 


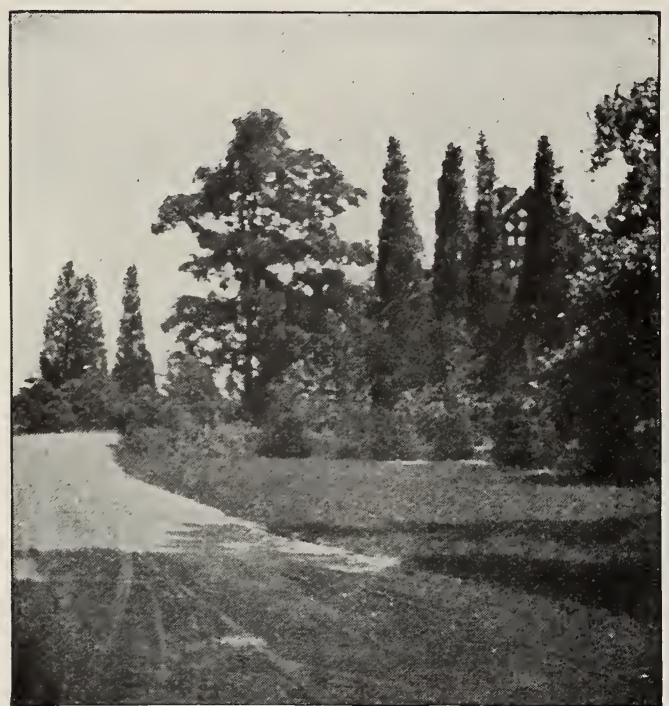

White Pine $30 \mathrm{tt}$. high, Cedar $15 \mathrm{in.}$ in diam., $35 \mathrm{tt}$. high, Spruce and Fir $24 \mathrm{ft}$. high, change the bleakest hill-top to comfort and beauty. Residence of Mr. Stanley Mortimer.

\section{ARBORVITAE. Thuya}

WHITE CEDAR OF THE NORTHERN STATES

American. T. occidentalis. Before the advent of the California Privet, the American Arborvitæ was the most popular hedge plant. It is bright green during the summer and turns to bronzegreen during the winter, and makes a thick screen the year round. Planted with pine, spruce or hemlock in groups or hedges, it will thrive and make an efficient windbreak. It sometimes winter-kills on Long Island, and therefore the Red Cedar is preferable.

Siberian. T. occidentalis, var Wareana; syn., Sibirica. This is not a native of Siberia, but merely a variety of American. It has darker green foliaze and a dense growth.

Pyramidal. T. occidentalis, var. pyramidalis. This is a dark green column resembling the young plants of Red Cedar. It will make a column 10 feet high and 2 feet wide and is therefore valuable in formal yardens.

Booth's. T. occidentalis, var. Boothii. A globe of dense foliage, useful in formal planting and at the edge of groups of tall evergreens. We have plants 5 feet high, resembling boxwood, trained as accurately as with a lathe. There are several other dwarf varieties.

Golden, or George Peabody. T. occidentalis, var. lutea. This has brilliant yellow foliage resembling Retinospora plumosa aurea.

Chinese. T. orientalis; syn., Biota orientalis. Of small value in this latitude. The winter color is brown or bronze.

\section{RED CEDAR. Juniperus Virginiana}

We have made the Red Cedar popular. It is the only evergreen which is native to all types of soil, and all degrees of exposures on Long Island. Our inventions have enabled planters to use thousands of Cedars 6 to 35 feet, heretofore considered difficult or impossible to transplant successfully. The Red Cedars are the best and cheapest trees to make a screen to an unsightly building, service court or laundry yard, and they make an effective windbreak. If a greater variety is desired, they will harmonize with white pine, spruce and other species of evergreen. A mutual protection against the wind will resule in developing the highest beauty of all the species in the group. For sand dunes and bluffs, or to keep sand from wasting and running down, make thick plantations of Cedars, pitch pines and other evergreens mixed with deciduous shrubs and plants.

The Cedar is the only hardy species of evergreen which will reproduce the effect of the cypress of Italy. We have trained speci-

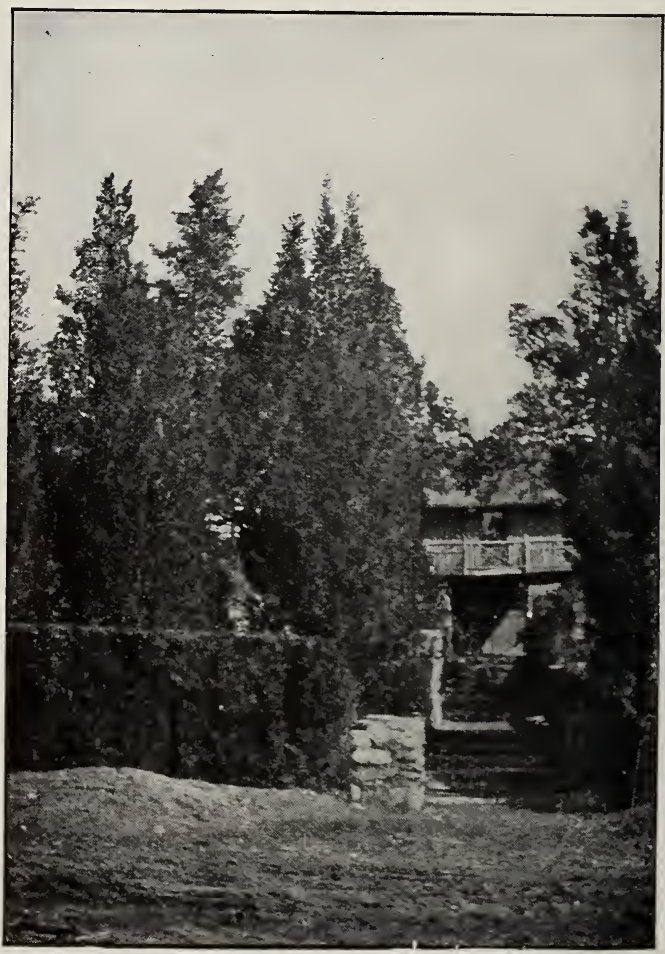

Part of a circle of Cedars moved by Hicks tree-movers in the Italian garden, Roslyn House. Steps lead to gymnasium. nursery. 


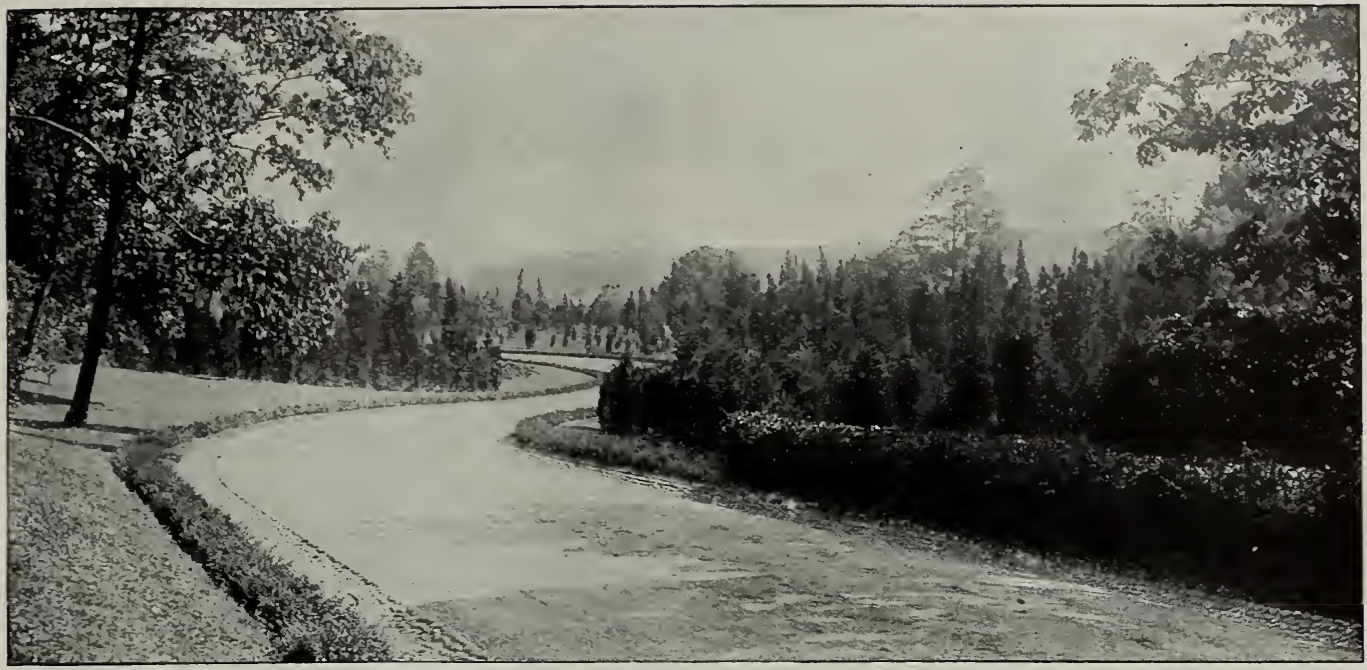

On the main drive at Harbor Hill, Roslyn. Estate of Mr. Clarence Mackey. Evergreens 5 to 30 feet high, moved by the Hicks tree-muvers, shut out an unsightly view of the railroad and the village.

\section{RED CEDARS, continued}

mens for formal gardens, from 3 to 35 feet high. For moving Cedars, we will send experienced men with machinery to do this work in the most successful and economical manner. There are many details essential to success, the omission of which may render the investment worthless.

Blue. Juniperus Virginiana, var. glauca. A variety of the above, having bluish foliage.

\section{CEPHALOTAXUS FORTUNEI}

A member of the Yew family that thrives in a moist, protected situation, and is suitable for woodland borders. A round bush with graceful branches and lustrous dark foliage.

\section{FIR. Abies, erroneously $p_{i c e a}$}

The Fir family includes some of the noblest trees. The best known species is the Balsam Fir of the northern forests, which is cut in large quantities for Christmas trees. Unfortunately it does not like the hot summers here, and gets ragged after a few years. Other species, as the Concolor Fir, the Nordmann's Fir and Veitch's Fir, thrive and are worthy of the most honorable place on the lawn, All the Firs are pyramidal trees, with pointed tops and low branches sweeping the ground.

Nordmann's. A. Nordmanniana. This species is a favorite with lovers of handsome trees. There is a richness and dignity about it which will remove the commonplace expression from any lawn. The foliage is a beautiful shade of lustrous dark green, with a silvery tint on the under side. The leaves remain on for eight years; therefore the center of the tree does not become bare or thin. We have the finest stock of large plants on the market, up to ${ }_{15}$ feet in height. These have been successfully transplanted by our tree-movers. This with the Oriental spruce is native of the high mountains of Asia Minor.

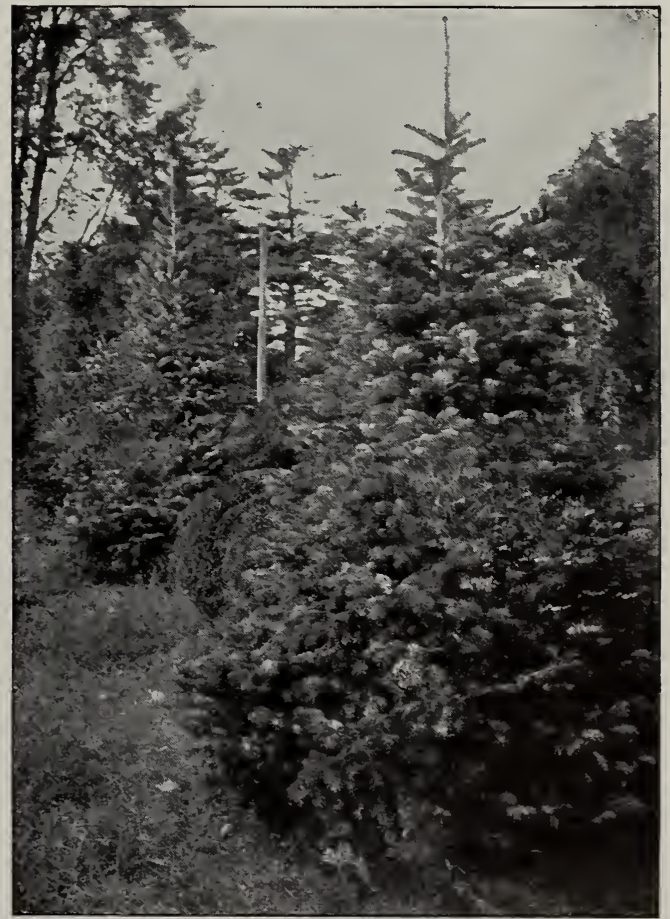

These Nordmann's Firs have been growing in our nursery for fifteen vears.

If you want big evergreens, cheap, hardy and beautiful, saving 25 years' wait, we can deliver them any week in the year. They are sure to grow. In our nursery we can show groves of hundreds of them 12 to 35 feet high. 


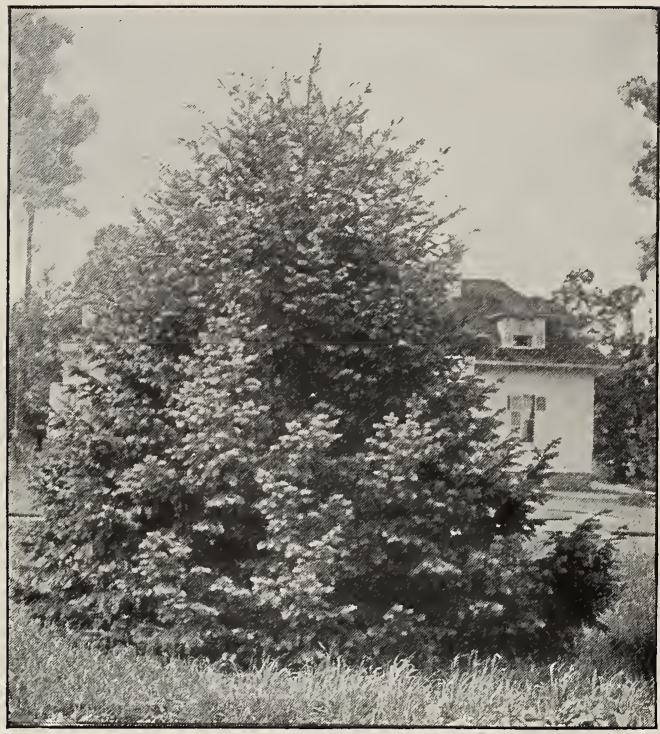

Douglas Spruce, moved with Hicks tree-mover to the grounds of Mr. William D. Guthrie, Locust Valley.
FIR, continued

Silver. A. picea; syn., $A$. pectinata. This species resembles the preceding, but is neither so thick in foliage nor so hardy. We offer specimens ro to I6 feet high.

Cephalonian. A. Cephalonica. A tree of dense foliage composed of sharp-pointed needles. It has proved valuable and hardy.

Fraser's Balsam. A. Fraseri. This will probably be a handsome tree for ten years or more, fitting it for temporary planting.

Concolor, or White. A. concolor. A tree destined to receive the enthusiastic appreciation of lovers of handsome trees, when its merits are known. The color of the foliage is a light blue-green; it harmonizes well with other foliage and does not contrast so strongly as the Colorado Blue Spruce. It is very hardy even in the severest winter, and can withstand the salt spray of the seaside, or a drought. This strong, noble tree is from the high peaks of the Rocky Mountains in Colorado. There are other forms of it from the California mountains which are not so hardy.

This selection of seed from the right locality and altitude is an essential part of our system of growing trees.

\section{HEMLOCK. Tsuga, erroneously Abies}

Common. T. Canadensis. The peculiar qualities that distinguish the Hemlock are feathery gracefulness and a pure and permanent green color. It is a native of the hills, and valleys north of them, on Long Island, there being a few old trees which have escaped the axe of the early settlers. It will endure partial shade, and may be planted along the borders of woods to add a greater beauty to the winter landscape. Some plantings of shrubs are uninteresting in winter. The Hemlock can be planted between the shrubs, and the latter thinned out as the Hemlock grows. The shrubs afford the best wind protection to develop the beauty of the Hemlock. The Hemlock does not like to stand alone in a windy place, nor within a mile of Great South Bay.

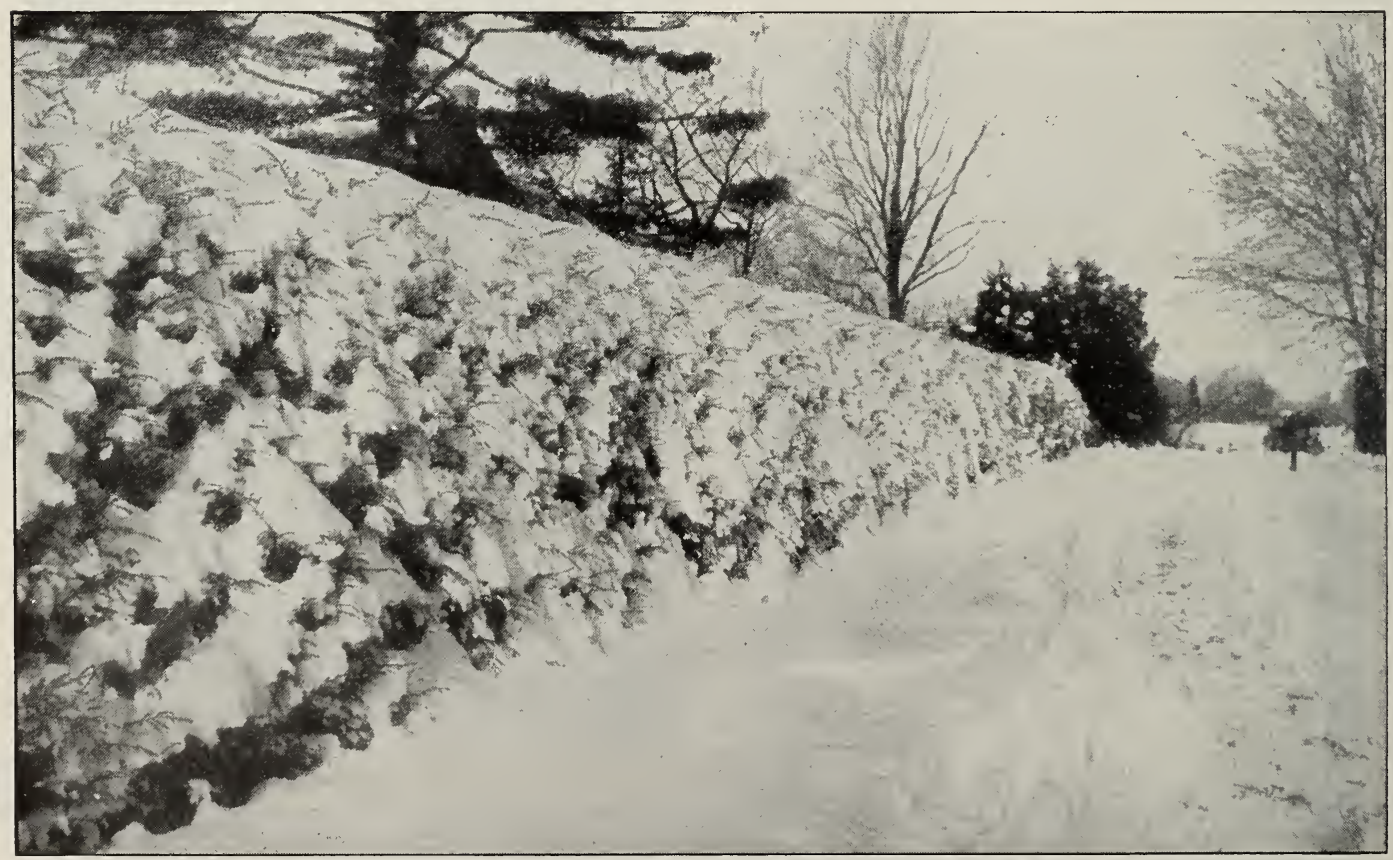

Hemlock hedge, to feet high, at the Westbury Nurseries. We offer similar hedges prepared for successful moving. An unequaled opportunity to reproduce in a formal garden the effect of the old Yew hedges of England. 


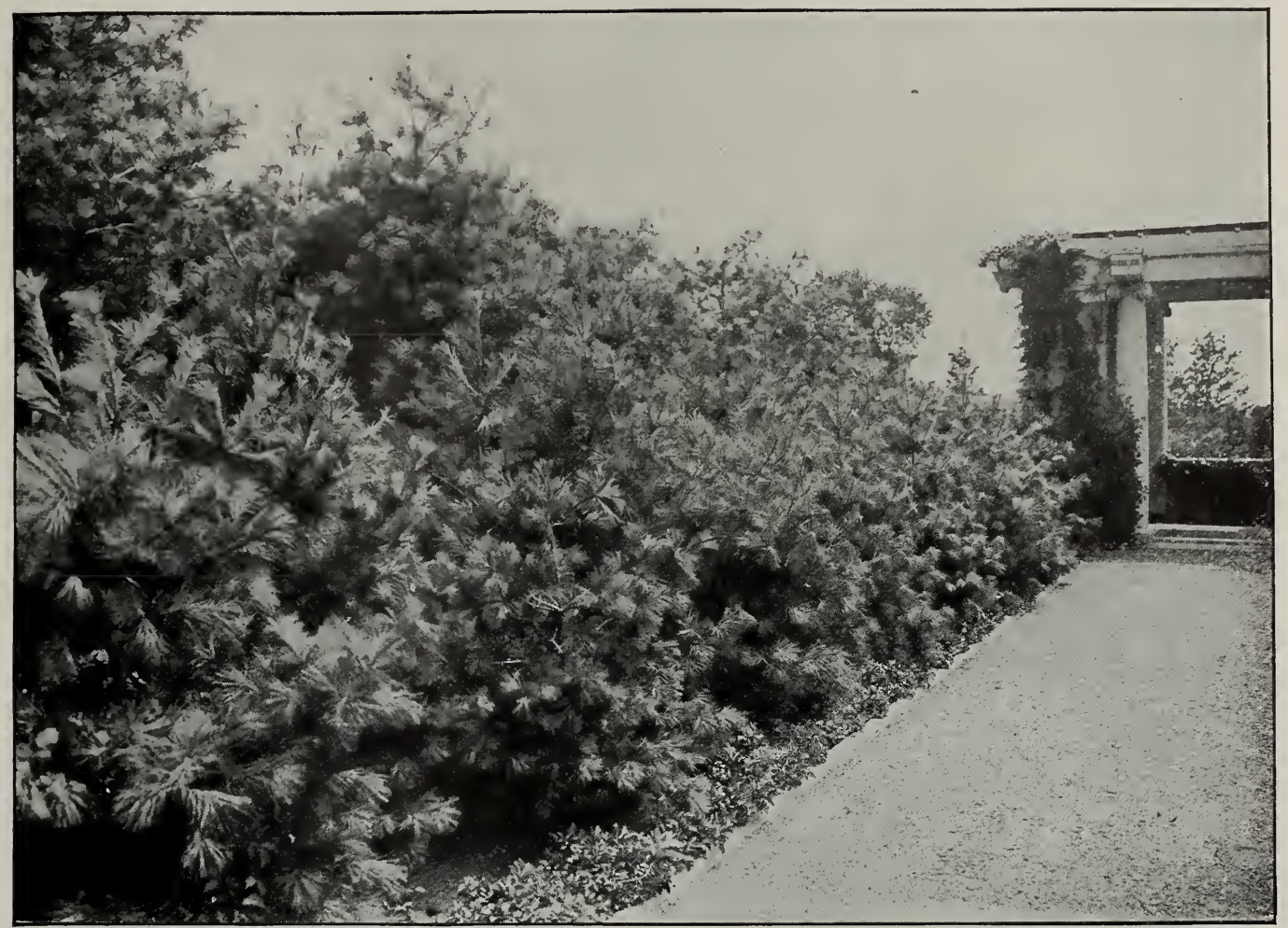

White Pine bank in formal garden. It is not generally known that by pruning in May and June it may be kept low, dense and full. Pachysandra terminalis is the low evergreen at the base.

\section{COMMON HEMLOCK, continued}

We offer an unparalleled opportunity to reproduce the effect of the old Yew hedges of England, having a hedge about 30 years old, 9 feet high and wide, clipped to a uniform shape, and prepared for successful transplanting. For taller effects, we offer a group 25 feet high, 40 feet long and 25 feet wide.

Carolina. T. Caroliniana. A graceful, hardy tree of a lighter green than the above.

\section{JUNIPER. Juniperus}

Most of the Junipers are small trees or shrubs, the Red Cedar being the most valuable of all as a tree. (See page 30.)

Irish. $J$. communis, var. Hibernica. This is accustomed to a more equable climate than ours, and frequently winter-kills here. It grows as a cylindrical column useful in formal planting. We recommend using the red cedar in its place, and offer large quantities of uniform specimens, trained by a machine of our invention.

Flat. J. communis, var. Canadensis. While botanists call this species the same as the Irish, it differs in hardiness and form. It makes a broad, saucer-shaped bush covering the rugged hillsides of New England, and is occasionally found on Long Island.

Golden. J. communis, var. Canadensis aurea. This makes a bright golden mat I to 2 feet high and 5 feet wide.
J. Chinensis, var. procumbens. The Japanese use this for holding the drifting sand at the seashore, and, like many Japanese plants, it is perfectly at home here. It looks like a carpet of bright green moss 6 inches deep, closely covering the ground. When it becomes more common, some one will make a charming effect with it as a ground cover. It may be used in front of evergreens on a steep bank, on the side of a terrace slope or in a rockery.

Prostrate, or Trailing. J. Sabina, var. prostrata. This attractive creeping Juniper is native to New England. It grows as a cushion to inches deep, or its long trailing branches hug the rocks and hang over the top of a wall or the crest of a surf-beaten cliff. It may be used as a border to evergreen plantings. 


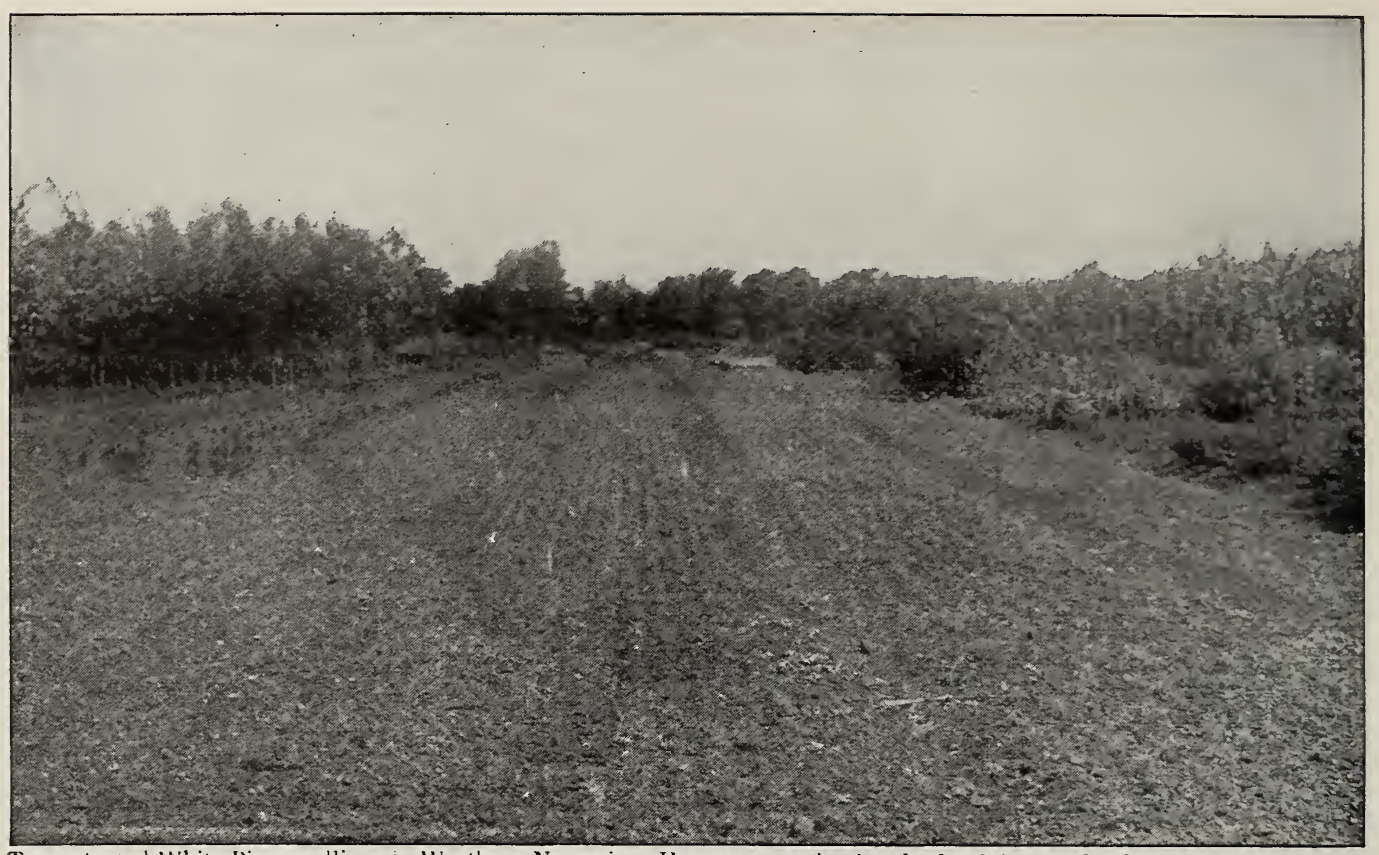

Transplanted White Pine seedlings in Westbury Nurseries. Here are growing hundreds of thousands of evergreens, oaks, etc., that fit Long Island and the northern states. A most extensive and scientific achievement in accurately fitting conditions

\section{PINE. Pinus}

WHITE. P. Strobus. We have 50,000 White Pine, from 2 inches high up to 40 feet, for any purfor you and for the future pose. It is a new opportunity to do some of the best things with land for you and for the future. The White Pine fits Long Island, where it has grown larger and lived longer

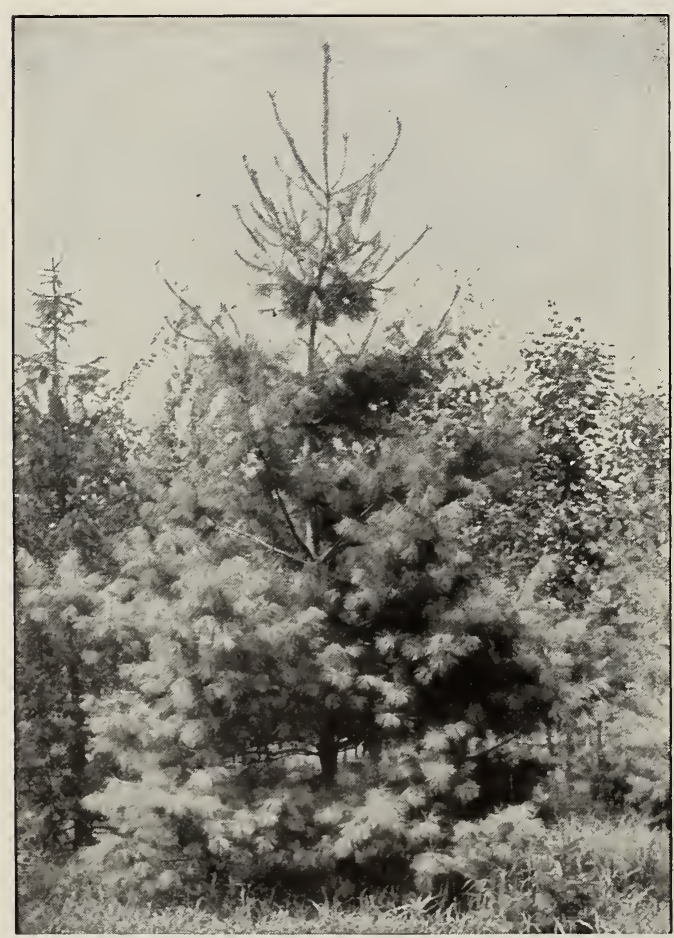

White Pine $16 \mathrm{ft}$. high in our nursery. We offer large White Pines in quantity up to 40 feet high. than any other evergreen. At Roslyn, East Norwich, Woodbury, Hernpstead, immense trees remain as remnants of the great forests cut by the early settlers. In the Scrub Oak and Pitch Pine region where the soil is dry, it grows rapidly and spreads aggressively by natural seeding under the Pitch Pines.

Millions have been wasted on Long Island for lumber that could have been grown here if the necessary foresight had been exercised with the skill of Germany and France.

The beauty of the White Pine is in its cheerful green foliage, the tall and massive trunk, the widespreading horizontal branches, with deep shadows between, and the tips glistening like steel-blue needles. It is one of the most rapid of evergreens, often making over two feet per year. Yet for small lawns and hedges it can be kept small and compact, thick-foliaged to the bottom by nipping out the tip of the leading shoot of the upper branches in May, June or July.

Privacy for part of a country place is one of the essential elements. With the lengthening country season that is coming with better transit, evergreens are essential. White Pine will form a large part of the plantings. Plant a belt from to to 100 feet wide. With a screen belt a small place has as much privacy as a larger area. 


\section{WHITE PINE, continued}

Forestry Is just beginning to attract the attention of far-sighted and intelligent people. The IVhite Pine is the most valuable forest tree native to the northeastern United States. It is now in greater demand for forest planting than any other tree. We are prepared to meet this demand with a large stock of young trees. We will gladly furnish advice on the subject of forest plans, but would suggest that those intending to go into this matter get the publications and advice of the forest service of the United States Department of Agriculture. The reason that the White Pine has so nearly disappeared on Long Island is that the mother trees were cut down, and fire or less valuable trees killed the young seedlings.

There are profitable forests planted in New England 40 years ago which yield 5 to 6 per cent. Other possible uses for land on I.ong Island may make it too high-priced for timber culture, but the land exists, and for much of it timber will reduce the expense of holding, besides being the most beautiful cover. Pines, oaks, chestnut and locust will be the mainstay of economic forestry for this region. Large country estates are expensive to maintain. Economic forests are the cheapest and most beautiful treatment for large portions. Nature takes care of them. There is satisfaction in playing the game according to the rules. Your experimental forest will teach you and your friends how to keep up the future value of industrial and transportation stocks. The best trees are there if the land should be subdivided for smaller resident sites. Planting for such sites is an excellent investment and improves the general landscape when properly done.

The White Pine has limitations. They do not veto it, but show why and how it should be planted by the thousand. Ice-storms break branches, but not seriously if the lower branches rest on the ground, or

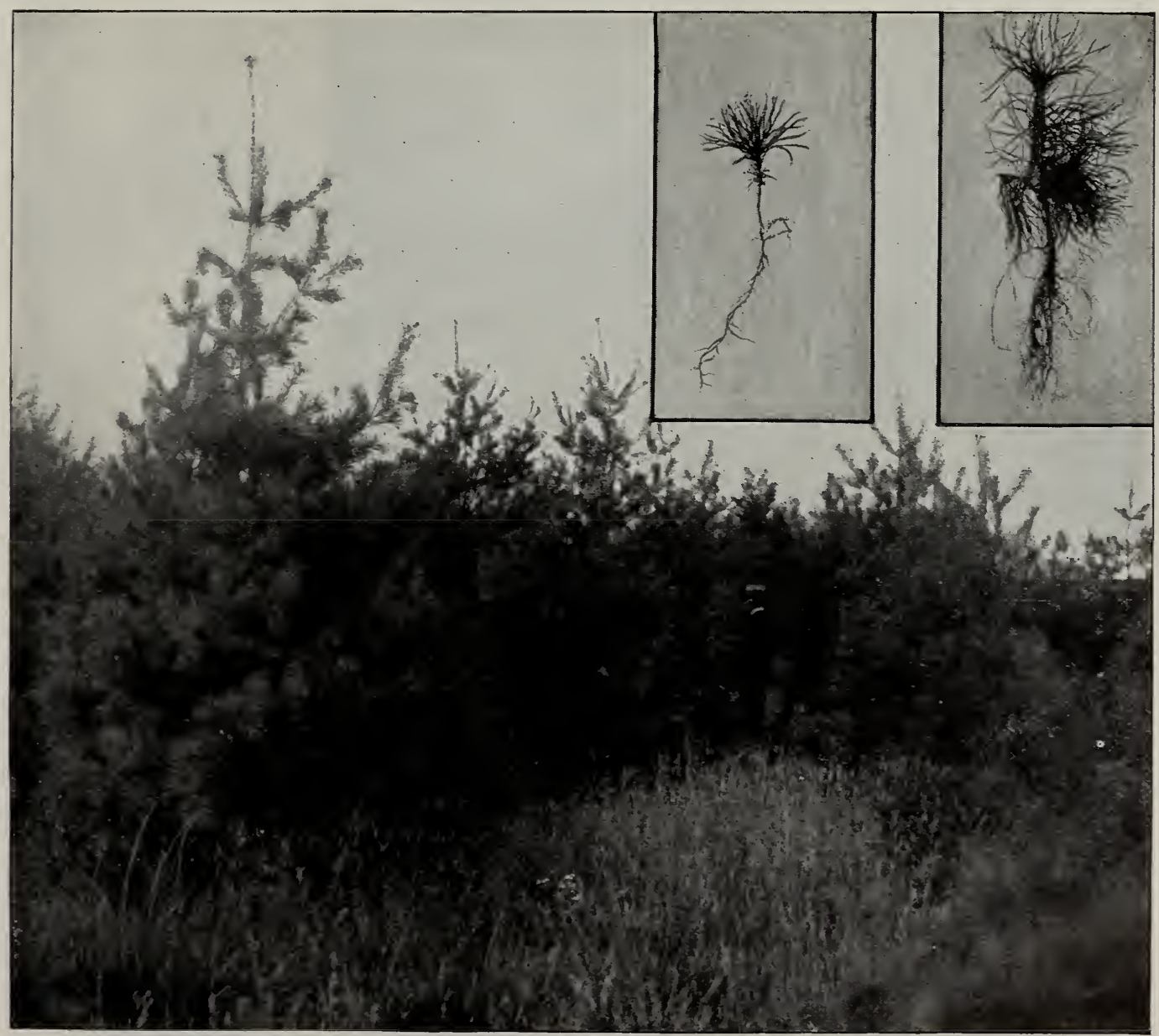

White Pine forest planted by us on sterile soil for Mr. E. D. Morgan, Wheatley Hills. Eight years' growth from the size shown in the corner. Dun't be afraid of small evergreens. Trees 4 inches high or trees 3 feet high, as shown on next page,
will give this effect in about the same time. The difference in cost is considerable. 


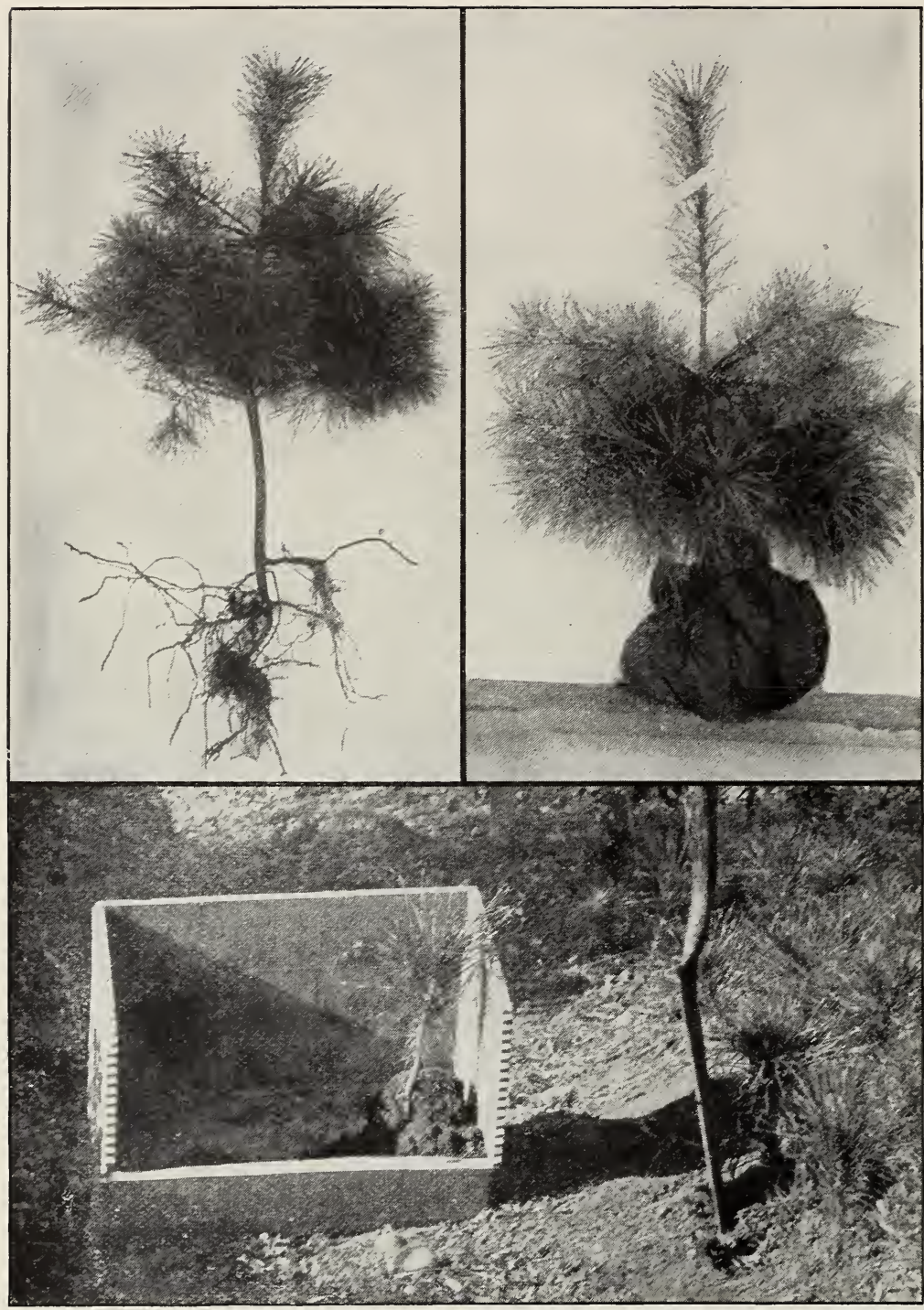

WHITE PINE, continued if the upper branches are shortened from a tower wagon. The White Pine disease which browns the foliage in summer and shortens the leaves and growth is not contagious. It affects only a small per cent, not so much as the necessary thinning. The White Pine does not like salt spray. Mix it with pitch, Scotch Austrian pine, red cedar, white spruce and deciduous trees when near the sea. The White Pine likes the company of pine and oak and likes the mulch of pine needles and the low branches which keep the frost from the roots and let the sap come up all winter.

WHAT TO DO. Order a few hundred or thousand White Pines, pitch pines, Scotch pines, oaks and chestnuts. Plant in the

Three ways of delivering evergreens : ( $\mathrm{I}$ ) Without earth on the roots. Root-pruned twice where the roots branch out. Dipping in thick mud keeps the roots moist. (2) With ball of earth wrapped in burlap. (3) In a box with earth. This keeps roots moist and prevents breaking. A thousand or more can be carried in a load this way and be safely planted. Nos. I and 2 White Pinea, No. 3 Austrian Pine.

grass or bushes of an abandoned field, plant in the sprouts of cut-over woodland, plant in a private nursery, plant a windbreak or screen on your lawn. We will plant them if you wish. Time of year is not important. We have successfully planted evergreens by the thousand in February, March, April, May, June, August and September, and the larger sizes from October to March. For small pines March, April, May, August and September are excellent. Don't forget that evergreens can be planted in August and September. It doubles your opportunities. Our stock is from Long Island seed and other hardy stock. For immediate results we offer White Pine, up to 40 feet in height. This is a new and important achievement in tree-moving. We have invented a distinct type of tree-mover for this work. For extensive plantings of screens and windbreaks we offer White Pines in quantity, Io to 20 feet high.

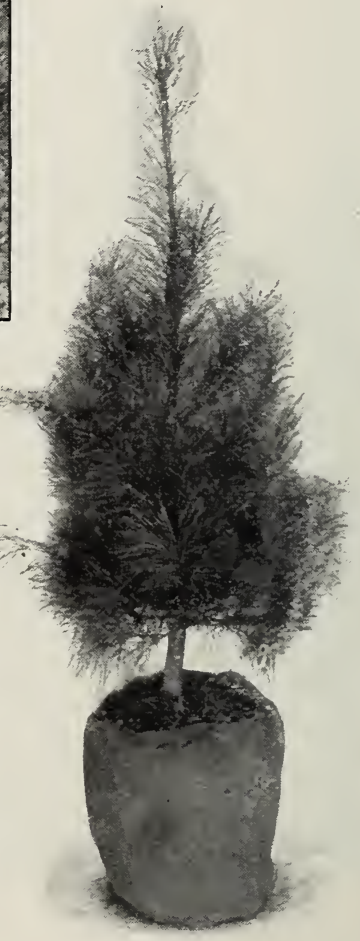

White Pine 3 feet high 


\section{PINES, continued}

Pitch. P. rigida. We have 20,000 Pitch Pine, from I cent to 75 cents each. They have a warm, sunny green foliage in thick rounded masses. The fragrance is pleasant and healthful. The beauty of Pitch Pine is not appreciated, because nearly all the trees seen have the branches burned off and the soil damaged by fire. The main thing is that they will work fast on the driest ground. When a severe drought stops many other trees, they are making a second growth. Nature has planted it over thousands of acres of the driest soil on Long Island. It is highly recommended for extensive planting In its shelter other trees will thrive which could not do so without it. There are thousands of residences along both shores and in the center of Long Island which should have Pitch Pine forming part of their shelter plantations. It is valuable both summer and winter. Nature uses it right out to the shore line mixed with oak and bayberry. For dry sand and gravel hills it is the best cover. Other trees can be mixed in. Sand bluffs along the shore of Long Island Sound are rapidly wasting away, narrowing the lawns and sometimes endangering residences. Sea-walls hold the bottom. Pitch Pine will help hold the sliding bank at a steeper angle than sod. The sod requires that the bank be graded back less steep, needs good soil, roots only a few inches deep and may slip or dry out. Pitch Pine and cedar root deeply, thrive on sterile sand and salt spray and work all the year. Damage is most severe in winter. The wind blows the sand loose even when frozen, and thawing lets the surface slide. The drifting snow carries sand with it. Beating rains gully out the bluff and carry the sand down. Pitch Pine will check all this. It keeps the wind off, holds the snow, prevents the frequent thawing, and lessens the gullying by the rain. Its deep roots anchor it and check sliding, and it holds the accumulating leaf-mold from the trees and shrubs which should accompany it. Road banks, steep terrace slopes, old sand pits, all provide economical uses for Pitch Pine. On the Rockaway and Montauk peninsulas it should form the backbone of groups. Add it to existing groups, and plant new ones. For holding sand dunes it may be worth thousands of dollars to many landowners. On Cape Cod the government uses it to prevent the drifting of sand. Plant 5 to ro feet apart.

Scotch. $P$. sylvestris. A blue-green tree of rounded form and rapid growth. It should be planted with the other pines and spruces. It may make the quickest growth for the first dozen years. Later it will be surpassed by the white pine, for it has not proved long-lived on Long Island. It is an excellent seaside tree and

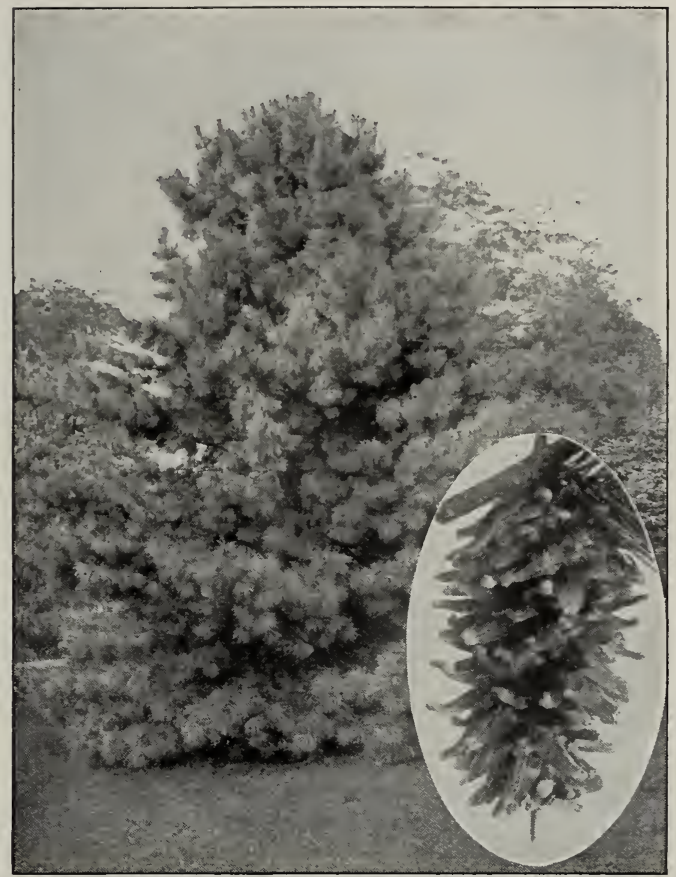

Korean Pine in the arboretum of the late Charles A. Dana. A beautiful blue-green tree of compact foliage and excellent nuts. A rare opportunity to get this species.

\section{Scotch Pine, continued}

thrives on bare sand-hills. We offer it by the thousand at very low rates. If you want a quantity, it is of slight or no advantage to plant larger trees, 3 to 6 feet high.

Austrian. P. Laricio, var. Austriaca. This sturdy tree is the favorite with some for seaside planting. It is a dense round-headed tree, with long, thick needles uninjured by salt spray or severe winters. It can be depended upon for 20 or 30 years when it begins to deteriorate here.

P. densiflora. A very promising Pine from Japan. It grows very rapidly and is hardy. Foliage thick and apparently adapted to exposed situations.

Korean. P. Koraiensis. A hardy beautiful tree and a valuable food-plant. The immediate cause of the Russian-Japanese war was a timber concession including this species on the Yalu River. As would be expected from the climate map on page 5 , it stands a more variable climate than ours with the same January average. Unlike some evergreens from high dry mountains, it does not suffer from summer fog at sea-level. The blue color is nearly as pronounced as the Colorado Blue Spruce. The density of the tree is remarkable. The nuts are the size of Hazelnuts, with thin shell and a nutritious meat of delicious flavor. The Piñon pine nuts of Arizona are similar, and furnish large food supplies. IVe have trees bearing at 6 feet high. 


\section{PINES, continued}

Mugho. P. montana, var. Mughus. The Mugho, or Mountain Pine, makes a dome of dark green foliage 3 to ro feet high, and of greater width. It is indispensable in some landscape situations, as on borders of taller groups on steep banks and terraces. On the brink of a bluff it allows a view, yet gives shelter and removes bleakness.

Red, or Norway. P. resinosa. A Pine closely resembling the Austrian, and native from Massachusetts westward on dry soil. It is a dark, handsome tree with long dark green needles. It is a long-lived, beautiful tree with no bad habits. The Red Pine is very rare in nurseries. Its exceedingly rapid, sturdy growth and evident determination to thrive should lead to its extended use.
Swiss Stone. P. Cembra. A slow-growing, compact pyramid of blue-green foliage that does not like the hot summers and is not long-lived here.

Bhotan. P.excelsa. The needles are the longest of any Pine growing here, and hang gracefully downward. It resembles our IVhite Pine, and makes a broader pyramid of light green foliage.

\section{UMBRELLA PINE. Sciadopitys}

S. verticillata. A small garden or lawn tree, which attracts attention by its dignity, refinement and aristocratic bearing. It is a pyramid of graceful, lustrous foliage. The leaves are 5 inches long and $1 / 4$ inch broad, arranged in a circle, like the rays of an umbrella.

\section{RETINOSPORA. Japan Cypress; Chamaecyparis}

The Retinosporas are the embroidery of the evergreen family. They are best used for masses or thickly planted groups, where the summer beauty of their foliage is seen close at hand. The tops of the group may be sheared off as coleus or other carpet-bedding plants. Some of the best examples of this use of Retinosporas are at Newport. The Obtusa and its variety have proven very hardy. The Pisifera and its varieties showed, in the winter of $1903-04$, that they do not like to stand alone in the wind in deep-frozen ground. In this way they resemble their closest relative, the White Cedar, or Chamacyparis sphceroidea. It is the least known native evergreen on Long Island. At Merrick it can be seen north of the railroad in the swamps of the Brooklyn water-works. It is a tall, dark column. This White Cedar of the coast swamps is different from the Arbovitæ, or White Cedar of the North. Our stock of Retinosporas consists of large, well-established plants with large root systems. They will be delivered with large balls of earth. The tops have been frequently sheared. These are offered at a low price. We recommend this stock highly for those who have a corner or border to fill in solidly with low evergreen foliage.

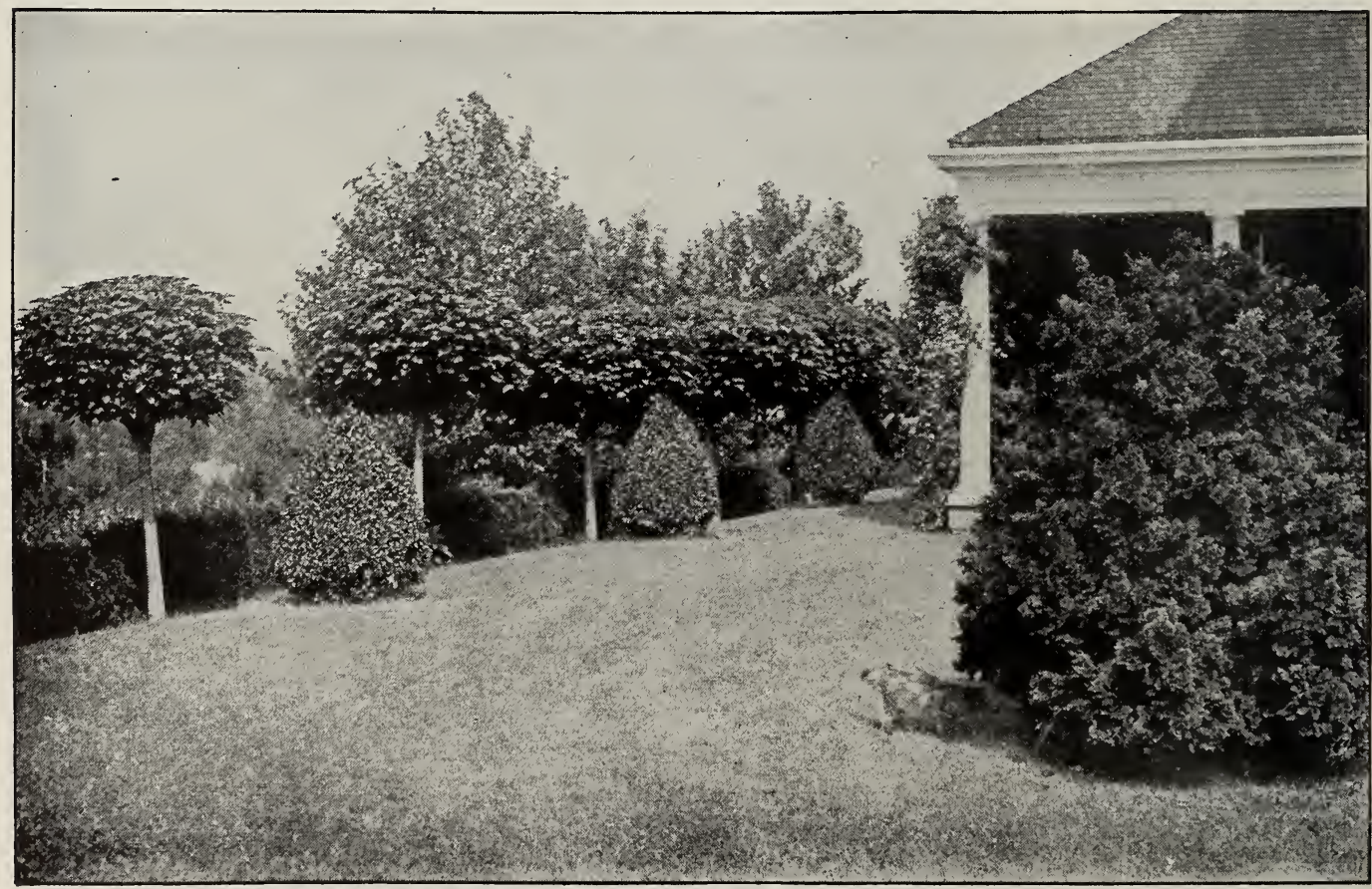

Retinospora ubtusa on the right. Catalpa Bunger standards and privet pyramids as a terrace planting 


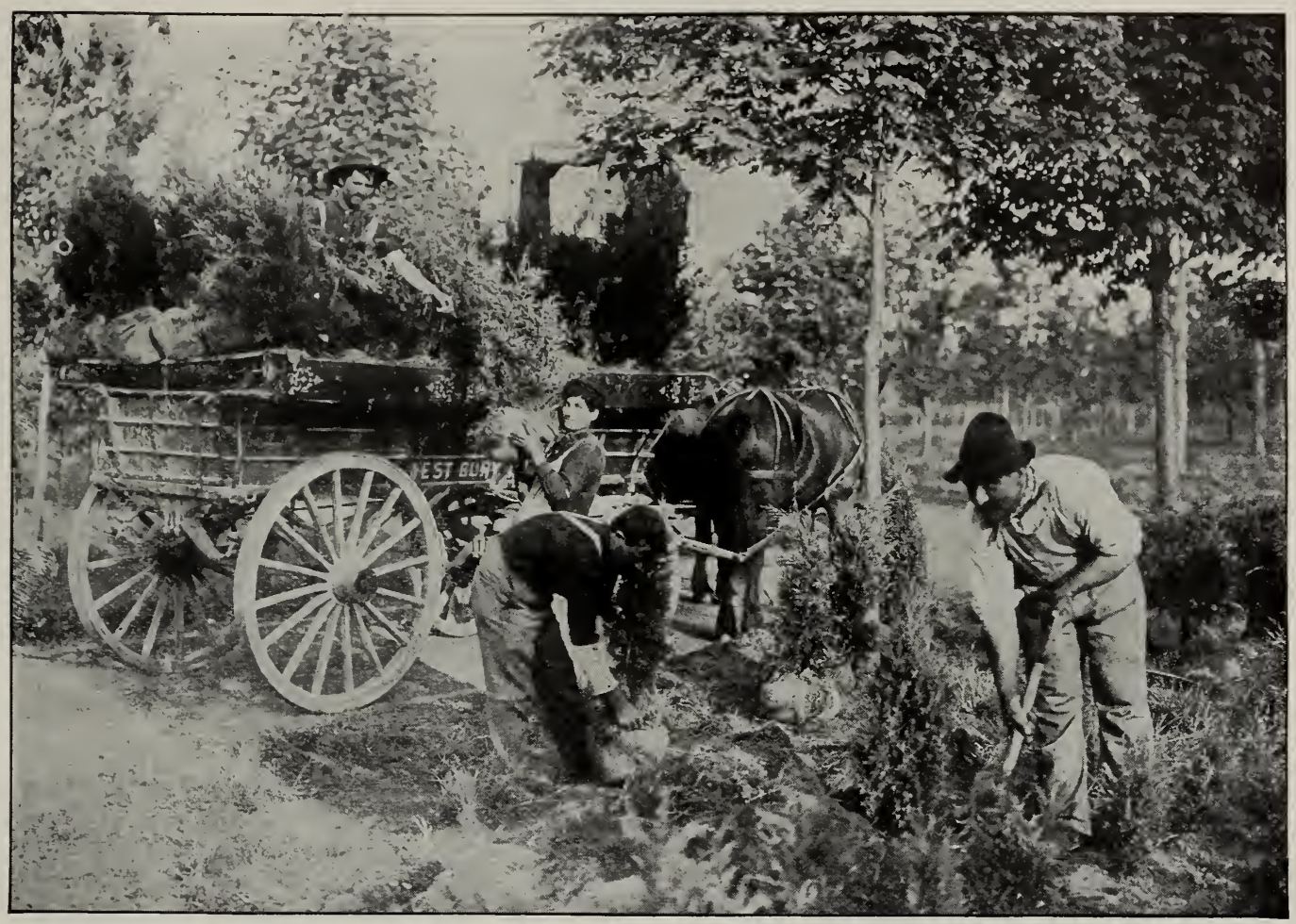

Our evergreens are mostly moved with larger balls than usual, or with ball of earth where it has not been customary Large balls of earth are a decided advantage on Long Island. Our prices are low and the degree of permanent success is high The picture shows how several hundred can be cheaply delivered. August and September is an excellent time, and so is the spring. By our methods we move evergreens all the year.

\section{RETINOSPORA, continued}

R. plumosa. C. pisifera, var. plumosa. Usually in the shape of a pyramid 3 to 8 feet high and wide, with light green foliage.

R. plumosa aurea (Golden Japan Cypress). $C$. pisifera, var. plumosa aurea. This is the best known variety. Its deep golden yellow foliage is brilliant all the year and adds a cheerful note to the landscape.

R. squarrosa (Blue Japan Cypress). C. pisifera, var. squarrosa. The silvery blue member of the family is a charming little tree. Its bright and fleecy foliage and happy expression win friends for it winter and summer.

R. filifera. C. pisifera, var. filifera. This is a light green pyramidal tree, with thread-like branches, 8 to 14 inches long, gracefully arching over its surface.

R. obtusa. C. obtusa. This distinct species differs from the graceful and delicate forms of the above in being dark green, strong, rugged and hardy in appearance. In Japan it is an important tim-
R. obtusa, continued

ber tree, and is worthy of general planting here. Fifth avenue auction rooms sell at fabulous prices the Chabo Hiba as 200 years old, the heirlooms of the ancient families. The skilful Japanese manufacture them from this species, twisting it in grotesque forms and grafting on numerous little branches of the dwarf variety. It then resembles the quaint gnarled plants made by patient dwarfing and starving in little pots for several generations.

R. obtusa nana (Japanese Dwarf Cypress). C. obtusa nana. A curious compact little plant, contorted as if it struggled with fate on the cliffs of alpine summits or by the sea, where the wind twisted and buffeted it about. Each plant grows after a different plan. It may be used in rockgardens or wherever a touch of darkest green in small form is needed. A weird and unique plant. There is a golden form of this beautiful variety.

Raising evergreens from seed in the middle Atlantic states has not been customary, because it is easy to import or to grow from cuttings; but such are not all reliably hardy or happy in dry soil. We have grown evergreens from seed of Long Island trees and others of similar climates. It has required scientific knowledge, foresight and skill. The result is ready. Will you take advantage of it? Evergreens mean comfort and beauty. They are coming into fashion. It is right that they should, because the beautiful and hardy evergreens are now available. 


\section{SPRUCE}

\section{Picea, erroneously Abies, including $P$ seudotsuga}

The Spruces are always pointed at the top. They generally have sharp needles and hanging cones. The firs also have pointed tops, but their needles are generally flatter and less sharp and the cones are erect. Hedges of Spruce are excellent because they hold their lowest branches to the ground. In trimming hedges, it is essential to favor the lower branches by leaving the bottom much the wider. Vertical sides mean open base with almost any hedge.

White. P. alba. A tree that has all the good qualities that an everyreen needs. It is very hardy. The severest winters do not hurt it in the least. In beauty it ranks with the highest. The foliage is a cheerful blue-green, dense and handsome. The growth is vigorous, and the form of the tree a broad-based cone. It thrives near the sea. It is a tree that holds itself up well. It will be the bulwark of comfortable homes.

Norway. P. excelsa. The good qualities of Norway Spruce are that it is cheaply imported from Europe, it grows quickly and it looks well while in the nursery and a few years after. There end the good qualities of 80 per cent on Long Island. The Norway Spruce is responsible for a frequent dislike of evergreens. When people say, "I don't like the evergreens ; they are gloomy and

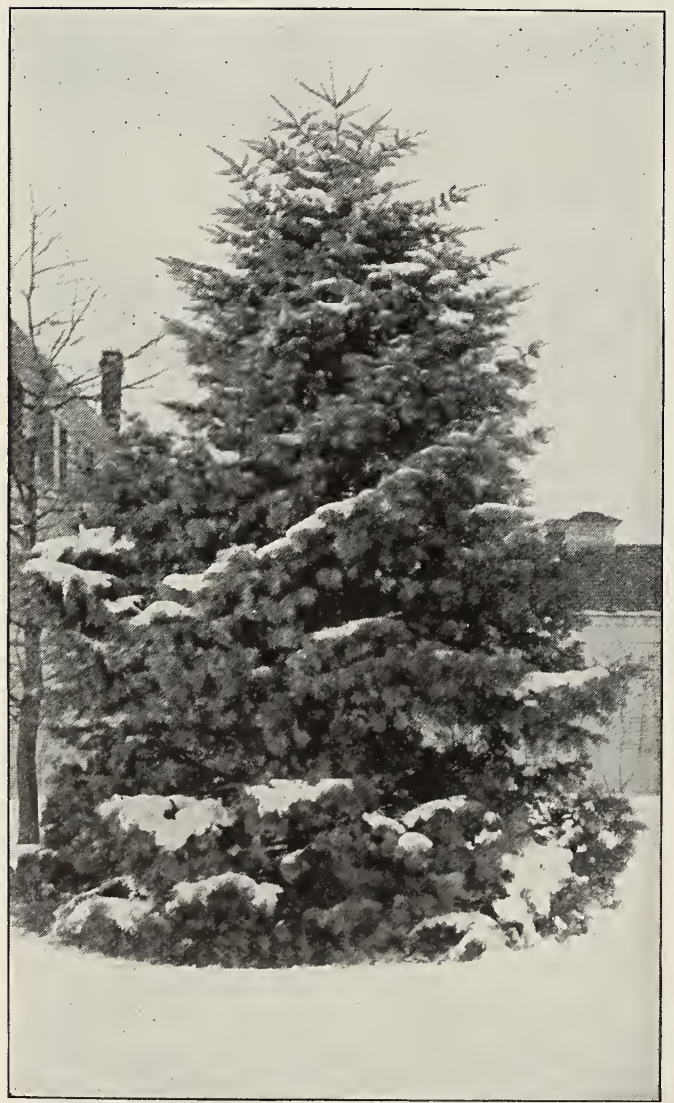

Concolor Fir (see page 32 ), moved on Hicks' Tree-Mover. Our stock of this tree is perfect in habit and density.
Norway, continued

melancholy," it is because the only evergreens they have in mind are Norway Spruces. They may remember them as shutting out the needed winter sunshine. Don't blame our forefathers. The little spruces looked pretty in the front yard and were about all the nurseryman had. The Norway Spruce does not like the alternation between bright warm winter sun and dry northwest winter winds. They drop some of the twigs and some of the foliage turns yellow. That makes them ragged, open, tattered and haggard. They look unhappy and have a depressing effect on the cheerfulness of the landscape.

Maxwell's Dwarf. P. Maxwelli. A cushion of the most compact foliage that in a dozen years will be 2 feet high and 4 feet wide.

Alcock's. P. bicolor; syn., Alcockiana. Worthy of planting as a specimen. It is a narrow, pyramidal tree, hardy and handsome. The unique feature is that it is bluer than the Colorado Blue Spruce on the under side of the foliage. It is a native of the mountains of Japan.

Oriental. P. orientalis. The darkest green hardy evergreen. It make a tall, slightly tapering tree of very dense foliage. It holds its foliage for nine years. Native of the Caucasus Mountains.

Colorado. P.pungens. The sage-green color and strong, needle-pointed leaves, on stiff, shelf-like branches, make this a beautiful and conspicuous tree. It is a strong, stern tree and can stand salt spray. In early summer its color approaches that of the Colorado Blue.

Colorado Blue. P. pungens, var. glauca. This conspicuous lawn ornament has become more quickly known and appreciated than any other evergreen. It instantly attracts the eye and forms the center of the picture. It cheerfully lights up a dark corner, and harmonizes with a background of White Spruce and darker Firs and Pines. The scintillations of its silver sheen are like a lace of hoar-frost sparkling in the sun.

We have several thousand trees of these two forms, and if any one wants to $g \in t$ a choice tree cheaply, plant these little trees in a garden bed and later plant them on the lawn. Of larger sizes we have trees up to ro feet.

Koster's Colorado Blue. P. pungens, var. glauca Kosterii. This is grafted from an extra blue tree. 


\section{SPRUCES, continued}

Engelmann's. $P$. Engelmanni. This valuable tree from the Rocky Mountains is a dark blue-green pyramid. Its hardiness is thoroughly proven, and it promises to be long-lived and to retain its beauty in old age.

Tiger-tail. $P$. polita. A distinct tree from Japan, with fiercely bristling needles of yellowish green color. It is an irregular, picturesque tree of great hardiness.

P. Omorika. Recently discovered in Montenegro, it shows that even in Europe new species can be discovered. So far as tested, it is a good tree. with a bluish cast to the under side of the foliage.

Douglas. Pseudotsuga Douglasii. This tree illustrates most clearly the importance of exact knowledge of the source of seed. Trees im-

\section{Douglas Spruce, continued}

ported from France grew rapidly for several years, and when 12 feet high some were killed to the snow-line. A large quantity of seed was planted that was said to have been collected at about 8,ooo feet on Pike's Peak, Col. They died even in a mild winter. Seed from the valleys in Colorado will not be hardy north of the Ohio River. The climate map on page 5 shows why the form from Oregon, with its equable climate, thrives in Scotland and fails in the variable climate here. Douglas Spruce from the higher altitudes in Colorado is hardy here, and never turned a leaf in the severe winters of $1903-04$. It is one of the most rapid-growing Spruces. It differs from others in having a softer texture and more graceful outline. The color ranges from a pure bright green to a dark blue-green.

\section{YEW. Taxus}

The Yews have a strong hold on the affections. Unfortunately thousands of dollars are wasted annually importing the English and Irish Yews, and planting them where they lead a ragged and miserable existence or soon die. There are a number of fine old English Yews on Long Island in places sheltered from the winds and partially shaded in winter, as in a hollow in open woodland or a slightly moist place in a partially shaded lawn. We have a quantity of established plants that we recommend for this purpose, and some Golden Yew suitable for carpet bedding with evergreens.

Japanese. T. cuspidata. There are forms of this which will make the Yew as valuable an element in landscape here as in England. This forms a spreading tree of several trunks ro feet high and twice as broad. The severest winter or bright sun does not injure it. Its foliage has the rich, solid, dark green lustrous tone that is expected of such aristocratic plants as Yew and Boxwood.

T. cuspidata, var. capitata. This forms a more upright plant, with the single leader giving it the form of a fir or hemlock.

Dwarf Japanese. T. cuspidata, var. brevifolia. This looks like a plant from up near the timberline. It is even darker green than the others.
Dwarf Japanese, continued

The growth is thick and stubby. It will grow to 3 feet high and 15 feet wide.

English. T. baccata. A thick-branched shrub with very dark leaves.

Golden English. T. baccata, var. aurea.

Spreading Yew. T. baccata, var. repandens. A graceful plant, growing 4 feet high and twice as broad. The branchlets arch gracefully at the tips. It is very rare and is hardy.

Canadian Yew. T. Canadensis. This will make a carpet of green moss 2 feet deep and several feet wide.

\section{A Final Word on Evergreens}

Before investing your land and time extensively in evergreens, you need impartial scientific facts. See "Notes on Cultivated Conifers," by Professor C. S. Sargent, Director of Arnold Arboretum, Harvard, in "Garden and Forest," October 6 to December 29, I 897.

See "The Best Hardy Evergreens for Every Place and Purpose," by Henry Hicks, "Garden Magazine," February, I905.

See "Soil and Climate Chart of Long Island." Ten pages in former edition of this catalogue, sent on request.

See pages 4,5 and 28 of this catalogue. Write us your location, or have an inspection and report. Then you wiil know what to plant. 


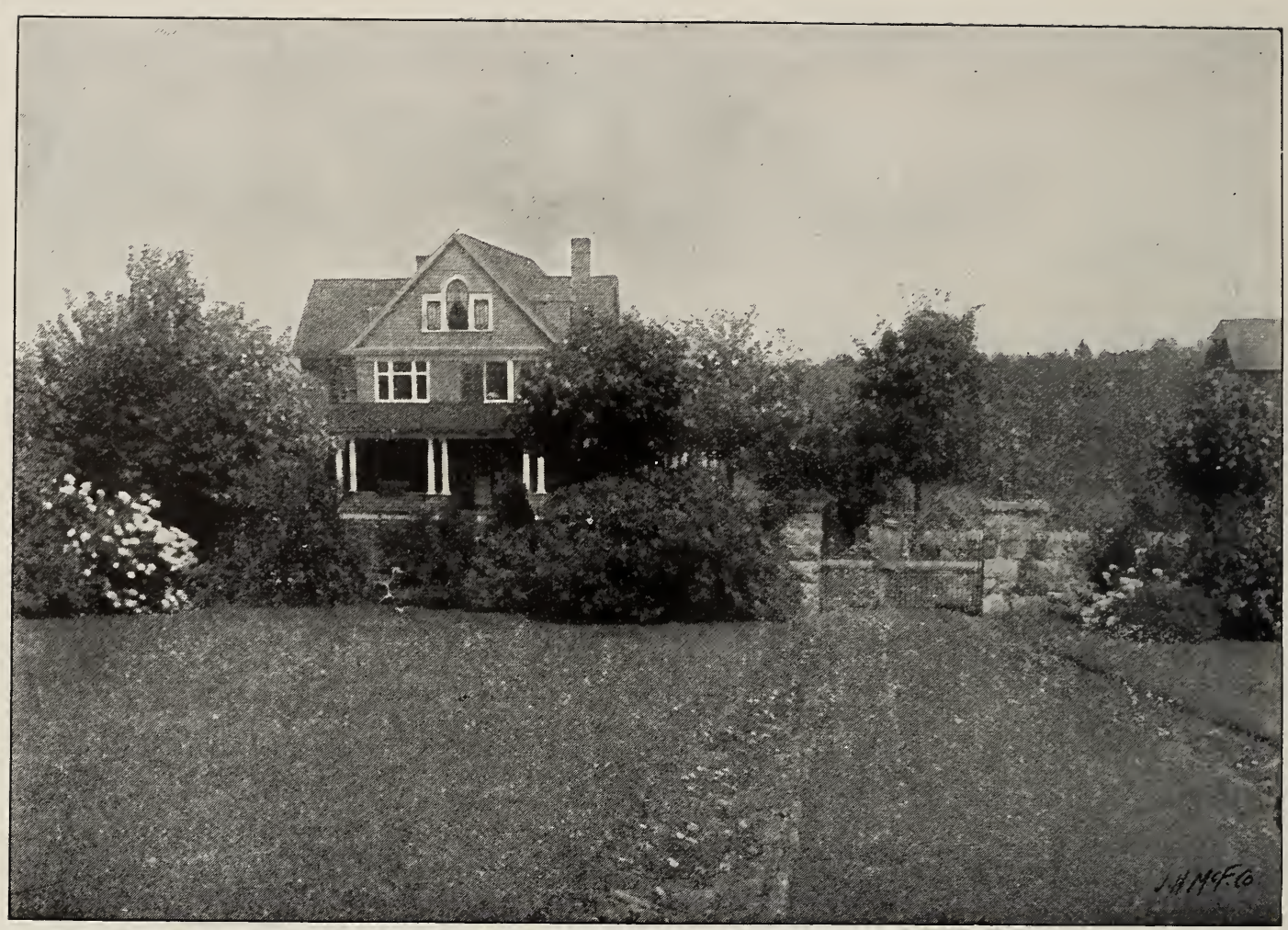

Shrub groups make the best boundary. The large white flowers are Hydrangea.

\section{Flowering Shrubs}

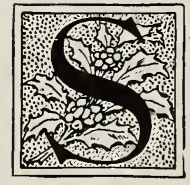

HRUBS are a necessary complement to trees in the landscape. In two or three years the shrubbery on a new place looks mature. With shrubs 6 feet high and trees 25 to 50 feet, mature results are attained the first year. The varying color, form and shadow effects from April to October, of flowers, foliage and bright berries are not exceeded even by the flower garden. The colored twigs are beautiful in winter.

To screen laundry and service court, kitchen, stable or road, tall shrubs are valuable. We offer shrubs 7 to Io feet high for this purpose. To carry the green of the lawn over a drive, a belt of low shrubs will preserve the unbroken sweep of green which is the keynote of a landscape. To round off the angular lines at the foundation of a house and connect the house with the ground, shrubs are indispensable. We train compact and symmetrical shrubs for the purpose.

Grading with shrubs is an economy little understood. For example, a road curving around a hill may have a steep and dangerous bank. Dense shrubs, as Berberis Thunbergi backed by taller shrubs, will make a thicket that will halt a bolting horse. With the same economy, masses of shrubs will fill in hollows or round off rough hillsides. See illustrations, pages 43 and 48 .

A prominent landscape architect says: "The foliage of shrubs that are well established remains green when dry weather turns grass brown. The broad mass of shrubbery will take care of itself when the grass needs frequent attention. It might with advantage replace grass upon all surfaces too steep to walk upon with comfort," and it might be added, too expensive, or impossible, to keep in good lawn.

Plant in broad masses, using large quantities. Group similar kinds together blending into the next. Long, graceful curves for outlines, with detached groups, produce most beautiful results and permit economical mowing with a horse lawn-mower. Plant low, thick-foliaged kinds, as Berberis Thunbergi, Deutzia gracilis and Rugosa Rose at the front, to hide the bare stems of those in the rear and hold the mulch.

Prepare the ground and maintain it as for a crop of potatoes, or mulch with straw, leaves or thatch.

To cover ground too poor and gravelly for grass, plant Wild Rose, Rugosa Rose, Trailing Rose, 
Bayberry, Sumach, Acacia, Indigo Shrub, Indian Currant, Huckleberry, Bearberry. For seaside exposure, drifting sand and bluffs, see Introduction, page 4 .

To brighten up shrubberies, in August and later when most are past blooming, we have grown many varieties of late-blooming shrubs and tall herbaceous plants, as well as those conspicuous for foliage and bright berries.

In pruning shrubs, avoid the prevalent dome top or balloon-shaped style. It results in few flowers, for flower-buds are made the previous year, excepting those of the Althea, Hydrangea and other late bloomers. Prune out the oldest and most scraggy branches immediately after flowering, or take out a few each winter.

Houses completed in May or June need shrubs around them. We have shrubs prepared for successful transplanting at any time.

\section{ACACIA (Rose Acacia) Robinia hispida}

An old-fashioned shrub of open, irregular habit, 3 feet high, with clusters of deep pink flowers resembling sweet peas in June and July. It will grow in poor soil and is useful for seaside planting.

\section{ALTHEA (Rose of Sharon) Hibiscus Syriacus}

In late summer the Altheas and Hydrangeas are the brightest ornaments to the shrubbery. The hollyhock-like flowers range in color through whit

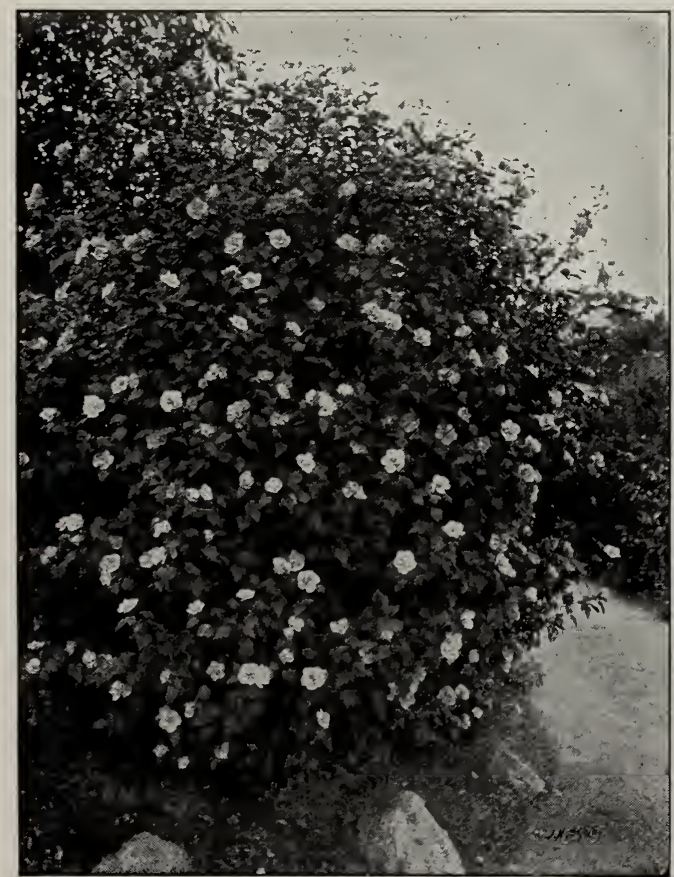

Althea, or Rose of Sharon. We have thousands at very low rates for hedges or mass planting. See price-list.

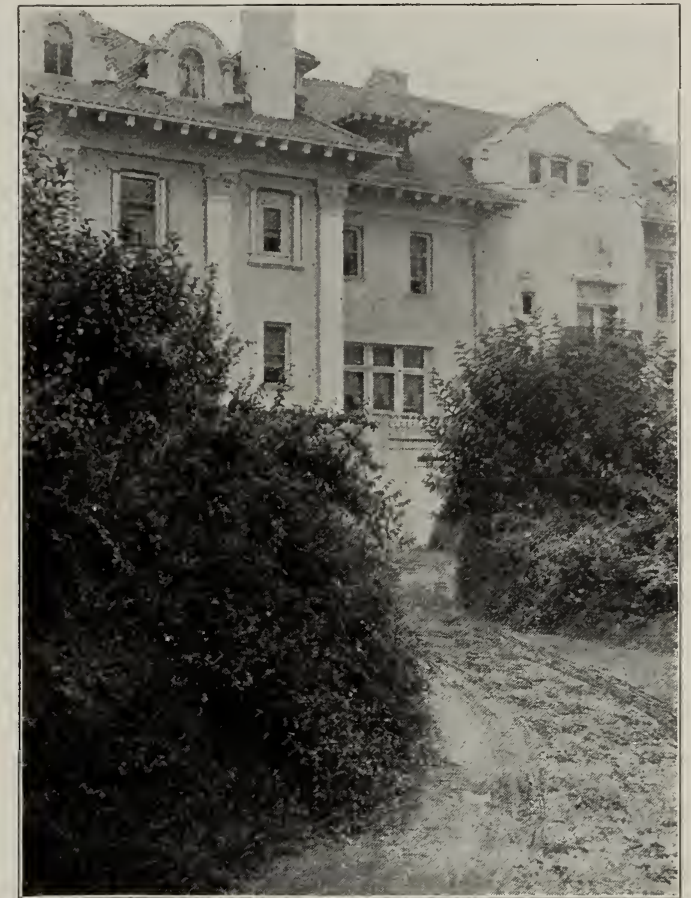

A new solution of the service court and laundry paddock problem. Court sunk to the basement level and having vertical walls of foliage, thus preventing a view from the street. The walls are built at a steep angle by laying sod, like bricks, with Honeysuckle between, and weeping Forsythia at the top. Residence of Mr. Alexander C. Humphreys, North Country Colony, Glen Cove, L. I.

pink and red, double and single. As a garden hedge it may be pruned each year and yet flower freely.

\section{AZALEA (Rhododendron)}

The Azaleas are the deciduous or leaf-dropping members of the Rhododendron genus. They are so beautiful that a collection of varieties is an essential in any scheme of lawn decoration. All the Azaleas when wild are under-shrubs in the woods, and, therefore, are well adapted for massing along the borders of woodland, or edges of streams and springy places.

\section{A. amœna. See Broad-leaved Evergreen Shrubs.}

Chinese. A. mollis. A vigorous round bush, covered in early May with large trusses of blossoms resembling the Rhododendron in form. The colors are lemon, yellow, salmon, orange and orange-red.

Flame. A. calendulacea. The brilliant colors of this species, ranging from yellow to orange-red, render it particularly attractive when planted in the shadowy borders of the woods.

Ghent. A. Pontica. A class of numerous varieties that are hybrids between the species of this country and that of the Himalaya mountains. They represent all the colors of the genus in many variations, beautifully shaded, and are both single and double. The flowers have the form of our native Azalea, and are especially pleasing in delicacy of color. 


\section{AZALEA, continued}

Pinxter Flower. A. mudiflora. One of the rarest gems of our woodlands. It is an open and graceful shrub bearing a profusion of bright pink flowers in May, as the leaves appear. We offer it by the hundred for planing in masses.

Southern. A. Vaseyi. This rare and new species from the North Carolina mountains is particularly charming with its delicate shell-pink flowers. One of the most beautiful of recent introduction.

Swamp. A. viscosa. When passing low, moist ground in midsummer, the perfume of the white flowers of this shrub is plainly noticeable.

\section{BAYBERRY (Wax Myrtle) Myrica cerifera}

A rich dark green bush of rounded form, a slow grower, reaching 9 feet in height. For clothing sterile hills, bluffs and sand-dunes, it is unequaled.

\section{BARBERRY. Berberis}

European. B. vulgaris. An European species that has established itseif on rocky hillsides. It is an upright, graceful shrub, 6 to ro feet high, ornamented during autumn and early winter with clusters of red berries.

Purple. B. vulgaris, var. purpurea. One of the best shrubs with purple foliage. The young shoots are bright red, and in May it has drooping racemes of small yellow flowers.

Japanese. $B$. Thunbergi. There is always need at the borders of shrubbery for a plant that will keep its foliage close to the ground. Berberis Thunbergi makes so close a mass of twigs that even in winter it fulfils this purpose. The foliage is a glossy bright green, turning to scarlet in autumn, and its coral berries hang on all winter. It thrives on all soils. A valuable hedge plant.

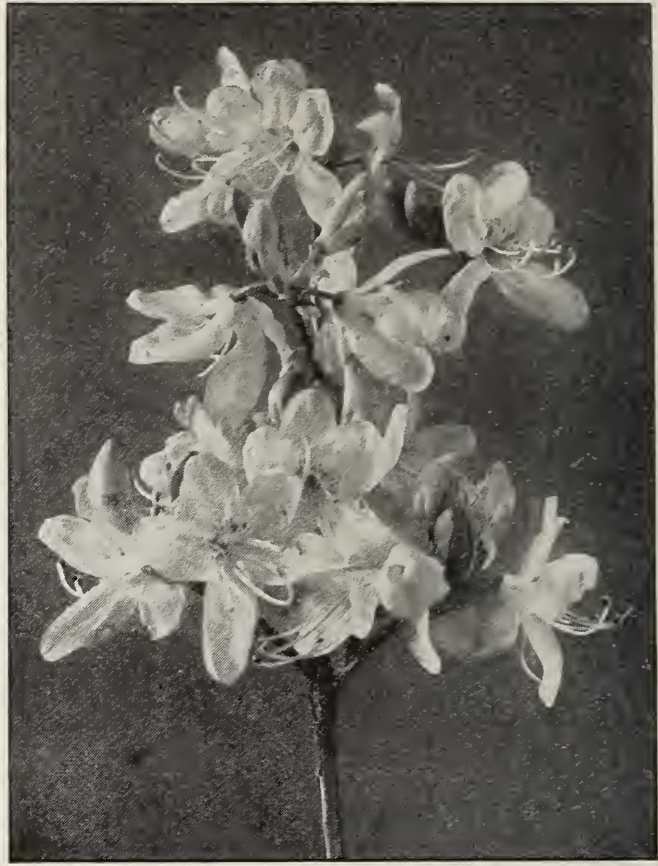

Flowers of Azalea Vaseyi. We have large plants of this newest and most beautiful Azalea.

\section{BUTTON BUSH. Cephalanthus occidentalis}

A useful shrub from the fact that it will thrive where the roots are covered with water in winter and spring, or on upland. The large leaves are dark green, and in midsummer it has white flowers in the shape of a button-ball. Form rounded, height 6 feet. Particularly appropriate in wild planting about ponds and lakes.

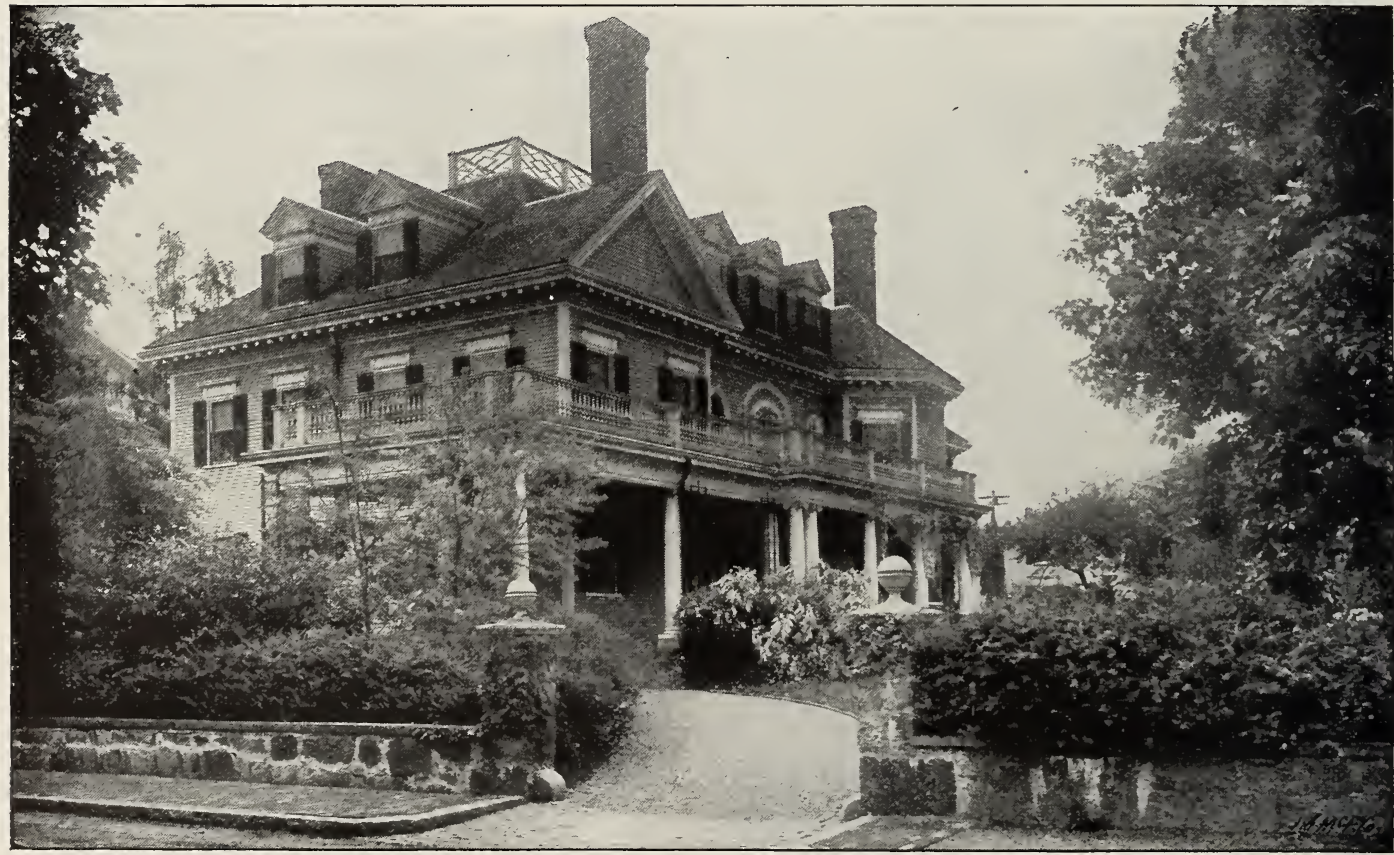

Hedge of Japanese Barberry over the wall. Spiraa Van Houtter in bloom next the house. A simple and dignified treatment of a small lawn. 


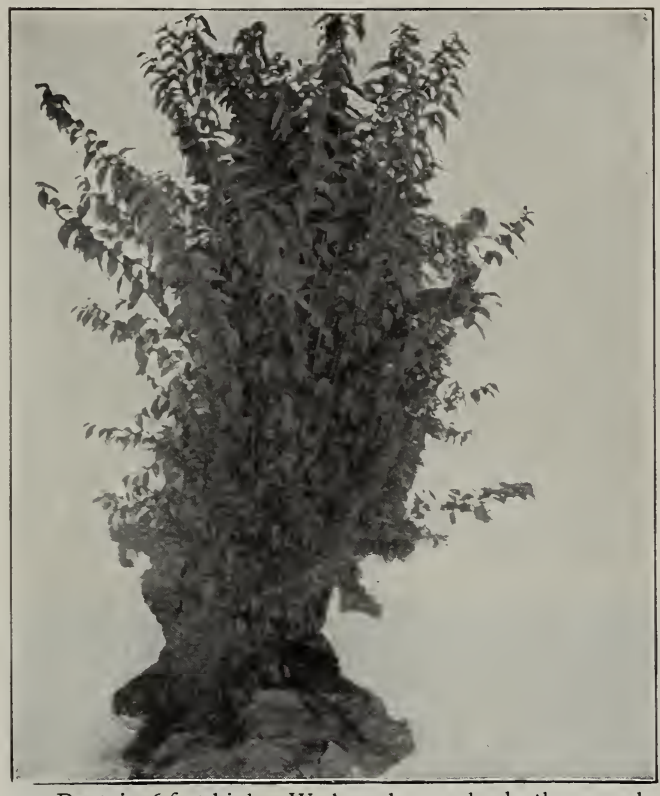

Deutzia, 6 feet high. We have larger shrubs than usual. They give immediate results. They may be planted wider apart, therefore the cost is no more than with smaller plants.

\section{CATALPA}

C. Bungei; syn., bignonioides, var. nana. A dwarf tree or shrub from China, growing from 3 to Io feet high. The leaves are very large and thick, which makes it suitable for seaside planting.

\section{CORCHORUS}

\section{Kerria Japonica}

Among the Boxwoods about many old farmhouses, the graceful green stems of the Corchorus are seen, bearing brilliant golden balls throughout the summer.

\section{DEUTZIA}

The Deutzias are among the most useful of tall shrubs, forming sturdy upright bushes 8 to I 2 feet high, with thick foliage that makes a good screen. The four varieties, D. scabra, D. crenata, D. candidissima, and Pride of Rochester are similar. In June they have showy white flowers, sometimes tinged with pink.

Dwarf. D. gracilis. Japanese Snow Flower. A broad, sturdy bush I to 3 feet high, wreathed with a profusion of delicate white flowers in June. Where a shrub is desired that does not grow out of bounds, as against the foundation of a house, near a path, or edging tall shrubs, this is to be recommended.

\section{DOGWOOD. Cornus}

Red-twigged. C. alba, var. Sibirica. In the winter this is the most showy of all the shrubs, standing out bright and cheerful with its brilliant red bark. It should be planted in groups where its color effect is visible at a distance. It has healthy, compact foliage, white flowers and white berries.

C. sanguinea. Dark red branches.

\section{ELDER. Sambucus}

Golden. S. nigra, var. aurea. A tall coarse shrub with clear yellow foliage throughout the summer. It should be planted at a distance for bold color effects.

\section{ELAEAGNUS}

E. umbellata. Silver Thorn. The Elæagnus is distinguishable by the silvery coating to the leaves, which forms a harmonious and striking contrast with other shrubs. It thrives especially well near the sea. In late summer and autumn it is covered with bright red berries, pleasantly acid.

E. longipes. Recently introduced for its cranberrylike fruit ripening in July, at which time it is highly ornamental.

\section{EXOCHORDA. Pearl Bush}

E. grandiflora. A shrub that is admired above others in May for its graceful festoons cf large pure white flowers. It is somewhat open and irregular and is therefore better planted at the rear of other shrubs than standing alone.

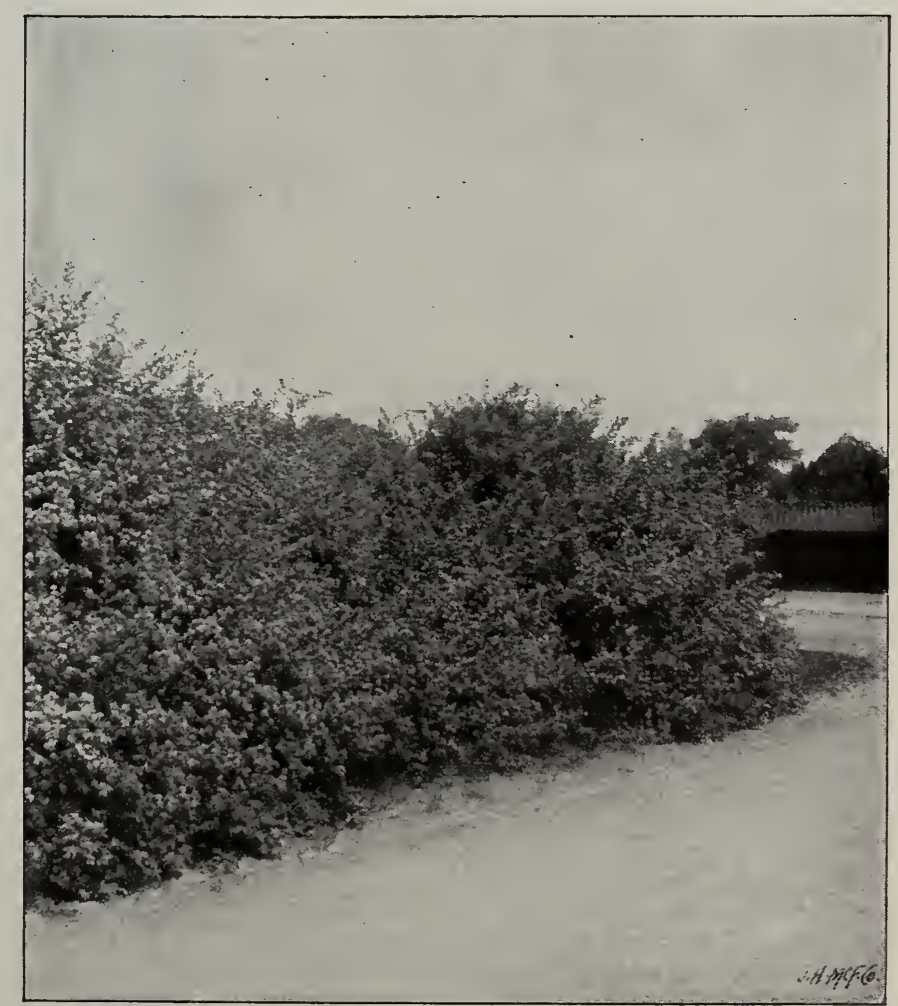

Lonicera Morrowi. One of the best of the Upright Honeysuckles A broad, spreading bush with yellow and white flowers and showy red fruit. 


\section{FORSYTHIA. Golden Bell}

The first shrub to make a conspicuous display of flowers is the Golden Bell, when its cheerful golden note in the landscape welcomes the spring. During the summer it maintains such luxuriant foliage that it is to be recommended for making tall thick screens and for covering steep banks.

F. Fortunei. $F$. suspensa, var. Fortunei. An upright shrub similar to the others, excepting that its yellow flowers are larger.

F. suspensa. A shrub of gracefully arching branches, which droop to the ground when it becomes mature. It is valuable in the margins of groups and to cover banks.

F. viridissima. An upright shrub with green stems and dark glossy leaves that turn to a rich purple in autumn.

\section{FRINGE. Chionanthus}

White. C. Virginiana. A large shrub or small tree with rich dark foliage that makes it a worthy companion to the Magnolia. On vigorous specimens the leaves resemble the India rubber plant. In June the graceful lace-like white flowers hang in drooping panicles between the leaves.

\section{GOLDEN BELL. See Forsythia}

\section{HERCULES' CLUB (Angelica Tree) Aralia spinosa}

The tropical luxuriance of the Aralia gives it a distinct appearance. On top of the tall, spiny stem is a crown of leaves 2 feet long, with a cluster of fleecy white flowers in its midst. It spreads by underground suckers and gives a quick effect in new shrubberies, or in wild rough places.

\section{HONEYSUCKLE. Lonicera}

Upright. L. Tatarica. One of the best classes of shrubs in every respect. They have a sturdy oak-like habit, growing 6 to ro feet high, and have good foliage, which renders them useful for screens and masses. They are made attractive by a profusion of small white, pink or red blossoms in May and June, followed by clusters of translucent coral berries in the fall.

L. Standishi. Sometimes, before the last snowstorm in March, this shrub bears its spicy creamcolored flowers.

\section{HORSE-CHESTNUT. Esculus}

Dwarf. A. parviflora; syn., macrostachya. By the middle of July when many flowering shrubs that have made the borders gay are past, and the autumn-blooming Hydrangea and Althea are still to come, this gap is admirably filled by the Dwarf Horse-chestnut. It is a broad, slowgrowing shrub, carrying upright panicles a foot long, of fleecy white flowers. The foliage is always in good condition and it becomes a handsome lawn elump. This rare shrub should be more extensively used in landscape planting.

\section{HYDRANGEA}

H. paniculata, var. grandiflora. This is the most showy shrub of late summer, with its immense plumes of white flowers, which become bronze in autumn and remain on the bush till winter. When closely pruned and fertilized, the plumes are over a foot wide. If planted in groups, the effect is a compact mass of white. See page 45 .

H. Hortensis, var. Otaksa. The Hydrangea witl pink or blue flowers, which is usually grown in tubs. It is hardy, with slight protection, near the north and south shores of Long Island.

H. radiata. A low shrub, that is noticeable because the leaves are white underneath; has small flat flowers.

H. quercifolia. Oak-leaved Hydrangea. A rare and interesting shrub with large leaves resembling the Red Oak. It has open panicles of white flowers.

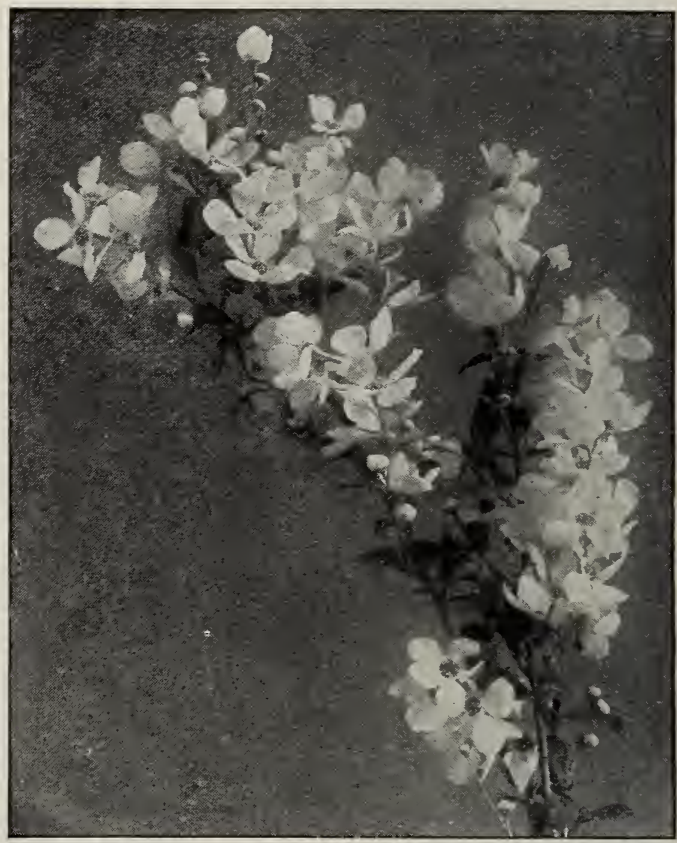

A spray of the chaste white flowers of Exochorda grandiflora. (See page 45.)

\section{INDIAN CURRANT (Coral Berry)}

\section{Symphoricarpus bulgaris}

The long runners of this shrub reach out like those of the Strawberry, and take root, enabling it to hold steep banks. Its low growth fits it for use in borders, where it is especially attractive in autumn and winter with its masses of coral berries.

\section{JAPANESE JUDAS \\ Cercis Chinensis; syn., Japonica}

A broad bush, the twigs of which are encircled with bright rose-colored pea-shaped flowers early in May, before the smooth, heart-shaped leaves appear. It makes a brilliant spot in the shrubbery. 


\section{LABURNUM. Golden Chain}

L. vulgare. A tall, slender shrub, or small tree, having delicate pea-green foliage festooned in May with racemes of yellow flowers similar to the wistaria.

\section{LILAC. Syringa}

All who love the old-time flowers have an affection for the Lilac. To the newer varieties are to be credited improvements in size, color and texture. We are growing these in quantity and can strongly recommend them. They are best grown on their own roots. If grafted ones are used, plant deep enough for roots to form above the graft.

\section{NAMED VARIETIES OF SYRINGA VULGARIS}

Charles X, Louis Van Houtte, Marie Legraye, Ville de Troyes, Virginalis, Mme. Lemoine, Le Gaulois, Emilie Liebig, Ludwig Spaeth, Frau Dammann, Condorset, and others.

Common. S. vulgaris. A tall shrub, with fragrant lilac or purplish flowers. The foliage generally becomes mildewed in late summer, so that it is better planted in the rear of plants with good foliage.

White. S. vulgaris, var. alba. Similar to the above, with fragrant white flowers.

Persian. S. Persica. This has slender arching branches, bearing clusters of flowers all along their length.

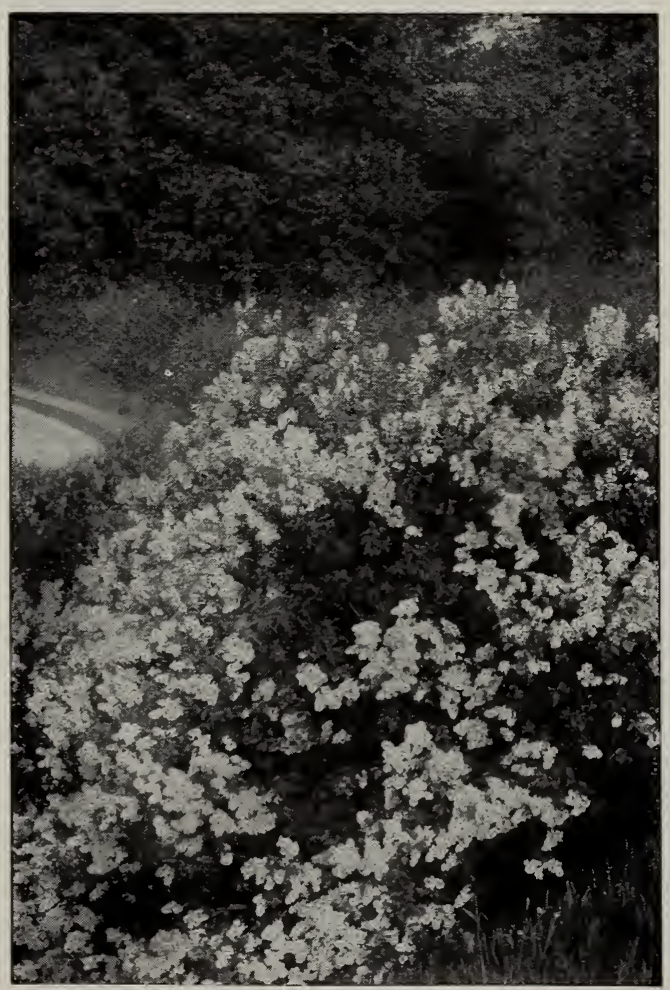

View in the collection of beautiful named lilacs in the Arnold arboretum.

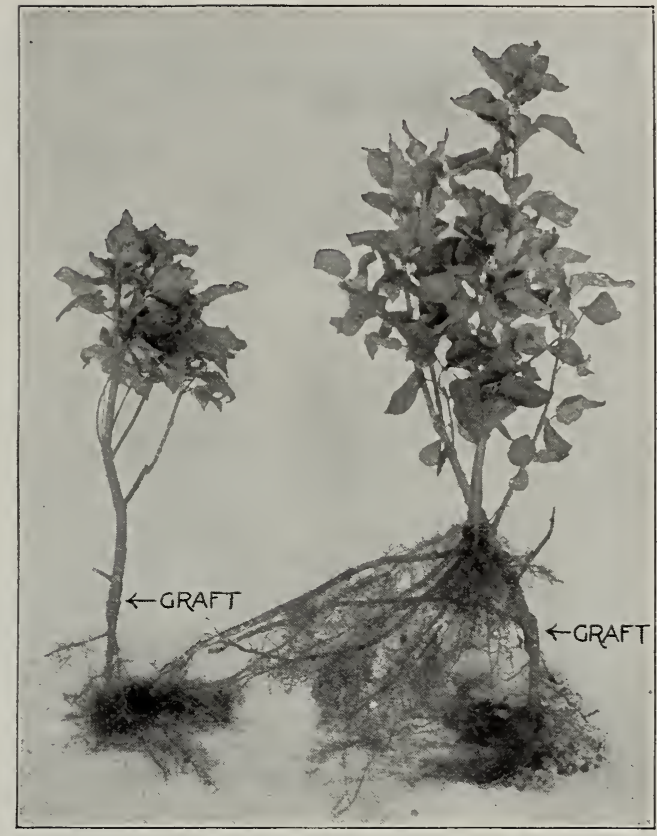

We grow the named lilacs so that they are permanently vigorous. As shown on the right, it has roots above the graft. The plant on the left will die in a few years.

LILAC, continued

S. villosa. An upright bush with pinkish white flowers after other Lilacs have passed.

Japanese. S. Japonica. A pyramidal tree, resembling the Cherry. In July it has broad panicles of white flowers.

\section{LONICERA. See Upright Honeysuckle}

\section{MAGNOLIA See Deciduous Trees}

The Magnolias have always been scarce and highpriced, difficult to transplant and difficult to ship. They are scarce and high because imported from Europe. In line with our policy to make the really good things available, we have grown Magnolias in large quantity from seed. We made them easy to transplant by frequent root-pruning. The smaller sizes transplant successfully if carefully dug without ball and planted in spring. The larger plants require a large ball of earth.

\section{MAPLE, JAPANESE Acer Japonicum}

These beautiful shrubs hold the same relation to others that the ferns do to the larger-leaved vegetation. The Japanese gardeners have developed from the one or two species a host of varieties, having delicate and gracefully arranged foliage that comprise our daintiest and most exquisite shrubs or small trees. They are especially adapted to gardens and lawns. ro to 5 feet.

A. palmatum; syn., polymorphum. The normal type, beautiful for the delicate shades of green and red in spring and autumn.

Blood-leaved. A. palmatum, var. atropurpureum. The foliage is a brilliant crimson, turning to purple during the summer. A vigorous grower. 


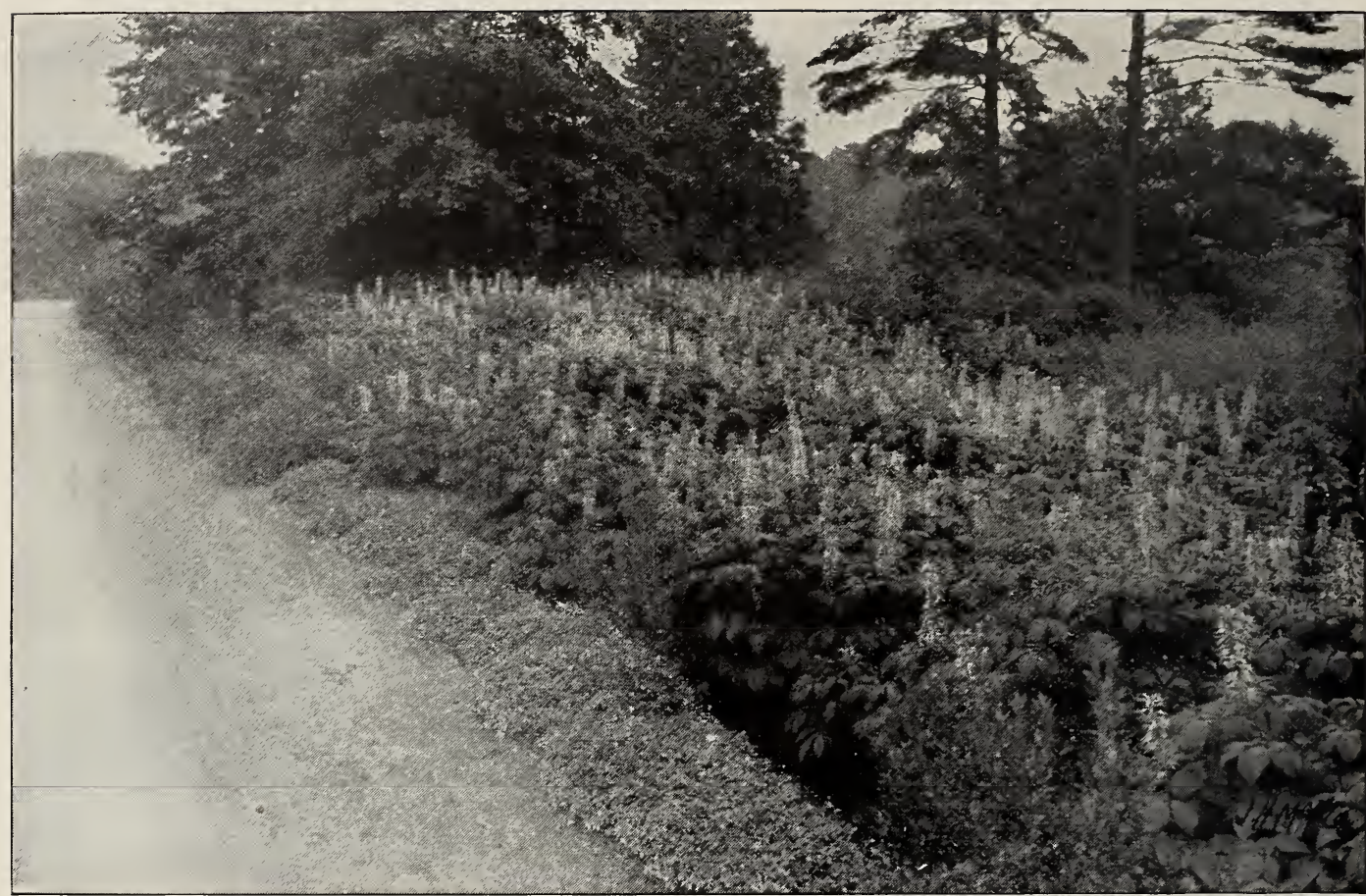

Dwarf Horse-chestnut. If you are tired of the monotony of the shrubbery in July, here is the remedy. A rare shrub of healthy foliage and large graceful white flowers.

JAPANESE MAPLE, continued

Cut-leaved. A. palmatum, var. dissectum. 'The foliage is so finely divided as to resemble a delicate fern. It grows in graceful, wide-arching sprays 2 to 3 feet high and greater in width, being typically Japanese in its form. Its growth is slow, but it is well worth the necessary waiting.

Purple Cut-leaved. A. palmatum, var. dissectum purpureum. Resembles the above, except that the foliage is red and purple throughout the season.

\section{California Privet, continued}

thick base devoid of the three-cornered open spaces frequently seen. It is economical, as a smaller number is required. In the after trimming it is advisable to keep the lower portion of the hedge wider than the top, so as to permit the sun to shine on and encourage the lower branches. Privet is one of the best plants to use in exposed windy situations and where the salt spray flies, as the thick glossy leaves will remain uninjured and make luxuri-

\section{PEARL BUSH. See Exochorda}

\section{PRIVET. Ligustrum}

Ibota. L. Ibota. This has proved perfectly hardy here and northward. It is native of China and Japan. The California Privet is also native of Japan, but near the coast. The reasons why it thrives and makes such a vigorous growth near the coast on Long Island are given on page 5 .

California. I. ovalifolium. The use of Privet as a hedge plant is well-nigh universal, taking the place of Arborvitæ, Osage Orange and other plants. Its one defect is the tendency to become thin at the base when not properly trimmed. We are developing a new method of growing to overcome this defect, pro ducing plants with numerous stems at the base. These when planted 6 inches deeper make a

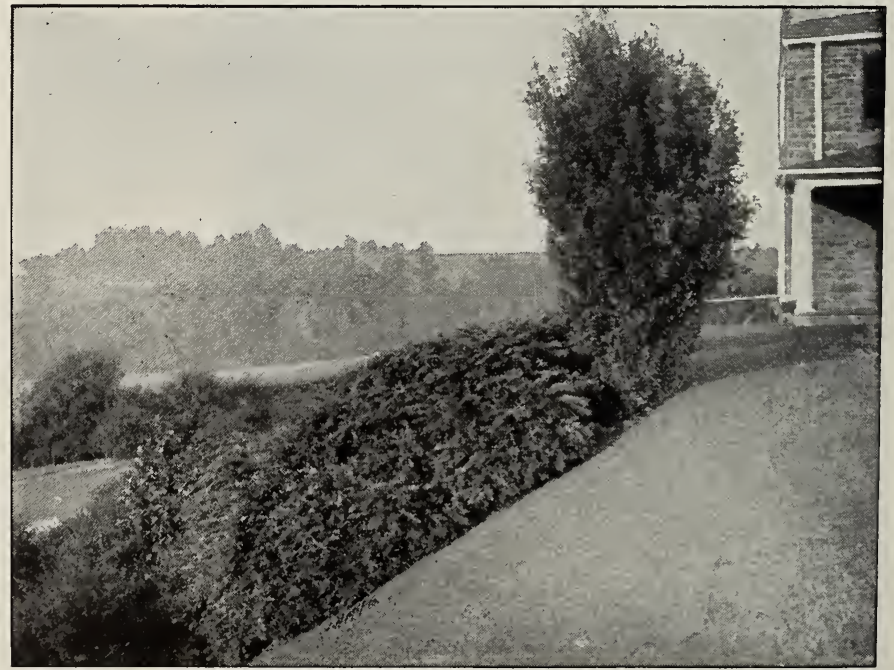

Grading with shrubs is cheaper than with soil. Here is a concavity on a steep sidehill filled out so that the house does not look too near the edge. The shrub is the prostrate privet which is solid from the ground up, and very hardy. Evergreens would be still better. 


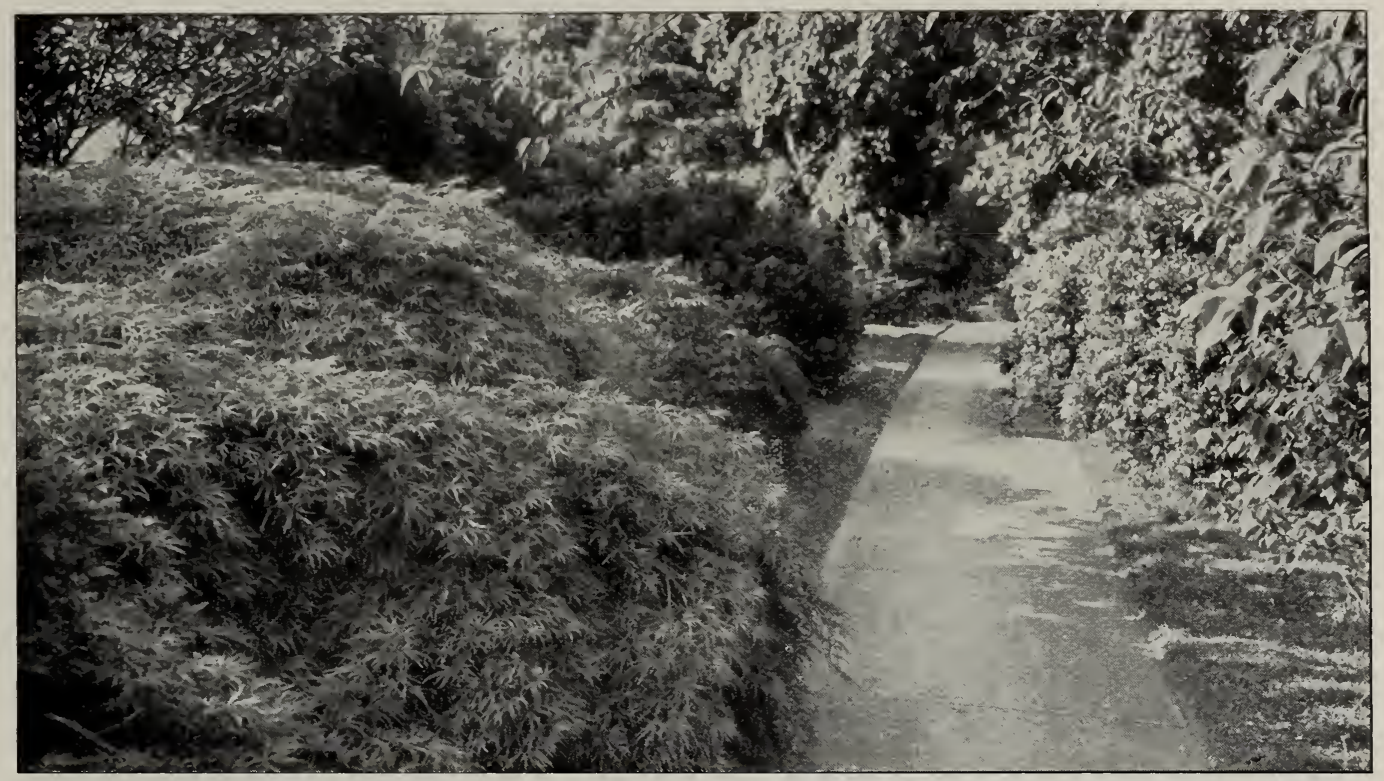

Cut-leaved Japanese Maple, at Dosoris, Glen Cove, L. I. This walk has been likened to an art gallery,-a new picture at every step.

\section{CALIFORNIA PRIVET, continued}

ant growth It is also excellent for holding raw banks by binding the soil with its many roots. When not trimmed, it will attain a height of 20 feet, and is valuable for screens and windbreaks. On the other hand, it may be kept trimmed to 4 inches in height, when it develops small leaves, and makes a good substitute for dwarf box edging. It takes kindly to the severe trimming necessary for hedges, and is largely used for training in various forms of topiary art in formal and Italian gardens.

Dome-shaped, Standards and Arches of Privet. We offer carefully trained specimens in a broad dome-shape, 6 feet wide at the base. The Privet in standard or bay-tree form has round, symmetrical heads that are flat at the base. They are trained by a new machine of our invention which makes them as accurate as if turned by a lathe. These can be furnished for planting in the ground, or established in tubs and terra-cotta pots. For entrances, flower gardens or courts, we have arches 7 feet in height.

Amoor. L. Ammrensis. A tall, graceful shrub, holding its dark green leaves till midwinter.

Prostrate. L. Ibota, var. Regelianum. This has all the vigor and healthfulness of the California Privet. The branches grow out horizontally, arching gracefully downward, adapting it well for the border of shrubberies.

\section{RHODOTYPOS}

R. kerrioides. Of neat habit and graceful form. The large white flowers resemble the syringa.

\section{SIBERIAN PEA TREE Caragana arborescens}

A small tree characterized by its yellow peashaped flowers.

SILVER THORN. See Elaeagnus.

\section{SMOKE TREE (Mist Tree; Purple Fringe) Rhus cotinus}

An old-time shrub or small tree of irregular habit. In summer it is enveloped with a mass of fleecy purple bloom resembling smoke or mist.

\section{SNOWBALL (Viburnum)}

V. Opulus, var. sterile. A vigorous old-fashioned bush, having a profusion of white balls of flowers.

Japanese. $V$. tomentosum, var. plicatum. There is a dignity and strength of character about this shrub which makes it of importance even when not in flower, and its healthful foliage gives it first rank. The flowers are clear white, in balls about 3 inches in diameter.

Large-flowering, or Chinese. $V$. macrocephalum, var. sterile. A very showy variety, with balls of flowers 7 to 8 inches across.

V. prunifolium. A native shrub or small tree; shining foliage and bright autumnal color.

\section{SPIREA}

Throughout the entire season some of the Spireas are sure to give a touch of color to the shrubbery. They should be extensively planted for their beauty and adaptability to various soils and climatic conditions. The varieties following are given in the order of blooming.

Thunberg's. S. Thunbergii. In early May the branches of this shrub are so thickly set with fine white flowers that it appears like a snowcovered evergreen. During the summer its foliage makes a distinct contrast with its neighbors. The graceful willow-like sprays of leaves arching to the ground present a billowy, fluffy mass, useful in rounding off groups of shrubbery. In autumn it turns to brilliant yellow and red. 3 to 4 feet. 


\section{SPIREA, continued}

Bridal Wreath. S. prunifolia, var. flore pleno. Blooming just after the last, its appearance is quite distinct, from its tall, upright habit. The tiny double white flowers are thickly clustered along a stiff stem before the leaves appear. The summer foliage is a glossy green that turns to orange and red in the fall.

S. Van Houttei. The most beautiful of the Spireas. It grows to 6 feet in height, and the graceful branches, weighed down with a wealth of white blossoms, curve till they touch the ground. It comes into bloom just before Decoration Day.

S. Reevesi ; syn., S. Cantoniensis, var. flore pleno. Similar to the above, but slightly tender.

Golden. Physocarpus opulifolius; syn., S. opulifolia, var. aurea. Nine-Bark. A coarse, tall shrub with yellowish green foliage.

S. Billardii. Its spikes of pink flowers contribute a bit of color to the shrubbery in July and August. Having a somewhat ragged appearance, it is best planted back of other shrubs.

S. Bumalda. A low, flat-topped shrub with pink flowers.

Anthony Waterer. A recent introduction that is worthy the high favor it has attained. It grows from I to 3 feet high, and is most useful as border, or for planting against the foundation of the house. Throughout the summer and autumn it is covered with brilliant crimson flowers.

\section{SUMACH. Rhus}

The Sumachs always make an attractive feature of the landscape, as nature has massed them on rocky hillsides and along dry roadways. The foliage is dark and rich in summer, and in early autumn changes to brilliant red. In some species the bright red fruit is retained all winter.

Smooth. R. glabra. A shrub 3 to ro feet high with smooth stems, rich foliage and large bunches of red berries. One of the best for planting.

Cut-leaved. R. glabra, var. laciniata. The leaves are finely divided and have a fern-like appearance.

Staghorn. $R$. typhina. This grows to a small tree, or it may be kept cut back, when it will produce long vigorous foliage of a tropical appearance. The stems are velvety. Its coarse growth precludes its use on small places.

Shining. R. copallina. We often find this species growing on sterile sand-banks. It is more compact than the other Sumachs, with rich summer and autumn foliage. It is especially good to use in quantity in shrubberies and wild planting.

R. semialata, var. Osbeckii. A vigorous Japanese tree with large panicles of yellow flowers in July and August. In autumn it has brilliant orange and red foliage.

\section{SWEET-SCENTED SHRUB Calycanthus floridus}

An old-time favorite with chocolate-colored flowers, having a delicate and lasting fragrance.

\section{SWEET PEPPER-BUSH Clethra alnifolia}

A native shrub of good foliage, bearing spikes of fragrant white flowers in July. It grows in damp places, and may be planted on upland.

\section{SYRINGA (Mock Orange) Philadelphus}

The common name of this shrub is the same as the botanic name of the lilac. The Syringa is onc of the tallest shrubs, shooting up long, vigorous branches to I 2 feet, which the following year are bent over with their burden of blossoms. The white flowers are an inch and a half in diameter and fragrant. Syringas are valuable for tall screens.

\section{TAMARISK. Tamarix}

In appearance, this is a cluster of frail wands of light, filmy foliage, and the plumes of tiny flowers look like a pink cloud. It grows rapidly and should be planted on seashore lawns, as it is native in such situations, and thrives in salt spray.

\section{VIBURNUM, See Snolvball.}

\section{WEIGELA. Dierbilla}

Whether standing alone or grouped in large masses, the Weigelas are always satisfactory. They are vigorous, broad shrubs, 5 to 8 feet high, producing such a wealth of bright flowers in early summer as to be indispensable. In Prospect Park, in the Vale of Cashmere, the Weigelas have been most happily used. Flowering at the same time as the Rhododendrons, they harmoniously extend the color effect at a distance. There are white, pink and red varieties. Eva Rathke is a new variety with brilliant red flowers.

\section{W I T C H - HAZEL Hamamelis Virginiana}

The last of all the flowers of the year. In October, when the leaves are falling, its narrow petaled flowers are scattered along the bare branches. At the same time the seeds, which are larger than buckshot, are fired for 20 feet from the stout seedpods.

\section{WILLOW. Salix}

The Willow family contains several members that may be grown as shrubs. Owing to their rapid grow th they produce the desired result in one or two seasons, after which they should be annually pruned In plantations at the seaside, and shelter-belts, the Willow shrubs should form a good proportion. See, also, description under trees.

Laurel-leaved. S. pentandra. A sprightly, quickgrowing bush with bright glossy leaves.

Yellow-barked. S. vitellina.

Red-barked. S. vitellina, var. Britzensis. This and the above variety grow 6 to Io feet per year. They are useful in shrubberies, and their bright bark gives a touch of color in the winter.

S. multinervis. This is a low, spreading shrub of silvery foliage, having soft gray flowers or pussywillows in February. From Japan.

\section{YELLOW ROOT Xanthorrhiza apiifolia}

A cover plant that is useful under the shade of trees and shrubs and in the woods. It is $\mathrm{I}$ to 2 feet in height and has a dense foliage that turns to brilliant yellow and orange in the fall. It is planted by thousands as a cover in large parks and estates. 


\section{Broad-Leabed Ebergreen Shrubs}

HOLLY, RHODODENDRON, LAUREL, BOXWOOD, YUCCA, ETC.

This class contains the gems of outdoor plants. Many lawns need the richness which they alone can give. They are erroneously considered the most difficult to grow because of the many expensive failures. Success will follow the application of the principles explained in this catalogue on pages 57 and $5 \mathrm{~S}$, Rhododendrons.

\section{ANDROMEDA. Pieris}

A. Japonica. P. Japonica. Bell-shaped flowers of chaste and delicate beauty hang in gracefully drooping racemes, 6 to Io inches long, resembling lily-of-the-valley in March or early April. The flower-clusters are prepared in the fall, and it needs wrapping with straw during the winter.

\section{AZALEA}

A. amœna. Lovely Azalea. In early May this is a mass of rosy purple flowers. The habit of the plant slightly resembles the Boxwood, the leaves being similar in size. It is best to give it a sheltered position from severe winds, and protect in winter.

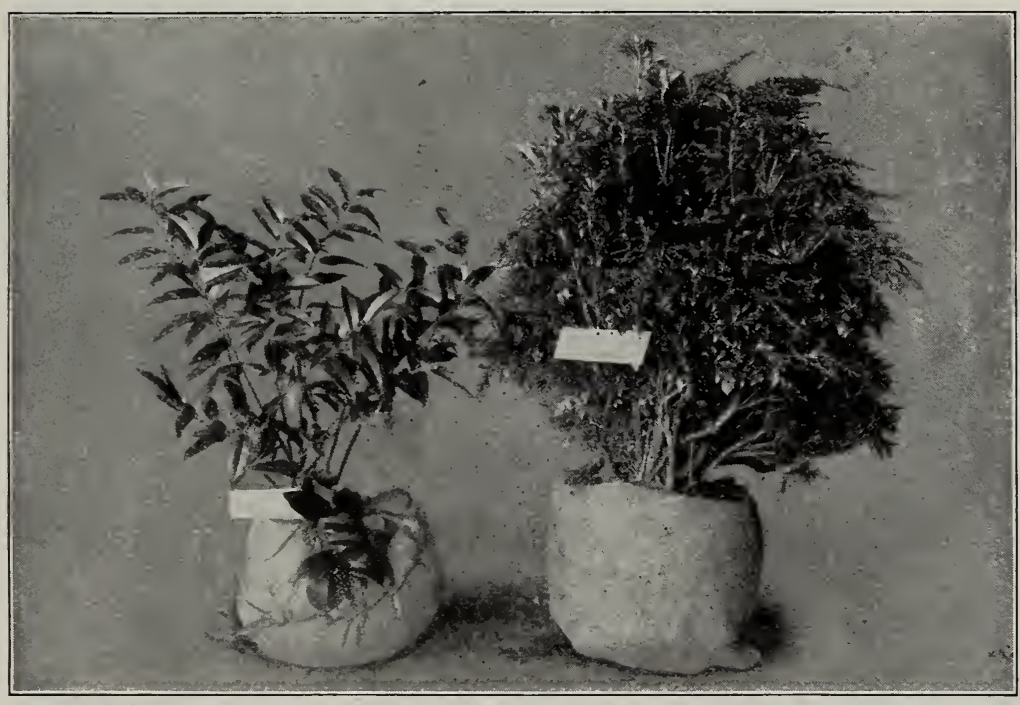

On the left Andromeda Japonica. On the right Leucothoë Catesbai, an evergreen worthy ot extensive naturalizing 111 shaay places; its foliage is very hardy. (See page 53.)
BOXWOOD, continued

settlers from New England to Virginia. IVe offer to send a crew of expert men and appliances to move old Boxwood or pack it for safe shipment.

Tree Box. B. sempervirens. We offer this in large quantities, 6 to 12 inches high, for borders and grouping with other evergreens next to house foundations. For formal planting we have specimens trained to broad domes, 2 feet wide, by a device of our invention that enables us to train them as accurately as with a lathe. They have deep, wide root systems adapted to local conditions. Pyramids 2 to 3 feet.

Narrow-leaved Box. B. sempervirens, var. angustifolia. A variety with compact dark foliage.

There are other varieties with golden and silver variegations.

Dwarf Box. $B$. sempervirens, var. suffruticosa. This is the form found in old gardens. Its slow growth accounts for its compact and even velvety texture. Protection is advisable in open places for the first few winters, as the bark is liable to split. For edging, we offer plants grown from layers with a deep root-system, and therefore less liable to winter-kill.

To repair old borders we offer compact sections 6 to 55 inches high. As a substitute for Box edging, California or Dwarf Chinese Privet, Myrtle and English Ivy, may be used.

\section{BOXWOOD. Buxus}

We have a large and varied collection of Boxwood, ranging from dwarf box edging to the old and well-developed specimens 75 years old. In moving several hundred of these large plants we have had success with all sizes. Sume specimens have been I 25 years old and I4 feet broad.

Boxwood is wild under the forests of England. A study of the chart of climate will explain why the best old Boxwoods are to be found about the old farm and village homes that are not far above the water level, as along the shores of Long Island and near the ponds. It is the Dwarf Boxwood that was planted by the early Dutch and English

\section{DAPHNE}

D. Cneorum. A narrow-leaved alpine resembling the trailing arbutus in habit, and exceeding it in perfume. The heads of bright pink flowers are scattered from May till October.

\section{EUONYMUS}

E. Japonicus. An upright shrub with very glossy evergreen leaves. In a shaded protected place it will grow 6 feet high. There are several variegated varieties. It is a native of southern Japan.

E. radicans. This clinging vine is destined to become widely used as a low shrub and ground cover. Left to itself it trails over the ground, or the stems cling to each other, making a pyramid 2 feet high. The bright green leaves are about 
EUONYMUS RADICANS, continued

an inch long, resembling myrtle. It is perfectly hardy, and is not browned when in exposed windy places. Native to northern Japan, it indicates that many more valuable plants could be secured from that region. See, also, under Vines, where it is described as a substitute for the less hardy English ivy.

E. radicans, var. Carrieri. A low shrub, with shiny, oblong-elliptic leaves $\mathrm{I}^{1} / 2$ inches long. Branches spread, forming a broad bush.

E. radicans, var. argenteo marginatus. A form with variegated leaves.

\section{HOLLY. Ilex}

American. I. opaca. Owing to our climate being tempered by the ocean, the Holly is native to both the north and south shores of Long Island. Specimens are found 12 inches in diameter and 30 feet high. It will grow in either upland or lowland, but prefers a moist, shady situation. There are no reasons why hedges of American Holly should not be planted and thrive as does the English Holly in its native land.

\section{ILEX}

I. crenata. This new Japanese plant resembles the Boxwood in foliage, with a sprightly varied outline. It promises to be of value for specimens and hedges.

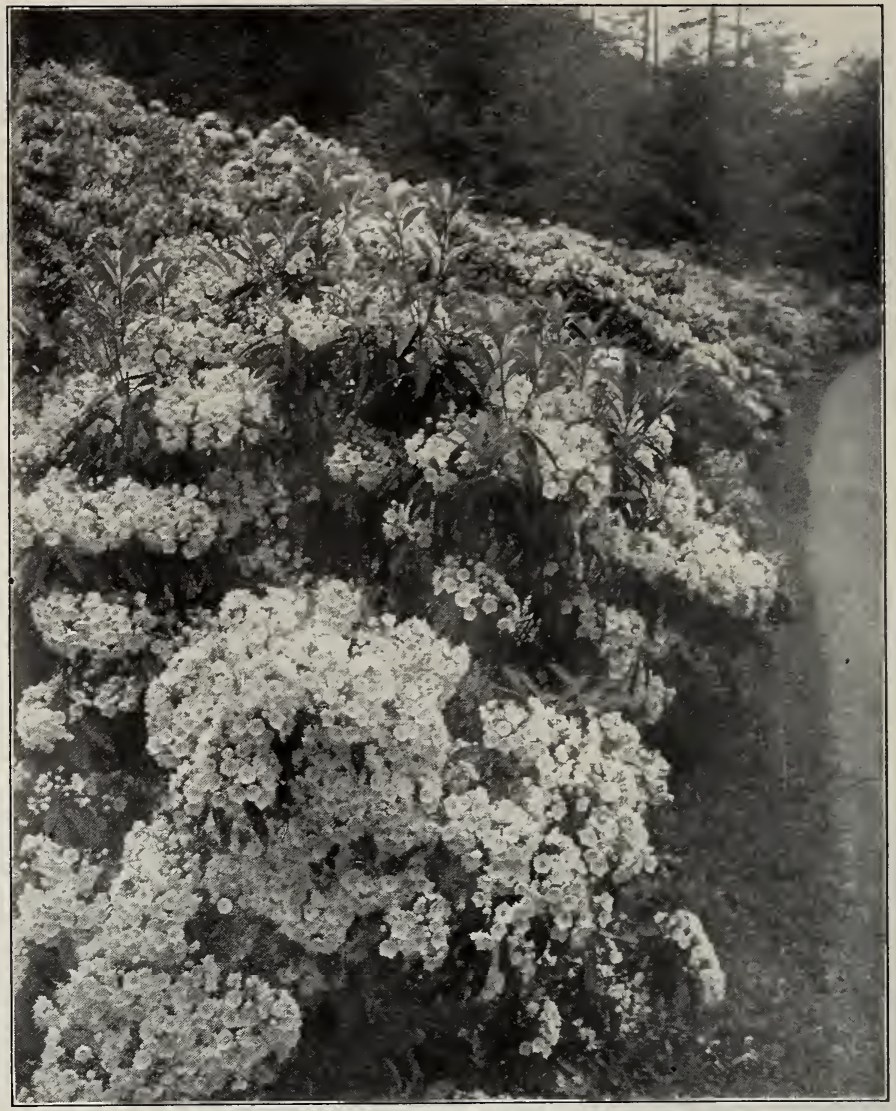

We have thousands of Laurel in our nursery. Come and see them when in bloom in June. Effects like this are easily attained on Long Island.

\section{INKBERRY. Ilex glabra}

Hundreds of acres of Long Island are covered with this shrub, which grows 3 to 5 feet high. It is about the only broad-leaved evergreen naturally growing in the full sun here. Growing in the sand around the ponds of the Brooklyn water-works, between Merrick and Massapequa, are domes as symmetrical as old Boxwood, demonstrating its landscape value. The foliage is larger and more open than Boxwood.

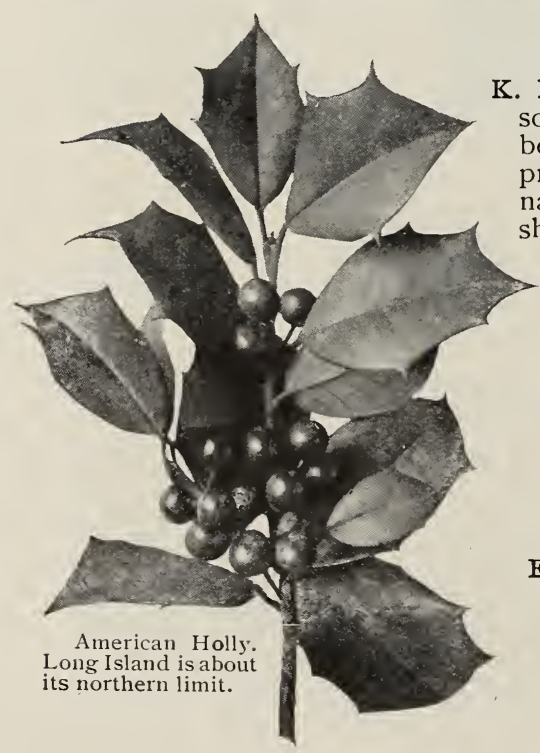

\section{LAUREL. Kalmia}

K. latifolia. The Mountain Laurel and the Rhododendron are the handsomest broad-leaved flowering evergreens. We have many hundred beautiful specimens. It will grow in the open and have a far greater profusion of flowers than in the woods. On Long Island it is usually native to the north slope of gravelly hills, where the canopy of oak shade is rather thinner than on heavier soil with chestnut and dogwood. From such places it is difficult to transplant successfully. In June, a little after the Rhododendrons have started, the beautiful clusters of white and pink flowers are opened. It should be used by the acre for cover, giving a cheerful touch of green to the winter landscape, both in the open and in the woodland. It may be grouped around the foundations of a house and kept sheared to a compact form. Trimmed for a low garden hedge or banking the north side of a wall, it will give satisfaction. Its ability to stand trimming is not generally understood, neither is the fact of its especial adaptability to Long Island soil and climate. We offer it in quantity at low rates.

English. Prumus Laurocerasus, var. Shipkcensis. This variety, from the Schipka Pass, Turkey, is hardier than the English forms. Its large, lustrous leaves are very handsome in early winter, when it should be covered till March. It will then enliven the garden with a brighter green than other evergreens. 


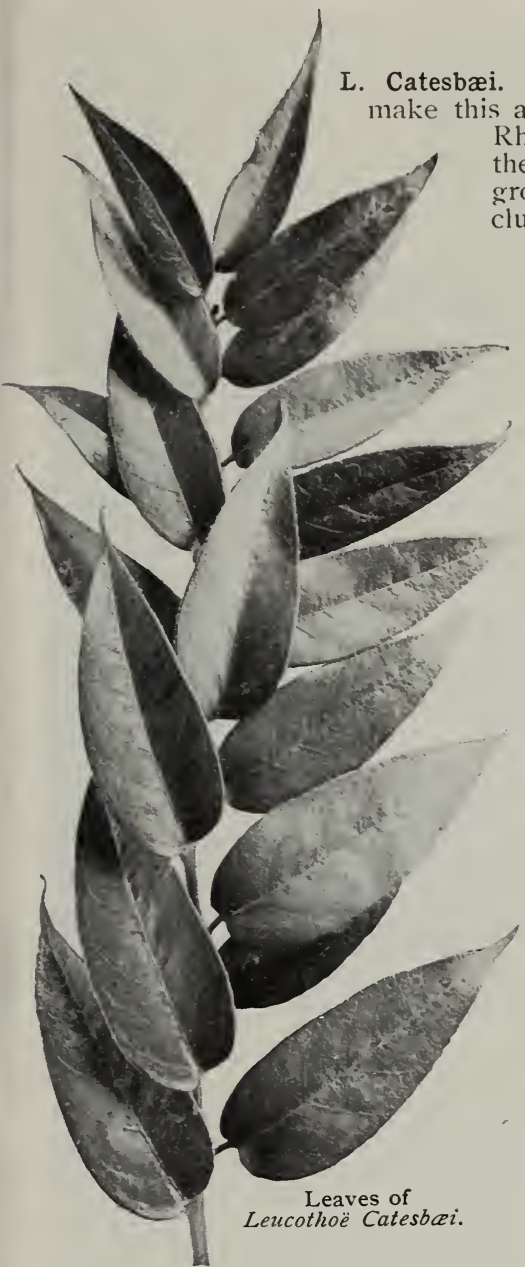

\section{LEUCOTHOË. Andromeda}

A. Catesbci. The long, arching sprays of clark glossy leaves a beautiful decorative plant. The pointed leaves are larger than Rhododendron leaves, and, in the sun, turn claret color in winter; in the shade it remains green. It should be used as a ground cover to group with Rhododendrons, and to cut with holly for decoration. The clusters of lily-of-the-valley-like flowers appear in May. Hardy.

\section{MAHONIA. Berberis}

Shrubs 2 to 5 feet high with holly-like foliage, and yellow flowers in May. They may be used as cover plants in moist, shady situations. If planted in the open they die back occasionally in winter.

M. aquifolium. B. aquifolizm. Oregen Grape. The glossy leaves are 8 inches long, divided into leaflets resembling Holly. It is unique and attractive in autumn and early winter, as the outer leaves change to bronze and purple.

M. Japonica. B. Japonica. A sturdy and striking plant worthy of wider culture. The strong, erect sterns standing 3 to 5 feet high bear leaves a foot long, with leaflets much larger and thicker than Holly, keeping their green color in winter.

B. ilicifolia. Native to Terra-del-Fuego, this indicates another little-explored region at the tip of South America, from which plants should be introduced. It has simple spiny leaves, green till midwinter. 3 feet.

\section{TRAILING MYRTLE (Periwinkle) Vinca minor}

The many thousands of this trailing vine we have sold in the past few years attest its recurring popularity as a corer plant. It forms a deep green, compact ground cover, either in the open or in the deep shade under $\mathrm{P}$ in es and Spruce trees. The close mat, 5 inches deep, ispleasant to walk upon. It will keep the leaves from blowing out from under Rhododendrons. It will hold steep terrace banks sloping in any direction. For wild gardens and bordering drives in the woods it is unexcelled. As a border for flower beds it keeps as green as Boxwood. Its bright blue flowers appear with the first violets.

Variegated. V. minor, var. aurea variegata. A brightly variegated carpet.

Double-flowering. $V$. minor, var. plena. A pretty variety with double purple flowers scattered through the summer.

White-flowering. $V$. minor, var. alba. Pure white flowers.

\section{RHODODENDRON}

The dignified rich green foliage and the magnificent flowers of the Rhododendron are the most beautiful element of decorative landscape. The universally admired results in English parks can be attained here by planting tall specimens of Rhododendron maximum with borders of the brighter colored hardy hybrids. The culture is simple and success certain.

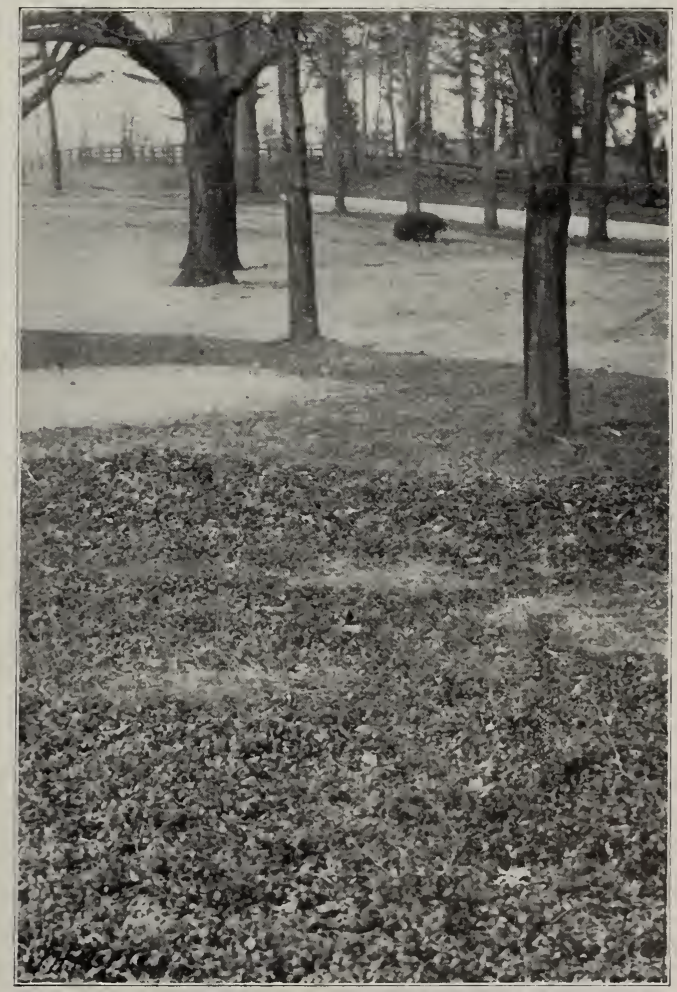

Myrtle under the trees on the lawn of Mr. H. B. Duryea. 


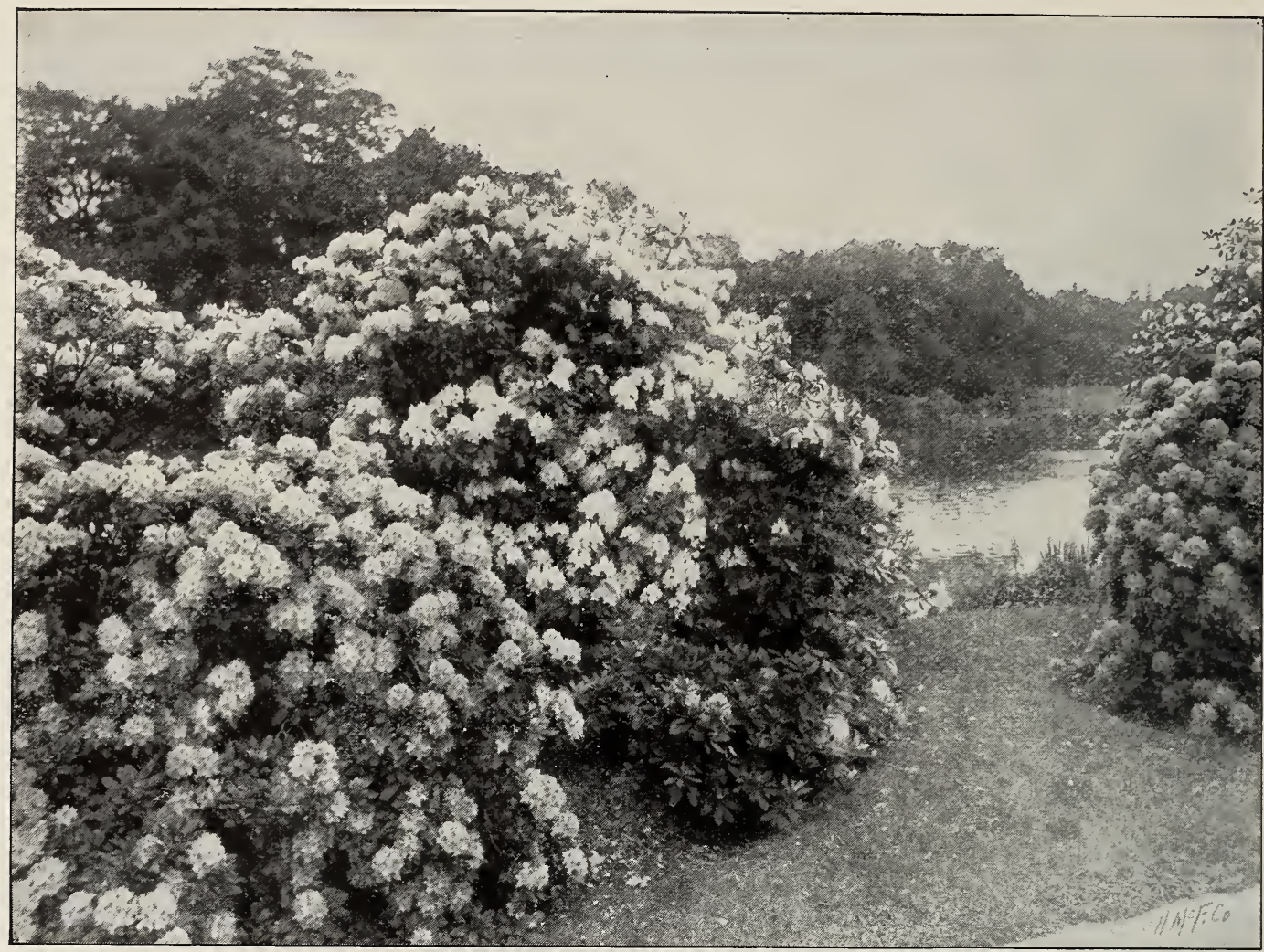

Rhododendron Catawbiense hybrids at Brookline, Mass., on the grounds of Prof. C. S. Sargent, Director of Arnold Arboretum. They will grow just as well on Long Island.

\section{RHODODENDRON CULTURE}

SoIL.-Loam, or loam well mixed with one-fourth to one-third leaf-mold or well-rotted manure. Soil 2 feet deep is preferable. Avoid clay, limestone and stagnant moisture, which are rare on Long Island.

Light.-Partial shade, at least in winter, as on a north slope, north of buildings, or by trees such as Oak and Locust. Avoid Silver Maple and trees that rob. They set most flower-buds in the open.

Culture. - Mulch annually with ro inches of rotted manure and leaves. This keeps the soil cool, moist and unfrozen in winter and provides humus, which the minute rootlets can penetrate. Water thoroughly once a week in a long drought if necessary. Remove seed-pods in July.

EXPOSURE.-Shelter from drying winter winds by planting in masses and by a windbreak of evergreen or deciduous trees, or a temporary winter fence. A good protection from both sun and wind is afforded by evergreen boughs or straw. Well-established hardy varieties may be open to view all the year.

These conditions are favorable to all of the Ericaceæ family, as Azalea, Laurel, Trailing Arbutus, Andromeda and many other woodland plants, as Ferns, Orchids, Lilies, etc. The chart of soil and climate, on pages 6 to 16 , shows why Long Island is favorable to the culture of Rhododendron Catazebiense, the hybrids in which it predominates and $R$. maximum. They are accustomed to 40 degrees annual range of temperature between the average of July and January. It show's the reason of the general failure here of Rhododendron Ponticum and similar species and hybrids from Armenia, the Levant, Sikkim and Nepaul, regions having only 20 degrees annual range. The latter thrive in England, Holland, France, and are the most easily propagated. The surplus is sent to this country and adorns the sidewalk plant market. The first to bloom is worth the price, but for permanent lawn planting they lead to disgust with Rhododendrons. An expert can generally separate hardy and tender varieties. Some of the points are; hardy Catawbiense hybrids-leaves oval, rounded at each end, glaucous beneath, leaf-stem and bark of twigs yellowish; tender Ponticum and hybrids-leaves elliptical, generally narrower and more pointed than the Catawbiense, pale green beneath, leaf-stem and bark of twigs generally green or purplish.

\section{ACCLIMATING}

To acclimate imported plants, get hardy varieties. They are scarce, slowly propagated and substitutes often sent. Soak the balls, loosen the surface, plant a little deeper to get the plant to make its own roots above the Ponticum stock. Shade and water for the first year. Pick off flower-buds as they expand. Our plants have been through this acclimating from two to six years. When imported the plants have small balls; they exhaust themselves by blooming and the roots may not push out of the ball, 
RHODODENDRON, con.

which hardens in our drier climate. 'They suffer drought, especially if not mulched, and do not ripen the wood for the next winter, and thus may gradually fail.

R. maximum. This species is a native of valleys and swamps from Georgia to Nova Scotia. It has long, glossy leaves and beautiful pink and white flowers in June and July, continuing the season much later than the others. We have planted many hundreds with entire success, for bordering drives in woodland, for planting in shady corners of the house, or making rich banks of green in the open. Growing in the

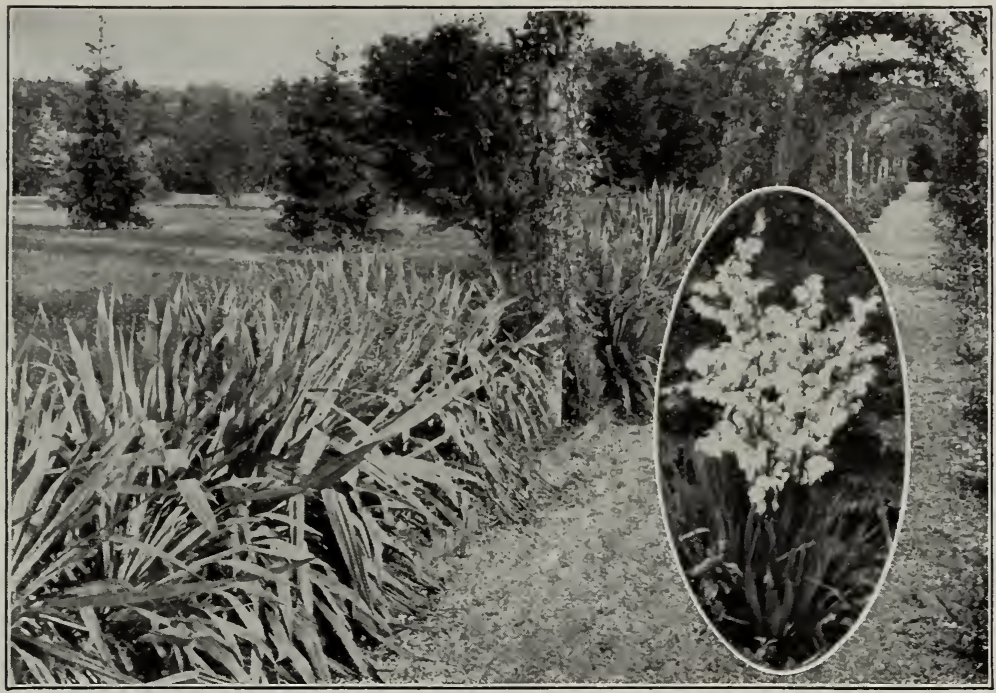
partial shade of our orchard are many large established clumps 5 to 9 feet high. Furnished in car-load lots at low rates.

R. punctatum. Pretty dwarf species; small leaves and pink flowers, blooming before the others.

R. Catawbiense. Flowers in June. Bright red-purple. This species is native of the higher peaks of the Alleghany Mountains, Virginia to Georgia, where zero weather, high winds, bright sun and dryness are often its lot, but with leaf-mold soil it survives.

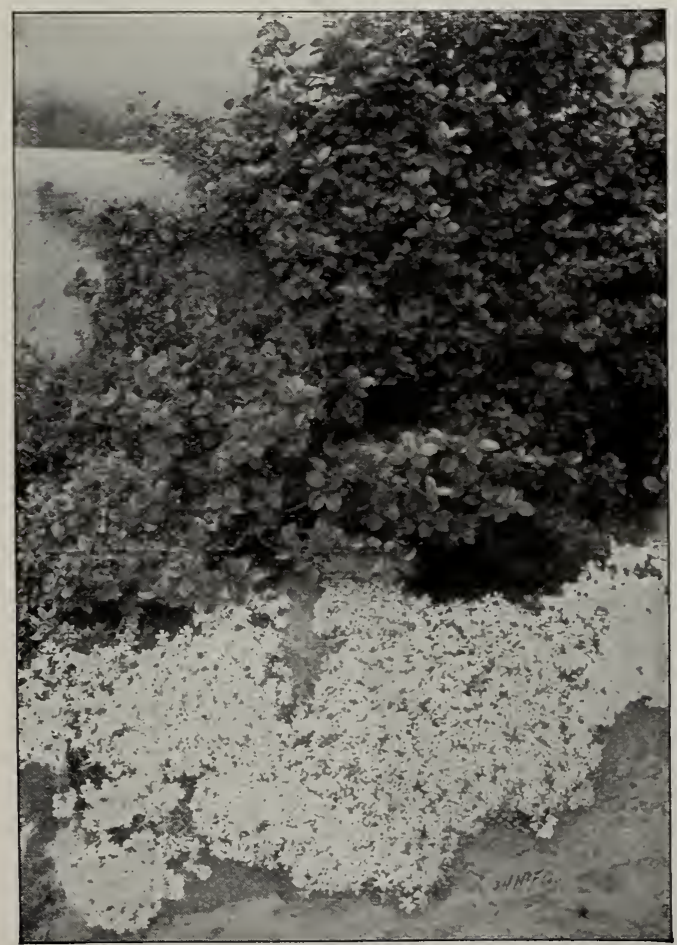

A combination that is beautiful all the year. It shows nothing bare and keeps down the weeds. Euonymus radicans climbing the wall and Phlox subulata hanging over the curb. It likes dry places.

Named Varieties of Catawbiense Hybrids of Tested Hardiness

Gloriosa. Very large bunch of blush white flowers.

Everestianum. This has long been the standard of hardiness. The plant is low and broad, as if it grew up near the snow line. Flowers rosy lilac, spotted and fringed.

President Lincoln. Rose color.

Caractacus. Crimson.

Lady Claremont. Rosy scarlet ; blotched petals. Album elegans. White. A tall, upright form which should be in the center of groups.

Abraham Lincoln. Rosy crimson.

Atrosanguineum. Dark red.

General Grant. Bright red.

Lady Armstrong. Pale rose.

Charles Dickens. Deep red.

Purpureum elegans. Purple.

Roseum elegans. Small lavender-pink flowers.

\section{YUCCA}

Y. filamentosa. Bear Grass; Spanish Bayonet; Adam's Needle. This stately garden flower has found a new use. It will cover dry, sterile gravel and sand banks, or grow near the beach. We sell it by the thousand at low rates for these purposes. It is native to dry hills from Virginia south, but is perfectly hardy here. The tropical foliage is 2 to 3 feet long, and maintains its green color all winter. It resembles and is related to the century plant. The lily-like flowers appear in July on stems 4 to 7 feet high.

\section{Vines}

\section{AKEBIA}

A. quinata. A vigorous Japanese climber that is adapted for quickly covering piazzas, arbors, wind-mill towers and rough ground. It is a clean attractive vine with nearly evergreen leaves, and inconspicuous fragrant brown flowers in May.

\section{BITTER SWEET. Celastrus scandens}

The bright orange and red berries make this native climber attractive in autumn and winter. 


\section{CLEMATIS}

C. Jackmani. A slender vine, having large deep violet-purple flowers. An abundant bloomer.

C. paniculata. This vine has rapidly gained popularity by its vigorous healthy growth, and its clouds of white flowers in August. The shrubbery at that time has but few flowers, and an occasional Clematis clambering over the top will look as beautiful as the Spirea Van Houttei in its season. It will transform an ugly fence into a beautiful hedge.

\section{DUTCHMAN'S PIPE \\ Aristolochia Sipho}

A strong, showy vine with leaves Io inches wide. The small green blossoms are in the shape of a pipe.

\section{EUONYMUS}

E. radicans. A valuable climber that may be considered a substitute for English ivy in this country, having the advantage over it of keeping the foliage uninjured by our bright winter sunshine. It grows on walls and trees, sending out horizontal branches in the manner of an old English Ivy. It makes a good evergreen ground cover, and is useful in covering stones and stumps in rock gardens. The glossy dark leaves are about an inch long by a half inch wide. See, also, under Broadleaved Evergreens. It has escaped and runs wild in our woods.

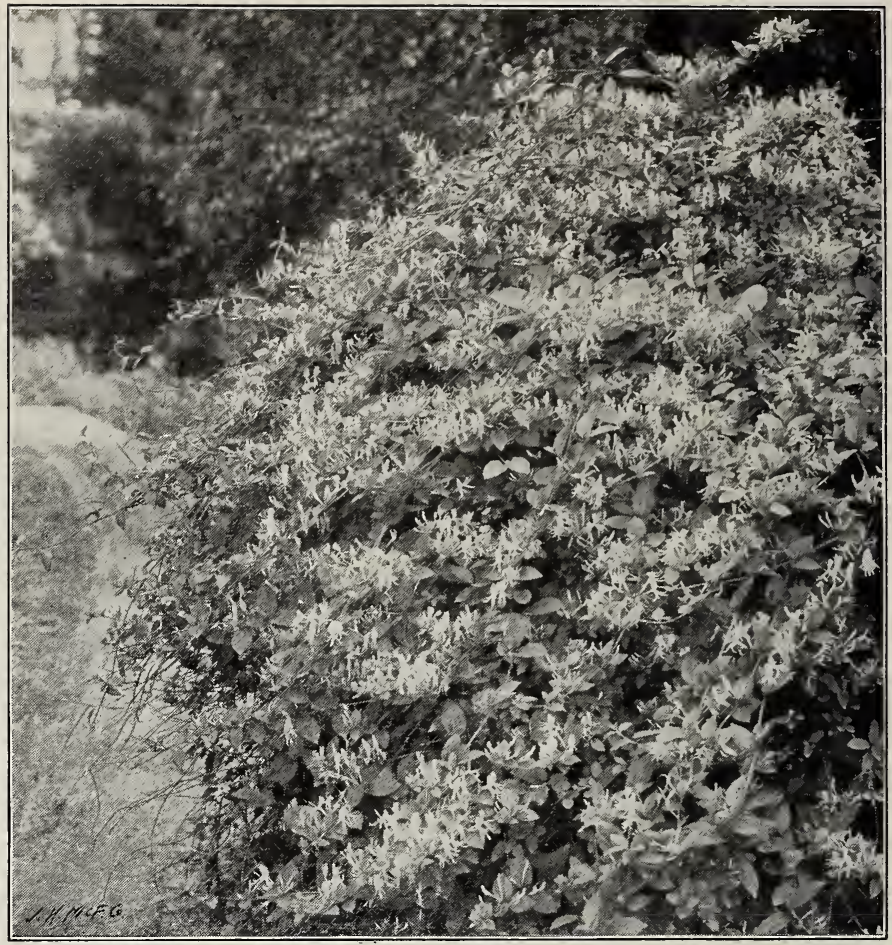

Japanese Honeysuckle is one of the best and cheapest bank covers.

\section{HONEYSUCKLE. Lonicera}

This large family contains a variety of useful vines. They are all hardy and vigorous in their growth and not at all particular as to soil or moisture.

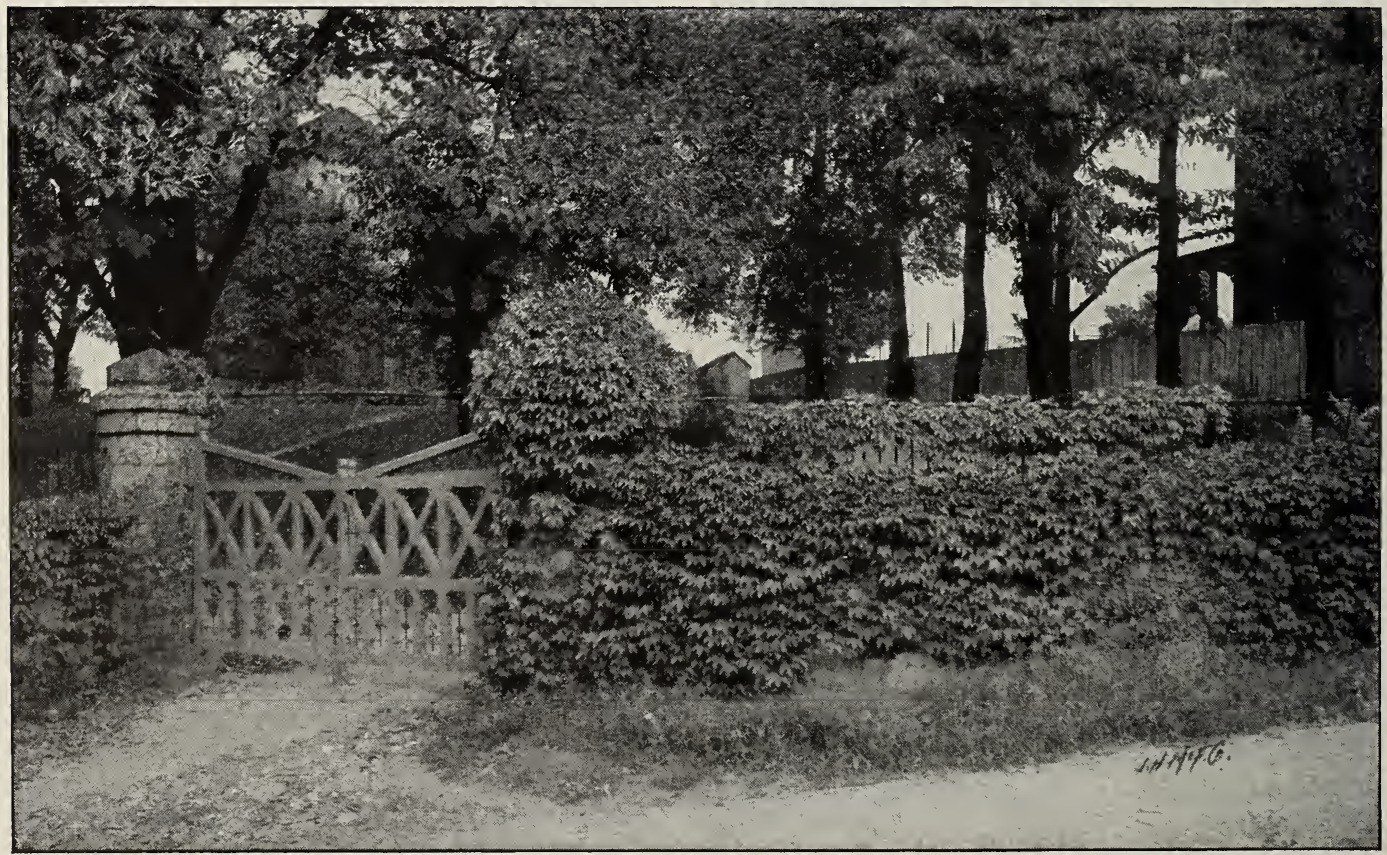

Japanese Ivy, Ampelopsis Veitchii, is about the quickest clinging vine. From early spring till late autumn it is beautiful and perfectly healthy. We have it at low rates. Plant a hundred on tree trunks, fences and walls. 


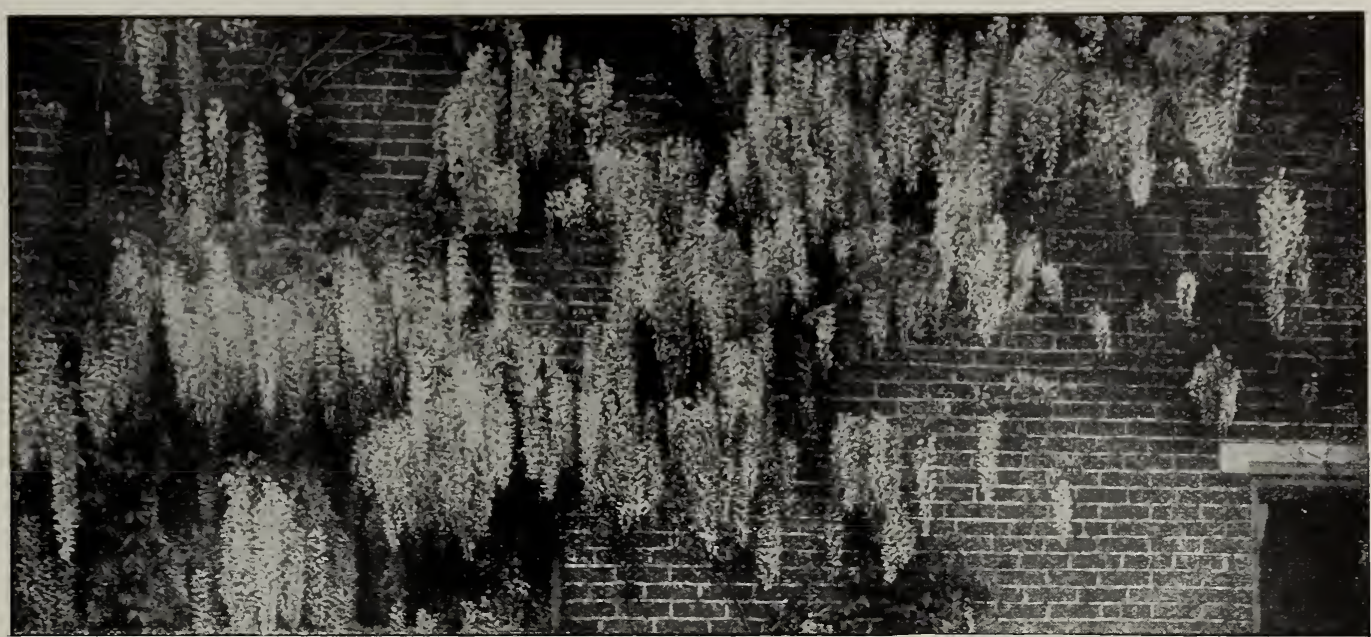

Wistaria is vigorous and always healthy. We have them in tree form, and the rare species witn racemes of fiowers 3 ft. long.

HONEYSUCKLE, continued

Japanese. L. Japonica. Hall's Honeysuckle. Leaves dark green, and are held throughout most of the winter. "The fragrant white and yellow flowers appear in early summier and again in autumn. It is a strong, rapid grower, and makes a most satisfactory vine for porch, pergola, hedge or ground cover. : For covering rough banks along the roadside, sandybluffs, stumps and rocks, or for holding up èmbankments, it has no equal. Trained to a slight wire fence and:trimmed, it thickens up its masses of rich foliage and forms a beautiful hedge. "We offer it at low rates per thousand for these purposes. We also offer long vines for immediately covering walls or porches.

Golden. L. Japonica, var. aurea reticulata. A striking object, with its leaves brilliantly marked with yellow and red.

Chinese. L. Japonica, var. Chinensis. Similar to the Japanese, with dark leaves, purple beneath.

Coral Trumpet. L. sempervirens. A climber, with long, tubular scarlet flowers during the summer.

L. Heckrotti. A low climber that is chiefly valuable from the profusion with which it flowers in October, and if in a sheltered place, it affords the rare opportunity of gathering flowers in November and December.

\section{IVY}

English. Hedera Helix. English Ivy is the ideal evergreen vine for clinging to stone and brick walls when the soil and climatic conditions are congenial, as in England. There are beautiful plants of it on Long Island, growing 5o feet high and sending out branches 12 feet wide, where protected from serere cold and brilliant winter sunshine. It makes a rich, dark border to garden paths. Its shade-enduring properties make it valuable for covering the ground and trunks of trees in woodland borders.

Japanese, or Boston. Ampelopsis tricuspidata; syn., $A$. Veitchii. The most popular of the clinging vines. It maintains its glossy and healthy foliage even in the dust and smoke of large cities, and thrives where there is apparently little soil to feed upon. It will cling to stone, brick and wood, but it will not twine upon wires or trellises. The brilliant autumn coloring is one of its attractive features. (See page 56.)
AMPELOPSIS HETEROPHYLLA

A vigorous, healthy vine from East Asia, with light blue berries in autumn. It is very good for covering banks, tree trunks; fences and tennis backstops. To limit the use of vines to porch decoration was the old idea; they are the most adaptable of landscape material. A large stock at low rates.

\section{KUDSU VINE}

Dolichos Japonicus; syn., Pueraria Thunbergiana

A vine exceeding all others in rapidity of growth, sometimes reaching 40 feet in height in a season. It dies back to about ro feet from the ground every winter in this latitude. Useful for quickly covering unsightly objects.

\section{ROSES, CLIMBING}

$$
\text { (See, also, Roses) }
$$

Roses should not be omitted from any general problem requiring the use of vines. Rosa Setigera and some of the new varieties, such as IV'ichuraiana, or Memorial Rose, and its hybrids are particularly valuable because of their persistence, healthy foliage and rapid growth.

\section{TRUMPET CREEPER. Tecoma}

T. radicans; syn., Bignonia radicans. Trumpet Vine. In late summer this vine is decorative with its clusters of orange-crimson trumpets 4 or 5 inches long. It clings closely to walls and trees, sometimes having a trunk 8 inches in diameter, and reaching to the top of locust trees 75 feet high. The foliage is glossy and healthy in all situations. We ofier it in quantity for decorating fences, locust groves and woodland borders.

T. grandiflora; syn., B. Chinensis. Chinese Trumpet Creeper. A species not so hardy as the last, but it will become established with slight protection. It may be grown on a low post or stake in the shrubbery, where it is very decorative with its wide scarlet trumpets. It is much more showy than the last and continues blooming later in the summer. It is appropriately planted by fences and tree-trunks. 


\section{VIRGINIA CREEPER (Woodbine) Ampelopsis quinquefolia}

The Virginia Creeper transforms some of our woodlands, especially groves of locust, into waving pillars of red foliage as a forerunner of the autumn change. As a vine for porches and summerhouses, it possesses the valuable feature of being rather open in growth, permitting the breeze to pass through, especially if it receives an annual pruning after the manner of its nearest relative, the grape-vine. It will cling to the bark of tree trunks, and the variety Engelmanni will cling to stone walls. It will thrive on the beach, even where washed over by high tides.

\section{WISTARIA. Kraunhia}

A genus of tall, twining vines, which maintain their health and vigor in dry and sterile soil. Even in the city, and with other unfavorable conditions,
WISTARIA, continued

the foliage is good. When Wistaria is trained in the form of a low tree, or standard, with a straight stem, and a wide-branching head, it is particularly beautiful at blooming time with its hanging masses of blue flowers.

Chinese. $W$. Chinensis. This is the common form that blooms profusely in May.

Japanese, or Loose-clustered. $W$. multijuga. A rare Japanese species with racemes of flowers $2 \frac{1}{2}$ to 3 feet long. In Japan, it is planted to grow over the bridges in the tea gardens, where its deep violet flowers are objects of great admiration.

W. magnifica. $W$. speciosa, var. magnifica. A vigorous vine, with racemes 6 to 8 inches long, borne in June after the others have passed.

White. $W$. Chinensis, var. alba flora. A variety with white flowers.

\section{Hardy Roses}

The short list of Roses we offer includes those varieties that are most popular because of their beauty and hardiness in this climate. If a greater variety is desired, we will procure them. The hybrid perpetuals bloom abundantly in June and occasionally during the summer and fall.

Anne de Diesbach. Carmine. A large, beautiful and fragrant Rose. Plant vigorous.

Baron de Bonstetten. Velvety maroon. One of the richest dark Roses.

Baroness Rothschild. Delicate pink. Large full flowers, growing close against the smooth, light green leaves. Very choice and beautiful. Not fragrant.

Francois Levet. Cherry-red. A valuable Rose from its strong growth and free blooming habit.

General Jacqueminot. Brilliant crimson. This is perhaps the most popular Rose. A vigorous plant with abundant large, fragrant blooms.

Hermosa. Bright rose-pink. One of the best bedding Roses that blooms constantly from June till October. A small, compact plant.

Jules Margottin. Carmine-rose. This grows to be a bush 5 to 6 feet high, and wide, with luxuriant foliage and abundant blossoms.

Madame Gabriet Luizet. Silvery pink. A beautiful Rose. Slightly fragrant.

Madame Plantier. Pure white. Foliage and stem light green. This makes a large bush that is useful for hedges or for massing in shrubbery. The white blossoms are borne in iarge clusters.

Magna Charta. Pink, suffused with carmine. The flowers are large and fragrant, borne on strong, light green stems.

Margaret Dickson. White. This Rose resembles Baroness Rothschild in its form and the close setting of leaves about the flowers. The large white blossoms with pale flesh center are very beautiful. Fragrant.

Paul Neyron. Rose-pink. The largest of the Roses. The stems are strong and smooth, and the foliage is a bright light green. A free bloomer. $A$ valuable exhibition variety.

Princess Adelaide. Moss Rose. Delicate rose-color. The buds are well covered with moss, and the foliage is dark.
Persian Yellow. A thorny bush with delicate foliage, bearing a profusion of small bright yellow Roses clustered thickly along the branches. A favorite in old-time gardens. Very hardy.

Harrison's Yellow. A deeper yellow than the preceding. A free bloomer.

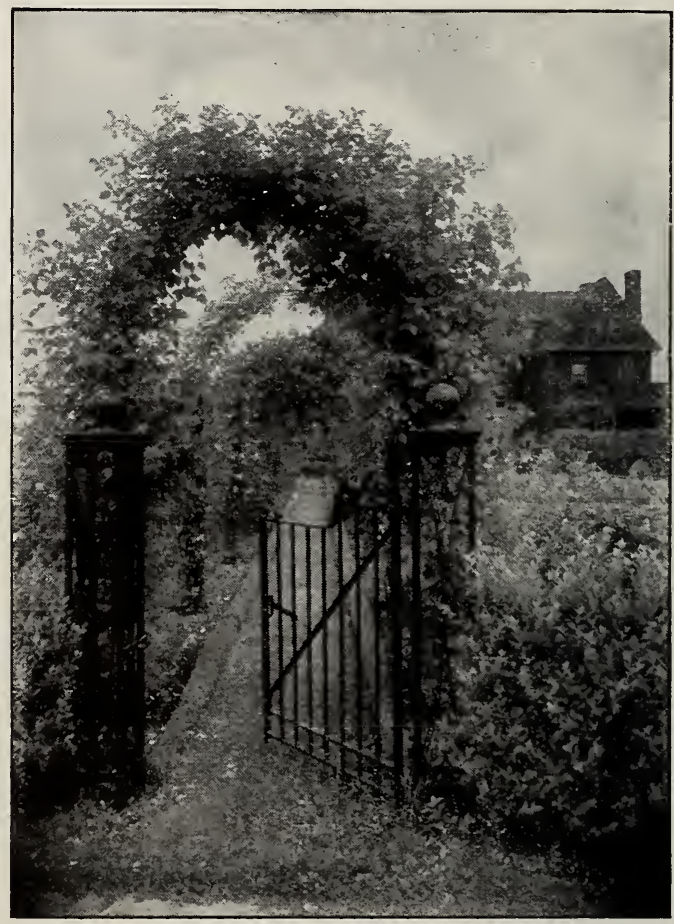

Arch of Prairie Rose. This effect can be produced in two years. We have the Roses and the iron arches. 


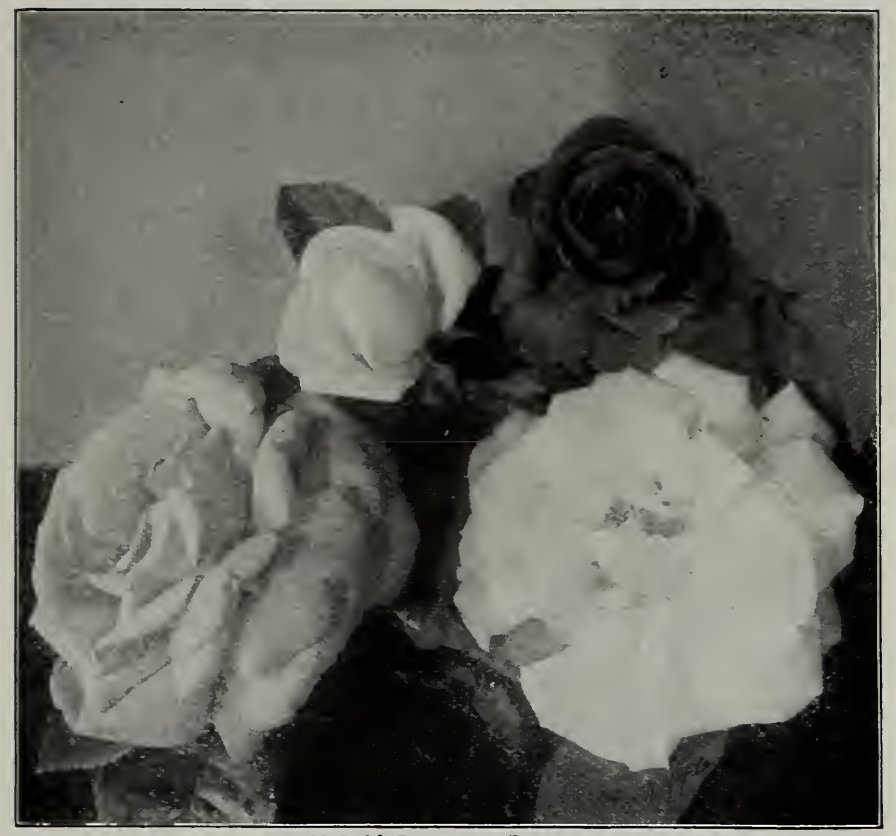

Hybrid Perpetuaı Roses.

\section{PRAIRIE ROSES}

Baltimore Belle. White. One of the most attractive and satisfactory of the old-fashioned climbing Roses. A strong plant bearing large clusters of white flowers and delicate pink buds.

Queen of the Prairies. A companion to the above, with large, bright rose-colored blossoms.

Setigera. This is the parent of Baltimore Belle and Queen of the Prairies. It is a rampant grower, with luxuriant foliage and clusters of single bright pink blossoms in July. It is effective planted among large shrubs. On a pergola or trellis, to form the background of a flower garden, it makes a solid bank of Roses, I5 feet high.

\section{CRIMSON RAMBLER}

This Rose has become one of the most popular of recent introductions. It will send up shoots Io to I5 feet in a summer, the side branches of which are weighed down with immense clusters of blossoms. These are semi-double, of the brightest crimson color and remain fresh for a long time. The foliage is a rich glossy green.

\section{ROSA RUGOSA}

\section{Japanese Rose}

This species has introduced a new type into American horticulture, and, like many of its compatriots from Japan, grows with the greatest luxuriance and vigor. Its extensive use at Newport, where it
ROSA RUGOSA, continued

succeeded after the failure of many other kinds of foliage, due to the caustic action of the salt air, has led to its general use for seaside planting. It is a most desirable shrub for groups and hedges. The thick, shining foliage is free from insect and mildew attacks. Large, single, rose-pink flowers borne in clusters during the summer are followed in autumn by large, bright red hips resembling crab-apples. VVe offer this at low rates by the hundred, for hedges, seaside and cover planting.

R. rugosa alba. Single white flowers.

Belle Poitevine. Foliage like the species and large double rose flowers.

Blanc Double de Coubert. A valuable acquisition to this race, for it combines the foliage of the species, with a pure white double flower 4 to 5 inches in diameter.

Madame Georges Bruant. This is a hybrid of Rosa rugosa. The long-pointed buds are creamy white and as delicately beautiful as a Tea Rose. It flowers freely in June and later in the summer. The foliage is slightly liable to mildew in danıp weather.

\section{SWEETBRIER. Rosa rubiginosa}

English Sweetbrier, or Eglantine, is an old-time favorite, with a profusion of delicate pink blossoms. The tender new shoots have a spicy fragrance that perfumes the air in damp weather. It is perfectly hardy, and very vigorous in growth. A good hedge plant.

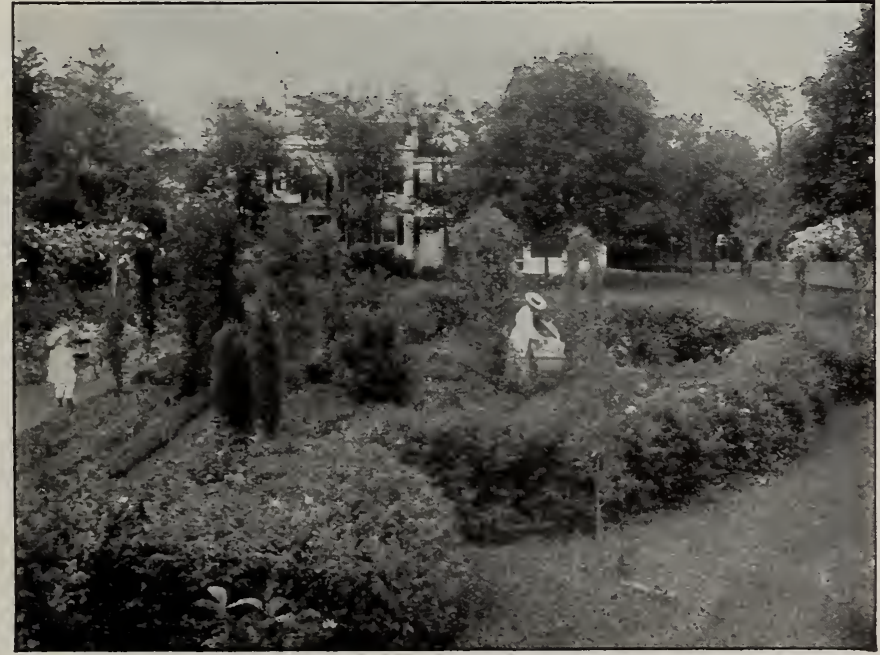

Hedge of Rugosa Rose around a flower garden designed and planted by us 


\section{MEMORIAL ROSE}

\section{Rosa Wichuraiana \\ TRAILING ROSE FROM JAPAN}

A nearly evergreen plant that trails along the ground, taking root and forming a thick mat. It is strong and vigorous and often grows $\mathrm{I}_{5}$ to 20 feet in a season. The thick lustrous foliage makes a rich background for the clusters of single creamy white tea-scented blossoms that come in July, after most of the Roses are past, and the rose-bugs are gone. It will grow on dry, poor soil, exposed situations, and at the seaside. It is a splendid carpet plant to cover banks, rocks, or under taller shrubs. It may also be trained up as a climbing Rose. There are a number of hybrids of this Rose that are distinct and beautiful.

Evergreen Gem. Rich bronzy green foliage remaining on all winter. Double flowers 2 to 3 inches in diameter, yellow in the bud, nearly white when open.

Gardenia. The flowers of this beautiful Rose are bright yellow, opening cream color, 3 to $3 \frac{1}{2}$ inches in diameter. A free bloomer and fragrant.

Jersey Beauty. Large, single, pale yellow flowers in profusion. Fragrant.

Manda's Triumph. Double white flowers in large clusters. Luxuriant foliage.

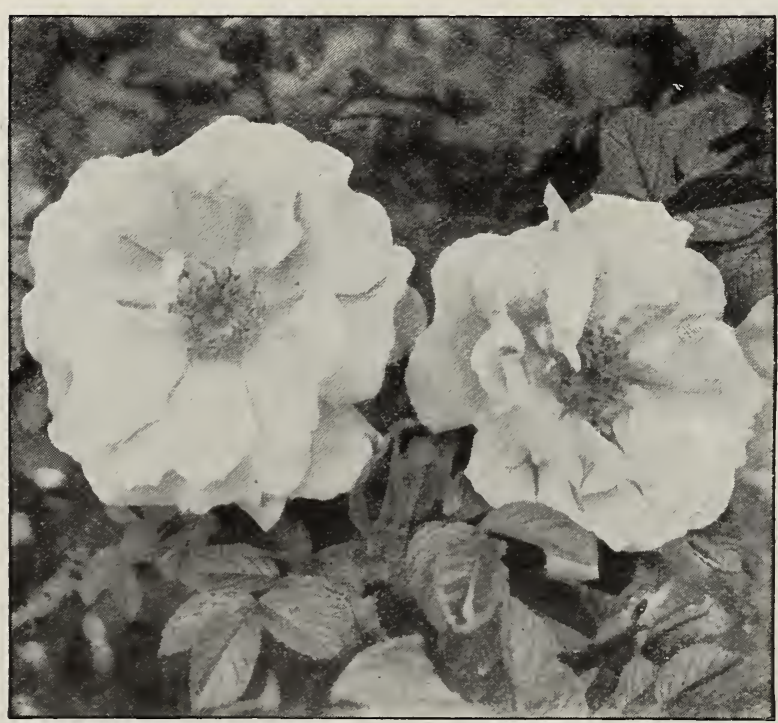

Blanc double de Coubert. This is the Rosa rugosa improved. It has the perfect foliage of the species, and beautiful large pure white flowers. It blooms before the rose bugs come. We have a large stock of this and its companion, Belle Poitevine.

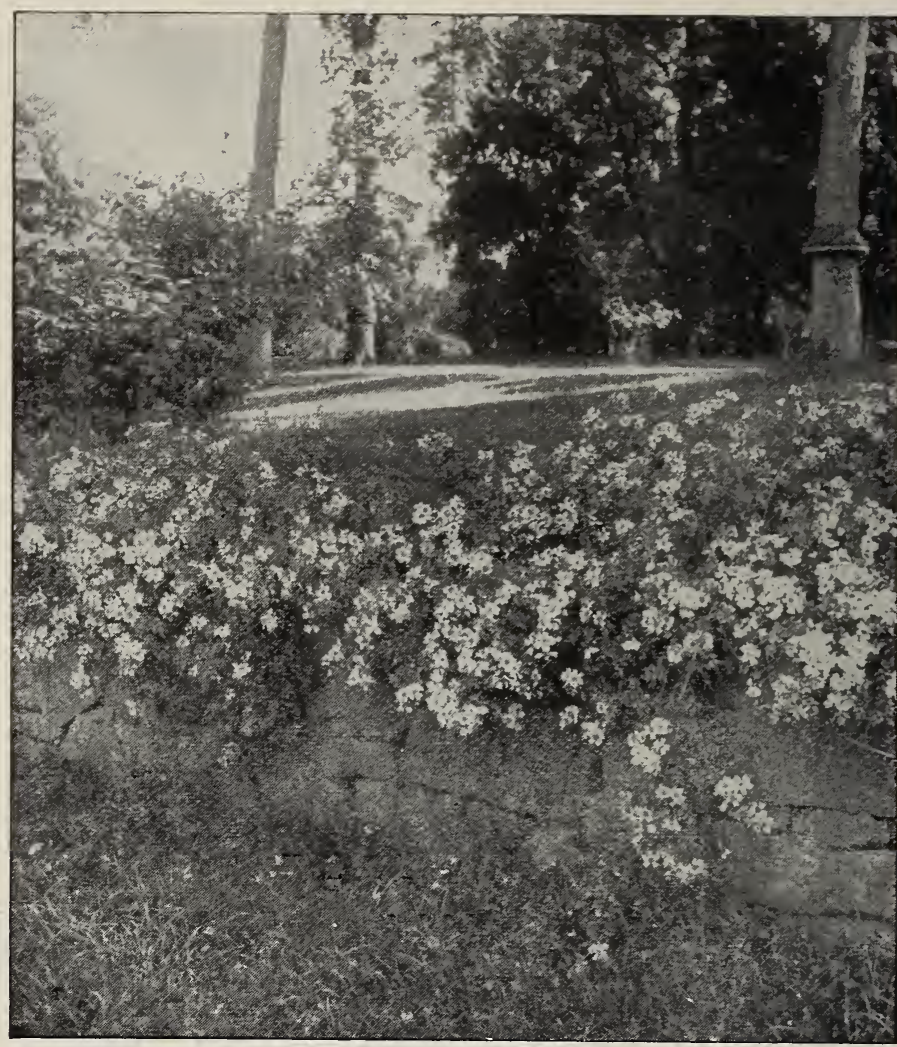

The Rosa Wichuraiana is going to be the parent of the most valuable class of Roses in the North.

Pink Roamer. Bright pink, fragrant, single flowers in close clusters.

South Orange Perfection. Small double blossoms in great profusion. Blush pink, changing to white.

Universal Favorite. Rose-colored double flowers, about 2 inches in diameter. A rampant grower.

\section{WILD ROSE (Rosa lucida)}

This native wild Rose grows as a shrub to 6 feet in height, but it is most effectively used when planted thicklv, as at the Arnold Arboretum, Boston, and kept down to 2 feet in height. Prepare the ground thoroughly and set the little plants I foot apart. They will grow rapidly and form a dense mass of handsome glossy foliage, giving a profusion of bright pink flowers. IThen they become too crowded, dig up the whole bed, separate the plants, replant again all desired there and the rest elsewhere. The winter color of the masses of brown stems and red hips is very beautiful wherever used. It is a shrub which should be planted in large masses, and as such is a most attractive and appropriate covering for all manner of rough embankments and wild corners where there is no passing, or none desired, as its prickles make it an effective barrier. It is a valuable plant for seaside use, as it will grow well under adverse conditions. 


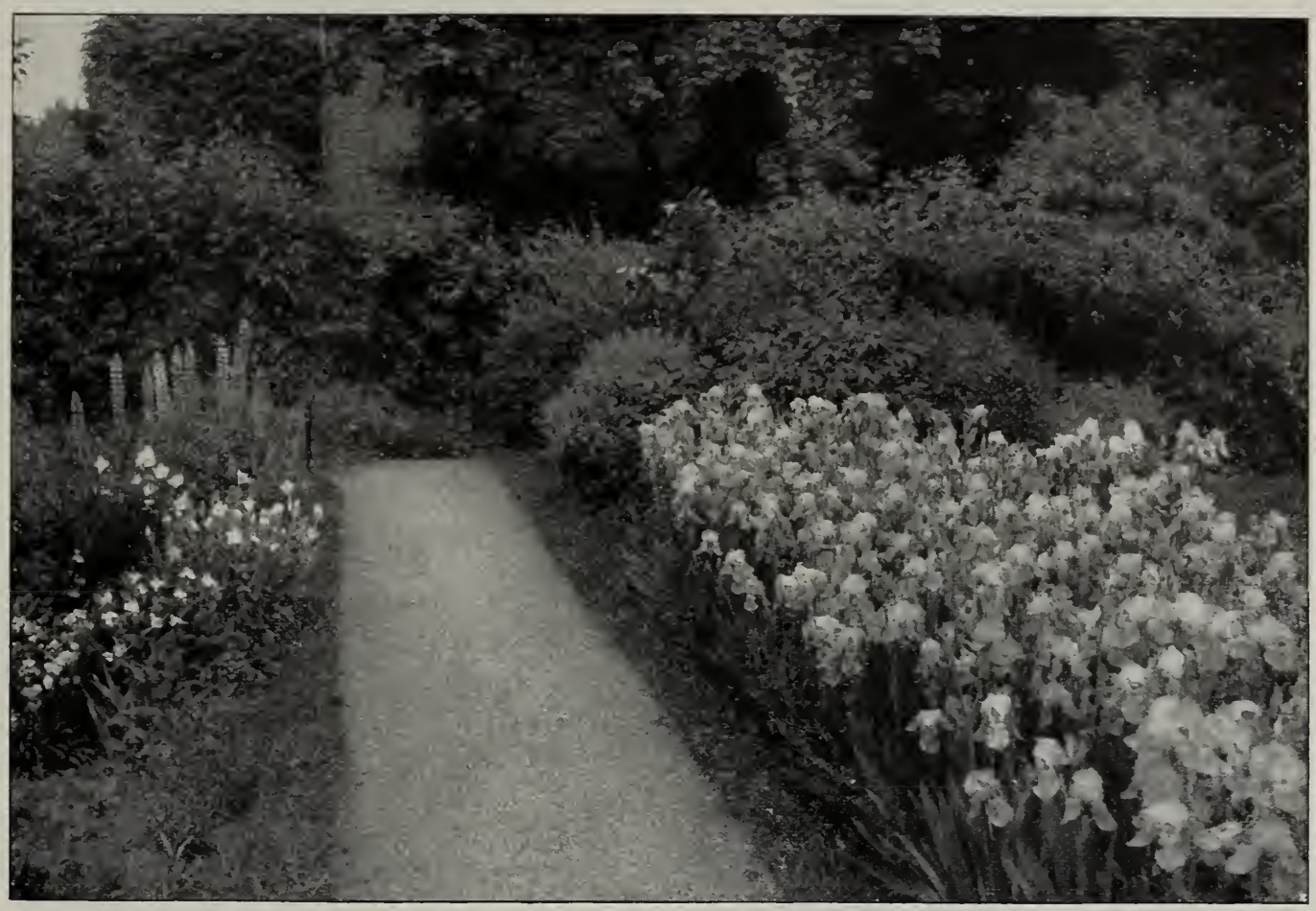

A small garden. German Iris at the right, Platycodon at the left.

\section{Hardy Garden Flolvers}

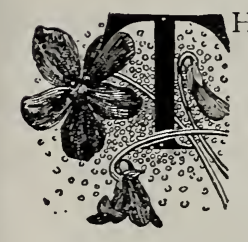

HE old-fashioned hardy garden is a continuous source of delight from the earliest spring, when the Crocus and Daffodils peep through the snow, through the long summer with its profusion of flowers, till late fall when the Chrysanthemum ends the flower season.

Such a garden, after it is once established, requires little care other than keeping down the weeds and the occasional division of the clumps that have become too crowded. In shrubberies the herbaceous plants give a desirable and pleasing effect, making a bright bit of color when the background of shrubs is not in bloom; thus the group is always a spot of interest and beauty.

ACHILLEA millefolium roseum. Rose-flowered Yarrow. Rose-colored form of the common yarrow. I $1 / 2$ feet. June to October.

A. Ptarmica flore pleno, "The Pearl." This plant makes a dense sod, and seems able to maintain itself in any soil. The clusters of small, double white flowers, resembling the Bridal Wreath spirea, are borne on long stems, and furnish a welcome addition to bouquets throughout the sumner. 2 to 3 feet.

A. Sibirica. A neat clump of foliage of dome form, surmounted with clusters of white flowers in July. 2 feet.

ADONIS vernalis. Bright yellow flowers 2 or 3 inches across, borne in earliest spring. Foliage finely cut. March to May.

AGROSTEMmA. See Lychnis.

ALTHÆA. See Hollyhock.

ALYSSUM saxatile compactum. Tufts of showy yellow flowers. April to June. A pretty plant for edging.
AMSONIA tabernæmontana. A woody perennial, with willow-like leaves and panicles of small, bluish flowers in May and June. 2 to 3 feet.

ANEMONE Japonica. The Japan Anemone ranks with the chrysanthemum as queen of the autumn flowers. The exquisite waxy white flowers 2 to 3 inches across, with golden stamens, continue in stately profusion after the early frosts, and are especially attractive when the other flowers are yellows, reds and purples. Should be freely planted. It needs a rich soil, and should remain undisturbed for several years, the ground being slightly mulched in winter. 3 to 4 feet. Sept., Oct.

A. Japonica, var. alba. Pure white.

A. Japonica, var. "Queen Charlotte." Large, semidouble flowers of La France pink.

A. Pennsylvanica. This has large cream-white flowers all summer. An excellent plant. I2 to I5 inches.

ANTHEMIS tinctoria. Chamomile; Golden Marguerite. Yellow daisy flowers and finely cut foliage. I $1 / 2$ to 2 feet. July. 
ANTHERICUM liliastrum. See Paradisea.

AQUILEGIA. Columbine. The flower of the Columbine differs from all others, the conspicuous feature being the long, tapering spurs arching gracefully upward, holding a drop of honey at the apex. It is the first flower ready for the hummingbird upon his arrival from the tropics. 2 to 3 feet. May and June.

A. cœrulea. Rocky Mountain Columbine. exquisite blue and white flower.

A. chrysantha. A long-spurred yellow variety. 3 feet. July and August.

A. alba. A white-flowered form of the above.

A. glandulosa. Shaded blue and white.

A. hybrids. A fine collection of double and single in many shades of blue, purple, yellow, white, red and pink.

ARMERIA plantaginea. Thrift, or Sea Pink. The plant is a low evergreen tuft of moss-like foliage. producing clusters of pink flowers on stems about 6 inches high. All summer.

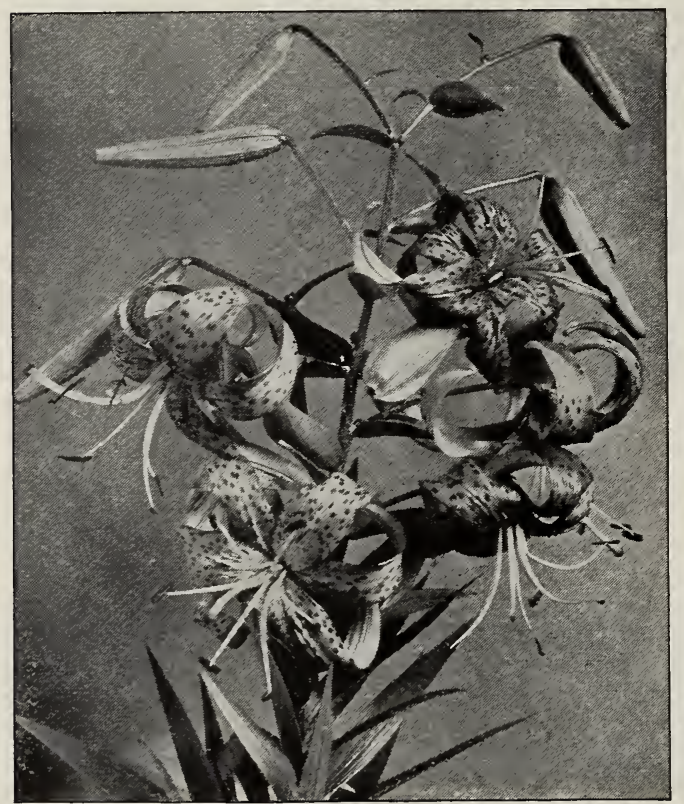

Tiger Lilies. Plant a group of these tall Lilies in the shrubbery.

ARTEMISIA Abrotanum. Southernwood; Old Man. The silvery gray, fern-like foliage has a strong aromatic odor. It thrives in the drier portions of the rock garden and combines well with cut-flowers.

ASCLEPIAS tuberosa. Butterfly Weed. One of the showiest perennials. Brilliant orange-colored flowers in compact umbels. Occasionally on dry hills. 2 feet. July to September.

ASTER. Under the name of Michælmas Daisy the various species of hardy Asters hold an important place in the English hardy gardens. Their brilliant star-like flowers are borne in such profusion that they make great masses of color during late summer. September and October.

A. grandiflorus. The most showy variety, with flowers of deep violet-blue, 2 inches in diameter. $\mathrm{I} / 2$ feet. October and November.
Aster Novæ-Angliæ. One of the best of our native Asters, with large purple or rose-colored blossoms in September and October. Excellent for bold groups among shrubs, and to produce masses of color at a time when there are but few flowers. 3 to 4 feet.

A. Tataricus. Large brilliant blue flowers, lasting even later than the above and valuable for the same purposes. A tall and stately plant. 6 to $7 \mathrm{ft}$.

ASTILBE Japonica. Spircea Japonica. The characteristics of this little plant are delicacy and refinement. The cut leaves are dark green, and the flower-spikes of feathery white. I foot. May.

BABY'S BREATH. See Gypsophila.

BAPTISIA australis. Blue IVild Indigo. The single upright stem branches like a little tree and bears spikes of indigo pea-shaped flowers in July. 2 to 3 feet.

BELEMCANDA Chinensis. Blackberry Lily. This is an iris-like plant with seed-clusters resembling the blackberry. The flowers are bright orange, borne on stems $2 \frac{1}{2}$ feet long during July and August.

BELLFLOWER. See Campanula and Platycodon.

BELLIS perennis. English Daisy. A little gem among plants. In early April it welcomes the spring with dainty pink and white flowers, which continue during the summer and appear freely again in the cool days of autumn. It should be placed at the front of the border with Forgetme-nots.

BEE BALM. See Monarda.

BETONICA. See Stachys.

BLACKBERRY LILY. See Belemcanda.

BLANKET FLOWER. See Gaillardia.

BLEEDING HEART. See Dicentra.

BLOODRO0T. See Sanguinaria.

BocconIA cordata. Plume Poppy; Tree Celandine. A bold, picturesque plant, having large, blue-green leaves and open panicles of creamwhite flowers, larger than the Hydrangea. Useful in shrubberies or wild planting, but its spreading roots render it unsuitable for the small garden. 5 to 8 feet. Midsummer.

BOLTONIA asteroides. A plant closely resembling the wild Asters and producing sheets of starry white flowers. Suitable for planting in masses in the shrubbery or near woodlands. Very effective and sure to give satisfaction. 4 to 6 feet. August and September.

BUTTERCUP. See Ranunculus.

CACTUS Opuntia. Prickly Pear. A native of some of the most gravelly soils on Long Island. It has delicate yellow flowers 3 inches in diameter. We have used it to plant on terraces, in wild gardens, which were nearly vertical, the soil being temporarily held by wire netting. It grows in the cleft of the rocks high up in the Palisades.

CAMPANULA. Canterbury Bell; Bellflower. These are old-time garden favorites. Tall, stately spikes.

C. persicifolia. Blue flowers in June and July. I $1 / 2$ to 2 feet.

C. persicifolia Moerheimei. Spikes of pure white, camellia-like flowers. I $1 / 2$ to 2 feet. 
CASSIA Marylandica. Wild Senna. A showy plant, with panicles of curious yellow and black-spotted flowers, from July to September. Useful for planting on dry: gravelly banks. 3 feet.

CENTAUREA macrocephala. A vigorous plant, with broad leaves surmounted with globular yellow, thistle-like flowers. 2 feet. June and July.

CERASTIUM tomentosum. Mouseeared Chickweed. A creeping plant, with silvery gray leaves and numerous white bells in May and June. Suitable for edging garden beds, for the rockery, or to cover steep banks. 6 inches.

Chamomile. See Anthemis.

CHRYSANTHEMUM. The hardy Chrysanthemum belongs to the pompon class. They are oldfashioned garden favorites, giving abundant flowers when the other flowers are gone. 2 to 3 feet. October.

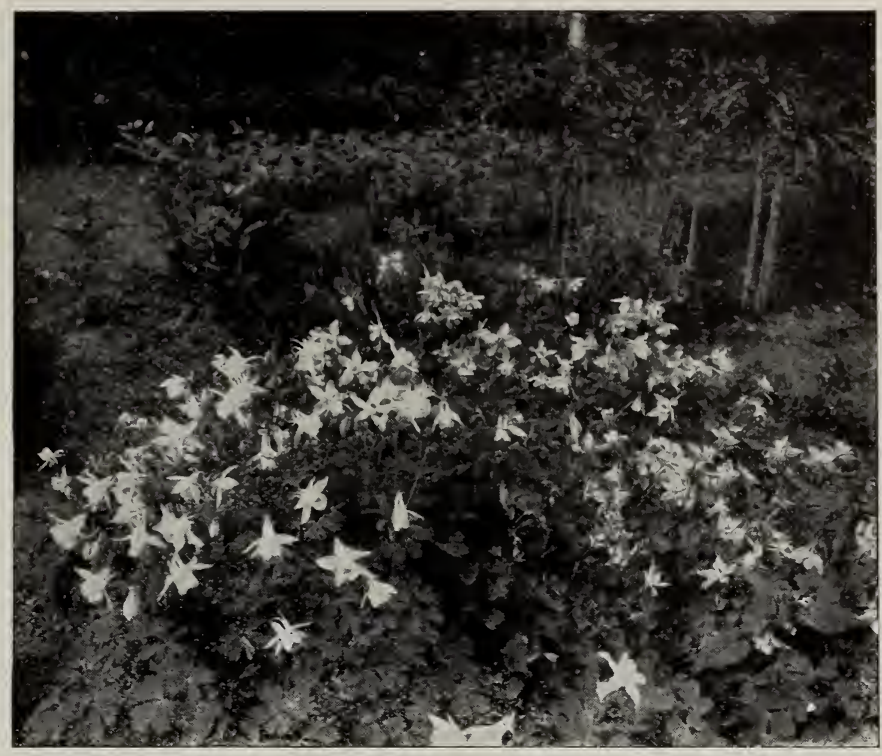

We offer a list of the best se-

lected varieties of white, pink, red and yellow.

Prince of Wales. Best white.

Anna Mary. Cream-white.

Eagle d'Or. Yellow.

Princess Louise. Bronze.

Julia Lagravere. Dark bronze.

Rhoda. Delicate pink.

St. Illoria. Silver-pink.

Little Pet. Rose.

c. inodorum. A tuft of fern-like foliage a few inches high, with small, pure white, double flowers in July.

C. uliginosum. Giant Daisy. A vigorous plant, covered with white daisy-like flowers, 3 inches in diameter. July to September.

CLEMATIS Davidiana. A shrub-like plant about 4 feet high, bearing fragrant blue flowers resembling Hyacinths, in clusters. August and September.

Clematis recta. A similar plant, with exquisite white flowers. Very fragrant. 2 to 3 feet. June to August.

CONE-FLOWER. See Rudbeckia.

CONVALLARIA. Lily-of-the-Valley. Spikes of fragrant white bells among luxuriant green leaves. It has a partiality for shaded situations, which explains its frequency on the north side of a house, as well as the persistency with which it covers the ground under old trees around oldfashioned gardens. 6 inches. May.

COREOPSIS. Among the numerous yellow Daisies this remains longest in bloom, affording a brilliant mass of color in the garden, and longstemmed graceful flowers for cutting, from June till September. 2 to 3 feet.

C. lanceolata. I to 2 feet. The best sort for cutflowers.

C. verticillata. I to 3 feet.

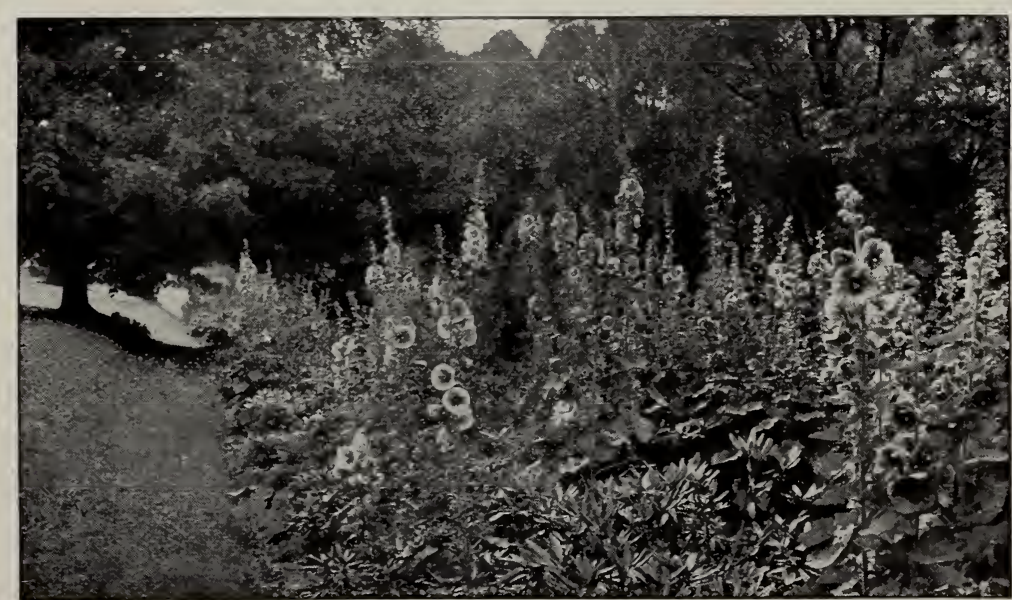

Hollyhock. We grow the rare and desirable old-fashioned single sorts in quantity.

COWSLIP. See Primula.

CYPRIPEDIUM acaule. Ladies' Slipper ; Moccasin Flower. A beautiful hardy native Orchid. Pouch - shaped flowers 2 inches long, of rose color, veined with deeper rose, are borne on slender stems above two leaves. Plant in the fern bed or dry oak woods. 6 to 8 inches. May. Of easy culture, this should be more often planted.

DAFFODILS. See Narcissus.

DAISY. See Bellis.

DAY LILY. See Funkia and Hemerocallis. 
DAPHNE Cneorum. A tiny alpine shrub with trailing woody branches and evergreen leaves. The bright pink, spicily fragrant flowers appear in early May and June, and occasionally during the summer. The plant has somewhat the habit and all the attractiveness of the Trailing Arbutus.

DELPHINIUM. Larkspur. The stately Delphiniums lend a classical dignity to the garden, and add the clear blue so rarely found. They have showy racemes of long-spurred blossoms in white and several shades of blue. 2 to 7 feet. June to September.

D. Cashmerianum. Pale blue. July and August.

D. grandiflorum, var. Chinense. Blooms continuously from June to September. Flowers of the lighter blues and white. The foliage is finely cut. I 8 inches.

D. formosum. Indigo-blue. The old-fashioned sort. Has a continuous succession of flowerspikes. 4 feet.

Kelway's Hybrids. A very fine range of colors, in tall, vigorous spikes. 5 to 7 feet.

DESMODIUM. See Lespedeza.
Dianthus plumarius. Double and single hardy garden Pinks in a variety of colors.

DICENTRA spectabilis. Bleeding Heart. An oldfashioned plant sending up branches of deeply cut foliage in early spring, followed by drooping racemes of pink heart-shaped flowers. Strong and luxuriant. 2 to 3 feet.

D. eximia. Dainty fern-like foliage and bright rosecolored flowers that continue all summer. I foot. This is one of the most valuable of the hardy herbaceous plants, because of persistent blooming qualities. Plant in the garden border or in the wild garden. (See illustration page 65.)

DIGITALIS. Foxglove. A dignified old-time plant with tall spikes of bells, ranging in color from white to rose and purple. June and July. 2 to 5 feet.

DORONICUM plantagineum excelsum. This attractive plant gives a bright yellow touch to the garden early in April. The leaves are broad, and the flowers, borne on tall, graceful stems, are 4 inches in diameter.

EULALIA. See Miscanthus.

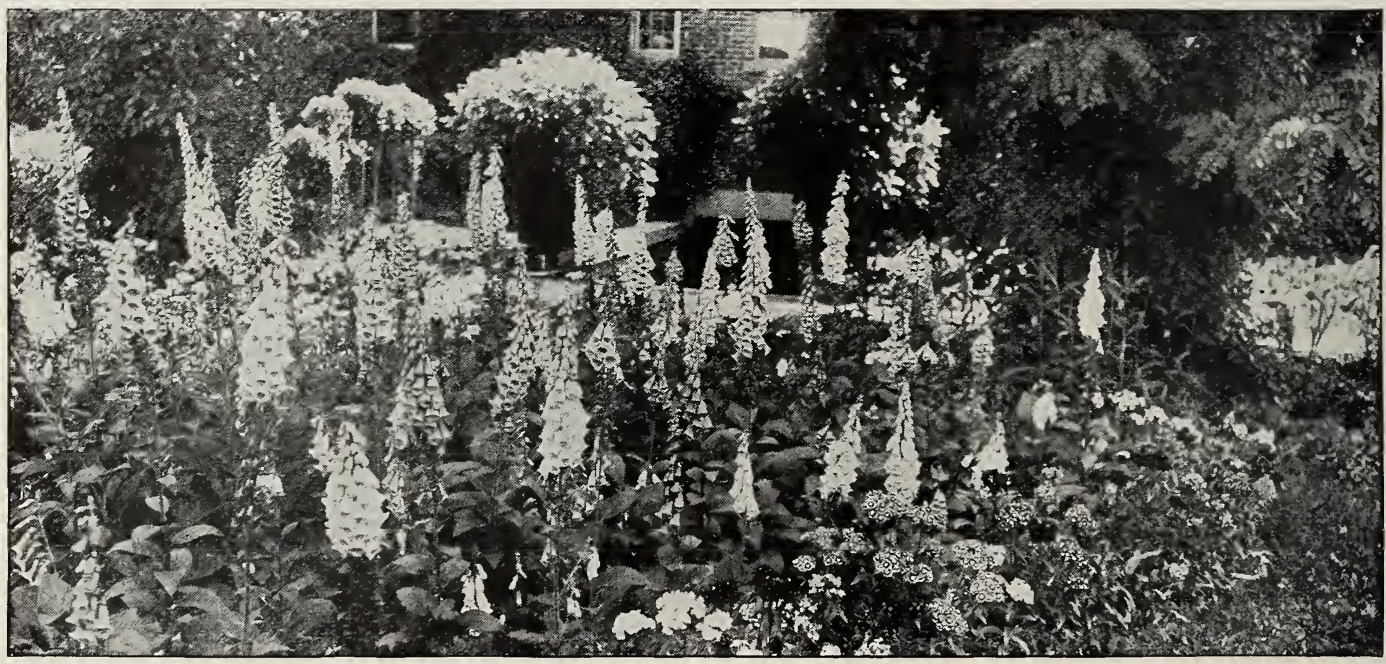

Foxglove and Sweet William. Two of the easiest flowers to grow.

DIANTHUS. Pink. The hardy Pink is the prototype of the carnation. The gray-green, grasslike foliage is attractive throughout the year. They prefer a rather dry position, such as the edge of a raised bed. I foot. May and June.

June Pink. White. The old-fashioned clovescented white Pink. Should be planted extensively. An excellent border plant.

D. barbatus. Sweet William. A showy old-fashioned perennial, with wide, flat heads of flowers in brilliant combinations of red and white. An excellent bedding plant for color effect. Fragrant. I foot. June and July.

D. Chinensis. China Pink. A biennial plant blooming brilliantly from May to October. The petals are brightly marked and splashed in many shades of red and pink and white. Fine for bedding for color effect. 6 inches.

D. delicata. Bright pink.

D. Homer. Rich rosy red, with dark center.
EUPATORIUM cœlestinum. The hardy Ageratum. A sheet of deep blue in August and September. Useful where an even mass of color is needed in formal gardening.

EUPHORBIA corollata, Flowering Spurge. The small milk-white flowers on wide branching panicles are useful for making up with other flowers in the same manner as Baby's Breath. I 8 inches. June to August.

FESTUCA glauca. Blue Fescue Grass. This makes a bright bluish green clump in the rock garden, or may be used as a border.

FEVERFEW. Double cream white flowers; button shape. All summer. I2 to I 5 inches.

FLEUR-DE-LIS. See Iris.

FORGET-ME-NOT. See Myosotis.

FOXGLOVE. See Digitalis.

FUNKIA. Day Lily, or Plantain Lily. 
FUNKIA ovata. Blue Day Lily. Broad leaves and graceful stems, bearing slender blue Lilies. I I $12 \mathrm{ft}$. August.

F. subcordata. White Day Lily. The white Day Lily of our grandmother's gardens. A clump of large rich leaves surmounted in midsummer with spikes of pure white Lilies, with golden stamens and the fragrance of the Madonna Lily. 2 feet.

F. lancifolia. Clusters of lance-shaped foliage, making a symmetrical plant 2 feet or more in diameter, and long, showy spikes of lavender flowers.

F. lancifolia, var. variegata Leaves handsomely variegated with green and gold. A low border plant.

GAILLARDIA aristata. Blanket Flower. One of the most showy and effective hardy plants that will thrive in any location. The newer varieties of Gaillardia give a wide range of red, orange and yellow. They afford a bowl of daisy-shaped flowers any day duringsummer or autumn. 2 feet.

GERANIUM sanguineum. A native hardy Geranium, having cut leaves and rosepurple flowers. I $1 / 2$ feet. June to August.

GENTIANA Andrewsii. Closed Gentian. Clusters of tubular flowers of most beautiful clear blue, which always appear as if in bud.

GOLDEN GLOW. See Rudbeckia.

GYPSOPHILA paniculata. Baby's Breath. Large, loose panicles of tiny white flowers, giving a misty effect. Excellent for use in bouquets. 2 feet. July and August.

G. repens. A creeping plant about 8 inches high, with pale rose flowers. Useful in the rock garden or in front of a border.

HELENIUM autumnale superbum. Sneezeweed. The yellow daisy-like flowers are borne on tall, rigid stems in August and September. It is useful in the rear of the flower garden, in shrubbery and in the wild garden. 5 to 6 feet.

HELIANTHUS. Perennial Sunflower. The perennial Sunflowers are the most vigorous and showy of the late summer and autumn flowers, producing great masses of golden color. Valuable for cut-Howers. 3 to 8 feet.

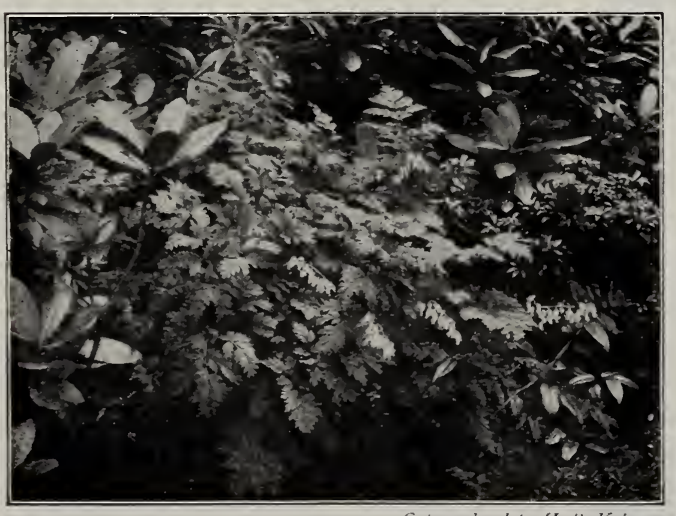

Dicentra eximia. One of the daintiest woodland flowers, ye it will grow in the open garden.

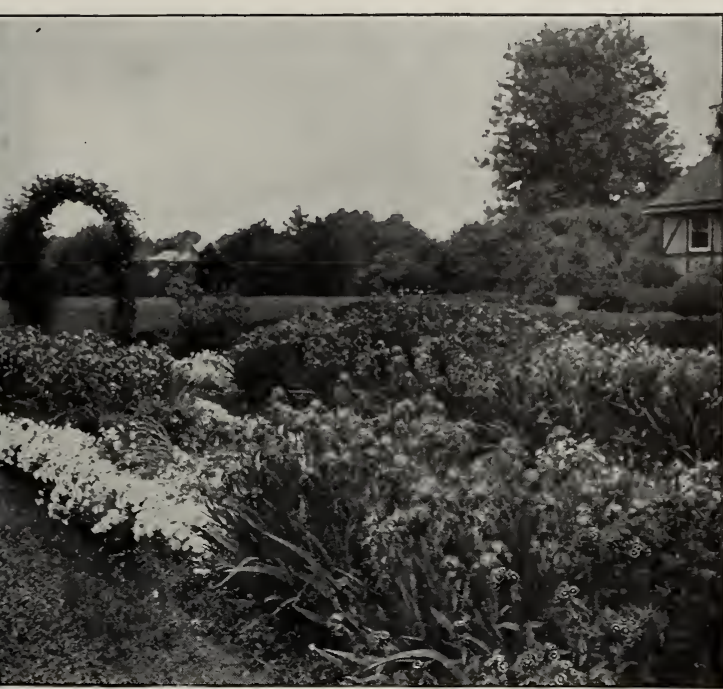

A hardy garden of Pinks and German Iris.

Helianthus Maximiliana. Single bright yellow flowers. Most effective planted in the shrubbery in connection with Aster Tataricus, as they, with the hardy Chrysanthemums, are the last to yield to frost. 6 to 8 feet. September and October.

H. mollis. Downy white foliage and single lemoncolored flowers. 4 feet. August and September.

H. orgyalis. Long, narrow, drooping foliage, surmounted by numerous golden flowers. Plant for foliage effect. 7 to 8 feet. September and October.

HELIOPSIS lævis, var. Pitcheriana. A plant resembling Helianthus, but dwarfer in habit, and blooming profusely in midsummer. Deep golden yellow. 3 feet.

\section{HEMEROCALLIS. Day Lily.}

H. flava. These Lilies grow freely in any situation. The flowers are lemon-yellow, appearing in June and July.

H. fulva. Tawny Day Lily. The old-fashioned tawny Lily often found by the ro: dside, escaped from old gardens. 3 feet. Effective in shrubberies. July.

H. fulva fl. pl., var. Kwanso. The double form, blooming longer than the preceding. 4 feet.

HIBISCUS. Marsh Mallow ; Rose Mallow. While the natural habitat of Marsh Mallows is the salt marsh, they are equally at home in the border. The flowers are larger than those of the Hollyhock, and are pink and white in color. 4 feet. August.

H. Moscheutos. Pink.

H. Moscheutos, Crimson Eye. White, with crimsor eye.

HOLLYHOCK. Althea rosea. These stately plants are indispensable in the garden or border. They are especially pleasing as they throw up their tall spikes of bright color against a vine-covered pergola or wall. IVe offer a good variety of sorts, including the single ones that have been so difficult to obtain in quantity. 5 to 7 feet. July and August. (See illustration, page 72.) 
IRIS. Fleur-de-Lis.

I. Germanica. German Iris. One of the most valuable and attractive plants, of easy culture, adapted to gardens, shrubberies or margins of water. The foliage is always good, and the flowers as delicate and beautiful as an orchid. Our collection comprises sorts ranging in color from white to deep blue, with variations of yellow, brown and maroon. They should be planted largely. A charming effect is produced by planting Iris and Columbine together. $21 / 2$ feet. May and June.

I. lævigata (Kæmpferi). Japanese Iris. The Japanese gardeners have exemplified their skill in the wide range of colors and blendings, and in the huge size to which they have developed this flower. In late June and July great flowers 6 inches or more across, in blues, purples, pinks, reds and whites, with innumerable variations, make a sight never to be forgotten. Plant in great masses in the shrubbery border, the garden, the aquatic garden, and by the edges of ponds, where they reach their highest development. 3 feet.

I. cristata. Early Iris. This grows 4 inches high and in May is a sheet of light blue flowers, spotted with yellow. Equally valuable in the garden border or water garden. We offer several thousand.

I. Sibirica. Siberian Iris. A variety with narrow leaves and intense deep blue blossoms borne on slender red stems. $2 \frac{1}{2}$ feet. June.

I. Hispanica. Spanish Iris. Yellow flowers, otherwise resembles the German Iris.

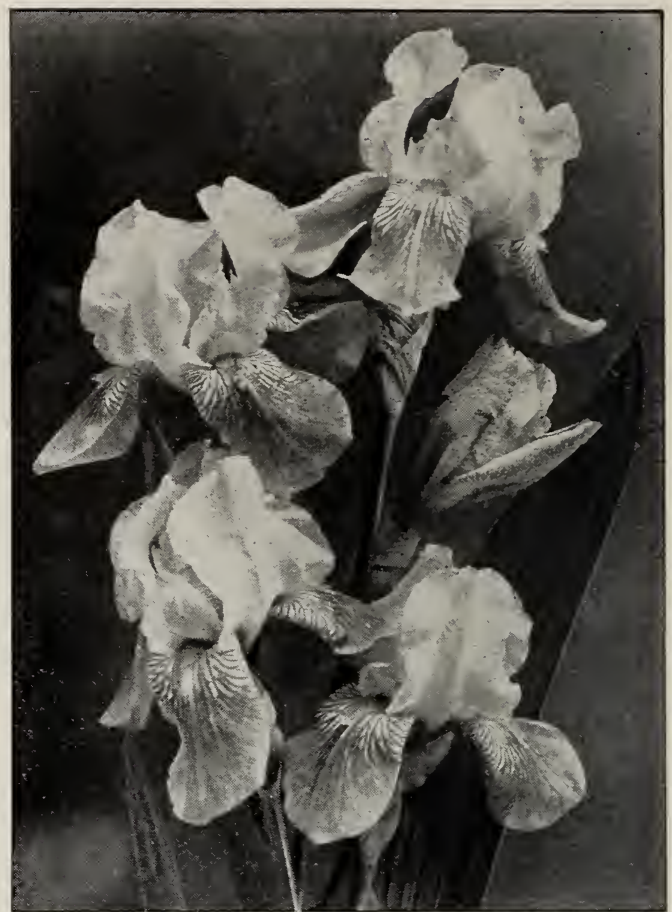

German Iris takes care of itself in wild gardens and borders of shrub groups, and thrives even where the ground is poor.

I. pumila hybrida. A cross between the German and dwarf early Irises. It blooms earlier than the German, and is a very attractive variety. I foot. May.

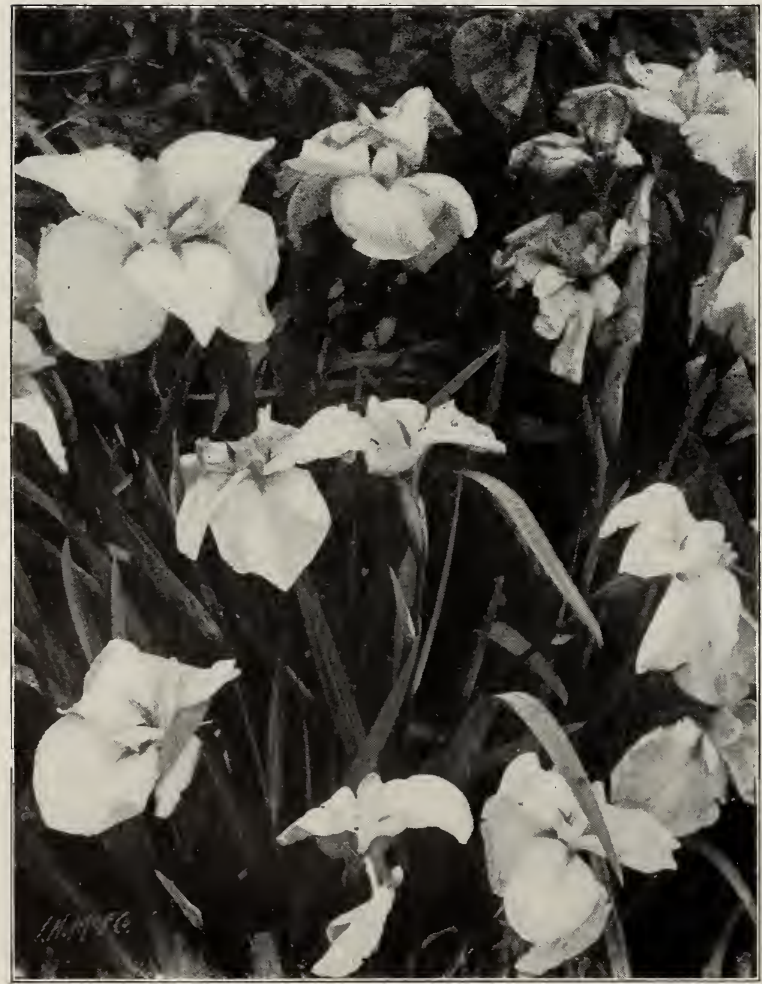

Japanese Iris. The most beautiful flower of its season.
I. Cyanea. Rich royal purple, with blackish shadings.

I. Eburna. Pure white, with creamy shadings.

I. florida. A beautiful lemon-yellow, shaded darker.

I. formosa. Upper petals deep violet-blue, lower petals light violet.

KNIPHOFIA Pfitzerii. Flame-Flower ; Tritoma ; Red-Hot-Poker Plant. Broad tufts of grass-like foliage, from which ascend spikes of brilliant flowers-deep scarlet in the bud, opening yellow-making a shaded flame of color. Mulch in winter. 4 feet. August to October.

LESPEDEZA Sieboldi, syn., Desmodium penduliflorum. This member of the pea family grows so vigorously that it is equally valuable in the shrubbery or in the garden. It is able to thrive in any situation. The flowers are rosy purple and borne in great profusion in early September. 4 to 5 feet.

LARKSPUR. See Delphinium.

LILY-OF-THE-VALLEY. See Convallaria.

LILIUM candidum. The Annunciation Lily. Tall spikes of fragrant white Lilies. 5 feet. June, July.

L. tigrinum splendens. Tiger Lily. One of the showiest and most easily grown Lilies, occasionally escaping to roadsides. The flowers are orange-red, spotted with black. Garden or shrubbery. 5 feet. August.

LOOSESTRIFE. See Lysimachia. 
LYCHNIS Chalcedonica. Maltese Cross, or Scarlet Lightning. The most brilliant scarlet in the garden, for the clusters of small flowers seem to glow like heated metal. 2 to 3 feet. July to September.

L. Haageana. Resembles the last, with larger flowers. 6 inches. May and June.

L. coronaria. Mullein Pink; Rose Campion. White woolly foliage and flowers of a rich crimson or white color and velvety texture. It blooms all summer. I to 2 feet.

L. Flos-cuculi. Ragged Robin. Sends up spikes of rose-crimson double flowers from a tuft of evergreen foliage. Blooms profusely for a long time. $I \frac{1}{2} \mathrm{ft}$. June.

LYSIMACHIA clethroides. Loosestrife. A plant 2 feet high, with gracefully bending spikes of white flowers. Brilliant foliage in the late autumn. July to September.

MALLOW. See Hibiscus.

MENTHA. Mint. A hardy plant used for flavoring.

MICH $Æ$ LMAS DAISY. See Aster.

MILKWEED. See Asclepias.

MISCANTHUS Sinensis. Eulalia Japonica. The Eulalia grass grows 7 to 8 feet high, and should be used in the shrubbery and water garden for immediate effect. In September the downy plumes appear and are used for winter decoration, as is the Pampas grass, which they closely resemble. The different varieties are M. Sinensis, var. gracillima, which has narrow leares and is perhaps the most ornamental ; var. variegata, with foliage striped green and white; var. zebrina, which has cross bands of yellow.

MOCCASIN FLOWER. See Cypripedium.

MONARDA didyma. Oswego Tea; Bee Balm. A showy herb, having aromatic foliage and flowers of an intense red. A brilliant mass of color in garden, shrubbery or water garden, rivaling the Salvia. 2 feet. June to September.

MYOSOTIS. Forget-me-not. No garden is complete without a border of these dainty blue blossoms. 6 inches. May and June.

NARCISSUS Pseudo-Narcissus. Common Double Daffodil. The hardy old-fashioned kind. Great golden balls. April.

N. incomparabilis. Single yellow. Increases rapidly and is particularly useful planted extensively in the grass. April.

N. pceticus. Poets' Narcissus. A pure white single Narcissus, the yellow central cup being edged with a red frill. I foot. May.

OLD MAN. See Artemisia.

P EONIA Sinensis. The Peony will grow and persist in any soil, but reaches its highest development in deep fertile loam. Fven when out of flower the foliage of the Peony is an ornament to the garden. We have many fine named varieties in a wide range of color, from white to deepest red. 2 to $2 \frac{1}{2}$ feet. June.

P. officinalis. This old-fashioned sort blooms early in May before the other Peonies. The red variety is of the deepest glowing color, while the pink and white are equally attractive.
Pæonia Moutan. Tree Peony. A slow-growing woody shrub of an irregular picturesque shape, bearing very beautiful silky blossoms. Decidedly Japanese in effect. 4 to 6 feet. May.

PAPAVER nudicaule. Iceland Poppy. From the clusters of low, fern-like foliage spring many stems bearing white, yellow and orange-scarlet Poppies. I foot.

P. orientale. Oriental Poppy. An entirely hardy Poppy. A clump will increase in vigor for years and present each June a most gorgeous sight with its great flowers in brilliant reds. $2 \frac{1}{2}$ feet.

PARADISEA Liliastrum. St. Bruno's Lily. A slender and delicate plant with a spray of little white lilies in May. I $1 / 2$ feet.

PENTSTEMON barbatus, var. Torreyi. A plant with very slender, graceful spikes of brilliant scarlet trumpets. 3 to 4 feet. June to August.

PERIWINKLE. Myrtle. See Vinca.

PHLOX decussata, or paniculata. Most of the named garden Phlox are of this species. In brilliancy of color the hardy Phloxes have been greatly improved, and we aim to keep only the best in each shade. Planted en masse they make a beautiful show and may be kept in flower until frost by pinching back some of the plants.

La Cygne. Pure white. Very fine.

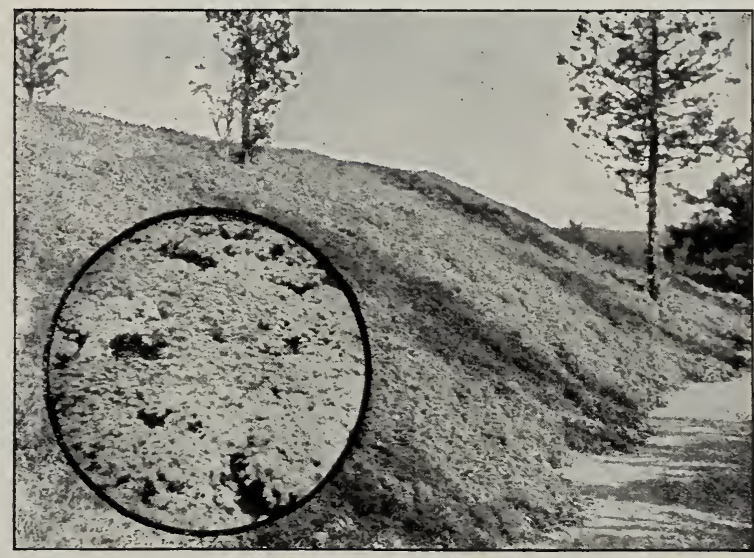

Phiox subulata covers steep sandy banks most cheaply, with no cost for maintenance. It is attractive all the year.

Bridesmaid. Pure white, with crimson center.

Coquelicot. Pure scarlet, carmine eye. The finest red yet known.

Cross of Honor. Pure white, with a band of roselilac across each petal, forming a Maltese cross.

Eclaireur. Purplish crimson, with white halo.

General Chanzy. An exquisite pink.

Fiancee. Large, pure white.

William Ramsay. Fine, deep rose-purple.

P. reptans. A low plant, forming a dense sheet of reddish purple flowers in May. 3 to 8 inches.

P. subulata. Moss Pink. This plant is an excellent substitute for grass on steep and dry terrace banks, as it revels in sunshine and sandy soil and quickly covers the ground to the exclusion of other vegetation. In May the mossy evergreen foliage is completely hidden by the flowers. IVe offer it by the thousand. It is cheaper than grass. 


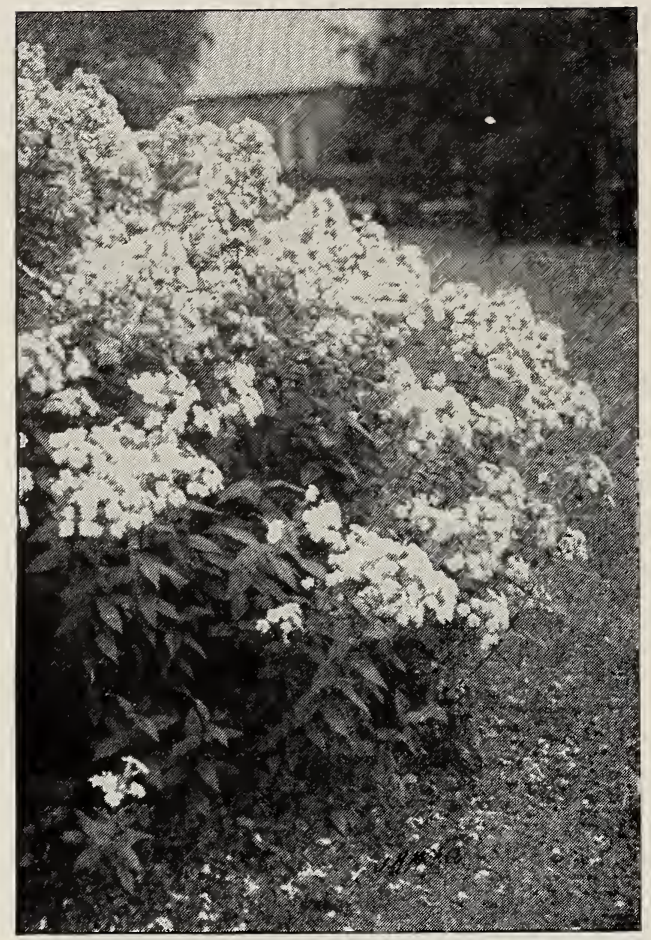

From June till frost the Phloxes make a bright showing We offer the best in each color.

Phlox subulata, var. rosea. A bright rose-pink. P. subulata, var. alba. Pure white.

PINKS. See Dianthus.

PLATYCODON grandifiorum. Campanula grandiflora; Chinese Bellflower. A valuable perennial, with blue or white bell-shaped flowers, resembling the Campanula, but having broader bells. I to 2 feet. June to October.

PLUME POPPY. See Bocconia.

POLYGONUM Sieboldi. P. cuspidatum; Knotweed. A large, bushy perennial, with stems gracefully curving outward, enveloped in clouds of fine whitish flowers. 4 to 7 feet. July.

P. sachalinense. Similar to, but larger than the above. They both spread rapidly, and should be planted where this habit is not a detriment. Effective for bold masses in wild places. 8 to I 2 feet. July.

POLYGONATUM. Solomon's Seal. A desirable plant for shady places. Graceful sprays, bearing pendent green-white bells, after the manner of Lily-of-the-valley. 2 to 3 feet. June.

POPPY. See Papaver.

PRICKLY PEAR. See Cactus.

PRIMULA. Primrose. Small compact plants, with bright blossoms, that should be found in every garden.

P. verıs. English Cowslip. One of the earliest spring flowers. The well-known hardy Primrose in a variety of colors-rich reds and yellows. 5 inches. April and May.

P. vulgaris. English Primrose. Canary-yellow and fragrant. The old sort. 5 inches.
PYRETHRUM roseum. An excellent flower for cutting. Flowers resemble the China Aster, and are about 3 inches across. White, pink and red. $I 1 / 2$ feet. May and June.

P. uliginosum. See Chrysanthemum uliginosum.

RANUNCULUS acris flore pleno. Double Buttercup. A neat clump of foliage, with shining yellow buttercups. I $1 / 2$ feet. May to August.

R. repens, var. flore pleno. A creeping plant, suitable for wild gardens, cover for banks and margins of water. Spreads rapidly. Double bright yellow. 8 inches. May and June.

RAGGED ROBIN. See Lychnis.

RED-HOT POKER PLANT. See Kniphofia.

RUDBECKIA laciniata, "Golden Glow." Coneflower. This popular plant is the most conspicuous object in the border in August. The blooming season may be prolonged by cutting back some plants before or after the first flowering. The flowers are double, rich golden yellow and shaped like Dahlias. Borne in great profusion. 6 to 8 feet. July to September.

R. maxima. Broad smooth green foliage, with very large bright yellow flowers with a central cone 2 inches long. 5 to 6 feet.

R. triloba. A neat, sprightly plant. The best of its sort. Completely covered with golden yellow flowers with black centers. 3 to 4 feet. August and September.

SALVIA azurea, var. grandiflora. In early autumn this bears loose panicles of pure blue flowers. 2 to 3 feet. August and September. A rare and beautiful addition to the flower border.

SANGUINARIA Canadensis. Blood-root. A harbinger of spring which appears too delicate for the cold winds of March. Pure white flowers 3 inches in diameter. Will grow in the open, but prefers the company of ferns.

SEA PINK. See Armeria.

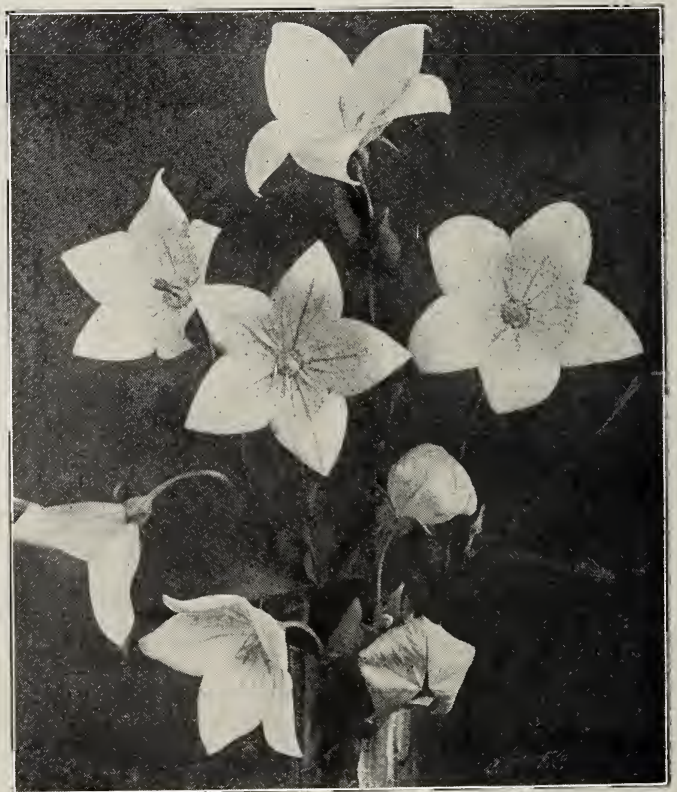

Platycodon, one of the Canterbury Bells. 
SEDUM acre. Stonecrop. A creeping plant with bright golden star-shaped flowers in May. Thrives in the driest portions of the alpine garden, and may be used at the top of stone walls as a cover plant.

S. album. A similar plant with white flowers.

S. spectabile. Japanese Live-forever. Has broad flat heads of rose-colored flowers. Excellent for edging beds.

SILPHIUM perfoliatum. Cup Plant. A stately plant with large leaves, squared stems and lemonyellow blossoms 3 to 4 inches across. 6 feet. Midsummer.

SOUTHERNWOOD. See Artemisia.

SPIRAA Japonica. See Astilbe.

SPIDERWORT. See Tradescantia.

STOKESIA cyanea. Stoke's Aster. A very beautiful blue flower 4 inches across. It resembles the Cornflower of Germany. Blooms continuously from July till October. I $1 / 2$ to 2 feet.

STACHYS Betonica rosea. Betony. Spikes of rosy red flowers about ro inches high. June and July.

STONECROP. See Sedum.

SUNFLOWER. See Helianthus.

SWEET WILLIAM. See Dianthus.

THERMOPSIS Caroliniana. Vigorous upright plant bearing spikes of yellow pea-shaped blossoms. Will thrive in poor soil. 3 feet. June and July.

THYMUS Serpyllum, var. citriodorus. Lemon Thyme. A low evergreen creeper. Its aromatic foliage is used for flavoring. Excellent for borders or as cover in dry places.
Thymus Serpyllum, var. aureus. A golden variegated form.

THRIFT. See Armeria.

TRADESCANTIA. Spiderwort. A plant of the old-fashioned gardens, sometimes persisting after the house has gone to ruins. Flowers bright violet-blue. 2 feet. June to September.

T. alba. A white form of the above.

TRITOMA. See Kniphofia.

TROLLIUS Europæus. A member of the Buttercup family, with bright yellow globular flowers 2 inches through. 2 feet. May to August.

VALERIANA. Valerian. An old-time garden favorite. The pinkish white flowers are borne in wide, open panicles. Spicy. 2 feet. May and June.

VERONICA spuria. $V$. amethystina; Speedwell. Amethyst-blue flowers in spikes. $2 \mathrm{ft}$. May and June.

V. spicata. Flower-spikes bright blue. I I $1 / 2$ feet.

VINCA. Myrtle, or Periwinkle. A beautiful evergreen cover plant. Leaves shining, rich green, with flowers of clear blue in May. For uses, see under Broad-leaved Evergreens. 6 inches. Low rates per thousand. See illustration on page 56 .

YUCCA. Spanish Bayonet; Adam's Needle. A fine evergreen plant, having long, sharp-pointed leaves or needles, somewhat resembling the Century Plant. The beautiful creamy bells are borne in stately spikes. To get the full effect of their beauty they should be seen against an evergreen background. Excellent for dry banks. Plant in masses. 4 to 7 feet. June and July. See illustration on page 58 .

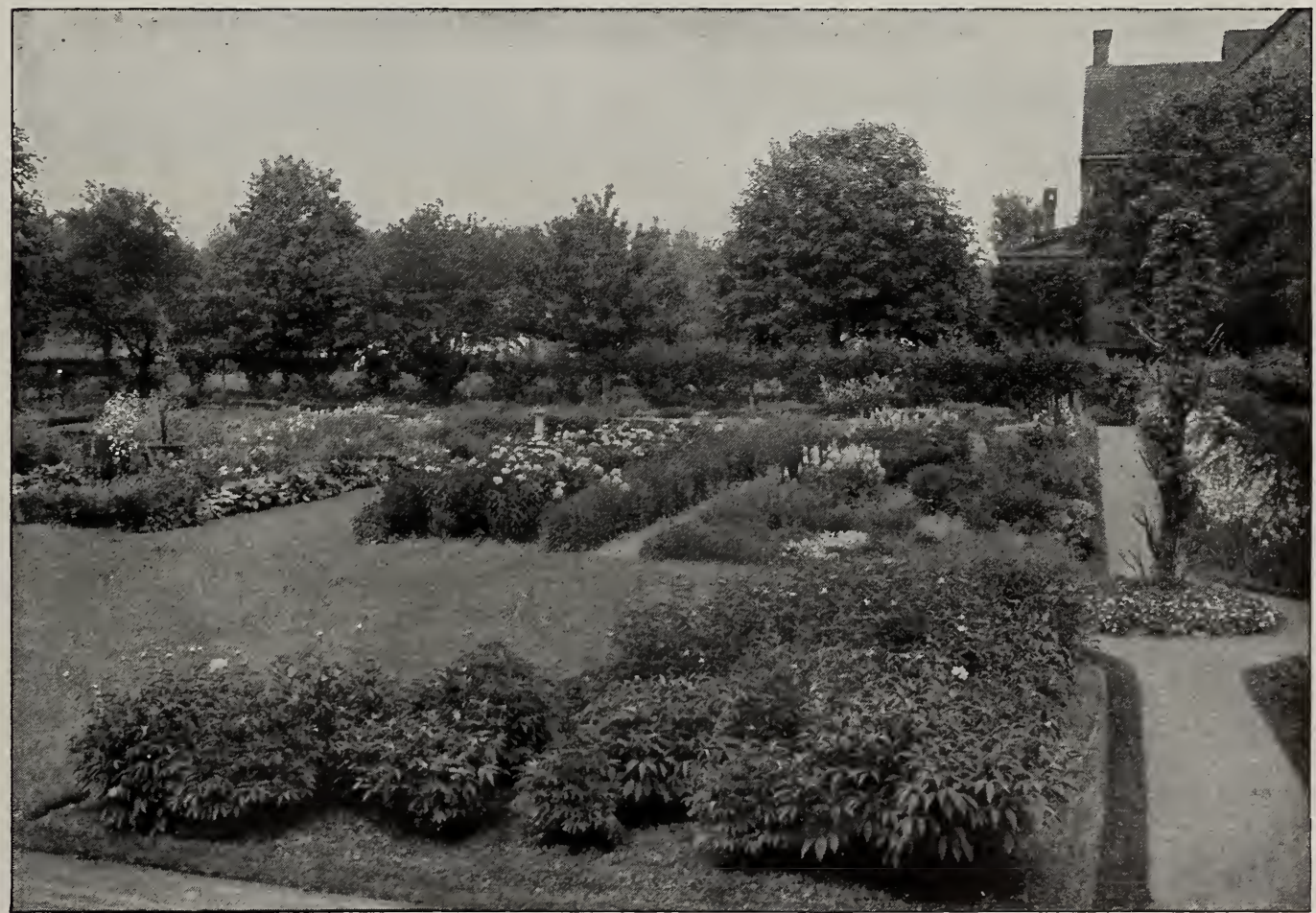

A gaiden like this is not expensive to start nor does it require skill to maintain. The paths may be of grass or gravel. Our plants are extra-large; come up with a big clump of roots and make a good showing the first year. 


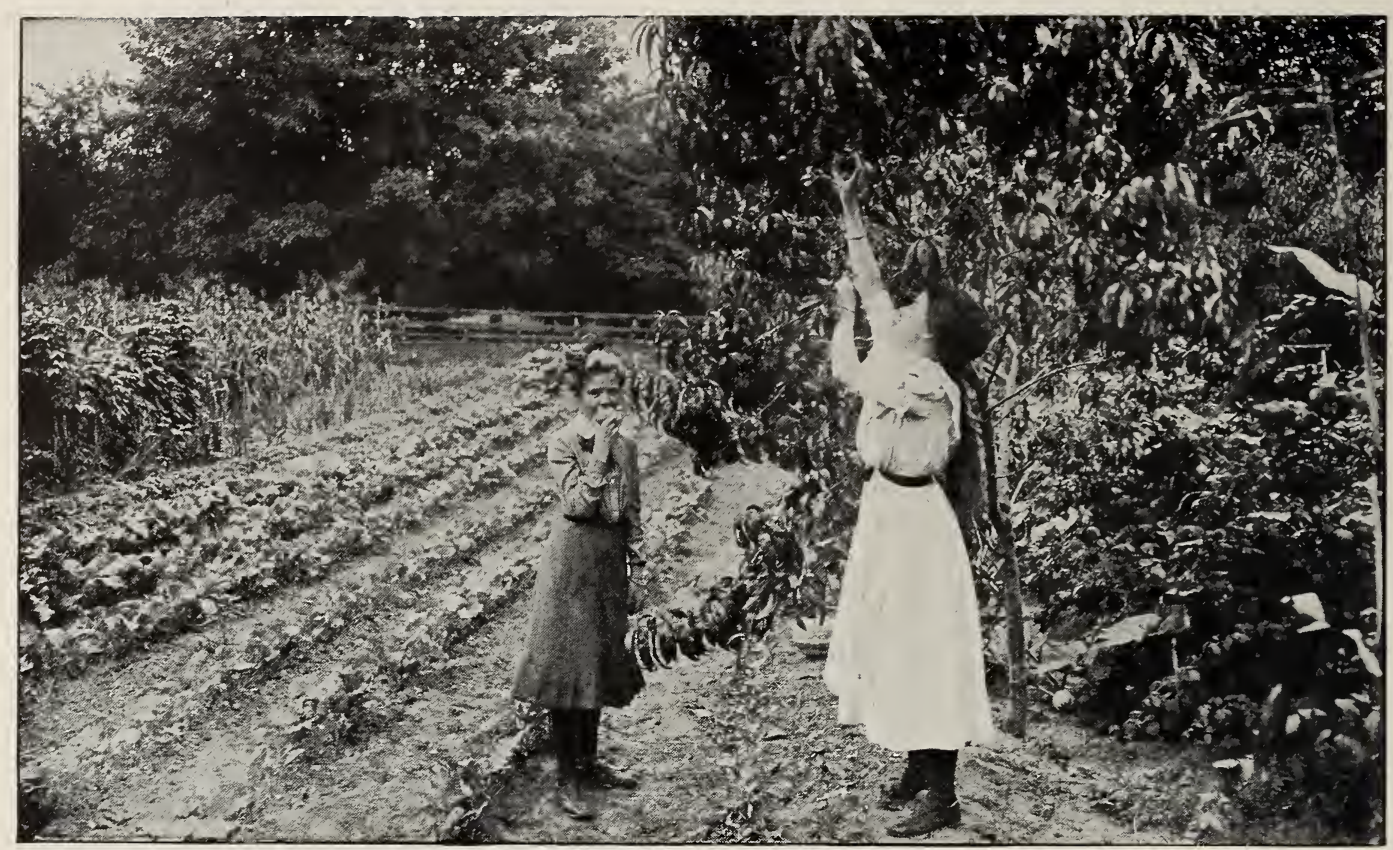

Cultivated ground is pest for young fruit trees.

\section{Fruits for Long Island}

\section{A FEW HINTS}

PLANTING.-Cut off broken roots and cut the ends of large roots smooth. Dig a wide hole, deep enough to let the tree stand the same depth as in the nursery. Spread the roots out and pack the soil firmly around them.

PRUNING-Blackberries and Blackcaps. Cut back to near the ground when planted. Cut off the tops of the young shoots in summer when 2 feet high. This will make them branch, produce more fruit, and stand up better. Do not neglect this pruning until the canes are 6 feet high. Allow but 4 to 6 canes per hill. Remove the old canes after fruiting, and the following spring shorten-in the side branches. In a small garden tie to a wire, trellis or stakes.

Red Raspberries. Prune same as above excepting the summer pruning.

Currants and Gooseberries need but little pruning; merely remove the branches over two or three years old.

Apple, Pear, Cherry, Peach, Plum and Quince. When planting, prune to reduce the top by one-half or three-quarters. Cut just above a strong bud. Do not leave opposite branches, that form crotches to be easily broken.

Later Pruning. Thin out the inside of the tree by removing weak branches, water sprouts or suckers, and branches that cross and rub. Some cut back one-half of each year's growth of the peach, on rich soil. If the flower-buds are partly winter-killed, omit this cutting back, as it reduces the flowers and fruit.

Cut all branches close, even if the wound is larger, and paint all wounds over two inches in diam. eter with coal tar or thick paint. Old decayed cavities should be cleaned out to sound wood, painted and filled with cement. Split crotches should be bolted together at or above the break. We furnish experts for this work.

Grapes. Cut grape-vines back to two buds when planting. Train the two shoots from these buds to a trellis or building, and the shoots from them will bear the following year. The next winter these shoots may be cut back to spurs of one or two buds, or the whole arm cut off to the trunk of the vine, and the new canes tied to the wire as before. During the summer, bearing shoots may be allowed to hang down, or tied to upper wires.

Time to Prune. Most severe pruning should be done between Octcber and April, when the plant is dormant. 
Heading-back too vigorous shoots, and removing undesirable branches, may be done at any tirie during the summer. Storm-damaged trees and decayed wounds may be repaired whenever necessary.

CULTIVATION and FEEDING (Fertilizing). All young fruit plantations should be kept cultivated the same as corn or potatoes; in fact, regetables may be profitably grown in young orchards. Cultivate once in two weeks or oftener, and especially the day following a heavy rain. This will make a mulch of about three inches of fine earth or dust, that prevents evaporation from the soil. Feed annually with stable manure or complete fertilizers, or both. Trees need a fertilizer rich in potash and phosphoric acid, rather than an excess of nitrogen; therefore, muriate of potash, unleached hardwood ashes, bone-flour and dissolved South Carolina rock are good special fertilizers. Crimson clover is valuable as a green manure, sown in August, before the last cultivating, and plowed under the following spring.

Borers in the trunks of trees should be dug out. Leaf-eating insects are killed by spray of Paris green, I lb. to Ioo gallons of water. Currant-worms are quickly killed by hellebore powder. Leafsucking insects are destroyed by spraying or washing with whale-oil soap or kerosene emulsion. Mildew and other fungous diseases of grapes and fruit trees are prevented by spraying with Bordeaux mixture or ammoniacal solution of carbonate of copper.

FOR SAN JOSE SCALE, which is being generally distributed by birds, use whale-oil soap, kerosene, petroleum, or lime, salt and sulphur wash. For instructions write to the State Agricultural Experiment Station, Geneva, N. Y.

Distances to plant tREes AND PLANTS

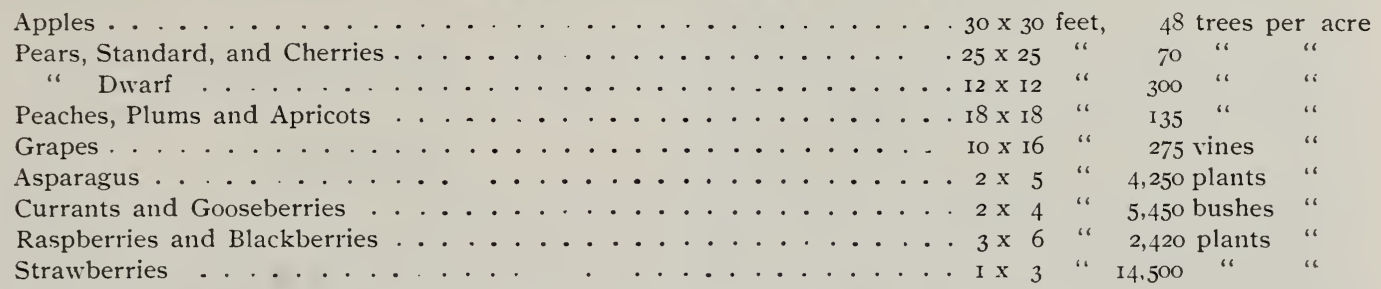

Closer planting and pruning is advised for small gardens.

THE VARIETIES ARE GIVEN IN ABOUT THE ORDER OF RIPENING

\section{APPLES}

Price, 5 to 6 feet, 35 cts. each, $\$ 2.50$ for $10 ; 6$ to 7 feet, 50 cts. each, $\$ 3.50$ for 10 ; larger trees, $\$ 1$ up.

In our old and extensive orchards most of the varieties here listed, and many others that have been discarded, have been tested. While some varieties will thrive anywhere under good culture, the loss entailed by planting and cultivating poor varieties is great, and emphasizes the importance of planting tested kinds. Many good varieties will occasionally fail to produce satisfactory crops through lack of culture and fertility, or insects and fungus.

LARGE ORCHARDS.-Those intending to plant large orchards are invited to correspond with us early in the season, before October or March. Low rates for trees of various qualities will be quoted.

\section{SUMMER}

Primate. An excellent early Apple, superior to the Harvest in flavor. Very tender; bright yellow; ripens in July.

Yellow Transparent. A Russian variety of value. Medium size; skin translucent yellow, with waxen surface ; flesh yellow ; sprightly acid. July. Usually bears the first year after planting.

Harvest. Medium size, pale yellow ; flesh white, tender and juicy; rather acid. Ripens in July.
Red Astrachan. Large, round, deep crimson, which takes a bright polish; flesh juicy. A vigorous, productive tree. Good for early market and dessert.

Sweet Bough (Early Bough). Large, pale yellow ; tender, sweet. An excellent variety for baking.

oldenburg (Duchess of Oldenburg). A Russian variety of value ; fruit above medium size, handsome, yellow, covered with streaks of crimson; flesh tender, juicy and pleasant. August.

\section{AUTUMN}

Gravenstein. Large, round, red and yellow ; flesh firm, brittle, juicy, high flavored, subacid. 'Tree vigorous and productive. A long time in ripening during August and September. The best market Apple of its season, and deservedly popular.

Wealthy. Medium size ; skin oily, dark red; flesh white, fine-grained, juicy, subacid. Tree a free grower and early bearer. Resembles the Fameuse. October and November.

Porter. Large, oblong, bright yellow ; flesh tender, rich, aromatic flavor. A very good fall Apple.

Fall Pippin. Very large, round, rich yellow ; flesh yellow, firm, tender, creamy and excellent flavor for dessert or cooking; tree vigorous and productive. An old and well-known variety; more subject to apple-scab than some others. It ripens in late autumn and keeps until midwinter. 


\section{AUTUMN APPLES, continued}

McIntosh Red. A good-sized Apple, resembling the well-known and popular Fameuse; flesh tender, white and sprightly. It is too soft for market.

Maiden's Blush. Large, round, pale yellow, with a beautiful red cheek; flesh tender and pleasant, but not highly flavored. Tree a vigorous grower. A very good market sort.

\section{WINTER}

Fameuse (Snow Apple). Sniall to medium in size, round, deep crimson; flesh snowy white, with crimson streaks, very tender, crisp, spicy and melting. One of the finest dessert fruits. November and December.

Hubbardston (Hubbardston's Nonesuch). Large, handsome, yellow, mostly covered with red; flesh tender, fine-grained, with an excellent and distinct flavor; tree upright and productive. Does not keep after midwinter.

Smokehouse. Large, flat, red and yellow; flesh yellow, firm, juicy and crisp; aromatic. An early and prolific bearer. Widely grown and popular. October to January.

Rhode Island Greening. Large, round, green or greenish yellow; flesh yellow and fine-grained, tender, with a rich subacid flavor. A favorite for cooking. A standard winter Apple. November to March.

Bellflower. Medium to large; pale yellow with blush cheek; flesh very tender, crisp, juicy, with a delicate spicy flavor; core large. Succeeds best on rather light soils.

Fallawater. Very large, flat; skin smooth, dark green, with dull red cheek ; flesh greenish white, coarse-grained, mild subacid. A very strong grower and productive bearer of large, latekeeping fruit, valuable for market and cooking. November to April.

Grimes' Golden. Above medium size ; yellow, with russet spots; yellowish white flesh, with a very agreeable flavor. November and December.

King (King of Tompkins County). A large, handsome red Apple of fair quality. Tree a good grower and moderate bearer.

Spitzenburgh (Esopus). Medium rich red Apple, with crisp yellow flesh, of a spicy acid flavor. A good keeper.

Jonathan. Of medium size ; skin yellow, nearly covered with dark red; fine-grained, very tender, and of excellent flavor. It commands a high price on the market. Tree needs careful culture. November to January.

Sutton's Beauty. An Apple from Massachusetts. Skin yellow, striped with crimson; flesh tender, subacid. December to February.

Baldwin. Large, red, with yellow on one side; crisp, juicy and rich. Tree vigorous and productive. A standard variety. November to April.

Roxbury Russet. Medium or large size, russet ; flesh greenish white, crisp, with a fine subacid flavor. Tree a good grower and productive. Keeps late.

Peck's Pleasant. Medium to large; waxen yellow, with blush cheek; resembles the Newtown Pippin; flesh yellow, fine-grained, crisp and brittle. We regard it as the best-flavored Apple. December to March.
Long Island Russet. A small to medium-sized yellow and russet Apple. The tree is most vigorous and productive, and the fruit keeps till May.

Ben Davis. Medium size; handsome deep red; flesh firm, white, subacid; a good shipper and late keeper; productive, but lacking in flavor. Tree vigorous and early bearer. January to April.

Newtown Pippin. A famous Apple, originating on Long Island. Fruit dull green; flesh greenish white, juicy, crisp, with fine aroma and delicious flavor; late keeper. Tree a feeble grower. It succeeds well in the heavy loam soil of Jericho, Huntington, Port Washington. January to May.

For home use the following will cover the season : Yellow Transparent, Red Astrachan, Gravenstein, Fall Pippin, Rhode Island Greening, Baldwin, Roxbury Russet.

\section{CRAB-APPLES}

For preserving, jellies and ornament.

Montreal Beauty. Large size of its class; yellow and rich red; flesh rich, firm, acid. September and October.

Transcendent. One of the best early varieties. Golden yellow, with a red cheek. September.

\section{PEARS}

Price, 5 to 6 feet, 50 cts. each, $\$ 3.50$ for $10 ; 6$ to 7 feet, 75 cts. each, $\$ 6$ for 10 ; larger trees, $\$ 1$ up.

Summer Doyenne (Doyenne d'Ete). Small ; flesh white, melting, sweet. Tree vigorous and productive. Ripens in July.

Manning's Elizabeth. Small to medium; yellow, with a red cheek; sweet and sprightly. Our best early dessert Pear.

Osband's Summer. Medium size; yellow, with reddish brown cheek; flesh white, granular, with sweet flavor. Ripens in early August.

Clapp's Favorite. Large, long; yellow, with red cheek ; flesh fine-grained, melting and of excellent flavor. It resembles the Bartlett, but is much earlier. It should be picked a week before it would ripen on the tree, and be ripened in the house, otherwise it softens at the center. A valuable Pear that should be in every garden. It ripens in August.

Bartlett. A standard sort too well known to need description; bears young and abundantly. It ripens in August and September, and is an excellent variety for dessert and preserving.

Tyson. Medium size; bright yellow ; flesh juicy, sugary and aromatic. A regular bearer.

Belle Lucrative. Above medium size; melting, very juicy and sweet. Subject to fungous attacks. September.

Boussock. Large; russet-yellow; flesh melting and of excellent flavor. The tree is large and vigorous. A valuable market Pear. October.

Sheldon. Large; greenish russet and red; flesh coarse, of fine flavor. Productive. September and October.

Howell. Rather large ; waxen yellow anci russet ; flesh granular, with a rich subacid flavor. A profuse bearer, and good for preserving. 
PEARS, continued

Seckel. Fruit small; brown, with a deep red cheek ; flesh very fine-grained, sweet and juicy ; the richest and highest flavored Pear known. Tree of small size and slow growth. Early to midautumn.

Anjou. Large; green and russet ; flesh white, buttery, with a rich, vinous flavor. Very productive. October and November.

Bosc (Beurre Bosc). Large, long; russet; flesh buttery, juicy, with rich and excellent flavor. It requires clay soll to reach perfection. November. 50 cts.

Kieffer. Large to very large ; yellow-russet, with red cheek; very juicy and of a peculiar flavor disliked by some when not properly grown and ripened. The general appearance of the tree is distinct; its growth is exceedingly vigorous, with dark, lustrous foliage. Some Long Island farmers have found it very profitable for market. It should be severely thinned when the fruit is small. December. Low rates in quantity.

Winter Nelis. Medium; dull russet; flesh finegrained, with rich, sprightly flavor. November and December. 50 cts.

\section{DWARF PEARS}

Price, two and three years old, 50 cts. each.

The following varieties, grafted on quince roots, succeed as dwarfs, and are valuable for small gardens :

Clapp's Favorite and Bartlett. See description of these varieties under Standard Pears.

Louise Bonne de Jersey. A large, beautiful yellow Pear, with a red cheek; rich flavor. Vigorous grower and an abundant bearer. September and October.

Angouleme (Duchesse d'Angouleme). One of the largest of the good Pears. Oct. and Nov.

Anjou. See description under Standard Pears.

\section{PEACHES}

Price, one-year, 4 to 6 feet, 25 cts. each, $\$ 1.80$ for 10 , $\$ 15$ per 100 ; two-year, 40 cts. each.

For early bearing and general satisfactory results, no fruit tree exceeds the Peach. They will commence to bear sixteen months after planting, and produce abundant crops nearly every year. Fertilize with wood ashes or potash. A new supply of trees should be planted every two or three years, in order to keep up a succession. This list is nearly in order of ripening.

The same skill that has developed the vegetable growing of Long Island to its high position will make the poorer land of Long Island profitable with Peaches. The local market is never supplied. The railroads should coöperate to develop an extensive Peach industry on the hills of Suffolk county.

Early Rivers. Large, white, juicy.

Champion. Large, creamy white and juicy. Said to be one of the most frost-proof of Peaches. An excellent early Peach.

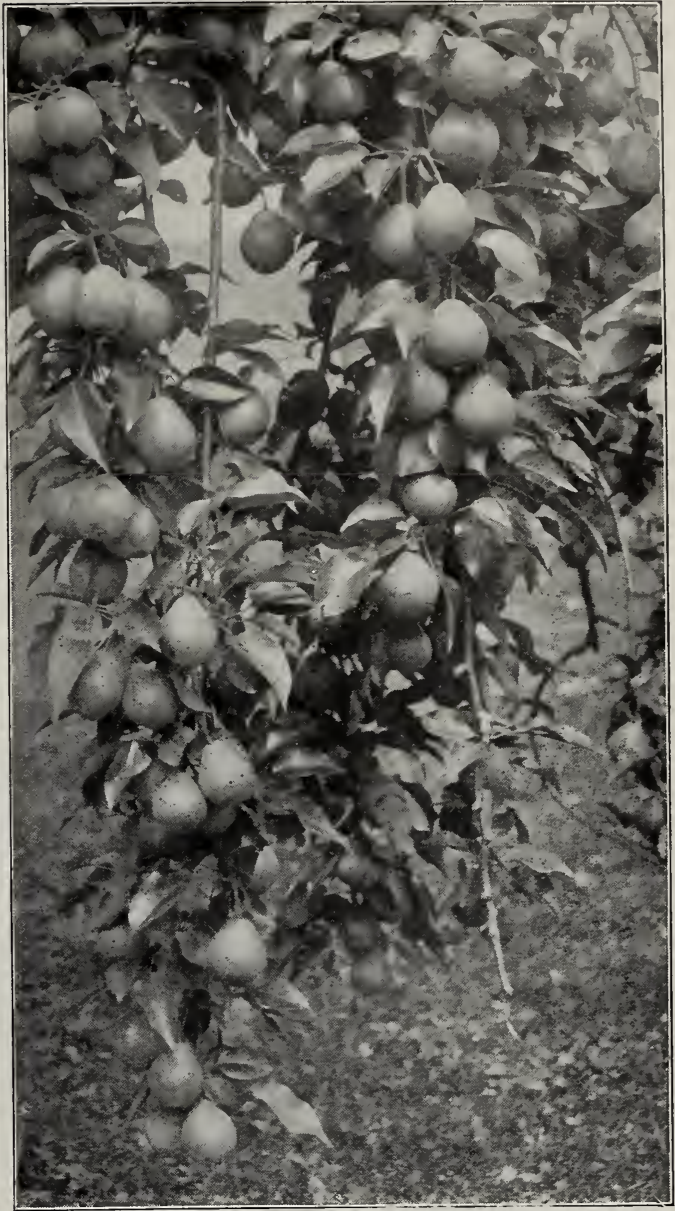

Kieffer Pear in a Long Island orchard.

Mountain Rose. Above medium size, round, white. Tree thrifty and an abundant bearer.

Yellow St. John. A large yellow freestone, with a deep red cheek; flesh yellow, sweet, juicy and high flavored. One of the best early Peaches.

Early York (Honest John). A larçe, beautiful white Peach. A valuable variety.

Foster. A very large Peach, resembling Crawford's Early, but earlier in ripening.

Crawford's Early. A magnificent, large, yellow Peach of good quality; tree vigorous and productive. September.

oldmixon. A productive variety that succeeds well in all localities. Flesh white, red at the stone, flavor excellent. A favorite canning variety.

Crosby. Medium size; bright yellow flesh, firm, sweet and good. It has stood many severe winters in New England.

Wheatland. Considered an improvement on Crawford's Late, and ripening just in advance of it.

Stephen's Rareripe. Large, oblong; white flesh, red skin. A heavy bearer. October.

Reeves' Favorite. Large ; yellow, juicy, melting, with a vinous flavor.

Elberta. One of the finest yellow Peaches; very large, handsome, juicy and of fine flavor. 


\section{PEACHES, continued}

Susquehanna. Very large; rich yellow, with a beautiful red cheek. A handsome and valuable variety for table use or canning.

Crawford's Late. A standard variety. Large; yellow, red at the stone.

Stump the World. Medium size; creamy white, juicy and high-flavored. Unexcelled for preserving.

Chair's Choice. Large, yellow, with red cheek; flesh firm and of good quality. The large Peach growers of Long Island report that this is a valuable variety.

Morris White. Medium size, creamy white skin; flesh white throughout, juicy, sweet. Good for preserving.

Hill's Chili. Medium size, yellow, hardy, productive.

Globe. Large, golden yellow, firm, sweet and delicious. A rapid grower and good bearer.

Smock. Medium to large, yellow, moderately juicy to dry; very late; sometimes it does not ripen here.

\section{JAPAN PLUMS}

Price, 5 to 6 feet, $50 \mathrm{cts}$. each, $\$ 3.50$ for $10 ; 6$ to 7 feet, 75 cts. each, $\$ 6$ for 10.

This new class of fruit we have thoroughly tested, and strongly recommend its planting in gardens and orchards. After one or two years the trees bear heavy annual crops of delicious fruit.

The peculiarly desirable features presented by these Japanese Plums on a conservative estimate are earliness and great productiveness. The quality is good when well thinned and ripened, but not always equal to the best of the common Plums.

They are the best Plums for Long Island, and should be largely planted.

Red June. A medium to large vermilion-red Plum; very showy. Flesh moderately juicy, of subacid, pleasant quality, but not so rich as some others. The best early Plum.

Abundance. Medium to large, globular; yellow, mostly covered with red; flesh firm and juicy, sweet and good when fully ripe. The tree is

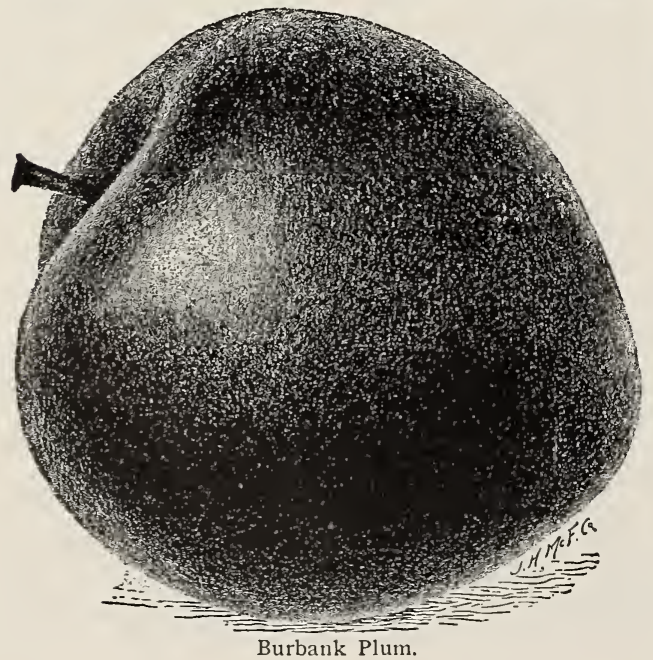

very productive, and the loads of fruit that young trees carry astonish all who see them. The fruit should be severely thinned out and the branches tied up. Ripens in early August.

Burbank. Medium to large; yellow, with red cheek; flesh firm, rich and sugary; the best flavored variety we have ever tested. The tree is very productive. Ripens last of August.

Wickson. The largest Japan Plum. Maroon-red; flesh firm and long-keeping, of good quality. A promising new variety.

Hale. A handsome, globular, red-speckled Plum. Flesh soft and juicy, of good quality and peachlike flavor. Tree a good grower and productive. A very promising new variety, just introduced.

Satsuma. Large ; very dark red ; flesh blood-red, acid, of fair quality when fully ripe. Productive and late.

October Purple. A reddish purple Plum of large size; good quality. Its late ripening and good keeping qualities make it one of the desirable varieties.

\section{EUROPEAN PLUMS}

The varieties of the common or European Plum (Prumus domestica) do best on heavy land, but will grow well on any soil, if given applications of ground-bone and potash.

Bradshaw. Fruit large, oval ; reddish purple ; flesh yellow, rather coarse, juicy and good. Tree very vigorous, and has good foliage.

German Prune. Fruit long-oval; purple, with white bloom; flesh green, sweet. Tree a poor grower.

Green Gage. Round, small, green fruit ; the flavor is exceedingly sweet and rich, unequaled by any other. A small, compact tree.

Lombard. Medium to large ; dark red; flesh deep yellow, of pleasant flavor, but not rich. The tree is one of the most vigorous of the Plum family, and is productive and well adapted to light soils.

\section{PERSIMMON, AMERICAN}

A large, handsome tree with lustrous leaves. Skin and flesh of fruit brick-red, soft and sweet after frost. Native to wet ground on Long Island. We are testing new named varieties.

\section{CHERRIES}

Price, 5 to 6 feet $50 \mathrm{cts}$. each, $\$ 3.50$ for $10 ; 6$ to 7 feet, 75 cts. each, $\$ 6$ for 10.

The Cherries are anong the most satisfactory fruits to raise for home use. They grow well on all Long Island soils, and annually set large crops. Cherries may be divided into four groups :

HeArTs, with soft flesh, heart-shaped, sweet. The dark red varieties are in this class. This and the next are sometimes called "Oxhearts."

Bigarreaus, with hard flesh, heart-shaped, sweet, mostly of the lighter colors.

Dukes. Like the above, but with acid or subacid fruit.

Morellos (Sour Cherries). Flesh sour; tree smaller than the others, with slender branches and narrow leaves. 


\section{HEART CHERRIES}

Governor Wood. Large, heart-shaped yellow fruit, marked with red; sweet juicy flesh. A rich and delicious Cherry.

Coe's Transparent. Medium size; amber color, with a red cheek; very tender, melting, sweet. Ripens early, just before Tartarian. Tree thrifty.

Black Tartarian. Fruit very large, nearly black. Flesh dark purple, firm, sweet and juicy, with a small pit. Tree a rapid grower. The long, upright branches of this variety, hung with luscious fruits, are a beautiful sight.

Downer's Late Red. Medium size ; red and amber ; flesh tender, melting, rich; not good till fully ripe. This variety is late, and hangs on the tree after it is ripe without decaying, as many other kinds do. Ripens first half of July. The birds molest it but little, as it ripens about the time of the wild Mazzards.

\section{GRAPES}

Price, 2-year old, 15 to 25 cts. each, $\$ 10$ to $\$ 20$ per 100. Extra-size, 3 years old, $30 \mathrm{cts}$. each.

Grapes are easily grown by any one, and on the smallest bit of ground. There is room along any garden fence or walk for a dozen vines to furnish this most delicious of fruits for home use, from August until November. Training on the sides of buildings is recommended, as the fruit is less liable to decay.

The rines will fruit under unfarorable conditions, but good culture, pruning and spraying pay, if fruit of best quality is desired. Commercial grapegrowers find it necessary to spray with Bordeaux Mixture, occasionally during the growing season, to keep in check mildew on the foliage, and rotting of the fruit. Protecting the clusters, as soon as formed, by pinning over them 2-pound paper bags, prevents injury from fungus, storm and birds.

\section{BIGARREAU CHERRIES}

Rockport. Large; clear red, shaded with amber; flesh firm, juicy, sweet, rich. Ripens early. Tree upright and vigorous.

Yellow Spanish. Very large, often an inch in diameter; waxen yellow, with a light red cheek; flesh firm, and of fine, rich flavor.

Napoleon. Very large, heart-shaped, pale yellow and amber, shaded with deep red. Flesh very firm and of good flavor. Ripens after midseason. Tree vigorous and productive.

Windsor. Large, mottled red; very firm and juicy, of good quality. The tree is upright, vigorous and a heavy bearer. A desirable late Cherry, as it hangs a long time and rots but little.

Mercer. A very dark red Cherry ; productive and early; of good flavor, and not liable to rot.

Schmidt's. The largest of all the black Bigarreau Cherries. The fruit grows in clusters; the flesh is dark, tender and very juicy.

\section{DUKE CHERRIES}

Mayduke. Large, round, red, changing to nearly black when ripe. Flesh very juicy and melting; acid. Quite early.

\section{MORELLO CHERRIES}

This class is excellent for cooking and preserving.

Early Richmond (English Pie Cherry). Small to medium in size, beautiful red, very juicy, acid. Tree productive.

Montmorency. Large, round, bright red; moderately sour. A good bearer, which fruits young. One of the best of its class.

Morello (English Morello). Medium to large ; dark red to nearly black. Flavor a rich acid, with some astringency, making it desirable for cooking. It ripens after midsummer.

\section{MULBERRIES}

\section{5 cts. to $\$ 1$ each.}

Downing Everbearing. Large, black, sweet and pleasant fruit. A handsome shade tree.

New American. Fruit of the best flavor. Ripens from June to September.

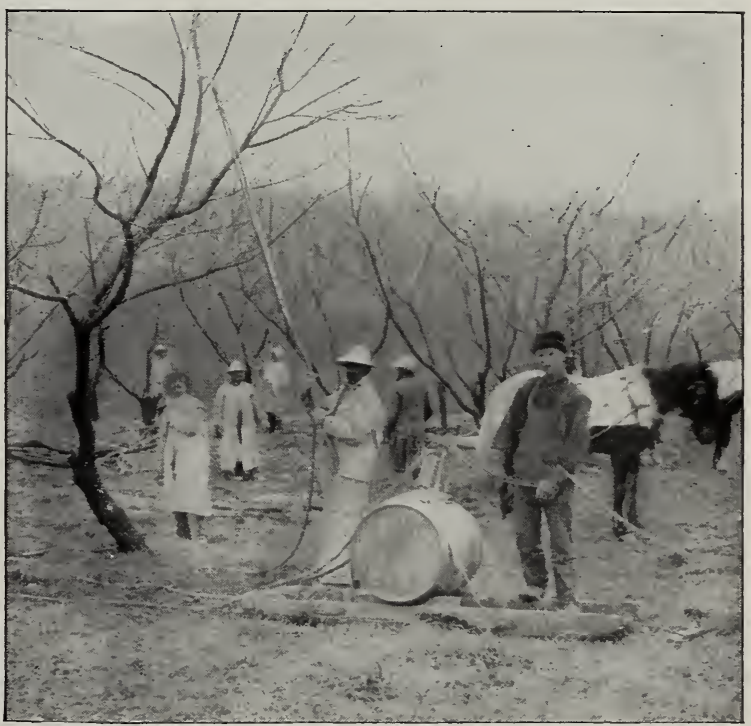

Spraying for San José Scale once a year with lime and sulphur costs but little

Cottage. Bunch small; berry large, black; pulp tough and sweet. A good early black variety.

Moore's Early. Large; black; good flavor.

Delaware. This early Grape is very distinct from all others, and worthy the care necessary to grow it. Bunch and berry small ; skin thin, light red, translucent ; exceedingly sweet and aromatic.

Brighton. Bunch medium to large; berries above medium in size, dark red; flesh tender, with small pulp, of very good quality. Yine vigorous, productive. A hybrid, partly, of the European Grapes. In the foggy climate of Long Island it mildews, and is worthless unless sprayed with Bordeaux mixture.

Lady. Bunch and berry medium size ; greenish yellow; tender and sweet; early.

Martha. Berries large, pale yellow ; sweet and juicy, slightly foxy in flavor. A good early white Grape.

Niagara. Bunch large, compact; berry large; skin pale yellow or white; flesh tender and sweet; vine vigorous and productive. The handsomest white Grape, ripening in midseason with Concord. 


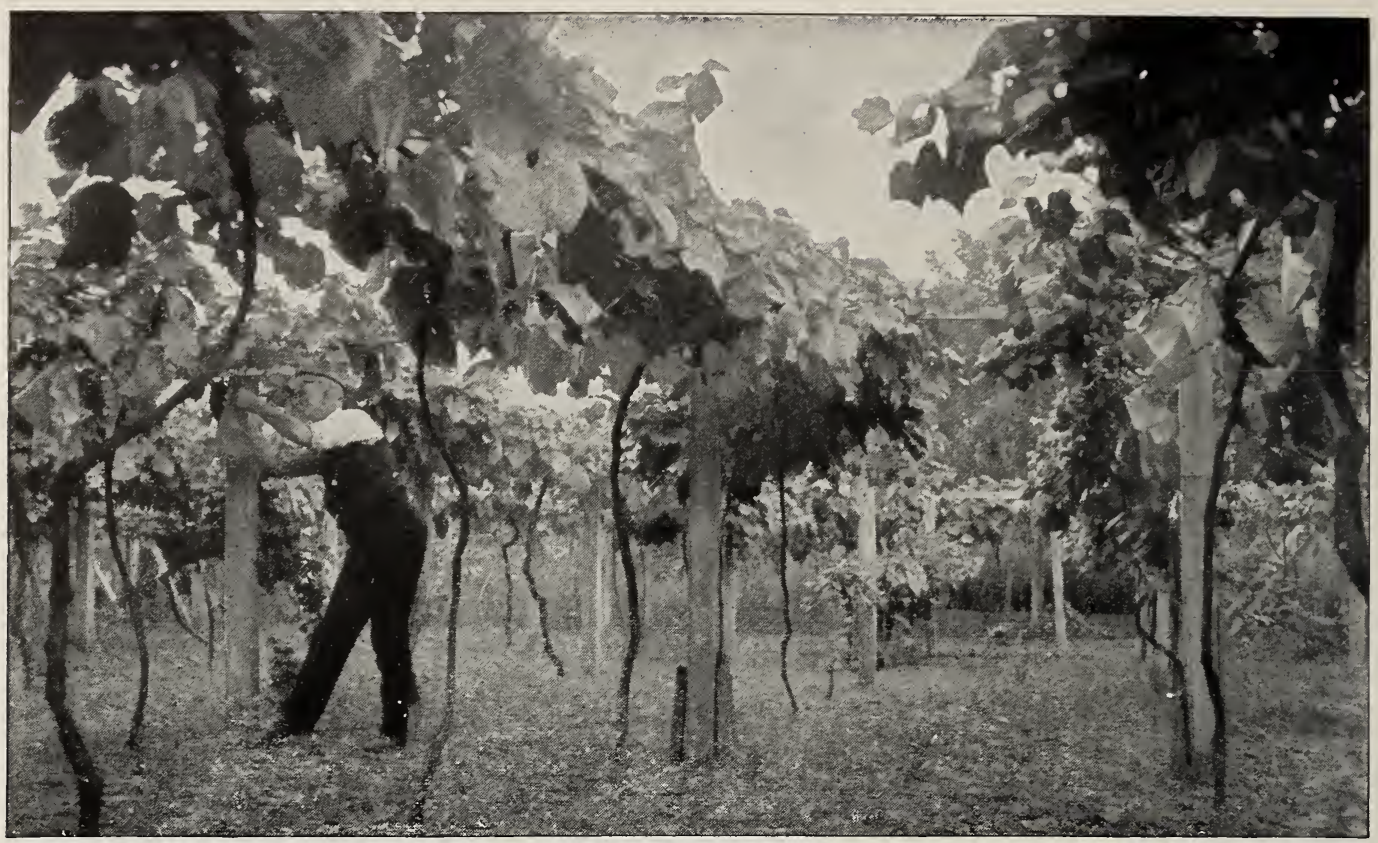

Vineyard of Mr. Corby, Montclair, N. J. Grapes from this vineyard have taken first premium at Mineola Fair. The Long Island Grapes were just as good, except they had not been protected from dust and mildew by paper bags. Grapes thrive anywhere on Long Island. Bordeaux mixture controls mildew.

\section{GRAPES, continued}

Worden. Berry very large, black; skin and pulp tender and sweet. Ripens ten days ahead of Concord, and is superior in quality.

Green Mountain. Berry of medium size, white; pulp tender, juicy, very sweet and rich.

Diamond (Moore's Diamond). Berry large, white, translucent; flesh juicy and almost without pulp; quality very good. Vine vigorous and productive.

Concord. Bunches compact, large ; berries large ; skin black and tender; flesh juicy and sweet. Extreme hardiness, vigor, productiveness, and the fine appearance of its clusters have rendered Concord the most popular Grape.

Herbert. Berry medium size, black ; tender, sweet and rich.

Salem. Bunch and berry large, dull red; tender, of good flavor.

Agawam. Bunch and berry large, dull reddish brown; flesh tender.

Catawba. Berries large, deep coppery red ; juicy, sweet and aromatic. Too late to ripen here except in sheltered places or near water.

Pocklington. A light golden yellow Grape of good quality, ripening after the Concord. A strong grower.

\section{GOOSEBE,RRIES}

Price, two-year-old bushes, 20 cts. each, $\$ 1.50$ for 10 . Gooseberries thrive in any garden soil, and are very satisfactory for home use.

Downing. Medium to large, pale green; very good; bush upright, spiny, productive.

Chautauqua. Bush very vigorous. Fruit large, smooth, translucent. Sweet and productive.

Industry. The best foreign variety. Berry very large, dark red. Bush vigorous, healthy and productive. $\$ 2$ per doz.

\section{CURRANTS}

Price, two-year-old bushes, 15 cts. each, $\$ 1$ for 10 .

Currants are easily grown, and are naturally fruitful. The worm is readily controlled by hellebore powder, and San José scale by lime, sulphur.

Cherry. Very large, dark red berries; clusters moderately short; quite acid.

Versailles. Large, closely resembling Cherry, but slightly less acid; bunches long ; productive and valuable.

Fay's Prolific. Very large berry ; sprightly and acid; on long stems; easily picked. A most popular variety.

White Grape. Large, beautiful white berry ; bunches short; quality excellent. A very pleasant Currant to eat off the bush, as it is less acid than the others.

Victoria. A prolific early variety. Berry smaller than the others; of good quality.

Black Naples. Large black bunches; berries small, with a strong musky flavor. Valuable for cooking and jams.

\section{RASPBERRIES}

Price, 50 cts. for 10, \$4 per 100.

The plants should be set in rows 6 feet apart and 3 feet apart in the row.

\section{RED AND YELLOW RASPBERRIES}

Miller's Red. Berry large, firm, bright red.

Marlboro. Bright scarlet fruit of large size. Early.

Cuthbert. Very large, pointed, deep red berries of delicious flavor. This beautiful variety should be planted largely. Ripens midseason to late. 
RED AND YELLOW RASPBERRIES, continued

Shaffer's Colossal. Very large, dull purplish berries, soft and rather acid. It is the most prolific and vigorous variety we have tested.

Columbian. A new variety, resembling the last, but sweeter.

Golden Queen. Yellow, soft, juicy, sweet fruit. Resembles Cuthbert in form and flavor, and therefore is an excellent dessert variety.

\section{BLACK-CAP RASPBERRIES}

These ripen earlier than the red kinds, and follow Strawberries.

Souhegan. Fruit large and handsome; plant a strong grower and hardy. Ripens early.

Gregg. One of the largest of the black-cap family ; fruit large, black, with a slight bloom ; moderately juicy, sweet and rich. Ripens late and evenly.

\section{BLACKBERRIES}

Price, 50 cts. for 10, \$4 per 100 .

Being easy to grow, Blackberries are a valuable fruit for home use. As they ripen from early July to the middle of August, they complete the season of small fruits until the peaches begin to ripen. To avoid too strong a growth and straggling habit, the ends of the shoots may be cut off at 3 feet in midsummer. Plant $6 \times 3$ feet.

Lucretia Dewberry. Large, coreless, juicy, sweet fruit; most delicious for the table. Ripens before all the others. A running Blackberry that can be trained to a trellis.

Erie. A valuable new variety; large, very early and productive. Desirable as a market berry.

Eldorado. Large berries, borne in large clusters ; vines are vigorous and hardy. One of the best for table use.

Early Harvest. Of medium size, good quality and proiific; very early. It is firm, and therefore a good shipper.

Agawam. A large berry of excellent flavor. Hardy and productive.

Snyder. Berries of medium size, nearly globular, of good flavor ; very hardy.

\section{STRAWBERRIES}

Price, $\$ 1$ per 100 ; in Aug. and Sept. $\$ 2$ per 100.

A garden without Strawberries is incomplete. If Strawberry plants are put out in August and September they will bear fruit the following June. They may be planted in April and May, and each plant allowed to make a dozen or more runners and young plants, which bear freely the follow- ing season. The beds had best be allowed to fruit only two years and then be renewed. Free cultivation should be followed the first year, and the plants covered with straw, manure, or salt hay for the winter. In spring, as the growth commences, this litter may be raked off between the rows to form a mulch, which prevents the growth of weeds and conserves the moisture, as well as protects the ripening berries from the soil. Clippings from the lawn make an excellent mulch for this purpose. By planting four or six varieties, early, medium and late, and giving them good ciltivation, the fruiting season will extend from the last week in May to the first week in July.

PER. indicates perfect-flowered.

IrP. indicates imperfect-flowered. Plant with perfect-flowered varieties near.

Excelsior. Per. A firm, productive, high-colored berry; the chief quality is earliness.

Sharpless. Per. Very large, conical or wedgeshaped; white at the tip when not fully ripe; good flavor.

Bubach. Imp. Fruit of largest size and excellent flavor. A prolific grower with vigorous foliage. A standard sort.

Bismarck. Per. This resembles the Bubach in its excellent qualities, and is slightly smaller.

Beecher. A vigorous, strong-growing variety with healthy foliage. Good flavor and size.

Glen Mary. Per. A long, tapering fruit of mild, sweet flavor.

Clyde. Per. Fruit large, abundant, mild flavor. Foliage not so strong as some others.

Nick Ohmer Per. A vigorous grower; handsome berries of good market quality.

Gandy. Per. One of the latest, if not the latest in cultivation.

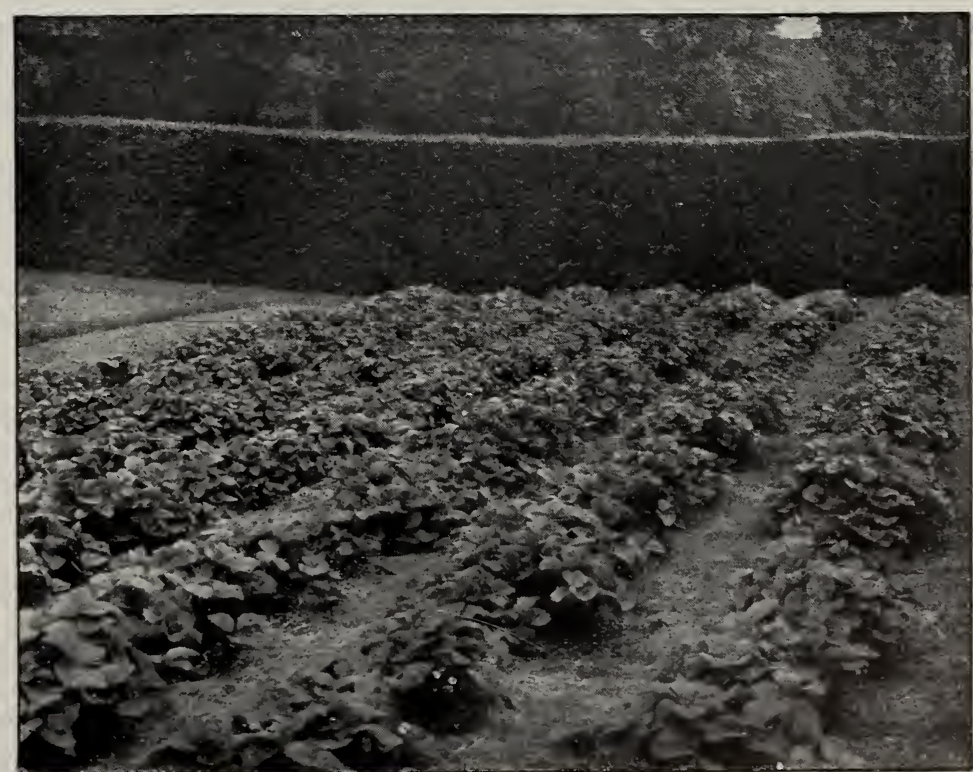

Strawverries grown in hills, the runners being pinched off. Ground mulched with lawn clippings, to conserve moisture and keep the fruit clean. Evergreen hedge makes a garden early and keeps out intruders. We have such hedges for immediate delivery. 


\section{Nut Trees}

In rural and suburban districts, the great economic possibilities of growing edible Nuts are but vaguely understood. They can often be planted along fence lines where they will not affect farming or gardening operations, and later will become a profitable source of income, either in the market or for the owner's use. The United States is importing vast quantities which might be raised at home with profit and credit. American Chestnut sprout growth is easily and cheaply grafted with more valuable sorts. These sorts bear early and abundantly.

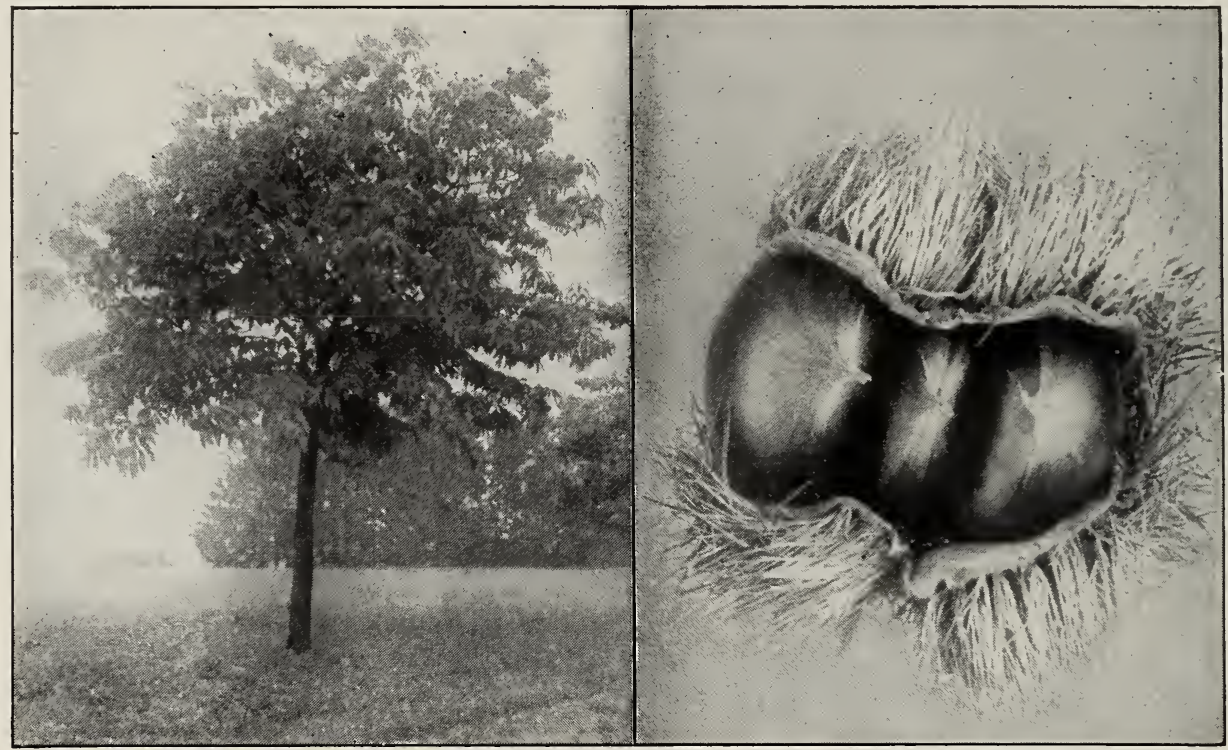

We have thousands of Chestnut trees that will quickly make avenues and groves of trees like this. On the right, one of the early large-bearing Chestnuts.

\section{CHESTNUTS}

American. Castanea Americana. The only species of our forest. The nuts are of finest sweet flavor. An immense, broad-spreading tree in the open. Plant 6o feet apart.

Paragon. A variety of Spanish or European Chestnut which is hardy, possibly a hybrid with the American. It is very precocious, bearing the year after grafting. The nut is large and of very good quality. It is the most uniformly successful Chestnut in the United States.

Japan. Nuts very large. Tree vigorous and productive, even when young. Plant 20 feet apart in the orchard.

\section{FILBERT, or HAZELNUT}

Kentish Cob. The large English variety. It grows and fruits weil here. $25 \mathrm{cts}$. each.

American. Our native Hazelnut.

\section{HICKORY}

Shagbark. Shell thin; meat of good flavor. These grow well on Long Island, and should be more extensively planted for their excellent nuts.

Mockernut. The common native Hickory of Long Island.

\section{WALNUT}

English. Madeira Nut. There are a number of productive trees on Long Island. Tree tender while young.

Japan. Similar to the English, but smaller. Tree vigorous and hardy. $\$ \mathrm{r}$.

Black. Nuts large, rough, black; kernel rich and oily.

\section{BUTTERNUT}

Nuts long; kernel of rich flavor. Plant in deep, moist soil for best results.

\section{GARDEN PLANTS}

ASPARAGUS, Conover's Colossal. I-year-old, 75 cts. per Ioo; 2-year-old, $\$$ I per Ioo, $\$ 7$ per I, OO०.

RHUBARB, Linnæus. Early, tender and very large; possessing a rich flavor. 25 cts. each; smaller roots, $15 \mathrm{cts}$.
SAGE, Broad-leaved. The tender leaves and tops of this plant are used in sausage, in stuffing, and in sauces. $25 \mathrm{cts}$.

THYME. Used for flavoring. $25 \mathrm{cts}$. each.

HORSE-RADISH. A few roots will give a supply of this fine relish. ro cts.

HOPS. I5 cts. each. 


\section{Planting a Tree}

HOLES. - Dig wide, deep holes. If the subsoil is poor, dig $2 \frac{1}{2}$ feet deep, and fill the bottom with a foot of good soil mixed with one-fourth rotted manure.

TRIMMING.-Trim as shown in the picture, cutting back half of last year's growth on the ends of the main branches. Cut out most of the inside twigs. Leave some buds on every branch. Cut close to a bud or side branch.

Trim Shrubs by removing the old or largest shoots. Do not trim to a round form.

R00TS.-Avoid breaking by rough handling. Cut smooth the broken roots, as at $\mathrm{A}$, and spread roots in natural position the same depth as before. Pack the soil firmly under and between the roots, leaving no air spaces. Soak the ground thoroughly.

MULCH.-Cover ground with a mulch of strawy manure, leaves or salt hay, or keep a dry, fine earth-mulch by hoeing 4 inches deep and wider than the roots extend, once in two weeks, all summer, especially a day after heavy rains or watering. The next spring dig in the mulch, add fertilizer and more mulch.

FERTILIZERS.-Manure is not a complete plant-food. Apply on top or mix in the soil, but not against the roots, one quart of fertilizer, which should contain 5 to ro per cent of potash. Woodashes and bone-flour are excellent. Aroid too much manure, as it may rot the roots.

WATER.-Water once a week, or once in two weeks, from May to August, by soaking the ground thoroughly with half a barrel of water, unless there are heavy and frequent rains. Over-watering and too frequent watering often kills trees.

Keep down weeds. A few weeds will take up more food and water than

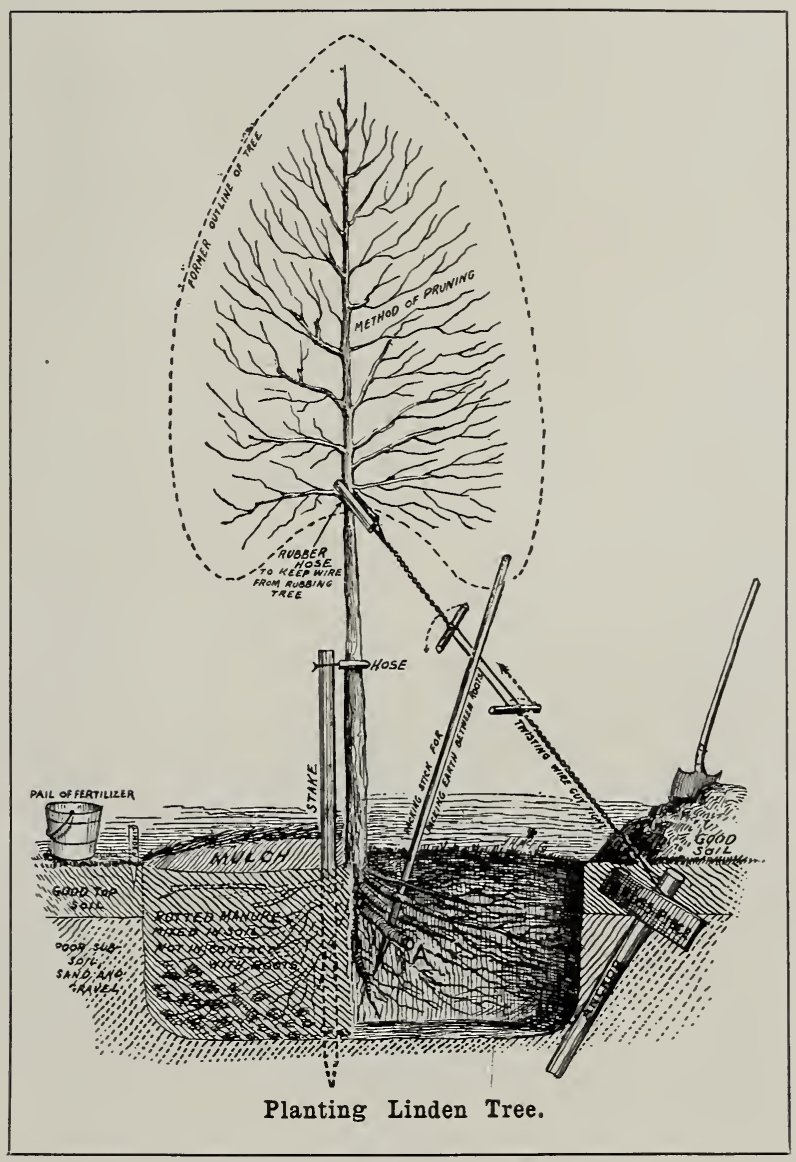
the tree.

HEELING-IN. - To heel-in, or temporarily plant trees on arrival, dig a trench large enough to contain all the roots and place the trees in it in a slanting position, spread out the roots, pack earth around, and water. Covering the ground with a mulch of leaves or litter will be found to be very beneficial to them.

STAKES.-Stakes or guys are needed only with tall or large trees, or those with poor roots. A tree of the size shown, with good roots, needs no stake or wire. For larger trees, rig three or four double wire guys, and twist tight, as shown. For smaller or slender trees use a $3 \times 3$-inch stake, running it up into the top if necessary, and fasten closely to the tree by cord and hose or burlap bands. To protect from horses on the street, place galvanized wire cloth ( $\mathrm{r}$-inch mesh) around the tree and nail it to the stake.

EVERGREENS.-Evergreen tree roots must not be allowed to dry out in the least. If possible, select a foggy time for moving them, and in doubtful cases, set a barrel of water near and sprinkle the tops several times a day for a week or two. When carting trees, use blankets or sail-cloth to cover the roots.

If these directions are intelligently followed, and trees do not live and grow, please write us 


\section{INDEX}

\begin{tabular}{|c|c|c|}
\hline PAGE & PAGE & PAGE \\
\hline Abies $. . \ldots \ldots \ldots \ldots \ldots 3^{1}, 3^{2}$ & Cypress „............. & Juniperus............ 33 \\
\hline Acacia................. 43 & Cypripedium ..........6. 63 & Kadsura Tree .............. 3 \\
\hline cer $\ldots \ldots \ldots \ldots \ldots, 20-22,47$ & Daphne ....... & Kalmia $\ldots \ldots \ldots \ldots \ldots \ldots 5^{2}$ \\
\hline chi lea $\ldots \ldots \ldots \ldots \ldots$. & Day Lily ........... & Kentucky Coftee Iree..... 6 \\
\hline Adam's Needle ...........69 & Deciluous Tries .... & Kerria ... \\
\hline $\begin{array}{l}\text { Adonis } \ldots \ldots \ldots \ldots \ldots \ldots \ldots \ldots \ldots \ldots \ldots,{ }^{61} \\
\text { Assculus } \ldots \ldots \ldots \ldots \ldots \ldots \ldots\end{array}$ & $\begin{array}{l}\text { Deciduous Trees, Moving } \\
\text { of } \ldots \ldots \ldots \ldots \ldots \ldots \ldots \ldots .8\end{array}$ & $\ldots 66$ \\
\hline 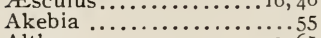 & 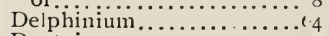 & $\begin{array}{l}\text { Koelreuter } \\
\text { Kraunhia. }\end{array}$ \\
\hline$\ldots \ldots \ldots \ldots .43,6 \mathrm{I}$ & Deutzia...... & Kudsu Vine \\
\hline ssum ............. & $\ldots \ldots 64$ & Laburnum .. \\
\hline elopsis ............. $5^{8}$ & Dicentra..... & Larch....... \\
\hline onia............... & Dierıilla..... & Larix ...... \\
\hline romeda...$\ldots$ 12 $^{2}, 51,53$ & .........6.64 & $\cdots \cdots \cdots \cdots 5^{1}, 5^{2}$ \\
\hline$\ldots \ldots \ldots \ldots \ldots 6$ I & $\operatorname{ros} \ldots \ldots \ldots \ldots \ldots{ }^{25}$ & $\ldots 69$ \\
\hline ee $\ldots \ldots \cdots \cdots 4^{6}$ & od $\ldots \ldots \ldots \ldots 14,15,45$ & $\ldots \ldots \ldots$ \\
\hline …......6. & ….....57 & othoë...............53 \\
\hline$\ldots \ldots \ldots \ldots 12,71,7^{2}$ & $\ldots \ldots \ldots \ldots 64$ & Ligustrum ............... 48 \\
\hline legia ................62 & sup.........68 & $\ldots .47$ \\
\hline$\cdots \cdots \cdots \cdots \cdot 4^{6}$ & an's Pipe ... .......56 & ....66 \\
\hline n.............30 & us...............45 & $\ldots \ldots \ldots \ldots \ldots, 18$ \\
\hline ............. $5^{6}$ & $\cdots \cdots \cdots 45$ & bar ........... \\
\hline$\ldots \ldots \ldots \ldots \ldots \ldots 66^{62}$ & .........15 & endron ............26 \\
\hline$\ldots \ldots \ldots \ldots \ldots \ldots 6^{62}$ & .........25 & $\ldots \ldots \ldots \cdots \cdots \cdots, 18$ \\
\hline .............62 & ip ........68 & $\cdots \cdots \cdots \cdots 4^{6}, 5^{6}$ \\
\hline ..............12 & Primiose.........68 & ...67 \\
\hline$\ldots \ldots \ldots \ldots \ldots 6_{62}$ & $\cdots \cdots 5^{1}, 5^{2}, 5^{6}$ & chia ..............67 \\
\hline ...........62 & ….....64 & ia ............. \\
\hline$\ldots \ldots \ldots \ldots 43,5$ I & $\ldots \ldots \ldots 64$ & \\
\hline$\ldots \ldots \ldots \ldots \ldots \ldots 62$ & horn......55 & ree ........... I5 \\
\hline ................ & e $\ldots \ldots 28-4 \mathrm{I}$ & .......20-22, 47 \\
\hline . $\ldots \ldots \ldots \ldots \ldots, \ldots \ldots 44$ & reen Trees, Moving & .......... \\
\hline anc...... & ........... 10 & $\cdots$ \\
\hline ada $\ldots \ldots \ldots \ldots \ldots \ldots$ & …......45 & $\ldots \ldots \ldots$ \\
\hline 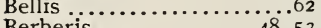 & ......12 & …... \\
\hline$\ldots \ldots \ldots \ldots \ldots 4^{8,} 53$ & $\ldots \ldots \ldots 6_{4}$ & Orange \\
\hline 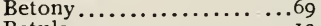 & .....64 & .....67 \\
\hline ................ & $\cdots 33^{I}, 32$ & ........22, 23 \\
\hline$\ldots \ldots \ldots \ldots \ldots{ }^{13}$ & $\ldots \ldots \ldots$ & Ash ...........22 \\
\hline et $\ldots \ldots \ldots \ldots 55$ & ubs .....42-50 & s........ 22, \\
\hline es.............77 & $\ldots \ldots \ldots \ldots+46$ & .........44 \\
\hline ...............68 & ….....12 & $\ldots 53,69$ \\
\hline .........6. & $\ldots \ldots 46$ & .67 \\
\hline$\ldots \ldots \ldots \ldots \ldots \ldots 62$ & $\ldots .64,65$ & .67 \\
\hline$\cdots \cdots \cdots \cdots \cdots 5^{1,5^{2}}$ & $\ldots \ldots 6_{5}$ & ey Tea. \\
\hline eaved Evergreen &. .78 & .78 \\
\hline$\cdots \cdots \cdots \cdots \cdots 5^{1-55}$ & & .. $\ldots 25$ \\
\hline n.m.n. & .65 & c........ 23-25 \\
\hline h ..............44 & ... I5 & ..........67 \\
\hline$\ldots \ldots \ldots$ & & \\
\hline & $\ldots \ldots 47$ & .67 \\
\hline us .............. 50 & ......76 & .25 \\
\hline la $\ldots \ldots \ldots \ldots \ldots 6^{62}$ & .75 & $.25,73$ \\
\hline .............49 & 6 & 1 Bush. \\
\hline$\ldots \ldots \ldots \ldots \ldots \ldots$ & iila .... & .72 \\
\hline$\ldots \ldots \ldots \ldots \ldots \ldots$ &. .26 & .67 \\
\hline$\ldots \ldots \ldots \ldots \ldots$ & $\ldots 50$ & \\
\hline .14 & -69 & 69 \\
\hline$\ldots \ldots \ldots \ldots \ldots, 43,45$ &. .26 & .25 \\
\hline s $\ldots \ldots \ldots \ldots . . . \ldots 48$ & .65 & .25 \\
\hline ........30 & .65 & delphus ...... \\
\hline & & $\ldots \ldots \ldots$ \\
\hline ..............55 & $\ldots \ldots 65$ & $\ldots 40,41$ \\
\hline .63 & $\ldots 32,33$ & $\cdots 5^{I}$ \\
\hline .......44 & lub & ....34-37 \\
\hline zus...... & $\ldots 4$ & \\
\hline & & \\
\hline$\ldots \ldots{ }_{3}$ & $\ldots \ldots{ }^{1} 5$ & a Tree.. \\
\hline$\ldots 16,46$ & & $\mathrm{P}$ \\
\hline & & \\
\hline ..... It & $\ldots 46,5^{6}$ & is ..............25, 74 \\
\hline & & $\ldots \ldots 25$ \\
\hline & & \\
\hline ork Tree........25 & $\ldots \ldots 46$ & \\
\hline & & $\mathrm{um} \ldots .$. \\
\hline & & \\
\hline & & \\
\hline$\ldots 5^{6,6} 6_{3}$ & ....66 & $\ldots \ldots 48$ \\
\hline & $\ldots 57$ & $\ldots \ldots 14,25$ \\
\hline & & \\
\hline$\ldots 63$ & da Tree ......26 & ple Fringe... \\
\hline$\ldots \ldots 4^{6}$ &. .46 & rethrum......... \\
\hline & $\ldots 69$ & \\
\hline & $\ldots 47$ & ...23-25 \\
\hline .......26 & ......16 & ..68 \\
\hline .69 & & \\
\hline & & \\
\hline
\end{tabular}

PAGE

ar...............30 Rhododendron $\ldots . . . \ldots \ldots \ldots . \ldots 38$ Rhodotypos..................49 Rhus $\ldots \ldots \ldots \ldots \ldots \ldots \ldots . \cdots \cdots \cdot 50$ Rose Acacia...............4 Roses, Climbing ............. 57 Rose of Sharon ..............43 Roses...................5 58-60 Rudbeckia...................68

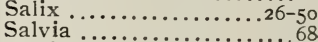
Salvia ....................68 Sanguinaria ................6. 68 Sassafras .................26 Sciadopitys..............38, 39 Sedum ..................69 Siberian Pea Tree......... 49
Silphium Silphium Beil, or snowdrop Tree ..................26 Silver Thorn .................45 Smoke Tree ................49 Snowball ................49 Solomon's Seal ...............68 Solomon's Seal ............68 Sorbus $\ldots \ldots \ldots \ldots \ldots \ldots \ldots \ldots \ldots \ldots . .22$ Spanish Bayonet..............55, 69
Speedwell Speedwell ...............6.69 Spirea ........................, 49 Spruce...................40,4I Stachys........................6, 69 Stokes' Äsier................69 Stokesia .................69 Strawberries...............77 Styrax ...................26 Sweet Gun ................ I8 Sweet Pepper-bush ..........50 Sweet-scented Shrub.........50 Symphoricarpus .............46 Syringa ................47,50 Tamarisk................. $5^{\circ}$ Tamarix $\ldots \ldots \ldots \ldots \ldots \ldots \ldots . .55^{\circ}$ Taxodium ................. I4

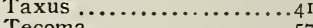
Tecoma.................57 Thermopsis................69

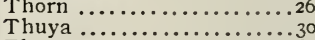
Thymus ................... 69 Tradescantia ................6 Tree-Moving ............. $8-10$ Tree Peony ..............6 67

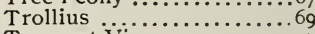
Trumpet 7 rime.................. Trumpet Creeper...........57 Tsuga $\ldots \ldots \ldots \ldots \ldots \ldots \ldots \ldots 2^{2}$ Tulip Tree $\ldots \ldots \ldots \ldots \ldots \ldots . \cdots 3^{8}$ Ulmus .................... I5 Valerian .................69 Valeriana..................69 Varnish Tree................... Veronica ...................69 Viburnum ................49 Vinca ....................53, 69 Vines .................55-58 Walnut Wax Myrtie .................44

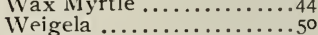
Weigela $\ldots \ldots \ldots \ldots \ldots \ldots \ldots, 50$

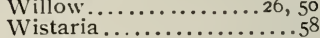
Witch-hazel .................5 Woodbine .................5 Xanthorrhiza .............5 $5^{\circ}$ Yellow Root................5 Yellow-wood ..............26

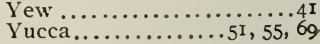




\title{
PRICE-LIST OF
}

\section{$\underline{\text { Trees for Long Island }}$}

\section{ISAAC HICKS AND SON}

\section{Large Tree Movers}

\section{WESTBURY NURSERIES}

\section{Westbury Station, Nassau Co., N. Y.}

\author{
Telephone, 76 W. Westbury
}

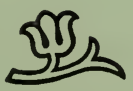

The prices in this list.are for trees and plants dug and loaded at Westbury Nurseries. Five plants at ten rate; fifty at hundred rate; five hundred at thousand rate. Specimens priced on selection. Prices subject to change without further notice. Delivery at railroad is free. A moderate charge is made to cover expense of packing for shipment by rail. When delivery is by wagon the charge is proportionate to distance and expense. See Business Terms, page 3 of General Catalogue. 


\section{DECIDUOUS TREES}

Page

12 ANDROMEDA arborea (Sorrel

Tree; syn., Oxydendrum. arboreum).

1 to $2 \mathrm{ft} . \ldots \ldots \ldots \ldots \ldots \ldots \ldots 0 . \ldots \ldots$

2 to $3 \mathrm{ft} . . . \ldots \ldots \ldots \ldots \ldots \ldots . .60$

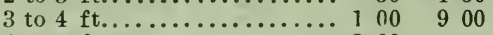

4 to $5 \mathrm{ft} . \ldots \ldots \ldots \ldots \ldots \ldots \ldots 200$

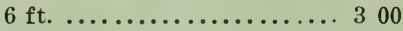

12 APPLE, Bechtel's Double-flowering (Pyrus Ioensis, var. Bechtel). 4 to $6 \mathrm{ft} . . . .$. .

12 ASH, White (Fraxinus Ameri$\operatorname{can} a)$.

14 to $16 \mathrm{ft} ., 1 \frac{1}{2}$ to 2 in...... 100

16 to $18 \mathrm{ft}$., 3 to 4 in........ 800

12 BEECH, English, or European (Fagus sylvatica).

3 to $4 \mathrm{ft} \ldots \ldots \ldots \ldots \ldots \ldots \ldots, \quad 75 \quad 700$

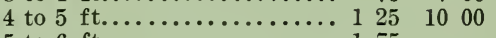

5 to $6 \mathrm{ft} . \ldots \ldots \ldots \ldots \ldots \ldots \ldots \ldots$

6 to $8 \mathrm{ft} . \ldots \ldots \ldots \ldots \ldots \ldots \ldots \ldots$

8 to $10 \mathrm{ft} . \ldots \ldots \ldots \ldots \ldots 3$ to 600

Specimens, 10 to $20 \mathrm{ft}$., 3 to

8 in. diam. Price on application.

12 Purple, or Copper ( $F$. sylvatica, var. purpurea).

10 to $13 \mathrm{ft} . \ldots \ldots \ldots \ldots+\$ 6$ to 800

12 Rivers' Purple ( $F$. sylvatica, var. purpurea Riversii).

3 to $4 \mathrm{ft} . \ldots \ldots \ldots \ldots \ldots \ldots \ldots \ldots \ldots$

4 to $5 \mathrm{ft} \ldots \ldots \ldots \ldots \ldots \ldots, 150$

5 to $6 \mathrm{ft} . \ldots \ldots \ldots \ldots \ldots \ldots \ldots \ldots$

6 to $7 \mathrm{ft} . \ldots \ldots \ldots \ldots \ldots \ldots \ldots \ldots \ldots \ldots \ldots \ldots 250$

8 to $10 \mathrm{ft} . \ldots \ldots \ldots \ldots \ldots \ldots .50$

10 to $12 \mathrm{ft.,} 2$ to $3 \mathrm{in} . . . \ldots . . .6$ Price on applica-

12 to $14 \mathrm{ft} ., 2$ to 3 in........

Specimens, 18 to $28 \mathrm{ft}$. Price on application.

12 Weeping Purple ( $F$. sylvatica, var. purpurea pendula).

$3 \mathrm{ft} . . \ldots \ldots \ldots \ldots \ldots \ldots \ldots, 400$

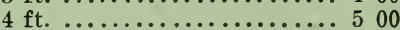

12 Weeping ( $F$. sylvatica, var. pendula).

4 to $5 \mathrm{ft} . \ldots \ldots \ldots \ldots \ldots \ldots 200$

5 to $6 \mathrm{ft} \ldots \ldots \ldots \ldots \ldots \ldots \ldots \ldots 250$

6 to $7 \mathrm{ft} . \ldots \ldots \ldots \ldots \ldots \ldots . . .300$

7 to $8 \mathrm{ft} . \ldots \ldots \ldots \ldots \ldots \ldots \ldots, 400$

12 Fern=leaf ( $F$. sylvatica, var. heterophylla).

3 to $4 \mathrm{ft} . \ldots \ldots \ldots \ldots \ldots \ldots \ldots \ldots \ldots$

4 to $5 \mathrm{ft} . \ldots \ldots \ldots \ldots \ldots \ldots .250$

5 to $6 \mathrm{ft} \ldots \ldots \ldots \ldots \ldots \ldots \ldots \ldots, 400$

6 to $8 \mathrm{ft} . \ldots \ldots \ldots \ldots \ldots \ldots 600$

12 American ( $F$. ferruainea).

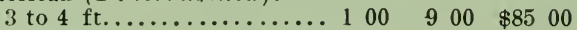

4 to $5 \mathrm{ft} \ldots \ldots \ldots \ldots \ldots \ldots \ldots \ldots \ldots \ldots$ 1 $50 \quad 1400$

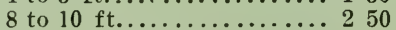

Specimens up to $16 \mathrm{ft}$. Price on selection.

\section{BIRCH, European White (Betula} a $l b a) .6$ to $8 \mathrm{ft} . \ldots \ldots \ldots . .50$

8 to $10 \mathrm{ft} . \ldots \ldots \ldots \ldots \ldots \ldots \ldots \ldots$

20 to $22 \mathrm{ft} ., 4 \frac{1}{2}$ to $5 \mathrm{in} . . . .3$ Price on applica25 to $35 \mathrm{ft} ., 6 \frac{1}{2}$ to $\left.10 \mathrm{in} . ..\right\}$ tion.

13 Canoe, or Paper (B.papyrifera). 6 to $8 \mathrm{ft} . \ldots \ldots \ldots \ldots \ldots \ldots .6 . \ldots \ldots$

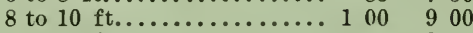
10 to $12 \mathrm{ft} . \ldots \ldots \ldots \ldots \ldots \ldots \ldots . .150 \quad 1250$

13 Cherry, Sweet, or Black ( $B$. lenta). 6 to $8 \mathrm{ft} . \ldots . . .650 \quad 550$ 8 to $10 \mathrm{ft} . \ldots \ldots \ldots \ldots \ldots \ldots \ldots \ldots$ 10 to $12 \mathrm{ft.}, 1 \frac{1}{2}$ in............ 150
13 CatalPa, Western (Catalpa spe-
Each
10
100
ciosa). 6 to $8 \mathrm{ft} . . . \ldots \ldots \ldots \$ 50 \quad \$ 400$
8 to $10 \mathrm{ft} . \ldots \ldots \ldots \ldots \ldots \ldots . . .6 \%$ 75 650
10 to $12 \mathrm{ft} . \ldots \ldots \ldots \ldots \ldots \ldots \ldots$
12 to $14 \mathrm{ft} ., 3 \mathrm{in} . . . \ldots \ldots \ldots . . .175$
14 to $16 \mathrm{ft}$., 3 to 4 in..... ?
14 to $18 \mathrm{ft}, 4$ to $5 \mathrm{in} . .$.
18 to $2 . \mathrm{ft} ., 4$ to 5 in....
18 to $22 \mathrm{ft}$., 4 to $5 \mathrm{in.....}$
20 to $24 \mathrm{ft}$., 6 to 7 in.....
20 to $26 \mathrm{ft}$, 7 to $8 \mathrm{in.....}$
22 to $26 \mathrm{ft}$., 8 to 9 in......
26 to $30 \mathrm{ft}$, 9 to $10 \mathrm{in...}$.
26 to $30 \mathrm{ft}$., 10 to $12 \mathrm{in..}$.
$33 \mathrm{ft} .13$ in...............
This presents an op- portunity for ob- taining big trees at low cost. They may be moved as late as May 15. Price on applica- tion.

13 Bungei (C'. bignonioides, var. Each nana; Bay Tree form).

$6 \mathrm{ft} ., 2$-yr. heads........\$1 25

Specimens with heads four to eight years old, 3 to $6 \mathrm{ft}$. Price on selection.

13 Bungei (Shrub form). Se e Shrubs.

13 C E R C I I PHY L L U M (Kadsura Tree). $6 \mathrm{ft} . \ldots \ldots \ldots \ldots .100$

14 CHERRY, Double-flowering $\mathrm{J}$ a $\mathrm{p}$ a nese (Prunus Pseudo. Cerasus, var. Sieboldi)

4 to $5 \mathrm{ft} . \ldots \ldots \ldots \ldots \ldots \ldots \ldots$

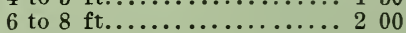

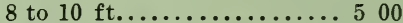

\section{Japanese Weeping Rose-flowered}

$(P$. pendula $) .4$ to $6 \mathrm{ft}$... 150

6 to $8 \mathrm{ft} . \ldots \ldots \ldots \ldots \ldots \ldots 250$

14 Wild Black (P. serotina). $8 \mathrm{ft}$. 75

14 CHESTNUT, American (Castanea Americana). $1 \mathrm{ft}$., $1-\mathrm{yr}$. seedlings...per $1,000, \$ 20$.

1 to $2 \mathrm{ft}$., transplanted..... per $1,000, \$ 100$.

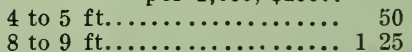

10 to $12 \mathrm{ft} . \ldots \ldots \ldots \ldots \ldots \ldots . . . .300$

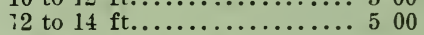

14 Spanish (Castanea savita; Paragon Chestnut).

3 to 4 ft................ 75

4 to $5 \mathrm{ft} . \ldots \ldots \ldots \ldots \ldots \ldots \ldots, 100$

6 to $7 \mathrm{ft} . \ldots \ldots \ldots \ldots \ldots \ldots \ldots \ldots$ \& 50

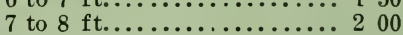

14 Japanese ( $C$. crenata).

$1 \mathrm{ft}$., seedlings..1,000, $\$ 40 . .08$

1 to $2 \mathrm{ft}$., transplanted ..... 18

CHINQUAPIN (Castanea pumila).

6 in.................... 50

1 to $2 \frac{1}{2} \mathrm{ft} . \ldots \ldots \ldots \ldots \ldots \ldots \ldots$. 75

14 CYPRESS, Deciduous ( $T$. distichum $) .5 \mathrm{ft} . . . \ldots \ldots \ldots 100$

$7 \mathrm{ft} . . . \ldots \ldots \ldots \ldots \ldots \ldots \ldots 200$

Specimens up to $18 \mathrm{ft}$. Price on selection.

14 Chinese Weeping ( $T$. distichum, var. imbricarium; syn., Glyptostrobus Sinensis).

Specimens up to $15 \mathrm{ft}$. Price on selection.

14 DOGW00D, Flowering (C.florida).

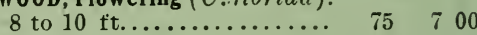

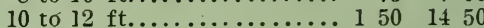

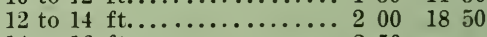
14 to $16 \mathrm{ft} . \ldots \ldots \ldots \ldots \ldots \ldots \ldots \ldots \ldots \ldots \ldots 250$

15 Red-flowering ( $C$. florida, var. rubra).

4 to $5 \mathrm{ft} . \ldots \ldots \ldots \ldots \ldots \ldots \ldots$. $200 \quad 1850$

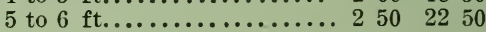

$\$ 200$

1500 $\$ 450$ 
DECIDUOUS TREES, continued

Page

15 Dogwood, Japanese ( $C$. Kousa). 2 to $2 \frac{1}{2} \mathrm{ft} . \ldots \ldots \ldots \ldots \ldots \ldots . \ldots 0$ 50 $\$ 300$

$21 / 2$ to $3 \mathrm{ft} \ldots \ldots \ldots \ldots \ldots \ldots$ 1 100 . 750

6 to $8 \mathrm{ft} . \ldots \ldots \ldots \ldots \ldots \ldots \ldots 20$

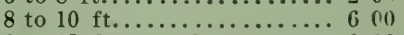

10 to $12 \mathrm{ft} .$, standards...... 800

15 Variegated (C. macrophylla, var. variegata). 1 to $1 \frac{1}{2} \mathrm{ft} .150$

15 ELM, American (Ulmus Americancl). 8 to $10 \mathrm{ft} . \ldots \ldots . .85$ 12 to $15 \mathrm{ft} . .11 / 2$ to $2 \mathrm{in} \ldots \ldots .150 \quad 1400 \$ 13000$ 12 to $15 \mathrm{ft} ., 21 / 2$ in......... 200 18. 50 Specimens, 16 to $30 \mathrm{ft}$., 3 to 8 in. Price on application.

Large specimens, 12 to $18 \mathrm{in.}$ diam., 30 to $50 \mathrm{ft}$. bigh, and 25 to $35 \mathrm{ft}$. spread of top and roots. Price on application.

15 Weeping ( $L^{\top}$. Americana, var. pendula).

10 to $12 \mathrm{ft} . \ldots \ldots \ldots \ldots \ldots . \ldots 100$

12 to $14 \mathrm{ft} . \ldots \ldots \ldots \ldots \ldots \ldots \ldots \ldots .150$

14 to $16 \mathrm{ft} . \ldots \ldots \ldots \ldots \ldots \ldots 200$

English ( $U$. campestris). $6 \mathrm{ft}$. $\quad 75$

15 GINKG0 biloba; syn., Salisburia adiantifolia. $\quad \pm$ to 8 in., seedlings .....1.000, $\$ 10$.

1 to $11 / 2 \mathrm{ft} . \ldots \ldots \ldots \ldots \ldots \ldots$

2 to $3 \mathrm{ft} . \ldots \ldots \ldots \ldots \ldots \ldots . . . .$.

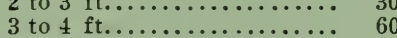

10 to $12 \mathrm{ft} ., 1 \frac{1}{4}$ to $1 \frac{1}{2}$ in..... 175

12 to $14 \mathrm{ft} ., 1 \frac{1}{2}$ to $2 \mathrm{in......2} 200$

14 to $16 \mathrm{ft} ., 2$ to $2 \frac{1}{2}$ in........ 350

15 H IC ORY, Mockernut (Hicoria tomentosa ; syn., $H$. Carya).

1-5r. seedlings, 4 to 8 in....

$2-y r$. trans., 4 to 8 in. .......

Specimens up tolt $\mathrm{ft}$. Price on application.

15 Shagbark ( $H$. ovata; syn., $H$. $a 7 b a)$.

1.-rr. seedlings, $\neq$ to 6 in....

2 -yr, trans., 4 to 8 in........

4 to $6 \mathrm{ft} . \ldots \ldots \ldots \ldots \ldots \ldots \ldots . \ldots 100$

15 HORNBEAM, European (Carpinus Betulus). $1 \frac{1}{2}$ to $2 \mathrm{ft} . .$. .

2 to $3 \mathrm{ft} . \ldots \ldots \ldots \ldots \ldots \ldots$

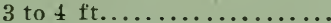

4 to $5 \mathrm{ft} . \ldots \ldots \ldots \ldots \ldots \ldots \ldots \ldots \ldots \ldots \ldots$

5 to $6 \mathrm{ft} . \ldots \ldots \ldots \ldots \ldots \ldots \ldots \ldots \ldots$

American. 4 to $6 \mathrm{ft} . \ldots \ldots \ldots$.... 75

16 HORSE - CHESTNUT (Esculus Hippocustanum).

1 to $1 \frac{1}{2} \mathrm{ft} ., 2-\mathrm{yr}$. seedlings. 05

8 to $10 \mathrm{ft} . \ldots \ldots \ldots \ldots \ldots \ldots . \ldots$

8 to $12 \mathrm{ft} ., 2$ to $2 \frac{1}{2}$ in....... 200

10 to $12 \mathrm{ft} ., 2 \frac{1}{2}$ to 3 in...... 250

10 to $12 \mathrm{ft} ., 3$ to $3 \frac{1}{2} \mathrm{in} . . . . .4400$

Larger specimens. Price on application.

Double-flowering White ( $\mathscr{E}$., var.

fl. $p l$.). 8 to $10 \mathrm{ft} . \ldots \ldots .200$

10 to $12 \mathrm{ft} . \ldots \ldots \ldots \ldots \ldots \ldots .400$

16 Red ( $E$. carnea; syn., $E$. vubicundu). 9 to $10 \mathrm{ft}$. . 250

Dwarf. See Shrubs.

Ohio Buckeye ( $E$. glabra).

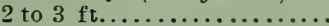

Specimens up to 5 in. Price on application.

16 JUDAS, American (Red Bud; Cercis Canadensis). 6 to $8 \mathrm{ft} . \ldots \ldots \ldots \ldots \ldots \ldots . . . \ldots 100$

Japanese ( $C$. Chinensis). See under Shrubs.
Page Each 10

100

16 KENTUCKY COFFEE TREE (Gymnocladus Canadensis).

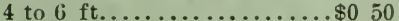

6 to $8 \mathrm{ft} . \ldots \ldots \ldots \ldots \ldots \ldots$

10 to $14 \mathrm{ft} . \ldots \ldots \ldots \ldots \ldots \ldots \ldots . \ldots 200$

Specimens up to $71 / 2$ inches in diameter. Price on appli cation.

16 KOELREUTERIA (Varnish Tree; Kolreuteria paniculatu).

6 to 8 in., seedlingrs....... 20 $20 \quad \$ 175$

10 to $12 \mathrm{ft} ., 2$ to $2 \frac{1}{2}$ in......... 200

LARCH, European (Lrwix decidua; syn., Europaea). 4 to $6 \mathrm{ft} . \quad 50$

6 to $8 \mathrm{ft} . \ldots \ldots \ldots \ldots \ldots \ldots 200$

8 to $10 \mathrm{ft} . \ldots \ldots \ldots \ldots \ldots \ldots \ldots . \ldots . \ldots . \ldots . \ldots 300$

leptolepis. 6 to $8 \mathrm{ft} . \ldots \ldots \ldots 200$

Kaempferi; syn., Pseudo-larix Kaempferi.

2 in., 1 -rr. seedlings........

2 to $3 \mathrm{ft} . \ldots \ldots \ldots \ldots \ldots \ldots \ldots . . \ldots 100$

3 to $3 \frac{1}{2} \mathrm{ft} . \ldots \ldots \ldots \ldots \ldots \ldots 200$

17 LINDEN, Silver (Tilia tomentosa syn., $T$. argentea; syn, a $7 b a) .6$ to $7 \mathrm{ft} . \ldots \ldots \ldots .650$ 8 to $9 \mathrm{ft} . \ldots \ldots \ldots \ldots \ldots \ldots \ldots . \ldots \ldots$

Larger specimens. Price on application.

17 spectabilis ( $T$. tomentosa, rar. spectabilis). 6 to $8 \mathrm{ft} . \ldots .150 \quad 1450$

8 to $9 \mathrm{ft} \ldots \ldots \ldots \ldots \ldots \ldots .200$

Larger specimens. Price on selection.

17 Weeping Silver ( $T$. petiolaris; syn., argentea rar. pen. dula). 6 to $8 \mathrm{ft}, 1$ in.... 100
$50 \quad 250$

$150 \quad 1200$

$100 \quad 800$

$200 \quad 1500$

225

2500

$450 \quad 4000$

700

1250

400
8 to $9 \mathrm{ft} ., 1 \frac{1}{2}$ in........... 200

Fine broad sp "eading specimens, as follows:

8 to $10 \mathrm{ft} ., 1$ to 2 in., 6 to $8 \mathrm{ft}$. wide.

10 to $12 \mathrm{ft} ., 2$ to 3 in., 8 to $10 \mathrm{ft}$. wide

12 to $14 \mathrm{ft} ., 2 \frac{1}{2}$ to $3 \frac{1}{2}$ in., 8 to $10 \mathrm{ft}$. wide. Price

14 to $16 \mathrm{ft} . .3$ to 4 in., 8 to $10 \mathrm{ft}$. wide.

Otbers up to 10 in. in diameter.

18 Small-leaved ( $T$. utmifotia;

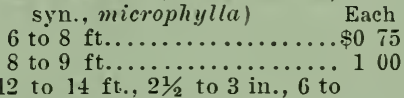

$8 \mathrm{ft}$. wide ............ $\neq 00$

12 to $15 \mathrm{ft.} 3$ to $3 \frac{1}{2}$ in....... 500

12 to $15 \mathrm{ft} ., 31 / 2$ to 4 in...... 500

Specimens up to 8 in. diameter. Price on applicaticn.

18 American ( $T$. Americana; Basswood).

16 to $18 \mathrm{ft}$., 3 to $3 \frac{1}{2}$ in..... 400

18 to $20 \mathrm{ft} ., 3 \frac{1}{2}$ to $1 \frac{1}{2}$ in. $\$ 5$ to 800

Specimens up to $35 \mathrm{ft}, 12 \mathrm{in}$. diameter. Price on application.

18 LIQUIDAMBAR (Sweet fum).

1 to $1 \frac{1}{2} \mathrm{ft} .2-\mathrm{rr}$. transplanted.

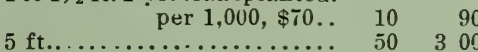

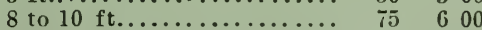

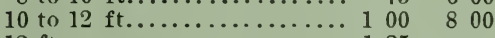

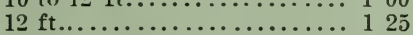

18 LOCUST, Honey (Gleditschia triacanthos). 11/2 to $2 \mathrm{ft}$. Excellent for defensire hedges................

6 to $8 \mathrm{ft} \ldots \ldots \ldots \ldots \ldots$

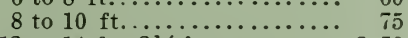

12 to $14 \mathrm{ft} ., 2 \mathrm{i} / 2$ in............... 250

Wide specimens, 14 to 16 by

$10 \mathrm{ft}$. Price on application. 


\section{DECIDUOUS TREES, continued}

Page

19 Magnolia, Umbrella (Magnolia tripetela). 1 to $2 \mathrm{ft} . \ldots \ldots \$ 025$

2 to 3 ft........................ 40 350

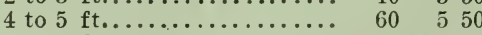

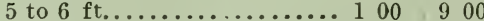

7 to $8 \mathrm{ft} . \ldots \ldots \ldots \ldots \ldots \ldots \ldots \ldots$

8 to $10 \mathrm{ft} . \ldots \ldots \ldots \ldots \ldots \ldots . . .200$

19 Large-leaved ( $\boldsymbol{M}$. macrophylla)

$1 \frac{1}{2}$ to $2 \mathrm{ft} . \ldots \ldots \ldots \ldots \ldots \ldots \ldots 125110010000$

2 to $3 \mathrm{ft} . \ldots \ldots \ldots \ldots \ldots \ldots \ldots 1401200$

19 Fraseri. $3 \mathrm{ft} . \ldots \ldots \ldots \ldots \ldots \ldots 150$ $4 \mathrm{ft} . \ldots \ldots \ldots \ldots \ldots \ldots \ldots \ldots 2 \mathrm{c} 0$

19 Cucumber ( $M$. acuminata).

1 to $2 \mathrm{ft} . \ldots \ldots \ldots \ldots \ldots \ldots .40$

19 hypoleuca.

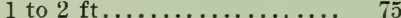

2 to 3 ft.................... 1 00

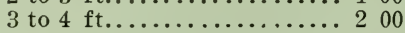

4 to $5 \mathrm{ft} . \ldots \ldots \ldots \ldots \ldots \ldots . \ldots 300 . \ldots$

19 Kobus. 2 to $3 \mathrm{ft} . \ldots \ldots \ldots \ldots . .100$

3 to $4 \mathrm{ft} . \ldots \ldots \ldots \ldots \ldots \ldots \ldots . \ldots \ldots$

4 to $5 \mathrm{ft} . \ldots \ldots \ldots \ldots \ldots \ldots \ldots .250 \quad 2250$

5 to $6 \mathrm{ft} . \ldots \ldots \ldots \ldots \ldots \ldots \ldots \ldots .400$

19 Yulan; syn., conspicua.

1 to $1 \frac{1}{2}$ ft............... 100

$11 / 2$ to 2 ft................ 150

2 to $3 \mathrm{ft} . \ldots \ldots \ldots \ldots \ldots \ldots \ldots 175$

3 to $4 \mathrm{ft} . \ldots \ldots \ldots \ldots \ldots \ldots \ldots \ldots . \ldots \ldots \ldots$

19 Soulangeana. 2 to $3 \mathrm{ft} . . . \ldots \ldots$ 75

3 to $4 \mathrm{ft} . \ldots \ldots \ldots \ldots \ldots \ldots \ldots . \ldots \ldots$

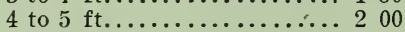

5 to $6 \mathrm{ft} . \ldots \ldots \ldots \ldots \ldots \ldots \ldots$. 400

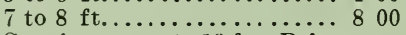

Specimens up to $18 \mathrm{ft}$. Price

on application.

19 Soulangeana nigra. 3 to $4 \mathrm{ft}$... 200

19 alba superba. $4 \mathrm{ft} . \ldots \ldots \ldots .200$

19 Alexandria. 4 to $5 \mathrm{ft}$....... 250

19 Lennei. 3 to $3 \frac{1}{2} \mathrm{ft} . \ldots \ldots \ldots 200$

19 speciosa. $3 \mathrm{ft} . \ldots \ldots \ldots \ldots \ldots 200$

19 Sweet Bay ( $M$. glauca).

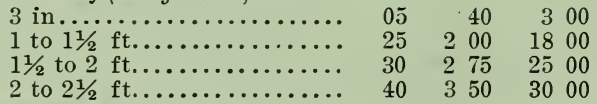

20 parviflora. 1 to $1 \frac{1}{2} \mathrm{ft} . \ldots \ldots \ldots 100$

$1 \frac{1}{2}$ to $2 \mathrm{ft} . \ldots \ldots \ldots \ldots \ldots \ldots . \ldots 200$

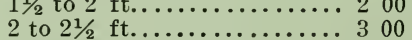

20 Watsoni. 1 to $11 / 2 \mathrm{ft} . \ldots \ldots \ldots 100$

2 to $2 \frac{1}{2}$ ft................. 200

$21 / 2$ to 3 ft..................... 50

20 obovata, var. gracilis. $2 \mathrm{ft} . \ldots . \quad 50$

$3 \mathrm{ft} . \ldots \ldots \ldots \ldots \ldots \ldots \ldots \ldots . \ldots \ldots+75$

20 stellata; syn., Halleana (Hall's Magnolia).

2 in. seedlings........... 15

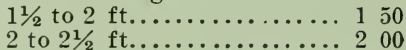

$2 \frac{1}{2}$ to $3 \mathrm{ft} \ldots \ldots \ldots \ldots \ldots \ldots . . \ldots 250$

3 to $3 \frac{1}{2}$ ft.................. 400

20 MAPLE, Norway (Acer platanoides).

8 to $10 \mathrm{ft}$.

10 to 19 ft. . . . . . . . . . .

10 to $12 \mathrm{ft}$., $1 \frac{1 / 2}{20} 1 \frac{13 / 4}{10}$ in....

12 to $14 \mathrm{ft} ., 13 / 4$ to 2 in...... 125

12 to $14 \mathrm{ft} ., 2$ to $2 \frac{1}{4}$ in..... 175

14 to $18 \mathrm{ft} ., 2$ to $2 \frac{1}{4}$ in...... 200

14 to $18 \mathrm{ft} ., 2 \frac{1}{4}$ to $2 \frac{1}{2}$ in.... 225

14 to $18 \mathrm{ft} ., 2 \frac{1}{2}$ to $23 / 4$ in.... 300

18 to $20 \mathrm{ft} ., 23 / 4$ to 3 in...... 500

The trees listed below are grown 10 to $15 \mathrm{ft}$. apart. They have perfect wide spreading tops. Splendid fibrous root system, $8 \mathrm{ft}$. in diameter and over. (See root picture on page 27 of Cata-
Maple, Norway, continued

logue.) Such trees are sure to succeed, and are an economy in saving time and money.

18 to $20 \mathrm{ft} ., 3$ to $3 \frac{1}{4}$ in......... $\$ 900$

20 to $24 \mathrm{ft} ., 3$ to $3 \frac{1 / 4}{4}$ in........... 1000

18 to $20 \mathrm{ft}$., $3 \frac{1}{4}$ to $3 \frac{1}{2} \mathrm{in} . . . .$.

20 to $24 \mathrm{ft}$., $31 / 4$ to $3 \frac{1}{2}$ in.......

18 to $20 \mathrm{ft}$., $3 \frac{1 / 2}{2}$ to $3 \frac{3}{4} \mathrm{in.......}$

20 to $24 \mathrm{ft} ., 3 \frac{1}{2}$ to $3 \frac{3}{4} \mathrm{in} . . . .$. .

18 to $20 \mathrm{ft} ., 3 \frac{3}{4}$ to $4 \mathrm{in} . . . . . . .$.

20 to $24 \mathrm{ft} ., 3 \frac{3}{4}$ to $4 \mathrm{in} . . . . . .$.

18 to $20 \mathrm{ft} ., 4$ to $41 / 4$ in.........

20 to $24 \mathrm{ft} ., 4$ to $4 \frac{1}{4}$ in...........

20 to $24 \mathrm{ft} ., 4 \frac{1}{4}$ to $4 \frac{1}{2}$ in........

20 to $24 \mathrm{ft} . \mathrm{s} 4 \frac{1}{2}$ to $4 \frac{3}{4}$ in......

20 to $24 \mathrm{ft} ., 43 / 4$ to 5 in.........

Larger trees up to $19 \mathrm{in}$. diam.

$40 \mathrm{ft}$. high and $33 \mathrm{ft}$. spread of

branches and roots.

Page

platanoides, var. globosum.

Each

10

$6 \mathrm{ft}$. , grafted................. \$1 00

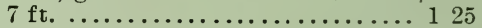

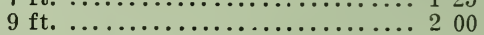

21 Schwedler's Purple Norway ( $A$. pla-

tanoides, var. Schwedleri).

6 to $8 \mathrm{ft}$.................. \$1 50

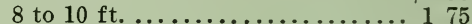

10 to $12 \mathrm{ft}, 1_{1 / 4}$ in.............. 250

$1 \frac{1}{2}$ to $2 \frac{1}{2}$ in. Price on application.

21 Reitenbach's Purple Norway ( $A$. platanoides, var. Reitenbachi).

$4 \mathrm{ft}$. , grafted............... 75

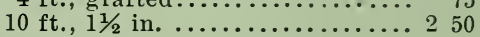

21 Sugar, Rock, or Hard (A. saccharum;

syn., $A$. sacchurinum).

14 to $16 \mathrm{ft} ., 1 \frac{1}{2}$ in. $\ldots \ldots \ldots \ldots$. 50

16 to $18 \mathrm{ft} ., 1 \frac{3}{4}$ to $2 \mathrm{in} . \ldots \ldots \ldots \ldots 250$

16 to $18 \mathrm{ft} ., 2$ to $21 / 4$ in.......... 350

18 to $20 \mathrm{ft} ., 21 / 4$ to $2 \frac{1}{2} \mathrm{in} \ldots \ldots \ldots .6600$

20 to $24 \mathrm{ft}, 2^{1 / 4}$ to $2 \frac{1}{2}$ in............ 800

20 to $24 \mathrm{ft} ., 2 \frac{1}{2}$ to $2 \frac{3}{4}$ in.......... 1200

20 to $24 \mathrm{ft} ., 23 / 4$ to $3 \mathrm{in}$. .........

20 to $24 \mathrm{ft} ., 3$ to $3 \frac{1}{2}$ in. ..........

20 to $24 \mathrm{ft}$., $3 \frac{1}{2}$ to $4 \mathrm{in}$............

20 to $24 \mathrm{ft} ., 4$ to $4 \frac{1}{2}$ in.

22 to $26 \mathrm{ft} ., 41 / 2$ to $5 \mathrm{in} . \ldots \ldots \ldots$

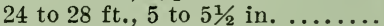

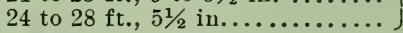

Price on selection.

Larger specimens up to $15 \mathrm{in}$ diam., $40 \mathrm{ft}$. high and $35 \mathrm{ft}$. spread of branches and roots.

22 Sycamore (A. Pseudo-platanus). Each 10 6 to $8 \mathrm{ft} \ldots \ldots \ldots \ldots \ldots \ldots \ldots \ldots \ldots \ldots 0 \quad \frac{15}{85} \quad \$ 00$

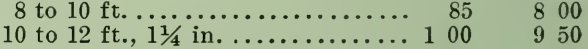

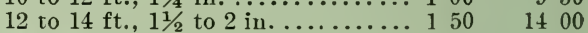
14 to $16 \mathrm{ft}, 2^{2}$ to $2 \frac{1}{2}$ in........... 250 14 to $16 \mathrm{ft}$, $2 \frac{1}{2}$ to 3 in............. 400 16 to $18 \mathrm{ft}$., 3 to $31 / 2$ in................. 600

18 to $22 \mathrm{ft} ., 3 \frac{1}{2}$ to 4 in........... 1000

22 to $26 \mathrm{ft} ., 4$ to $4 \frac{1}{2}$ in. ........

22 to $26 \mathrm{ft} ., 4 \frac{1}{2}$ to $.5 \mathrm{in}$.

22 to $26 \mathrm{ft}$., 5 to $6 \mathrm{in}$. .

Price on se22 to $26 \mathrm{ft}$., 6 to $7 \mathrm{in}$.

Silver Maple (A. dasycarpum).

Each $1 \frac{1}{2}$ to $2 \mathrm{ft}$

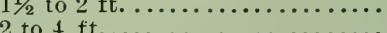

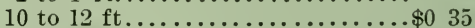

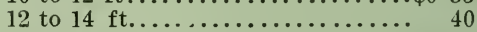

14 to $18 \mathrm{ft}$., $11 / 2$ to $2 \mathrm{in.............} 50$

14 to $18 \mathrm{ft} ., 2$ to $21 / 4$ in........... 65

14 to $18 \mathrm{ft} ., 21 / 4$ to $21 / 2$ in........... 85

20 to $24 \mathrm{ft} ., 21 / 2$ to 3 in............ 200

20 to $24 \mathrm{ft} ., 3$ to $3 \frac{1}{2}$ in........... 300

20 to $24 \mathrm{ft} ., 3 \frac{1}{2}$ to 4 in........... 400

20 to $24 \mathrm{ft} ., 4$ to $t^{1 / 2} \mathrm{in..............6} 600$

24 to $28 \mathrm{ft}, 41 \frac{1}{2}$ to $5 \mathrm{in...........} 1000$

28 to $34 \mathrm{ft.}, 4 \frac{1}{2}$ to 5 in........... 1500

24 to $28 \mathrm{ft} ., 5$ to $5 \frac{1}{2}$ in..............20 00
$\$ 300$

350

450

600

800

1750

2750

3750

5500

9000

14000

17000 


\section{DECIDUOUS TREES, continued}

Yage Silver Maple, continued

28 to $32 \mathrm{ft} ., 5$ to $51 / 2 \mathrm{in} . . . \ldots \ldots \ldots . \$ 2200 \$ \$ 18000$

28 to $34 \mathrm{ft} ., 51 / 2$ to 6 in................... $2500 \quad 20000$

28 to $34 \mathrm{ft} ., 6$ to $6 \frac{1}{2}$ in.......... 3500

The above trees, over 4 inches in diameter, are growing 10 to 25 feet apart for perfect derelopment. They furnish the greatest amount of foliage mass for the least money. They are trained to single leaders; the side branches are cut back to give a symmetrical, compact form.

25 to $35 \mathrm{ft}$, 6 to 7 in.........

25 to $35 \mathrm{ft} ., 7$ to 8 in ..........

30 to $40 \mathrm{ft} ., 8$ to $9 \mathrm{in} . \ldots \ldots \ldots \ldots$. Prices on selec-

36 to $38 \mathrm{ft} ., 9$ to $10 \mathrm{in} . . \ldots \ldots . .6$. tion.

35 to $40 \mathrm{ft}$., 10 to 12 in........

$46 \mathrm{ft} ., 14$ in....................

22 Wier's Weeping (A. saccharinum, rar. Each Wieri). 18 to $20 \mathrm{ft} ., 2$ to $2 \frac{1}{2}$ in...\$2 00

Specimens up to $26 \mathrm{ft}$. Price on application.

22 Scarlet, or Red (A. rubrum).

$1-y$ r. seedlings.... per $100, \$ 2.50$.

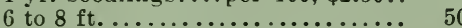

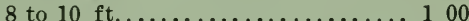

10 to $14 \mathrm{ft}, 1 \frac{1 / 4}{4}$ in............... 125

12 to $14 \mathrm{ft}, 2$ to $21 / 2$ in................ 200

Large specimens up to 13 in. in diam., 40 by $20 \mathrm{ft}$. Price on selection.

Japanese. See under Shrubs.

22 MULBERRY, New American (Morus).

$6 \mathrm{ft} \ldots \ldots \ldots \ldots \ldots \ldots \ldots \ldots \ldots \ldots . \ldots \ldots$

22 Downing's Everbearing. 5 to $6 \mathrm{ft} . \ldots . \quad 75$

23 Russian (M. alba, var. Tatarica).

6 to $8 \mathrm{ft} . \ldots \ldots \ldots \ldots \ldots \ldots \ldots \ldots \ldots \ldots \ldots$

Specimens 10 to $12 \mathrm{ft}$., by 10 to $12 \mathrm{ft}$. wide................... 500

Weeping, Teas' ( $M$. alba, rar. $T a$ tarica pendula)

4 to $5 \mathrm{ft}$., $2-y r$. heads, $21 / 2 \mathrm{ft}$. wide. 100

5 to $6 \mathrm{ft}$., 2 -yr. heads........... 150

The three sizes following are grafted at the ground. A new and good landscape material. Low broad luxuriant foliage masses for shrubbery and banks. Grows 7 feet in a year.

4 to $6 \mathrm{ft}$.

6 to $8 \mathrm{ft}$. $\ldots . . . . . . . .$.

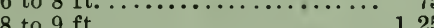

10 to $15 \mathrm{ft}$. wide. Trained as summer houses, with foliage to the ground. Price on application.

$7 \mathrm{ft}$. high, 5-yr. heads. For pergolas.................... 800

Extra specimens. Price on application.

\section{OAK}

Reasons for planting some of the 100,000 0aks in our Nursery from 6 inches to 40 feet high: Raised from Long Island seed. The same species from further south may be tender. More than 60 per cent of Long Island forests are Oak. For each type of soil, moisture supply and climate exposure there is a change in the Oak forest. They are drought-resisters. They are quick to grow. When some of the quicker-growing poplars and willows are beginning to fail in five or ten years on the drier subsoils, the Oaks keep right on. If you want a border of foliage 10 to 30 feet high it is not necessary to use poplars and willows. We offer Oaks up to 40 feet. If you have poplars and willows, plant Oaks to come on for permanent trees. If you have a stretch of land too poor for lawn, or costing ton much to make a good lawn, plant it with Oaks and pines and let it alone. They take care of themselres. When they crowd, thin them out. Evergreens like company. Our Oaks and pines are the best solution of the windbreak and screen problem on Long Island. We will plant them. See also Pine, page 34.
Page

2t 0AK, Pin (Quercus palustris).

8 to 10 in., $1-y$ r. seed-

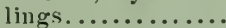

1 to $2 \mathrm{ft} . \ldots \ldots \ldots \ldots$

6 to $8 \mathrm{ft} . \ldots \ldots \ldots \ldots \ldots \ldots 100$

8 to $10 \mathrm{ft} \ldots \ldots \ldots \ldots \ldots 125$

10 to $12 \mathrm{ft} ., 1 \frac{1}{4}$ to $1 \frac{1}{2}$ in. 150

10 to $12 \mathrm{ft} ., 1 \frac{1}{2}$ to $1 \frac{3}{4}$ in. 200

12 to $14 \mathrm{ft} ., 13 / 4$ to $2 \mathrm{in.} .225$

12 to $14 \mathrm{ft} ., 2$ to $2 \frac{1}{2}$ in.. 275

14 to $16 \mathrm{ft}$., $2 \frac{1}{2}$ to $3 \mathrm{in}$..

$\$ 4$ to 600

In our Nursery are 80 Pin Oaks 16 to $20 \mathrm{ft}$., 50 Pin Oaks 20 to $30 \mathrm{ft}, 30$ Pin Orks 30 to $40 \mathrm{ft}$ high. addition, we have prepared for successful moving 50 Pin Oaks 25 to $45 \mathrm{ft}$. high, with diameters up to $22 \mathrm{in}$. and $30 \mathrm{ft}$. spread of tops and roots This is an unparalleled opportunity to select big trees. They are unalleled opp
surpassed.

24 Scarlet $(Q$. coccinea). Each $10 \quad 100 \quad 1,000$

3 to 6 in., $1 \mathrm{yr}$. seed-

lings...............

1 to $2 \mathrm{ft}, 2$-r.

planted ..............

8 to $10 \mathrm{ft} . \ldots \ldots \ldots \ldots \ldots \$ 200$

10 to $12 \mathrm{ft} ., 11 / 1$ to $1 \frac{1}{2}$ in. 250

Specimens up to $18 \mathrm{ft}$.

Price on application.

$24 \operatorname{Red}(Q . r u b r a) .8$ to 12 in., 1-yr. seedlings.

5 to $6 \mathrm{ft} . \ldots \ldots \ldots \ldots \ldots$.

6 to $8 \mathrm{ft} \ldots \ldots \ldots \ldots \ldots \ldots, 100$

8 to $10 \mathrm{ft} . \ldots \ldots \ldots \ldots \ldots 17$

10 to $12 \mathrm{ft} . \ldots \ldots \ldots \ldots \ldots 250$

14 to $16 \mathrm{ft} ., 2 \frac{1}{2}$ in. Price on selection.

Specimens up to $2 t \mathrm{ft}$. Price on application. See photograph on page 24 of Descriptive Catalogue.

25 Willow (Q. Phellos).

6 to $8 \mathrm{ft}$............ 150

8 to $10 \mathrm{ft} . \ldots \ldots \ldots \ldots 200$

Specimens up to $24 \mathrm{ft}$.

Price on application.

25 White $(Q . a l b a) .3$ to 6 in., $1-\mathrm{rr}$. seedlings.....

4 to 6 in., 2 -yr. trans. planted .............

4 to $6 \mathrm{ft} . \ldots \ldots \ldots \ldots$

Specimens ip to $23 \mathrm{ft}$. Price on application.

25 Swamp White (Q. bicolor).

6 to $10 \mathrm{in}$. seedlings.

10 to $12 \mathrm{ft} . . . \ldots \ldots . .200$

12 to $14 \mathrm{ft}, 2$ to $2 \frac{1}{2}$ in. 400

25 Mossy Cup, or Bur ( $R$. macrocarpa).

6 to 10 in., 1-yr. seedlings................

4 to $6 \mathrm{ft} \ldots \ldots \ldots \ldots \ldots \ldots 100$

6 to $8 \mathrm{ft} \ldots \ldots \ldots \ldots \ldots \ldots .150$

8 to $10 \mathrm{ft} . \ldots \ldots \ldots \ldots 225$

Specimens up to $24 \mathrm{ft}$. high, $6 \frac{1}{2}$ in. diam. Price on selection.

25 English, or Royal ( $Q$. pedunculata ; syu., Q. Robur).

1 to $1 \frac{1}{2} \mathrm{ft}$., $1-y r$. seed.

1 to $1 \frac{1}{2} \mathrm{ft}$., $2-5 \mathrm{r}$.,

transplanted .........

4 to $6 \mathrm{ft} . . . \ldots \ldots \ldots$.

6 to $8 \mathrm{ft} . \ldots \ldots \ldots \ldots \ldots \ldots$

8 to $10 \mathrm{ft} . \ldots \ldots \ldots \ldots \ldots . . \cdots \cdots$

10 to $12 \mathrm{ft} ., 1 \frac{1}{2}$ to 2 in. 150

12 to $14 \mathrm{ft} ., 1 \frac{1}{8}$ to $2 \frac{1}{2}$ in. 2001800

Specimens up to $22 \mathrm{ft}$., 5 in. diaz.
$\$ 050 \quad \$ 250 \$ 2000$

$150 \quad 1000$

$50 \quad 250 \quad 2000$

$\begin{array}{lllll}50 & 250 & 20 & 00\end{array}$

$\begin{array}{llllll}1 & 50 & 10 & 00 & 80 & 00\end{array}$ 5

$\begin{array}{lllll}50 & 2 & 50 & 20 & 00\end{array}$

$50 \quad 250$

$\begin{array}{lllll}50 & 2 & 50 & 20 & 00\end{array}$

$\begin{array}{llllll}150 & 10 & 00 & 80 & 00\end{array}$

$\begin{array}{llll}3 & 50 & 25 & 00\end{array}$

$900 \quad 8500$ 
Page
25 Oak, Pyramidal English $(Q$. pedunculata, var. fastigiata). 4 to $5 \mathrm{ft} . \$ 100$

5 to $6 \mathrm{ft} . \ldots \ldots \ldots \ldots . . . .175$

Black Jack ( $Q$. Mary landica). 3 to 6 in., $1-\mathrm{yr}$. seedlings.....

Chestnut 0 ak (Q. Prinos).

1 to $1 \frac{1}{2}$ ft., $2-\mathrm{yr}$.,

transplanted ........

5 to $6 \mathrm{ft} . \ldots \ldots \ldots \ldots \cdots \cdots, 75$

6 to $8 \mathrm{ft} \ldots \ldots \ldots \ldots \ldots 100$

8 to $10 \mathrm{ft} . \ldots \ldots \ldots \ldots 150$

10 to $12 \mathrm{ft} . \ldots \ldots \ldots \ldots 250$

Black (Q. velutina).

3 to 6 in., seedlings...

10 to 12 in., 2 -yr.,trans.

2 to $3 \mathrm{ft} . . . \ldots \ldots \ldots$

3 to $4 \mathrm{ft} . \ldots \ldots \ldots \ldots$.

Post (Q. stellata; syn., obtusiloba).

3 to $\dot{b}$ in., 1-yr. seed-

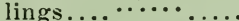

4 to 8 in., 2 -yr., trans.

Turkey (Q. Cerris).

8 to 10 in., 1 yr. seed-

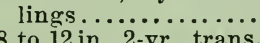

8 to 12 in., 2 -yr., trans. 100

Scrub $(Q$. ilicifolia). 4 to $6 \mathrm{ft} . \ldots \ldots \ldots \ldots . .6 \%$

25 PAULOWNIA imperialis (Em- Each press Tree). 4 to $6 \mathrm{ft} . . . \$ 100$

specimens up to 11 in. diam.,

28 by $27 \mathrm{ft}$. Price on selection.

25 PEACH, Double - flowering (Prunus Persica, var. camellceflora plena). 4 to j ft......... 75

7 to $8 \mathrm{ft} . \ldots \ldots \ldots \ldots \ldots \ldots \ldots .100$

25 PEPPERIDGE (Nyssa sylvatica; Sour Gum).

4 to $6 \mathrm{ft} . \ldots \ldots \ldots \ldots \ldots \ldots \ldots 100$

25 PHELlOdENDRON A mu re n s e (Chinese Cork Tree).

6 to $8 \mathrm{ft} . \ldots \ldots \ldots \ldots \ldots \ldots, 60$

8 to $10 \mathrm{ft} . \ldots \ldots \ldots \ldots \ldots \ldots \ldots, \quad 75$

10 to $12 \mathrm{ft} . \ldots \ldots \ldots \ldots \ldots \ldots \ldots \ldots \ldots$

12 to $14 \mathrm{ft} ., 2$ in........... 150

Specimens. Price on application.

25 PLANE TREE (Platanus orientalis). 8 to $10 \mathrm{ft} . \ldots \ldots \ldots .100 \quad \$ 900$

10 to $12 \mathrm{ft} ., 11 / 2$ in,$\ldots \ldots \ldots . . .125 \quad 1000$

10 to $12 \mathrm{ft} ., 2$ to $2 \frac{1}{2}$ in........ $250 \quad 2250$

14 to $18 \mathrm{ft} ., 3$ to 4 in....... $500 \quad 4750$

18 to $24 \mathrm{ft}$., 4 to 5 in... $\$ 10$ to 2000 on selection.

25 POPLAR, Carolina (Populus deltoides, var. Caroliniensis).

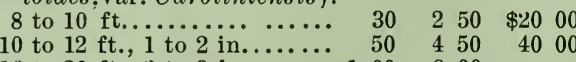
16 to $20 \mathrm{ft} ., 2$ to 3 in.......... $100 \quad 800$

Specimens up to 11 in. Price on application.

25 Lombardy (P. nigra, var. Italica; syn, P. fastigiata;

Japanese (P. suaveolens). 8 to $10 \mathrm{ft} . \ldots \ldots \ldots \ldots \ldots \ldots .6 \%$ syn.. dilatata). 6 to $8 \mathrm{ft}$. 8 to $10 \mathrm{ft} . \ldots \ldots \ldots \ldots \ldots$ 10 to $12 \mathrm{ft} ., 1$ to $11 / 2$ in....... 12 to $14 \mathrm{ft} ., 11 / 2$ to 2 in......

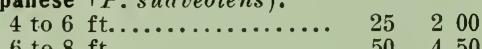
6 to $8 \mathrm{ft} . \ldots \ldots \ldots \ldots \ldots \ldots . .50 \quad 450$

10 to $12 \mathrm{ft} ., 1 \frac{1}{4} \mathrm{in} . . . \ldots \ldots \ldots . . .125$

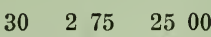

\section{TREES, continued}

\section{Page}

Poplar, Japanese, continued

12 to $14 \mathrm{ft} ., 1 \frac{1}{2}$ to 2 in...... $\$ 140 \$ 13 \quad 00 \$ 12500$

10 to $14 \mathrm{ft} . .2$ to $2 \frac{1}{2}$ in...... 200

Specimens 7 to 14 in. diameter. 35 to $45 \mathrm{ft}$. high.

Price on selection.

Balsam ( $P$. balsamifera).

8 to $10 \mathrm{ft} . \ldots \ldots \ldots \ldots \ldots \ldots .50$

16 to $18 \mathrm{ft} ., 2$ to 3 in......... 125

26 S O P H ORA Japonica (Japan Pagoda Tree). 3 to $4 \mathrm{ft} . . .125$

26 STYRAX Japonica. See Shrubs.

26 SILVER BELL, or SNOWDROP TREE (Halesia tetraptera; syn., Mohrodendron tetraptera)

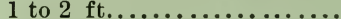

2 to $3 \mathrm{ft} . . . \ldots \ldots \ldots \ldots \ldots . .$.

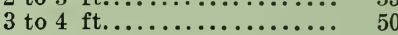

26 T H O R N, Paul's Double Scarlet (Hawthorn: Cratcegus monogyna, var. Pauli).

4 to $5 \mathrm{ft} . . . \ldots \ldots \ldots \ldots . . . .$.

26 Cockspur (C. Crus-galli). As a substitute for the English Hawthorn hedge this is the best. 2 to $3 \mathrm{ft} . . \ldots \ldots \ldots$.

3 to $4 \mathrm{ft} . \ldots \ldots \ldots \ldots \ldots \ldots$.

4 to $5 \mathrm{ft} . \ldots \ldots \ldots \ldots \ldots \ldots$

TULIP (Liriodendron Tulipifera).

6 to $8 \mathrm{ft} . \ldots \ldots \ldots \ldots \ldots \ldots \ldots$

8 to $10 \mathrm{ft} . \ldots \ldots \ldots \ldots \ldots \ldots \ldots$

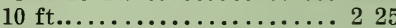

Specimens up to $24 \mathrm{ft}$. Price on application.

26 Pyramidal. 2 to $4 \mathrm{ft} . \ldots \ldots \ldots 100$

26 Y E L L 0 W.W 00 D (Cladrastis tinctoria). 4 to $5 \mathrm{ft} . . .$. .

5 to $6 \mathrm{ft} . \ldots \ldots \ldots \ldots \ldots \ldots . .6 \%$

16 WILLOW, Babylonian Weeping (Salix Bubylonica).

$21 / 2$ to $3 \mathrm{ft} . \ldots \ldots \ldots \ldots \ldots \ldots . .20 \quad 175$

26 Salamon's (S. Babylonica, var. Salamonii). 6 to $8 \mathrm{ft} . . .50$

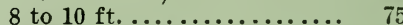

27 Golden ( $S$. vitellina, var. aurea). 6 to $8 \mathrm{ft} . \ldots \ldots \ldots .50$ 8 to $10 \mathrm{ft} . \ldots \ldots \ldots \ldots \ldots \ldots \ldots .75$ 12 to $14 \mathrm{ft} . \ldots \ldots \ldots \ldots \ldots \ldots \ldots \ldots \ldots \ldots, 125$ 14 to $16 \mathrm{ft} . \ldots \ldots \ldots \ldots \ldots \ldots 150$

27 Royal (S. regalis). 2 to $4 \mathrm{ft}$.. 15

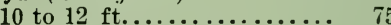

27 Laurel-leaf ( $S$. pentandra).

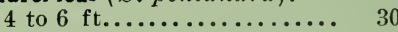
6 to $8 \mathrm{ft} . \ldots \ldots \ldots \ldots \ldots \ldots .60$ $12 \mathrm{ft} . \ldots \ldots \ldots \ldots \ldots \ldots \ldots \ldots . . .6150$

27 WALNUT, Black(Juglans nigra). 1 -yr. seedlings ............ 15 2 to 4 ft................... 30 6 to $8 \mathrm{ft} . \ldots \ldots \ldots \ldots \ldots \ldots .6 .75$ 12 to $14 \mathrm{ft} ., 2$ to $2 \frac{1}{2}$ in........ 200 14 to $16 \mathrm{ft} ., 21 / 2$ to $31 / 2$ in.... 300 18 to $20 \mathrm{ft}$., $4 \frac{1}{2}$ in......... 800

27 Butternut $(J$. cinerea).

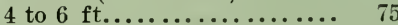
6 to $8 \mathrm{ft} . \ldots \ldots \ldots \ldots \ldots \ldots \ldots \ldots \ldots \ldots \ldots, 100$ 12 to $14 \mathrm{ft} ., 2$ to 3 in......... 200

27 English (J. regia). 3 to $4 \mathrm{ft} . .100$ 4 to $6 \mathrm{ft}$................. 125

27 Japanese (J. cordiformis).

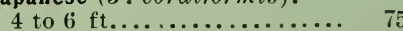
6 to $8 \mathrm{ft} . \ldots \ldots \ldots \ldots \ldots \ldots, 125$

10 to $12 \mathrm{ft} . . . \ldots \ldots \ldots \ldots \ldots 200$

\section{$\begin{array}{llll}3 & 00 & 20 & 00\end{array}$ \\ $\begin{array}{llll}4 & 00 & 30 & 00\end{array}$ \\ 500}

900 1

400

$120 \quad 1000$

$\begin{array}{llll}50 & 20 & 00\end{array}$

$550 \quad 5000$ 


\section{EVERGREEN TREES}

Page ${ }^{\text {ARB } 0 \text { RVITAE, American ('I huya }}$ Each occidentalis).

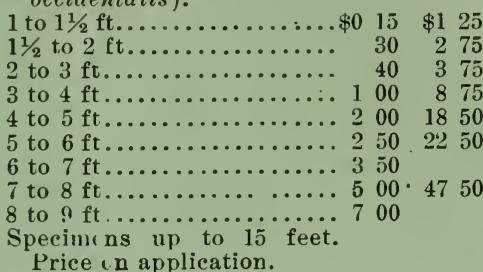

30 Siberian ( $T$. occidentalis, var. Wareana; syn., 'T. Sibir. ica).

$11 / 2$ to 2 ft.............. $75 \quad 600$ 2 to $21 / 2 \mathrm{ft} . \ldots \ldots \ldots \ldots \ldots \ldots . . .100 \quad 1000$ $21 / 2$ to $3 \mathrm{ft} \ldots \ldots \ldots \ldots \ldots \ldots \ldots \ldots \ldots$ 3 to $3 \frac{1}{2} \mathrm{ft} \ldots \ldots \ldots \ldots \ldots \ldots \ldots \ldots \ldots+250 \quad 2250$ $31 / 2$ to 4 ft.................. $300 \quad 2750$ 4 to $5 \mathrm{ft} . \ldots \ldots \ldots \ldots \ldots \ldots \ldots .500 \quad 4500$

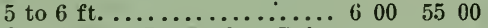
Specimens, 7 to $10 \mathrm{ft}$. Price on application.

30 Arborvitae, Pyramidal ( $T$. occidentalis, var. pyramidalis).

4 to $5 \mathrm{ft} . \ldots \ldots \ldots \ldots \ldots \ldots \ldots 200 \quad 1800$

5 to $6 \mathrm{ft} . \ldots \ldots \ldots \ldots \ldots \ldots . .350 \quad 3250$

$61 / 2$ to $7 \mathrm{ft} . \ldots \ldots \ldots \ldots \ldots \ldots \ldots \ldots+700$

Specimens, 7 to $14 \mathrm{ft}$. Price on application.

30 Booth's (' $T$. occidentalis, var. Boothii).

6 in.....................

1 to $1 \frac{1}{2} \mathrm{ft} . \ldots \ldots \ldots \ldots \ldots \ldots \ldots$

Large domes, 5 to $9 \mathrm{ft}$. high, trained by machine to uniform shape, 10 to 15 years old. Price on selection.

30 Golden, or George Peabody ( $T$. (occidentalis, var. lutea).

1 to $11 / 2 \mathrm{ft} . \ldots \ldots \ldots \ldots \ldots \ldots 100 \quad 900$

2 to $21 / 2 \mathrm{ft} . \ldots \ldots \ldots \ldots \ldots \ldots \ldots 125 \quad 1200$

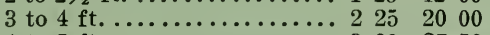

4 to $5 \mathrm{ft} . \ldots \ldots \ldots \ldots \ldots \ldots 300 \quad 2750$

Specimens, 5 to $8 \mathrm{ft}$. Price on application.

30 Arborvitae, Chinese ( $T$. orientalis; syn., Biota orientalis).

3 to $4 \mathrm{ft} . \ldots \ldots \ldots \ldots \ldots \ldots . \ldots 150$

Specimens up to $8 \mathrm{ft}$. Price on application.

Globe ( $T$. occidentalis, var. globosa; syn., occidentalis compacta globosa).

1 to $1 \frac{1}{2} \mathrm{ft} . \ldots \ldots \ldots \ldots \ldots \ldots .50 \quad 50 \quad 450$

$11 / 2$ to 2 ft.................. $100 \quad 850$

2 to $2 \frac{1}{2} \mathrm{ft} . \ldots \ldots \ldots \ldots \ldots \ldots 200 \quad 1850$

$2 \frac{1}{2}$ to $3 \mathrm{ft} . \ldots \ldots \ldots \ldots \ldots \ldots 250 \quad 2250$

These are trained by ma.

chine to uniform shape for

formal gardens.

30 CEDAR, Red (Juniperus Virginiana).

1 to $1 \frac{1}{2} \mathrm{ft} . \ldots \ldots \ldots \ldots \ldots \ldots$

$11 / 2$ to 2 ft. ...................

2 to $21 / 2 \mathrm{ft} . \ldots \ldots \ldots \ldots \ldots .$.

$21 / 2$ to $3 \mathrm{ft} . \ldots \ldots \ldots \ldots \ldots .$.

3 to $4 \mathrm{ft}$.

4 to $5 \mathrm{ft} . \ldots . . .6$.

5 to $6 \mathrm{ft} . \ldots \ldots \ldots \ldots \ldots$. Price on application.

6 to $7 \mathrm{ft}$.

(n)

8 to $10 \mathrm{ft} \ldots \ldots \ldots \ldots \ldots \ldots$

Shearer specimens of above sizes for formal gardens.

10 to $12 \mathrm{ft}$.

12 to $14 \mathrm{ft} . \ldots \ldots \ldots \ldots \ldots \ldots \ldots$

$1+$ to $16 \mathrm{ft}$.......................
100

$\$ 1200$

2500

3500

8500

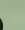

\section{Page Cedar, Red, continued}

16 to $18 \mathrm{ft}$............... Price on application.

18 to $20 \mathrm{ft}$

In addition we have growing in quantity in the nursery, specimens 20 to $35 \mathrm{ft}$. Sheared symmetrical specimens priced on selection.

For extensive plantings of hedges, sereen groups, windbreaks, etc., write for prices on cedars delivered and planted direct from the collecting fields.

Cedrus Atlantica glauca. $\quad$ Each ${ }^{10}$
3 to 4 ft................. $\$ 250 \$ 2000$ 3 to $4 \mathrm{ft} . \ldots \ldots \ldots \ldots \ldots \ldots \ldots 250 \$ 2000$

100

31 CEPHALOTAXUS Fortunei.
3 to $3 \frac{1}{2} \mathrm{ft} . \ldots \ldots \ldots \ldots \ldots \ldots \ldots, \ldots \ldots$

4 to $4 \frac{1}{2} \mathrm{ft} . \ldots \ldots \ldots \ldots \ldots \ldots . . . \ldots 350$

pedunculata, var. fastigiata; syn., Podocarpus Koreana. A black - green columnar evergreen. A suitable substitute for Irish Yew.

1 to $1 \frac{1}{2} \mathrm{ft} . \ldots \ldots \ldots \ldots \ldots \ldots .100$

2 to $21 / 2 \mathrm{ft} \ldots \ldots \ldots \ldots \ldots \ldots \ldots . . .175$

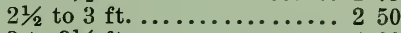

3 to $3 \frac{1}{2} \mathrm{ft} . \ldots \ldots \ldots \ldots \ldots \ldots \ldots, 400$

31 FIR, Nordmann's (Abies Nordmanniana $). \quad 6$ in....... 20

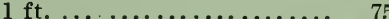

$11 / 2$ to $2 \mathrm{ft} . \ldots \ldots \ldots \ldots \ldots \ldots \ldots, 125$

2 to $2 \frac{1}{2} \mathrm{ft} . \ldots \ldots \ldots \ldots \ldots \ldots \ldots \ldots, 200$

$21 / 2$ to $3 \mathrm{ft} . \ldots \ldots \ldots \ldots \ldots \ldots \ldots, 250$

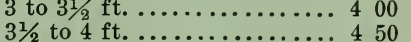

4 to $4 \frac{1}{2} \mathrm{ft} . \ldots \ldots \ldots \ldots \ldots \ldots \ldots, 6,600$

$41 / 2$ to $5 \mathrm{ft} . \ldots \ldots \ldots \ldots \ldots \ldots . .600$

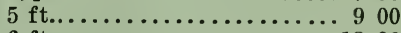

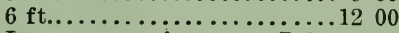

Larger specimens. Price on application.

32 Silver (A.Picé; syn., A.pec-

tinata). 3 to $3 \frac{1}{2} \mathrm{ft} . \ldots \ldots \ldots 150$

$11 \mathrm{ft} . . \ldots \ldots \ldots \ldots \ldots \ldots . . .1500$

32 Cephalonian (A. Cephalonica).

$11 / 2$ to $2 \mathrm{ft} . \ldots \ldots \ldots \ldots \ldots \ldots, 100$

2 to $21 / 2 \mathrm{ft} . \ldots \ldots \ldots \ldots \ldots \ldots .200$

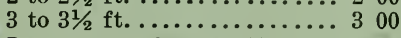

Larger specimens, 10 to 20 years old. Price on selection.

Balsam ( $A$. balsamea).

1 to $2 \mathrm{ft} . \ldots \ldots \ldots \ldots \ldots \ldots . \quad 20$

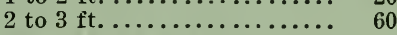

32 Fraser's Balsam (A. Fraser $i)$.

1 to $2 \mathrm{ft} . \ldots \ldots \ldots \ldots \ldots \ldots \ldots \ldots .60$

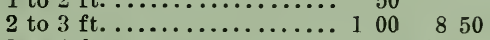

3 to $4 \mathrm{ft} . \ldots \ldots \ldots \ldots \ldots \ldots . \ldots 150 \quad 1000$

32 Concolor, or White $(A$. concolor). 1 to $1 \frac{1 / 2}{2} \mathrm{ft} . \ldots \ldots \ldots 100 \quad 900$ $11 / 2$ to $2 \mathrm{ft} . \ldots \ldots \ldots \ldots \ldots \ldots \ldots \ldots$

2 to $2 \frac{1}{2} \mathrm{ft} . \ldots \ldots \ldots \ldots \ldots \ldots \ldots .250 \quad 2000$

$2 \frac{1}{2}$ to 3 ft.................. 300

Lasiocarpa (A. lasiocarpa).

$11 / 2$ to $2 \mathrm{ft} . \ldots \ldots \ldots \ldots \ldots \ldots 200$

Nobilis glauca $(A$. nobilis glauca). 1 to $2 \mathrm{ft} . . . \ldots .200$

A. Veitchii. 1 to $11 / 2 \mathrm{ft} \ldots \ldots \ldots 150$

2 to $2 \frac{1}{2} \mathrm{ft} . \ldots \ldots \ldots \ldots \ldots \ldots+400$

32 HEMLOCK, American ('Tsuga Canadensis). $1 \frac{1}{2}$ to $2 \mathrm{ft} . \quad 40 \quad 350 \quad 3000$ 2 to $21 / 2$ ft................ $50 \quad 4 \quad 75 \quad 4500$

3 to 4 ft.................... $125 \quad 1200 \quad 11500$

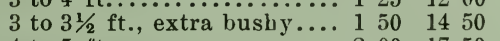

4 to $5 \mathrm{ft} . \ldots \ldots \ldots \ldots \ldots \ldots . .200 \quad 1750 \quad 16000$

$4 \mathrm{ft} .$, extra bushy .......... 225

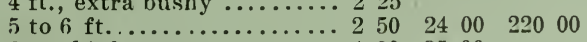

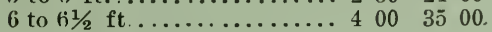

Specimens up to $14 \mathrm{ft}$. Price on selection.

All our Hemlocks above $2 \mathrm{ft}$. liave been repeatedly cut to make a denser growth. 
EVERGREEN TREES, continued

Page

33 Hemlock, Carolina ( $T$ 'suga Caroliniana). 1 to $1 \frac{1}{2} \mathrm{ft} . \ldots \$ 035$

2 to $3 \mathrm{ft} . \ldots \ldots \ldots \ldots \ldots \ldots . \ldots \ldots$

3 to 4 f.t................ 100

-JUNIPER (Juniperus).

33 Irish (J. communis, var. $H i$ bernica).

2 to $3 \mathrm{ft} \ldots \ldots \ldots \ldots \ldots \ldots \ldots$. 75

3 to $3 \frac{1}{2}$ ft.................... 100

33 Flat (J. communis, var. Canadensis).

1 to $1 \frac{1}{2} \mathrm{ft}$. wide........... $75 \quad \$ 700$

$11 / 2$ to $2 \mathrm{ft}$. wide........... 1. 251100

2 to $3 \mathrm{ft}$. wide............. 200

33 Golden ( $J$. communis, var.

Canadensis aurea).

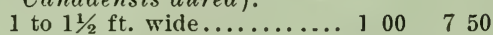

$11 / 2$ to $2 \mathrm{ft}$. wide........... $125 \quad 1000$

2 to $2 \frac{1}{2} \mathrm{ft}$. wide............. 2252000

33 Chinensis, var. procumbens.

1 to $1 \frac{1}{2} \mathrm{ft}$. wide............ $125 \quad 1000$

$1 \frac{1}{2}$ to $2 \mathrm{ft}$. wide........... 1501250

2 to $2 \frac{1}{2} \mathrm{ft}$. wide........... 175

33 Prostrate, or Trailing ( $J$. $S a$ -

bina, var. prostrata).

$1 \frac{1}{2}$ to $2 \mathrm{ft}$. wide ........... 100

Virginiana. See Cedar.

$\begin{array}{lllll}\text { Each } & 10 & 100 & 1,000\end{array}$ Strobus). 2 in., 1 -yr. seedlings .....

3 to 5 in., 2 -yr. seedlings............... 2 yr. transplanted.

8 to 12 in.............

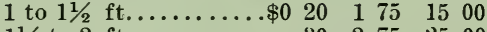

$11 / 2$ to $2 \mathrm{ft} . \ldots \ldots \ldots \ldots . .30 \quad 30 \quad 2 \quad 75 \quad 2500$

2 to $3 \mathrm{ft. \ldots \ldots \ldots \ldots \ldots ..} \quad 40 \quad 3 \quad 75 \quad 3500$

3 to $4 \mathrm{ft} . \ldots \ldots \ldots \ldots \ldots, \quad 75 \quad 6 \quad 50$

4 to 5 ft............ 100

5 to $6 \mathrm{ft} . \ldots \ldots \ldots \ldots \ldots, 300$

6 to $7 \mathrm{ft} . \ldots \ldots \ldots \ldots \ldots 600$

7 to $8 \mathrm{ft} . \ldots \ldots \ldots \ldots \ldots$

8 to $10 \mathrm{ft} . . . . . . . . .$.

10 to $12 \mathrm{ft} . \ldots \ldots \ldots \ldots . . .6$ Price on application.

12 to $14 \mathrm{ft}$.

14 to $16 \mathrm{ft} . \ldots \ldots \ldots . . .$.

Specimens up to $40 \mathrm{ft}$. Price on selection.

Au unequaled opportunity to get large evergreens.

37 Pitch $(P$. rigida $) \quad \begin{array}{llll}\text { Each } & 10 & 100 & 1,000\end{array}$ 14 in., 2 -yr.seedlings.

6 to 14 in., 2 -yr. trans. planted ..............

1 to $11 / 2 \mathrm{ft} . \ldots \ldots \ldots \ldots \ldots \ldots+\ldots$

$11 / 2$ to 2 ft..............

37 Scotch (Pinus sylvestris). 6 to 14 in., 2 -yr. seedlings............

6 to 14 in., 2 -yr. transplanted ..............

1 to $1 \frac{1}{2}$ ft..............

$11 / 2$ to 2 ft............ $40 \quad 300$

2 to $2 \frac{1}{2}$ ft.............. 100900

37 Austrian ( $P$ Laricio, var. Austriaca). 2 to 4 in., $1-y r$. seedlings......

4 to 8 in., 2-yr. transplanted .............

6 to 12 in.............

1 to $1 \frac{1}{2} \mathrm{ft} . \ldots \ldots \ldots \ldots$.......

$11 / 2$ to 2 ft................

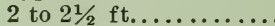

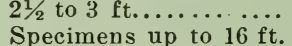

Price on selection.

$50 \quad 450$

$\begin{array}{lllll}75 & 6 & 00 & 50 & 00\end{array}$

$\begin{array}{lllll}00 & 9 & 00 & 85 & 00\end{array}$ $\begin{array}{llll}10 & 90 & 8 & 00\end{array}$ $\begin{array}{lllll}\text { Page Each } & 10 & 100 & 1,000\end{array}$

37 Pine, densiflora. 4 to 6 in. seedlings........... $\$ 100 \$ 800$ 1 to $1 \frac{1}{2}$ ft........... $\$ 020 \quad 180 \quad 1500$

37 Korean (P. Koraiensis).

3 in., 2 -yr............ $30 \quad 2 \quad 75 \quad 2500$

$11 / 2$ to $2 \mathrm{ft} . \ldots \ldots \ldots \ldots 150$

2 to $3 \mathrm{ft} \ldots \ldots \ldots \ldots \ldots .250$

$3 \mathrm{ft} . \ldots \ldots \ldots \ldots \ldots \ldots, 600$

38 Mugho ( $P$. montana, var.

Mughus). 1 to $1 \frac{1}{2} \mathrm{ft} .150125010000$ 2 to $2 \frac{1}{2}$ ft............ 250

38 Red, or Norway ( $P$. resinosa). $1 \frac{1 / 2}{2}$ to $2 \mathrm{ft} \ldots \quad 50 \quad 450 \quad 4000$ 2 to $2 \frac{1}{2}$ ft........... $75 \quad 700 \quad 6500$

3 to $4 \mathrm{ft} \ldots \ldots \ldots \ldots \ldots \ldots 5004500$

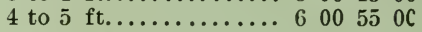

38 Swiss Stone (P. Cembra).

$1 \frac{1}{2}$ to $2 \mathrm{ft} . \ldots \ldots \ldots \ldots$....... 00

2 to $3 \mathrm{ft} \ldots \ldots \ldots \ldots \ldots 200$

3 to $4 \mathrm{ft} . \ldots \ldots \ldots \ldots \ldots 250$

38 Bhotan ( $P$. excelsa)

2 in., 1-yr. seedlings... $\quad 100 \quad 800$

2 to $2 \frac{1}{2}$ ft............ $100 \quad 900$

3 to 4 ft.............2 $200 \quad 18 \quad 50$

4 to $5 \mathrm{ft} . \ldots \ldots \ldots \ldots . . . .350$

38 Umbrella (Sciadopitys verticillata).

2 to $3 \mathrm{ft} \ldots \ldots \ldots \ldots \ldots 300$

3 to $4 \mathrm{ft}, \ldots \ldots \ldots \ldots, 00$

4 to $5 \mathrm{ft} . \ldots \ldots \ldots . \$ 8$ to 1200

RETINOSPORA plumosa. Each 10

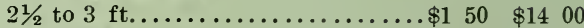

3 to $31 / 2$ ft...................... $200 \quad 1850$

$31 / 2$ to 4 ft....................... $300 \quad 2750$

4 to $41 / 2$ ft........................... $350 \quad 3250$

$41 / 2$ to $5 \mathrm{ft} . \ldots \ldots \ldots \ldots \ldots \ldots \ldots \ldots \ldots+450 \quad 4250$

5 to $51 / 2$ ft.................. 500

39 plumosa aurea (Golden Japan C5-

press). 2 to $2 \frac{1}{2} \mathrm{ft} . \ldots \ldots \ldots \ldots \ldots, 125$ $31 / 2$ to 4 ft........................ 250

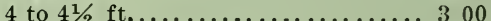

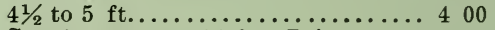

Specimens, 5 to $14 \mathrm{ft}$. Price on application.

39 squarrosa (Blue Japan Cypress).

2 to $2 \frac{1}{2} \mathrm{ft} . \ldots \ldots \ldots \ldots \ldots \ldots \ldots \ldots \ldots \ldots \ldots$

$21 / 2$ to 3 ft.................... 250

3 to $31 / 2$ ft........................ 300

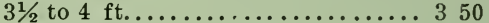

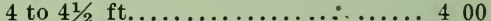

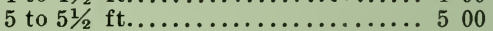

39 filifera (Thread-branched Japanese Cypress).

1 to $1 \frac{1}{2} \mathrm{ft} . \ldots \ldots \ldots \ldots \ldots \ldots \ldots \ldots . .60$

$21 / 2$ to $3 \mathrm{ft} . \ldots \ldots \ldots \ldots \ldots \ldots \ldots \ldots . .200$

3 to $3 \frac{1}{2}$ ft....................... 300

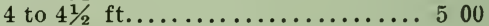

Specimens from 5 to $9 \mathrm{ft}$. Price on application.

39 obtusa (Obtuse-leaved Japanese Cypress). 3 to $3 \frac{1}{2} \mathrm{ft} . \ldots \ldots \ldots \ldots . .300$ 4 to $41 / 2$ ft................... 400

$41 / 2$ to $5 \mathrm{ft} . \ldots \ldots \ldots \ldots \ldots \ldots \ldots \ldots \ldots \ldots \ldots \ldots$

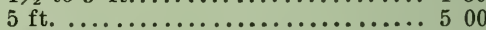

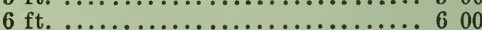

39 obtusa nana (Dwarf Obtuse-leaved Japanese Cypress).

6 to 12 in..... 50

6 to 12 in........................... plication.

39 obtusa nana aurea. $1 \frac{1}{2}$ to $2 \mathrm{ft} . \ldots \ldots 200$ 3 to $3 \frac{1}{2}$ ft.................... 400 pisifera, var. aurea (Golden Peafruited Japanese Cypress).

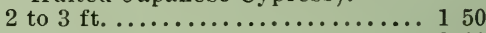

3 to 4 ft............................. 200

4 to $4 \frac{1}{2}$ ft...................... 350
2250 2750 3250 3750 4750

1000 2250 (1) 
EVERGREEN TREES, continued

\section{Page}

40 SPRUCE, White (Picea alba).

1 to 3 in , 1-yr. seedlings... per $1,000, \$ 20$.

4 to 8 in., 2-yr. seedlings...\$0 $10 \$ 080$

1 to $11 / 2 \mathrm{ft} . \ldots \ldots \ldots \ldots \ldots \ldots 25 \quad 200$

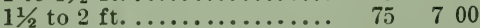

$2 \frac{1}{2}$ to $3 \mathrm{ft} \ldots \ldots \ldots \ldots \ldots \ldots \ldots 1501250$

3 to $4 \mathrm{ft} . \ldots \ldots \ldots \ldots \ldots \ldots 250$

4 to $5 \mathrm{ft} . \ldots \ldots \ldots \ldots \ldots \ldots . \ldots 0$

Larger specimens up to 25

ft. Price on application.

\section{Norway ( $P$. excelsa). 1 to}

$$
11 / 2 \mathrm{ft} . \ldots \ldots \ldots \ldots \ldots \ldots \ldots
$$

$11 / 2 \mathrm{to} 2 \mathrm{ft} \ldots \ldots \ldots \ldots \ldots \ldots$

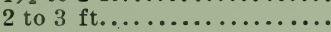

3 to $4 \mathrm{ft} . \ldots \ldots \ldots \ldots \ldots \ldots \ldots . \ldots 100$

4 to $5 \mathrm{ft} . \ldots \ldots \ldots \ldots \ldots \ldots \ldots . \ldots \ldots$

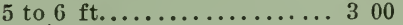

6 to $7 \mathrm{ft} . \ldots \ldots \ldots \ldots \ldots \ldots \ldots 400$

7 to $8 \mathrm{ft} . \ldots \ldots \ldots \ldots \ldots \ldots \ldots 60 . \ldots \ldots$

Specimens 10 to $25 \mathrm{ft}$. Price on application.

Weeping ( $P$. excelsa, var. inverta).

3 to $3 \frac{1}{2}$ ft.......................... 00

4 to $5 \mathrm{ft} . \ldots \ldots \ldots \ldots \ldots \ldots \ldots 500$

5 to $6 \mathrm{ft} . \ldots \ldots \ldots \ldots \ldots \ldots \ldots \ldots . \ldots \ldots$

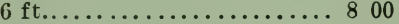

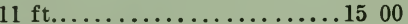

Golden Norway ( $P$. excelsa, rar. aurea)

5 to $6 \mathrm{ft} . \ldots \ldots \ldots \ldots \ldots \ldots 450$

$7 \mathrm{ft} . \ldots \ldots \ldots \ldots \ldots \ldots \ldots \ldots 600 . \ldots 60 . \ldots$

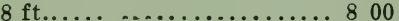

Norway ( $P$. excelsa, rar. pyramidalis). Pyramidal Norway. Specimens 6 to $13 \mathrm{ft}$. Price on application.

Maxwell's Dwarf ( $P$. Maxuelli).

6 in.................. $100 \quad 900$

Alcock's ( $P$. bicolor; syn. Alcockiana).

1 to $1 \frac{1}{2} \mathrm{ft} \ldots \ldots \ldots \ldots \ldots \ldots \ldots$. 75

$11 / 2$ to $2 \mathrm{ft} . \ldots \ldots \ldots \ldots \ldots \ldots 200$

2 to $21 / 2$ ft. ................ 250

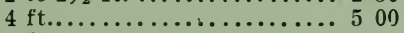

$5 \mathrm{ft} . \ldots \ldots \ldots \ldots \ldots \ldots \ldots \ldots \ldots 600$

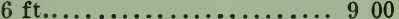

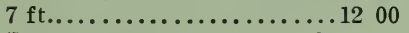

Specimens up to $11 \mathrm{ft}$.

Prices on application.

40 Oriental ( $P$. orientalis).

$1 \frac{1}{2}$ to $2 \mathrm{ft}$............... 200

2 to $2 \frac{1}{2}$ ft. .................. 250

Specimens up to $20 \mathrm{ft}$. Price on application.

40 Colorado ( $P$. pungens).

2 to 6 in., $2-y r$. transplanted. per $1,000, \$ 50$.

900

850

2750

\section{$140 \quad 1200$}

$225 \quad 2000$

$\$ 300$

700

1800

6500

\section{1}

Page

10

100

40 Spruce, Colorado Blue ( $P$. pungens, var. $g(a u c a)$. 2 to 6 in., 2-yr. transplanted; selected blue............ \$0 $30 \quad \$ 250 \quad \$ 2000$ 1 to $1 \frac{1}{2} \mathrm{ft} . \ldots \ldots \ldots \ldots \ldots \ldots \ldots 100 \quad 900 \quad 8500$

$11 / 2$ to $2 \mathrm{ft} . \ldots \ldots \ldots \ldots \ldots \ldots \ldots 1251100$

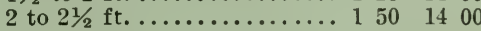

$21 / 2$ to $3 \mathrm{ft} . \ldots \ldots \ldots \ldots \ldots \ldots \ldots .250 \quad 2250$

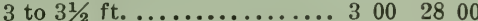

40 Koster's Colorado Blue ( $P$. pungens, var. glauca hos-

terii). $11 \%$ to $2 \mathrm{ft}$....... i 50

2 to $21 / 2$ ft........\$2.50 to 350

3 to $31 / 2 \mathrm{ft} \ldots \ldots \ldots \ldots \ldots \ldots \ldots . \ldots . \ldots 300$

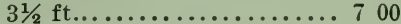

41 Engelmann's ( $P$. Éngelmanni).

$11 / 2$ in., 1-yr. seedlings ....

per $1,000, \$ 10$.

3 to 6 in., 2-yr. transplanted. 20

1 to $11 / 2 \mathrm{ft} . \ldots \ldots \ldots \ldots \ldots \ldots \ldots, 100$

$11 / 2$ to $2 \mathrm{ft} . \ldots \ldots \ldots \ldots \ldots \ldots 200$

Specimens up to $15 \mathrm{ft}$. Price on selection.

41 Tiger-Tail (P. polita). 1 to $1 \frac{1}{2} \mathrm{ft} .100 \quad 900$ $11 / 2$ to 2 ft.............. $200 \quad 1800$

41 P. 0morika. 1 to $1 \frac{1}{2} \mathrm{ft} . \ldots \ldots \ldots 100 \quad 900$ 3 to $4 \mathrm{ft} . \ldots \ldots \ldots \ldots \ldots \ldots \ldots \ldots$............ 00

41 Douglas (Pseudotsuga Douglasi). $1 \frac{1 / 2}{2}$ to $2 \mathrm{ft} . \ldots \ldots \ldots$.... $75 \quad 700$ 2 to $21 / 2$ ft................... 1501250 $21 / 2$ to 3 ft............... $200 \quad 1850$ 3 to $4 \mathrm{ft} . \ldots \ldots \ldots \ldots \ldots \ldots \ldots \ldots 250 \quad 2250$

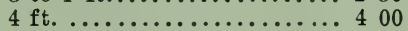

Specimens up to $15 \mathrm{ft}$. Price on application.

Black ( $P$. nigra; syn., $P$. Mariana). 2 to $2 \frac{1}{2} \mathrm{ft}$...

TORREYA nucifera ; syn., Tunion nucifera. A hardy dark green plant of yew-like foliage. $3 \mathrm{ft} . \ldots . \ldots . \ldots 300$

41 YEW, Japanese (Taxus cuspi. data). $1 \frac{1}{2}$ to $2 \mathrm{ft} . \ldots \ldots \ldots 400$ data). $1 \frac{1}{2}$ to 2 ft......... 400 3 to $3 \frac{1}{2}$ ft.............. 500

41 Spreading English ( $T$. repandens). 10 to 15 in....... $150 \quad 1400$ 1 to $11 / 4$ ft................. $200 \quad 1850$

41 Canadian ( $T$. Canadensis).

$2 \mathrm{ft}$. wide .............. 200

41 English (T. baccata). 1 to $1 \frac{1}{2} \mathrm{ft}$. $\quad 75$

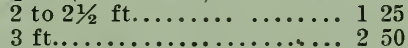

41 Golden English ( $T$. baccata, rar. elegantissima). Hardier than the English.

1 to $1 \frac{1}{2} \mathrm{ft} \ldots \ldots \ldots \ldots \ldots \ldots \ldots . \ldots \ldots$ $11 / 2$ to $2 \mathrm{ft} . \ldots \ldots \ldots \ldots \ldots \ldots \ldots 1501200$ 2 to $2 \frac{1}{2}$ ft................... 200
500 1000

6000 11000 


\section{FLOWERING SHRUBS}

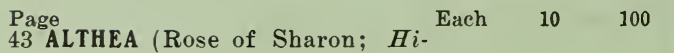
biscus Syriacus). In va-

riety from seed, 2 to $4 \mathrm{ft}$. per $1,000, \$ 80 \ldots \$ 0 \quad 12 \quad \$ 100 \quad \$ 900$

Named varieties. 2 to $3 \mathrm{ft} . . . .20$

3 to 4 ft................... 30

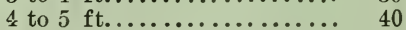

ANDROMEDA recurva. 2 to $3 \mathrm{ft.} .40$

AZALEA amoena. See Broadleaved Evergreens.

arborescens. 1 to $1 \frac{1}{2} \mathrm{ft} . \ldots . \quad 50 \quad 400$ 2 to $2 \frac{1}{2} \mathrm{ft} . \ldots \ldots \ldots \ldots \ldots \ldots \ldots \ldots \ldots \ldots$

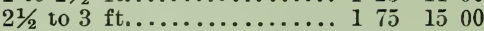

43 Chinese (Azalea mollis). Bushy plants, well es-

tablished. 15 to 18 in.... $50 \quad 400$

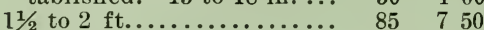

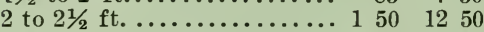

$21 / 2$ to $3 \mathrm{ft} . \ldots \ldots \ldots \ldots \ldots . .200 \quad 1750$

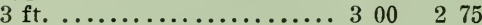

43 Flame (A. calendulacea).

1 to $11 / 2 \mathrm{ft} . \ldots \ldots \ldots \ldots \ldots . .45 \quad 400$

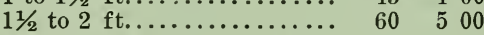

43 Ghent (A. Pontica). Named varieties, double and single. Large bushy plants, well established.

$11 / 2$ to $2 \mathrm{ft} . \ldots \ldots \ldots \ldots \ldots \ldots \ldots$

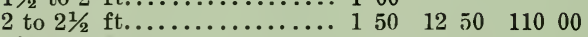

$21 / 2$ to $3 \mathrm{ft} . \ldots \ldots \ldots \ldots \ldots \ldots 200 \quad 1800$

3 to $31 / 2$ ft................ 250

$31 / 2$ to 4 ft.................. \& 00

4 to $4 \frac{1}{2}$ ft................ 600

$4 \frac{1}{2} \mathrm{ft} . \ldots \ldots \ldots \ldots \ldots \ldots, 700$

44 Pinxter Flower (A. nudiflora).

1 to $11 / 2$ ft................ 30

$11 / 2$ to $2 \mathrm{ft} . \ldots \ldots \ldots \ldots \ldots \ldots, 5 . \cdots, 50$

44 Southern (A. Vaseyi).

1 to $1 \frac{1}{2} \mathrm{ft} . \ldots \ldots \ldots \ldots \ldots \ldots . .40 \quad 350$

$11 / 2$ to 2 ft................ 75

2 to $21 / 2 \mathrm{ft} . \ldots \ldots \ldots \ldots \ldots \ldots \ldots \ldots \ldots$

$21 / 2$ to 3 ft.................. 200 1750

3 to $3 \frac{1}{2} \mathrm{ft} . \ldots \ldots \ldots \ldots \ldots \ldots . . .300 \quad 2500$

44 Swamp (A. viscosa). $2 \mathrm{ft} . \ldots .75$

44 BAYBERRY (Wax Myrtle; $\boldsymbol{M} y$ rica cerifera). $1 \frac{1}{2}$ to $2 \mathrm{ft}$

$3 \mathrm{ft} . \ldots . . . . .$.

44 BARBERRY European (Berberis vulgaris $)$. 2 to $3 \mathrm{ft} . . . . . .$. 3 to $4 \mathrm{ft} . \ldots \ldots \ldots \ldots \ldots . . . . .$.

44 Purple ( $B$. vulgaris, var. pur purea). 3 to $4 \mathrm{ft} . . . . . .$. .

44 Japanese ( $B$. I'hunbergi).

4 to 8 in., transplanted....

per $1,000, \$ 40$.

1 to $1 \frac{1}{2} \mathrm{ft}$.... per $1,000, \$ 70$.

$11 / 2$ to 2 ft...................

2 to $21 / 2 \mathrm{ft} . \ldots \ldots \ldots \ldots \ldots \ldots$.

44 BUTTON BUSH (Cephalanthus occidentalis). 2 to $3 \mathrm{ft}$...

CALLICARPA Japonica. 3 to $4 \mathrm{ft}$. 4 to $5 \mathrm{ft} . \ldots \ldots \ldots \ldots \ldots \ldots$.

45 CATAlPA Bungei, Bush form. A good shrub for massing, as it gives vigorous quick effects. It is excellent at the seaside.

$11 / 2$ to $2 \mathrm{ft} . \ldots \ldots \ldots \ldots \ldots$

2 to $3 \mathrm{ft} . \ldots \ldots \ldots \ldots \ldots \ldots$

3 to $4 \mathrm{ft} . \ldots \ldots \ldots \ldots \ldots \ldots$

4 to 5 ft...................

$5 \mathrm{ft} . \times 5 \mathrm{ft} . \ldots \ldots \ldots \ldots \ldots \ldots, 100$

CHOKE BERRY (Aronia nigra; syn., Pyrus arbutifolia).

3 to $4 \mathrm{ft} . . . . \ldots \ldots \ldots \ldots . . . .$.

4 to 5 ft..................
Page
45 CORCHORUS (Kerria Japonica). $4 \mathrm{ft} . \ldots \ldots \ldots \ldots \ldots \ldots \ldots \ldots+\ldots \ldots$

CORNELIAN CHERRY (Cornus

Mas).

2 to $3 \mathrm{ft} . \ldots \ldots \ldots \ldots \ldots \ldots .25$

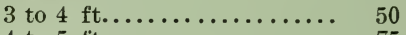

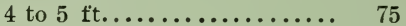

DAPHNE Gwenka. $1 \frac{1}{2} \mathrm{ft} . \ldots \ldots 100$

45 DEUTZIA scabra, crenata, candidissima, Pride of Rochester and Fortunei. 2 to $3 \mathrm{ft} . .$.

3 to $4 \mathrm{ft} . \ldots \ldots \ldots \ldots \ldots \ldots$

4 to $5 \mathrm{ft} . \ldots \ldots \ldots \ldots \ldots \ldots . . . . . .$.

5 to $6 \mathrm{ft} . \ldots \ldots \ldots \ldots \ldots \ldots$

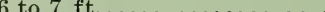

45 gracilis. 1 to $1 \frac{1}{2} \mathrm{ft} . \ldots \ldots \ldots . . .25$

$11 / 2$ to 2 ft................ 30

2 to $2 \frac{1}{2} \mathrm{ft} . \ldots \ldots \ldots \ldots \ldots \ldots . .35$

Lemoinei. 2 to $3 \mathrm{ft} . \ldots \ldots \ldots \ldots$. 35

45 DOGW00D, Red-twigged (Cornus alba, var. Sibirica):

$1 \frac{1}{2}$ to $2 \mathrm{ft} . \ldots \ldots \ldots \ldots \ldots \ldots . .12 \quad 100 \quad 900$

3 to 4 ft.................. $25 \quad 200$

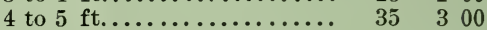

Silky ( $C$. sericea). $1 \frac{1}{2}$ to $2 \mathrm{ft}$. $12 \quad 100$

2 to $3 \mathrm{ft} . \ldots \ldots \ldots \ldots \ldots \ldots . .25 \quad 2500$

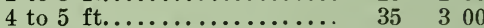

5 to $6 \mathrm{ft} \ldots \ldots \ldots \ldots \ldots \ldots \ldots \ldots$

1800

$400 \quad 3500$

45 ELDER, Golden (Sambucus nigra, var. aurea).

2 to $2 \frac{1}{2} \mathrm{ft} \ldots \ldots \ldots \ldots \ldots \ldots, 08$

4 to $5 \mathrm{ft} . \ldots \ldots \ldots \ldots \ldots \ldots \ldots \ldots . .25$

6 to $7 \mathrm{ft} . \ldots \ldots \ldots \ldots \ldots \ldots . .6 . .35$

50

300

45 ELAEAGNUS umbellata (Silver Thorn).

$11 / 2$ to $2 \mathrm{ft} \ldots \ldots \ldots \ldots \ldots \ldots .20$

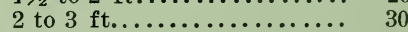

argentea. $1 \frac{1}{2}$ to $2 \mathrm{ft} . \ldots \ldots \ldots . \quad 20$

2 to $3 \mathrm{ft} . \ldots \ldots \ldots \ldots \ldots \ldots, 30$

ENKIANTHUS campanulatus; syn., Andromeda campanulats.

$2 \frac{1}{2}$ to $3 \mathrm{ft} . \ldots \ldots \ldots \ldots \ldots .200$

45 EXOCHORDA grandiflora (Pearl Bush). 2 to $3 \mathrm{ft} . . . . . .$.

3 to $4 \mathrm{ft} . \ldots \ldots \ldots \ldots \ldots \ldots$

4 to $5 \mathrm{ft} . \ldots \ldots \ldots \ldots \ldots \ldots . .6 \%$

FONTANESIA Fortunei. 4 to $5 \mathrm{ft}$. 35

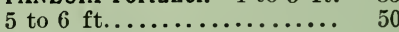

46 FORSYTHIA (Golden Bell) Fortunei. 3 to $4 \mathrm{ft} . . \ldots \ldots \ldots$.

5 to $6 \mathrm{ft} . \ldots \ldots \ldots \ldots \ldots \ldots \ldots$

46 suspensa. 3 to $4 \mathrm{ft} . \ldots \ldots \ldots \ldots .20$

4 to $5 \mathrm{ft} . \ldots \ldots \ldots \ldots \ldots \ldots . . .6$

5 to $6 \mathrm{ft} . \ldots \ldots \ldots \ldots \ldots \ldots \ldots$

7 to $8 \mathrm{ft} . \ldots \ldots \ldots \ldots \ldots \ldots$

46 viridissima. 3 to $4 \mathrm{ft} . \ldots \ldots \ldots$

4 to $5 \mathrm{ft} . \ldots \ldots \ldots \ldots \ldots \ldots \ldots$

5 to $6 \mathrm{ft} . \ldots \ldots \ldots \ldots \ldots$

6 to $7 \mathrm{ft} . \ldots \ldots \ldots \ldots \ldots \ldots . . . . .$.

46 FRINGE, White (Chionanthus Vir. ginica). 1 to $2 \mathrm{ft} . \ldots . . .$. 2 to $3 \mathrm{ft} . . \ldots \ldots \ldots \ldots \ldots \ldots . .35$

GOLDEN BELL. See Forsythia.

HAZELNUT (Filbert), American (Corylus Americana).

1 to $2 \mathrm{ft} . . . \ldots \ldots \ldots \ldots \ldots . .25$

English (C. Avellana). 4 to $5 \mathrm{ft} . \quad 50$ 46 H E R C U L E S' C L U B (Angelica Tree; Aralia spinosa).

4 to $5 \mathrm{ft} . \ldots \ldots \ldots \ldots \ldots \ldots .20$

12 to $14 \mathrm{ft} . \ldots \ldots \ldots \ldots \ldots \ldots \ldots \ldots \ldots \ldots, 100$
2500

250

350

500

2000

4000 
FLOWERING SHRUBS, continued

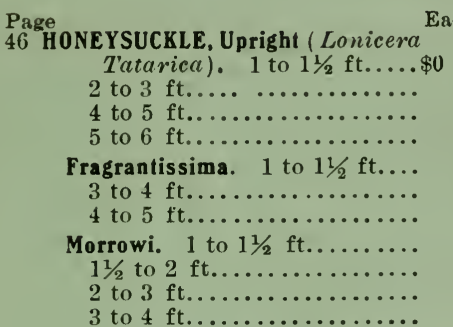

46 HORSE-CHESTNUT, Dwarf ( $E s c u$ lus perviflora; s y n., macrostachya). $1 \frac{1}{2}$ to $2 \mathrm{ft}$.

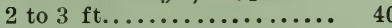

3 to 4 ft..................... 50

46 HYDRANGEA paniculata grandiflora. 3 to $4 \mathrm{ft}$........... 25

46 Hortensis, var. Otaksa.

2 to 3 yr., large clumps ....

46 radiata. $2 \mathrm{ft} . \ldots \ldots \ldots \ldots \ldots$.

46 quercifolia (Oak-leaved). $11 \frac{1}{2}$

to $2 \mathrm{ft} . . . . . . . . . . . . . .$.

HYPERICUM densiflorum. 2 to $3 \mathrm{ft}$.

46 INDIAN CURRANT (Coral Berry; Symphoricarpus vulgaris ). 2 to $3 \mathrm{ft} . \ldots \ldots \ldots .25$

3 to 4 ft.................... 30

ILEX monticolor. 3 to $4 \mathrm{ft} . \ldots . \quad 50$

4 to $5 \mathrm{ft} . \ldots \ldots \ldots \ldots \ldots \ldots, 75$

5 to $6 \mathrm{ft} . \ldots \ldots \ldots \ldots \ldots \ldots \ldots, 100$

6 to $7 \mathrm{ft} . \ldots \ldots \ldots \ldots \ldots \ldots \ldots$

verticillata (Black Alder).

3 to $4 \mathrm{ft} . \ldots \ldots \ldots \ldots \ldots \ldots .25$

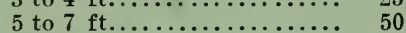

46 JAPANESE JUDAS (Cercis Chinensis; syn., Japonica).

8 to 12 in..................

$11 / 2$ to $2 \mathrm{ft} . \ldots \ldots \ldots \ldots \ldots \ldots . .$.

2 to $2 \frac{1}{2}$ ft...................

47 LABURNUM vulgare (Golden Chain). 6 to 12 in........

47 L ILAC (Syringa vulgaris). Named varieties. Grafted.

6 to 12 in., 1 yr. ...........

1 to $2 \mathrm{ft} . \ldots \ldots \ldots \ldots \ldots \ldots . .35$

2 to $3 \mathrm{ft} . \ldots \ldots \ldots \ldots \ldots \ldots \ldots . \quad 50$

3 to $4 \mathrm{ft} . \ldots \ldots \ldots \ldots \ldots \ldots \ldots, 100$

4 to $5 \mathrm{ft} . \ldots \ldots \ldots \ldots \ldots \ldots, 1 \leq 0$

47 Common (S. vulgaris).

$11 / 2$ to $2 \mathrm{ft} . \ldots \ldots \ldots \ldots \ldots . .20$

2 to $3 \mathrm{ft} . \ldots \ldots \ldots \ldots \ldots \ldots \ldots, \quad 30$

3 to $4 \mathrm{ft} . \ldots \ldots \ldots \ldots \ldots \ldots \ldots . .35$

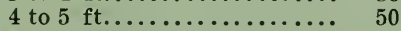

5 to $6 \mathrm{ft} . \ldots \ldots \ldots \ldots \ldots \ldots \ldots$

White (S. vulgaris, var. alba). 3 to $4 \mathrm{ft}$................. 35

47 Persian (S.Persica). 4 to $5 \mathrm{ft}$. 75

47 villosa, var. Emodi. $1 \frac{1}{2}$ to $2 \mathrm{ft}$. 30

2 to $3 \mathrm{ft} . \ldots \ldots \ldots \ldots \ldots . . . . . .50$

3 to $4 \mathrm{ft} . \ldots \ldots \ldots \ldots \ldots \ldots \ldots \ldots \ldots, \quad 75$

4 to $5 \mathrm{ft} . \ldots \ldots \ldots \ldots \ldots \ldots \ldots \ldots$

47 Japanese (S. Japonica).

2 to $3 \mathrm{ft} . \ldots \ldots \ldots \ldots \ldots \ldots . .50$

3 to $4 \mathrm{ft} . \ldots \ldots \ldots \ldots \ldots \ldots \ldots \ldots, \quad 75$

4 to 5 ft..................... 100

Rothmagensis ( $S$. Chinensis). 1 to $2 \mathrm{ft} . . . \ldots \ldots \ldots \ldots . .30$

L ONICERA. See Upright Honeysuckle.

MAGNOLIA. See Magnolia, under Trees.

\begin{tabular}{rrrrr}
\multicolumn{1}{c}{10} & \multicolumn{1}{c}{100} \\
$\$ 0-90$ & $\$ 8$ & 00 \\
1 & 40 & 12 & 00 \\
3 & 50 & & \\
5 & 50 & 50 & 00 \\
& 90 & 8 & 00 \\
& & & & \\
& & & & \\
& 90 & 8 & 00 \\
1 & 40 & 12 & 00 \\
2 & 00 & 18 & 00 \\
3 & 50 & 30 & 00
\end{tabular}

5

5

$-$

0
12
15

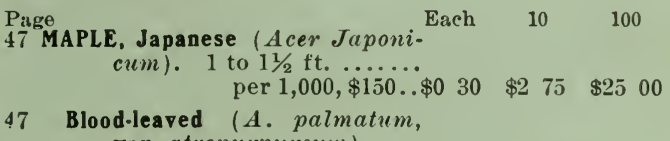

MISSOURI FLOWERING CURRANT

(Ribes aureum). 3 to $4 \mathrm{ft} . \quad 40$

ORANGE, Hardy (Citrus trifoliata; syn., Limonia).

1 to $2 \mathrm{ft} . . . . . \ldots \ldots \ldots \ldots \ldots . .15 \quad 1500$

2 to $3 \mathrm{ft} . \ldots \ldots \ldots \ldots \ldots \ldots . .25 \quad 2000$

An excellent defensive hedge plant, There are plants on a sand hill at Westbury 10 feet high, and so thick that a cat cannot get through. Our plants are grown from local seed. It was originally imported from Japan by the Department of Agriculture, and they have improved the size and flavor of the fruit.

0sage. 8 to $9 \mathrm{ft} \ldots \ldots \ldots \ldots \ldots+\ldots 0_{75}^{\text {Each }} 10 \quad 100$

48 PRIVET (Ligustrum Ibota).

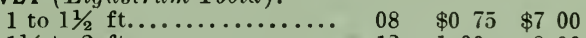
$1 \frac{1}{2}$ to 2 ft................... 12 1 $00 \quad 800$

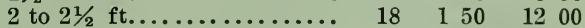

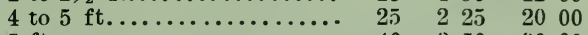

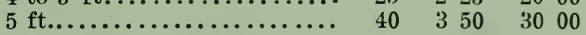

49 Prostrate (L. Ibota, var. Regelianum). 1 to $1 \frac{1}{2} \mathrm{ft} \ldots \quad 10 \quad 90 \quad 800$ $11 / 2$ to $2 \mathrm{ft} . \ldots \ldots \ldots \ldots \ldots \ldots . .20 .190 \quad 1600$

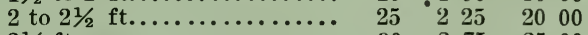

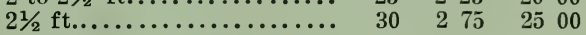

8 California ( $L$.ovalifolium).

1 to $1 \frac{1}{2} \mathrm{ft} . \ldots \ldots \ldots \ldots$........... $10 \quad 100 \quad 1.000$ per $10,000, \$ 150 . . \quad \$ 200 \$ 1800$ $1 \frac{1}{2}$ to $2 \mathrm{ft} ., 2$-yr. transplanted, cut back, bushy..............\$0 $06 \begin{array}{llllll}50 & 4 & 00 & 30 & 00\end{array}$

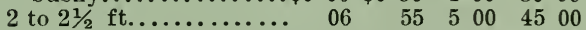
$21 / 2$ to $3 \mathrm{ft} . \cdots \cdots \cdots \cdots \cdots \cdots \cdots \cdots \cdots$

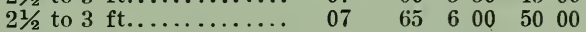

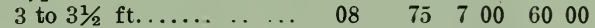

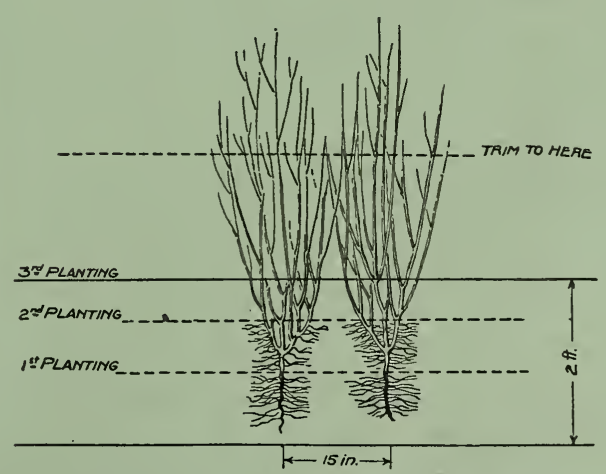

"OUR WAY OF GROWING PRIVET"

Illustration from article on Ligustrum, by Henry Hicks, in Cyclopedia of American Horticulture

The usual method is to plant a double row, using two plants per foot. Such untransplanted narrow stock may be cheaper per plant, but costs more per 100 feet than ours. Our Privet is cut back several times the first year to get a wide base, then transplanted wide apart and jeeper to get new roots on then transplanted wide apart and deeper to get new roots on the branches. You can plant them $1 \frac{1}{2}$ to 2 feet apart and get
a hedge thick at the base. 
FLOWERING SHRUBS, continued

Page

Privet, California. continued

$3 \frac{1}{2} \times 2 \frac{1}{2} \mathrm{ft} \ldots \ldots \ldots \ldots \ldots \ldots \$ 0 \quad 18 \quad \$ 160 \quad \$ 1500$ $4 \times 3$ to $3 \frac{1}{2} \mathrm{ft} \ldots 1,000, \$ 150 \ldots \quad 20 \quad 190 \quad 1800$ $4 \frac{1}{2} \times 3$ to $3 \frac{1}{2} \mathrm{ft} . \ldots \ldots \ldots \ldots .25252500$ $5 \times 3$ to $4 \mathrm{ft} . \ldots \ldots \ldots \ldots \ldots \ldots .6 .30 \quad 275 \quad 2500$ $6 \times 4 \mathrm{ft} . \ldots \ldots \ldots \ldots \ldots \ldots .6 .6 \% \quad 40 \quad 375$

The above is very heavy stock, repeatedly cut back, wide, dense. Especially valuable where mature effects are desired. No more expensive than smaller stock for the same space. For example:

$2 \frac{1}{2} \mathrm{ft}$. Privet planter $1 \mathrm{ft}$. apart for $100 \mathrm{ft}$., is .... $\$ 600$ $4 \mathrm{ft}$. Privet planted $2 \frac{1}{2} \mathrm{ft}$. apart for $100 \mathrm{ft}$., is. ... 720 The gain is two years in size and density. We can deliver and plant Privet hedges within fifteen miles.

$5 \mathrm{ft}$. sheared pyramids, $\$ 1$ each.

Dome-shaped Privet, $5 \mathrm{ft}$. high by $8 \mathrm{ft}$. Price on application.

Standard Privet. Price on application.

Arches of Privet. Price on application.

49 RHODOTYPOS kerrioides.

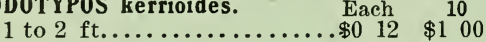

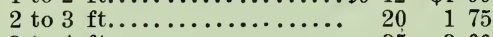

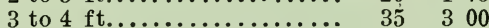

49 SIBERIAN PEA TREE (Carygana

arborescens). 8 to 12 in... 08

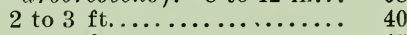

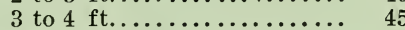

SILVER THORN. See Elæagnus.

49 SMOKE TREE (Mist Tree; Purple Fringe; Rhus cotinus).

4 to $5 \mathrm{ft} . . . \ldots \ldots \ldots \ldots \ldots \ldots . . .40$

6 to $7 \mathrm{ft} . \ldots \ldots \ldots \ldots \ldots \ldots \ldots \ldots, \quad 75$

SNOWBALL. See Viburnum.

49 S PIR E A, Thunberg's (Spircea Thunbergii). $11 / 2$ to $2 \mathrm{ft}$.

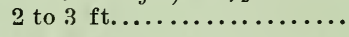

50 Bridal Wreath ( $S$. prunifolia, var. flore pleno). 3 to $4 \mathrm{ft} . .$.

5 to $6 \mathrm{ft} . \ldots \ldots \ldots \ldots \ldots . . . . .40$

opulifolia, var. aurea. 5 to $6 \mathrm{ft}$. 30

6 to $7 \mathrm{ft} . \ldots \ldots \ldots \ldots \ldots \ldots$.........

50 Van Houttei. $11 / 2$ to $2 \mathrm{ft} . . . . . \quad 15$

2 to $3 \mathrm{ft} . \ldots \ldots \ldots \ldots \ldots \ldots . .25$

3 to 4 ft..................... 30

4 to $5 \mathrm{ft} . \ldots \ldots \ldots \ldots \ldots . . . . . .40$

50 Reevesi; syn., S. Cantoniensis, var. flore pleno. 3 to $4 \mathrm{ft}$.

50 Golden (Physiocarpus opulifolia; syn., S. opulifolia, var. aurea; Nine-Bark).

2 to $3 \mathrm{ft} . \ldots \ldots \ldots \ldots \ldots . . . \ldots \ldots$

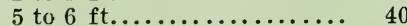

6 to $7 \mathrm{ft} . \ldots \ldots \ldots \ldots \ldots \ldots \ldots, \quad 50$

50 Bumalda. 3 to $4 \mathrm{ft} . \ldots \ldots \ldots .25$

50 Bumalda, var. Anthony Waterer.

$11 / 2$ to $2 \mathrm{ft} . . . \ldots \ldots \ldots \ldots . . . .$.

2 to $21 / 2 \mathrm{ft} . \ldots \ldots \ldots \ldots \ldots \ldots \ldots$

3 to $3 \frac{1}{2}$ ft................

callosa. 3 to $4 \mathrm{ft} . \ldots \ldots \ldots \ldots$.

4 to $5 \mathrm{ft} . \ldots \ldots \ldots \ldots \ldots \ldots \ldots \ldots \ldots \ldots \ldots \ldots$

Douglasi. 2 to $3 \mathrm{ft} . \ldots \ldots \ldots . .20$

4 to $5 \mathrm{ft} \ldots \ldots \ldots \ldots \ldots \ldots \ldots \ldots \ldots . .25$

STAPHYLEA Bumalda. 4 to $5 \mathrm{ft}$. 50 STEPHANANDRA flexuosa.

$1 \frac{1}{2}$ to $3 \mathrm{ft} . \ldots \ldots \ldots \ldots \ldots . . . .25$

STUARTIA pentagyna. 5 to $6 \mathrm{ft} . .125$

STYRAX Japonica. 1 to $2 \mathrm{ft} . \ldots . \quad 15$

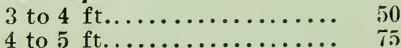

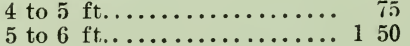

200

350

450

175

900

140

400

600
$\$ 100$

600

50 TAMARISK (Tamarix A fricana).

3 to $4 \mathrm{ft} . \ldots \ldots \ldots \ldots \ldots . .25$

VACCINIUM corymbosum. 3 to $4 \mathrm{ft}$. 7 ĩ

VIBURNUM acerifolium. 2 to 3 ft. ........per $1,000, \$ 90$..

cassinoides. 3 to $4 \mathrm{ft} . . . \ldots$...

dentatum. 2 to $3 \mathrm{ft} . . . . . . .$. .

3 to $4 \mathrm{ft} . . . \ldots \ldots \ldots \ldots \ldots . . . . .$.

dilatatum. 8 to 12 in..........

2 to $3 \mathrm{ft} . \ldots \ldots \ldots \ldots \ldots \ldots . . . . . .$.

Lantana. 3 to $4 \mathrm{ft} . . . . \ldots \ldots$.

Nepalense. 4 to $5 \mathrm{ft} . . . \ldots \ldots$.

nudum. 2 to $3 \mathrm{ft} . \ldots \ldots \ldots \ldots$.

opulus. $1 \mathrm{ft} . \ldots \ldots \ldots \ldots \ldots . . . .$.

opulus, var. sterile (Snowball; Guelder Rose). 1 to $2 \mathrm{ft} . ., 15$

2 to $3 \mathrm{ft} . . . \ldots \ldots \ldots \ldots . . . .$.

49 prunifolium (Black Haw). $1 \frac{1}{2}$

Sieboldii. $1 \mathrm{ft} . \ldots \ldots \ldots \ldots \ldots .25$

49 tomentosum, var. plicatum (Japanese Snowball).

1 to 2 ft................. 25

2 to $3 \mathrm{ft} . \ldots \ldots \ldots \ldots \ldots \ldots$

3 to 4 ft......................

800

200

550

225

2000

1500

2000

450

$200 \quad 1500$ pentandra). See under

\section{5}

50

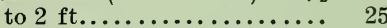

50 WEIGELA Diervilla. In variety.

4 to $5 \mathrm{ft} . . . . \ldots \ldots \ldots . . . .$.

5 to $6 \mathrm{ft} . \ldots \ldots \ldots \ldots \ldots \ldots . .$.

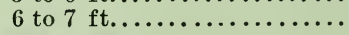

Eva Rathke. 1 to $2 \mathrm{ft} . . . \ldots$.

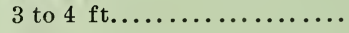

0thello. 4 to $5 \mathrm{ft} . \ldots \ldots \ldots \ldots$.

Diervilla lonicera ; syn., trifida. Layers.................

50 WITCH-HAZEL (Hamamelis Virginiana). 4 to $5 \mathrm{ft} . . . .6$ 6 to $7 \mathrm{ft} . \ldots \ldots \ldots \ldots \ldots \ldots . . . .125$

WILLOW, Laurel-leaved (Salix Trees.

Japanese Pussy ( $S$. multinervis). $4 \times 4 \mathrm{ft} . . . \ldots \ldots \ldots$.

50 YELLOW ROOT (Xanthorrhiza

apiifolia) ................
10

100

25

75

15

25

50

30

$30 \$ 200$ $\begin{array}{lll}50 & 4 & 00\end{array}$

60

$225 \$ 2000$

$\begin{array}{lll}375 & 35 & 00\end{array}$

550

550

\section{5}

125

300

1000

20

08

40

$100 \quad 900$

$200 \quad 1800$

\section{$350 \quad 30 \quad 00$}

400

350

125
$50 \quad 400$

$\begin{array}{lllll}20 & 1 & 50 \quad 1200\end{array}$ 


\section{BROAD-LEAVED EVERGREEN SHRUBS}

Eage
ANDROMEDA floribunda. $1 \mathrm{ft} . \ldots \$ 150$

51 Japonica. $1 \frac{1}{2}$ to $2 \mathrm{ft}$......... 150

2 to $2 \frac{1}{2} \mathrm{ft} . \ldots \ldots \ldots \ldots \ldots \ldots, 200$

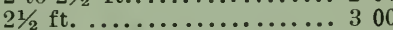

51 AZALEA amoena. 15 to 18 in.... $150 \$ 1250$

51 B0X Tree (Buxus sempervirens). 6 to 10 in................

10 to 12 in.................

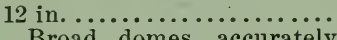

Broad domes accurately trained by machine, 10 to 12 years old, 2 to $3 \frac{1}{2} \mathrm{ft}$. Price on selection.

Pyramids. $2 \mathrm{ft} . \ldots \ldots \ldots \ldots \ldots 125$

$3 \mathrm{ft} . \ldots \ldots \ldots \ldots \ldots \ldots \ldots \ldots, 25 . \ldots \ldots \ldots \ldots, 25$

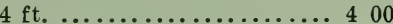

51 sempervirens, var. Hands . worthii. An upright opengrowing variety.

$1 \frac{1}{2}$ to $2 \mathrm{ft} . \ldots \ldots \ldots \ldots \ldots \ldots . .50 \quad 400$

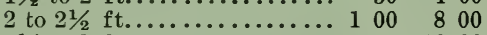

$21 / 2$ to $3 \mathrm{ft} . \ldots \ldots \ldots \ldots \ldots \ldots \ldots$. $125 \quad 1000$

3 to $3 \frac{1}{2} \mathrm{ft} . \ldots \ldots \ldots \ldots \ldots \ldots .2001800$

51 Dwarf $(B$. sempervivens, var. suffruticosa). 4 to 6 in...

6 to 8 in.....................

DAPHNE Cneorum............ 75

DENDRIUM prostratum. 1 to $1 \frac{1}{2} \mathrm{ft} .100$

51 EUONYMUS radicans ........... 25

52 HOLLY, American (Ilex opaca).

1 to $1 \frac{1}{2} \mathrm{ft} . \ldots \ldots \ldots \ldots \ldots \ldots \ldots .75$

$11 / 2$ to 2 ft.................. 150

2 to $21 / 2 \mathrm{ft} . \ldots \ldots \ldots \ldots \ldots \ldots 200$

$21 / 2$ to $3 \mathrm{ft} . \ldots \ldots \ldots \ldots \ldots \ldots 250$

3 to 4 ft.................... 300

4 t.o 5 ft.................... 500

52 ILEX crenata. 1 to $1 \frac{1}{2} \mathrm{ft} \ldots \ldots . .75$ $11 / 2$ to 2 ft................. 150

2 to $2 \frac{1}{2} \mathrm{ft} . \ldots \ldots \ldots \ldots \ldots .200$

52 INKBERRY (Ilen glabra). 1 to

$2 \mathrm{ft} . . . \ldots \ldots \ldots \ldots \ldots \ldots$

25

52 LAUREL (Kalmia latifolia). In nursery, bushy clumps full of bloom buds.

1 to $1 \frac{1}{2} \mathrm{ft} . \ldots . . .1,000, \$ 200$. .

$11 / 2$ to $2 \mathrm{ft} \ldots \ldots . .1,000,8200$.

2 to $21 / 2 \mathrm{ft} . \ldots \ldots 1,000, \$ 375 \ldots \quad 60 \quad 500$

3 to $3 \frac{1}{2} \mathrm{ft} . \ldots \ldots \ldots \ldots \ldots \ldots . . .100 \quad 7 \quad 100$

$\begin{array}{rrrrr} & 60 & 5 & 00 \\ 1 & 25 & 10 & 00 \\ 2 & 00 & 15 & 00 \\ & & & & \\ 6 & 00 & & \\ 14 & 00 & 125 & 00 \\ 18 & 00 & & \\ 20 & 00 & & \\ 25 & 00 & & \\ & & & & \\ & & & & \\ & & & & \\ & & & & \\ & & & & \\ & & & & \\ & & & & \\ 3 & 00 & & 25 & 00 \\ 4 & 00 & & & \\ 5 & 00 & & 40 & 00 \\ 7 & 50 & & 60 & 00\end{array}$

Page

52 Laurel, English (Prunus laurocerasus, var. Schipkonsis).

$1 \frac{1}{2}$ to $3 \mathrm{ft} . \ldots \ldots \ldots \ldots \ldots \ldots 100$

53 LEUCOTHOE Catesbaei ( $A n d r o m-$ eda Catesboi).

6 to 12 in................ 30

1 to $11 / 2 \mathrm{ft} \ldots \ldots \ldots \ldots \ldots \ldots \ldots .6 \% \quad 50 \quad \$ 400 \quad \$ 3500$

$11 / 2$ to $2 \mathrm{ft} . \ldots \ldots \ldots \ldots \ldots \ldots .6 .650$

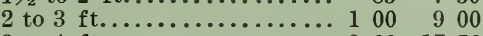

3 to $4 \mathrm{ft} . \ldots \ldots \ldots \ldots \ldots \ldots .200 \quad 1750$

53 MAHONIA aquifolia (Berberis aquifolium). $1 \frac{1}{2}$ to $2 \mathrm{ft.} .100 \quad 900$

53 Japonica (B. Japonica). 11/2 to $2 \mathrm{ft} . \ldots \ldots \ldots \ldots \ldots \ldots, 100 \quad 900$

53 MYRTLE, Trailing (Periwinkle; Vinca minor). For ground cover ..... per $1,000, \$ 10 \ldots$

$53 \quad$ Variegated................. $15 \quad 125 \quad 1000$

53 Double-flowering $\ldots \ldots \ldots \ldots \ldots .615 \quad 125 \quad 1000$

53 White $\ldots \ldots \ldots \ldots \ldots \ldots \ldots \ldots . \ldots 15 \quad 125 \quad 1000$

PACHYSANDRA terminalis ...... $25 \quad 2 \quad 25 \quad 2000$

55 RHODODRENDRON maximum.

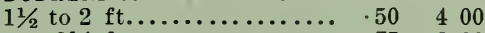

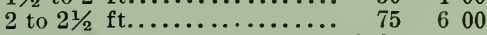

3 to $4 \mathrm{ft} . \ldots \ldots \ldots \ldots \ldots \ldots \ldots \ldots \ldots+300$

4 to $5 \mathrm{ft} . \ldots \ldots \ldots \ldots \ldots \$ 4$ to 600

Larger specimens priced on selection. Collected plants at low rates in quantity.

55 Catawbiense. 10 to 12 in..... 50 $11 / 2 \mathrm{ft} . \ldots \ldots \ldots \ldots \ldots \ldots \ldots \ldots$

55 Named Hardy Hybrids. Imported plants with blooin buds. 15 to 20 in. ....... $100 \quad 1000$

Acclimated plants growing here from 1 to 6 years:

15 to 18 in............... 150 18 to 24 in.................. 200 2 to $2 \frac{1}{2} \mathrm{ft} . \ldots \ldots \ldots \ldots 2.50$ to 300

$21 / 2$ to $3 \mathrm{ft} . \ldots \ldots \ldots \ldots \$ 3.50$ to 500

3 to $4 \mathrm{ft} . \ldots \ldots \ldots \ldots \ldots \ldots 3.50$ to 600

Specimens priced on selection.

RHODORA. 6 to 12 in......... 40

1 to $1 \frac{1}{2} \mathrm{ft} . \ldots \ldots \ldots \ldots \ldots \ldots . .5 \%$. $50 \quad 4.00$

55 YUCCA filamentosa. For ground cover ...... per $1,000, \$ 10$.

200

\section{ROSES}

Page Hardy Roses (See page 58 for Each
varieties). 2-yr., fieldgrown ............... $\$ 025$

Prairie Roses. Baltimore Belle. Queen of the Prairies; Setigera. 2 to $3 \mathrm{ft}$. ......

5 to $6 \mathrm{ft} \ldots \ldots \ldots \ldots \ldots \ldots$

Crimson Rambler ..................

Extra strong................

Baby Rambler............... 50

Dorothy Perkins............. 40

Rosa Rugosa (Japanese Rose).

1 to $1 \frac{1}{2} \mathrm{ft}$., seedlings.......

$11 / 2$ to $2 \mathrm{ft}$...........

2 to $3 \mathrm{ft} . \ldots \ldots \ldots \ldots \ldots \ldots \ldots \ldots$

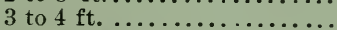

Rosa rugosa alba $\ldots \ldots \ldots \ldots \ldots \ldots$

Rosa rugosa Hybrids.

Belle Poitevine. Strong layers, 2 to $4 \mathrm{ft}$. Strong layers,

100
Blanc Double de Coubert. Strong layers, 2 to $4 \mathrm{ft}$.......... $\$ 030$

Madame Georges Bruant....... 40

Conrad Ferdinand Meyer....... 60

Roseraire de l'Hay........... 60

Sweebrier (Rosa rubiginosa) ... 25

Lord Penzance Hybrids, 6 varieties ................... 3 ј

Memorial Rose (Rosa Wichuraiana). 2 yr................

Wichuraiana Hybrids. Evergreen Gem, Gardenia, Jersey Beauty, Manda's Triumph, Pink Roamer, South Orange Perfection, Universal Favorite 2-yr....

Wild Rose (Rosa lucida)....... 25

$250 \quad 2000$ 1500 


\section{VINES}

\begin{tabular}{|c|c|c|c|c|}
\hline \multicolumn{3}{|c|}{ 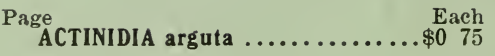 } & \multirow[t]{2}{*}{10} & \multirow[t]{2}{*}{100} \\
\hline & $\begin{array}{r}\text { AKEBIA quinata. } 2 \mathrm{ft} . \ldots \ldots \ldots \ldots \\
4 \mathrm{ft} . \ldots \ldots \ldots \ldots \ldots \ldots\end{array}$ & $\begin{array}{l}30 \\
50\end{array}$ & & \\
\hline & $\begin{array}{c}\text { BITTER SWEET, Japanese (Ce- } \\
\text { lastris articulata). } 3 \mathrm{ft} . .\end{array}$ & 25 & & \\
\hline & 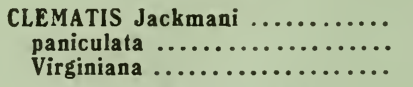 & $\begin{array}{l}50 \\
25 \\
25\end{array}$ & & \\
\hline & $\begin{array}{c}\text { DUTCHMAN'S PIPE (Aristolochia } \\
\text { Sipho). } 4 \mathrm{ft} . \ldots \ldots \ldots \ldots\end{array}$ & 100 & & \\
\hline & EUONYMUS radicans............ & 25 & $\$ 200$ & $\$ 1500$ \\
\hline & 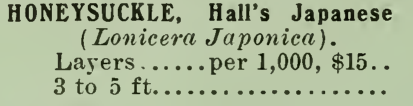 & 25 & & 200 \\
\hline & $\begin{array}{c}\text { Chinese }(L ., J a p o n i c a, \quad \text { var. } \\
\text { Chinensis }) \ldots \ldots \ldots \ldots \ldots \ldots\end{array}$ & 35 & , & \\
\hline & IVY, English (Hedera Helix).... & 35 & & \\
\hline & $\begin{array}{c}\text { Japanese, or Boston (Ampelop- } \\
\text { sis tricuspidata; syn., A. } \\
\text { Veitchii) } \ldots \ldots \ldots \ldots \ldots \ldots \\
\text { Larger plants } \ldots \ldots \ldots \ldots \ldots\end{array}$ & $\begin{array}{l}15 \\
25\end{array}$ & 100 & \\
\hline & $\begin{array}{r}\text { KUDSU VINE (Dolichos Japoni- } \\
\text { cus; syn., Pueraria Thun- } \\
\text { bergiana) ............... }\end{array}$ & 50 & & \\
\hline
\end{tabular}

Page

Roses.
57 TRUMPET CREEPER (Tacoma radicans; syn., Bignonia radicans). 1 to $2 \mathrm{ft} . \ldots . . \$ 025 \quad \$ 150$

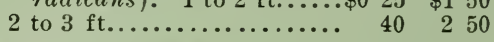

57 Chinese ( $T$. grandiflora: syn. B. Chinensis) .......... 75

58 VIRGINIA CREEPER (Woodbine; Ampelopsis quinquefolia).

A. heterophylla. We offer this excellent vine very cheap. Its healthy foliage quickly covers fences, pergolas, tree trunks and banks...

58 WISTARIA, Chinese (Kraunhia; Wistaria Chinensis).

$11 / 2$ to $2 \mathrm{ft} . \ldots \ldots \ldots \ldots \ldots \ldots . .20 \quad 175 \quad 1500$

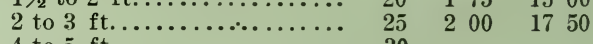

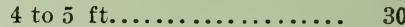

Tree form ............ $\$ 1$ to 500

58 White ( $W$. Chinensis, var. alba). 2 to $3 \mathrm{ft} . \ldots \ldots \ldots . . . .40$

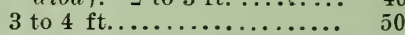

58 Japanese, or Loose clustered (W. multijnga). 11/2 to $2 \mathrm{ft}$. 60

400

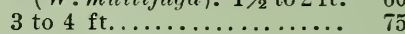

\section{HARDY GARDEN FLOWERS}

\begin{tabular}{|c|c|c|c|c|c|c|c|}
\hline $\begin{array}{l}\text { Page } \\
61 \text { ACHILLEA millefolium roseum..... }\end{array}$ & $\begin{array}{ll}\text { ach } \\
\\
12\end{array}$ & $\$ 100$ & $\$ 800$ & $\begin{array}{l}\text { Page } \\
62 \text { B 0LTONIA asteroides ....... }\end{array}$ & $\begin{array}{l}\text { ach } \\
12\end{array}$ & $\$ 100$ & $\$$ \\
\hline 61 Ptarmica flore pleno," The Pearl." & 12 & 100 & 800 & 62 CACTUS 0 puntia $\ldots \ldots \ldots \ldots \ldots$ & 15 & & \\
\hline Sibirica..$\ldots \ldots \ldots \ldots \ldots \ldots$ & 12 & 100 & 800 & 62 CAMPANULA persicifolia. Blue.. & 15 & 125 & \\
\hline 1 ADONIS vernalis.. & 25 & 200 & & persicifolia alba ................... & 15 & 125 & \\
\hline ALYSSUM saxatile compactum ... & 15 & 125 & 1200 & persicifolia Moerheimei ......... & 25 & 200 & \\
\hline AMSONIA tabernaemontana ...... & 15 & 125 & 1000 & 63 CASSIA Marylandica......... & 12 & 100 & 800 \\
\hline ANEMONE Japon & 15 & .125 & 1200 & 63 CENTAUREA macrocephala ...... & 15 & 125 & 1000 \\
\hline var."Queen Charlotte" & 15 & 125 & 1200 & 63 CERASTIUM tomentosum .... & 12 & 100 & 800 \\
\hline $\begin{array}{l}61 \text { Pennsylvanica. } \ldots \ldots \ldots \ldots \ldots \ldots \\
61 \text { ANTHEMIS tinctoria (Chamomile; }\end{array}$ & 12 & 100 & 800 & & & & \\
\hline $\begin{array}{l}\text { Golden Marguerite)........ } \\
\text { AQUILEGIA co o rulea (Rocky } \\
\text { Mountain Columbine)...... }\end{array}$ & 15 & 125 & 1200 & $\begin{array}{l}\text { following varieties of white, } \\
\text { pink, red and yellow: Prince } \\
\text { of Wales, Anna Mary, Eagle } \\
\text { d'0r, Princess Louise, Julia }\end{array}$ & & & \\
\hline chrysantha $\ldots \ldots \ldots \ldots \ldots \ldots$ & 15 & 125 & 1200 & $\begin{array}{l}\text { Lagravere, Rhoda, St. Illoria, } \\
\text { Little Pet......................... }\end{array}$ & 15 & 125 & 1200 \\
\hline 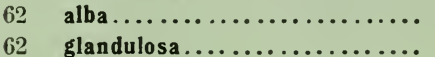 & $\begin{array}{l}15 \\
15\end{array}$ & $\begin{array}{l}125 \\
125\end{array}$ & $\begin{array}{ll}12 & 00 \\
12 & 00\end{array}$ & The Old-fashioned Tiny Yellow & & & \\
\hline $\begin{array}{l}\text { glandulosa } \ldots \ldots \ldots \ldots \ldots \ldots \ldots \ldots \\
\text { Hybrids } \ldots \ldots \ldots \ldots \ldots \ldots \ldots \ldots\end{array}$ & 15 & $\begin{array}{l}120 \\
125\end{array}$ & 1200 & (........... & 12 & 100 & 8 \\
\hline $\begin{array}{l}\text { ARMERIA plantaginea (Thrift, or } \\
\text { Sea Pink) ............................ }\end{array}$ & 15 & 125 & 1000 & 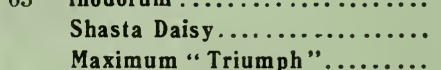 & $\begin{array}{l}15 \\
15 \\
15\end{array}$ & $\begin{array}{l}125 \\
125 \\
125\end{array}$ & 1000 \\
\hline $\begin{array}{r}2 \text { ARTEMISIA Abrotanum (South- } \\
\text { ernwood) ................... } \\
\text { ASCLEPIAS incarnata (Butterfly }\end{array}$ & 15 & 125 & 1000 & $\begin{array}{l}63 \text { CLEMATIS Davidiana } \ldots \ldots \ldots \ldots \ldots \\
63 \quad \text { recta } \ldots \ldots \ldots \ldots \ldots \ldots \ldots \ldots\end{array}$ & $\begin{array}{l}25 \\
25\end{array}$ & $\begin{array}{ll}2 & 00 \\
2 & 00\end{array}$ & $\begin{array}{l}1800 \\
1800\end{array}$ \\
\hline 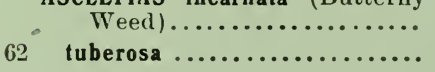 & $\begin{array}{l}15 \\
15\end{array}$ & $\begin{array}{l}125 \\
125\end{array}$ & & $\begin{array}{c}63 \text { CONVALLARIA (Lily - of - the- } \\
\text { Valley). Clumps............ }\end{array}$ & 15 & 125 & 1200 \\
\hline 2 ASTER grandiflorus . ............... & 25 & 200 & & 63 CORE0PSIS lanceolata . ........... & 15 & 125 & . \\
\hline Novae-Angliae................ & 15 & 125 & 1200 & 64 DAPHNE Cneorum ......50 ets. to & 75 & & \\
\hline Tataricus................... & 15 & 125 & 100 & & 15 & & 12 \\
\hline 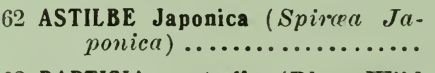 & 20 & 150 & & & 15 & $\begin{array}{l}125 \\
125\end{array}$ & $\begin{array}{l}1200 \\
1200\end{array}$ \\
\hline $\begin{array}{l}62 \text { BAPTISIA australis (Blue Wild } \\
\text { Indigo) }\end{array}$ & 15 & 150 & 1000 & Kelway's Hybrids ............. & 20 & 150 & 1500 \\
\hline $\begin{array}{l}\text { 32 BELEMCANDA Chinensis (Black- } \\
\text { berry Lily) ....................... }\end{array}$ & 12 & 100 & & $\begin{array}{l}64 \text { Chine } \\
64 \text { delica }\end{array}$ & $\begin{array}{l}12 \\
12\end{array}$ & 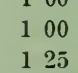 & $\begin{array}{rr}800 \\
1200\end{array}$ \\
\hline 2 BELLIS perennis (English Daisy). & 12 & 100 & 800 & 64 & 15 & 125 & 1200 \\
\hline $\begin{array}{r}2 \text { BoCconia cordata (Plume Pop- } \\
\text { py }) . \ldots \ldots \ldots \ldots \ldots \ldots \ldots \ldots\end{array}$ & 12 & 100 & & $\begin{array}{l}\text { plumarius } \ldots \ldots \ldots \ldots \ldots \ldots \ldots \\
\text { barbatus }(\text { Sweet William)..... }\end{array}$ & $\begin{array}{l}12 \\
12\end{array}$ & $\begin{array}{l}100 \\
100\end{array}$ & $\begin{array}{ll}8 & 00 \\
8 & 00\end{array}$ \\
\hline
\end{tabular}




\section{HARDY GARDEN FLOWERS, continued}

\begin{abstract}
Page
(i) DICENTRA spectabilis (Bleeding
Heart) $\ldots \ldots \ldots \ldots \ldots \ldots \ldots \ldots$..............
64 eximia

DIGITALIS

6t alba...

(it D 0 R 0 N IC UM plantagineum ex.

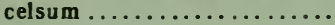

64 EUPATORIUM coelestinum.

64 EUPHORBIA corollata (Flowering Spurge).................

64 FESTUCA glauca.............

65 FUNKIA ovata (Blue Day Lily)..

65 subcordata (Thite Day Lily)..

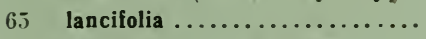

65 lancifolia, rar. variegata ......

65 GAILLARDIA aristata (Blanket Flower) .................

65 GERANIUM sanguineum........

65 GEN T I A N A Andrewsii (Closed Gentian) ................

65 GYPSOPHILA paniculata (Baby's

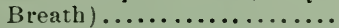

$$
\text { repens }
$$
\end{abstract}

Each

$\$ 0 \quad 25 \$ 200$

(Foxglove) ... 15 1 , 1500

$20 \quad 150$

65 HELENIUM autumnale superbum (Sneczeweed).............

65 HELIANTHUS Maximiliana (Sunflower $\ldots \ldots \ldots \ldots \ldots \ldots \ldots$.

65 mollis $\ldots \ldots \ldots \ldots \ldots \ldots \ldots \ldots$

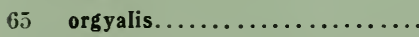

65 HELIOPSIS Iaevis, var. Pitcheriana.

65 HEMEROCALLIS flava..........

65 fulva (Tawny Day Lily)......

65 fulva fI. pl., var. Kwanso.......

Dumortierii ...

FIorham

65 HIBISCUS Moscheutos ..........

65 Moscheutos, Crimson Eye.....

6.) HOLLYHOCK (Althat rosea) ....

66 IRIS Germanica (German Iris)-

Florentina (Orris Root) .....

Mme. Chereau............

spectabilis ...............

Walnerii. .... per $1,000, \$ 50 \ldots$

No. $1 \ldots \ldots \ldots \ldots \ldots \ldots \ldots$.

No. $2 \ldots \ldots \ldots \ldots \ldots \ldots \ldots$

No. $3 \ldots \ldots \ldots \ldots \ldots \ldots \ldots$

No. 4 .................

No. $5 . \ldots \ldots \ldots \ldots \ldots \ldots$.

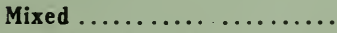

vigata (Kaempferi) (Japanese Iris) -

Named Varieties............

Fine Mixed

66

cristata (Early Iris) $.1,000, \$ 40$.

For Ground Cover..........

pumila hybrida $=$

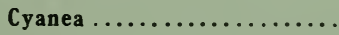

Eburna .................

florida ................

formosa ...............

Sibirica (Siberian Iris) .......

Sibirica alba ...............

66

$\begin{array}{lllll}15 & 125 & 12 & 00\end{array}$
$15 \quad 125 \quad 1200$

$15 \quad 125 \quad 1200$

15

$15 \quad 125 \quad 1200$

$20 \quad 150$

$15 \quad 125$

$15125 \quad 1200$

$12 \quad 100 \quad 800$

$20 \quad 150$

15 125

$15 \quad 125$

$15 \quad 125 \quad 1000$

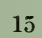

15

$15 \quad 125$

15125

$15 \quad 125$

$15 \quad 125$

$15 \quad 125$

15 1 125

$50 \quad 450$

$15 \quad 125$

$15 \quad 125$

$15 \quad 125$

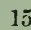

15

15

15

15

15125

$15 \quad 125$

$15 \quad 125$

$15 \quad 125$

12100

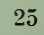

15

12

20

20

20
20

12
15

15
15

1200

1200

1200

800

800

1500

1500

$175 \quad 1500$

175

100

125

125
800
Page

PfPHOFIA
Flower; Tritoma; Red-Hot

Poker Plant.............\$0 $20 \quad \$ 150$

66 LESPEDEZA Sieboldii; syn., Desmodium penduliflorum.... 35

LIATRIS pycnostachya (Button Snakeroot) $\ldots \ldots \ldots \ldots \ldots \ldots$.

scariosa ................. $15 \quad 125$

spicata (Devil's Bit)........ $15 \quad 125$

66 LILIUM candidum (Annunciation Lily)...................

66 tigrinum (Tiger Lily) ........ auratum (Japanese GoldenBanded Lily)............. speciosum album........... rubrum, or roseum

67 LYCHNIS Chalcedonica (Maltese Cross, or Scarlet Lightuing)

67 coronaria (Mullein Pink; Rose Campion)...............

67 Flos-cuculi (Ragged Robin)...

MENTHA (Mint)

67 MISCANTHUS Sinensis (Eulalia Japonica) ...............

67 MONARDA didyma (Oswego Tea ; Bee Balm)................

67 MYOSOTIS (Forget-me-not).....

67 NARCISSUS Pseudo - Narcissus (Common Double Dafforil).

67 incomparabilis ..............

67 poeticus (Poets' Narcissus'...

OENOTHERA Lamarkiana. (Evening Primrose $) \ldots \ldots \ldots \ldots \ldots$.

67 PAEONHA Sinensis-

Named varieties ............ 50 450

Named colors.............. $25 \quad 200$

67 officinalis................ $30 \quad 250$

67 Moutan (Tree Peony)........ $125 \quad 1000$

67 PAPAVER nudicaule (Iceland Poppy) .............. $15 \quad 125$

67 orientale (Oriental Poppy) ......

67 PARADISEA Liliastrum (St. Bruno Lily) ............... $12 \quad 100$

67 PE N T S T E M N Darbatus, var.

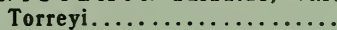

67 PHLOX decussata, or paniculata. .

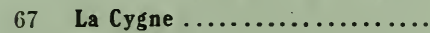

Bridesmaid

Coquelicot

Eclaireur

67 General Chanzy ............ $20 \quad 180$

67 Fiancee................. $20 \quad 180$

Le Soleil ................. $20 \quad 180$

Lemoine.................. $20 \quad 180$

Miss Lingard ............ $20 \quad 180$

William Ramsay............ $20 \quad 180$

decussata, Mixed........... $12 \quad 100$

67

reptans.................. $12 \quad 100$

1500

800

800

subulata (Moss Pink) ........

subulata atropurpurea ........ per $1,000, \$ 30 \ldots .612 \quad 100 \quad 600$

68 subulata alba...per $1,000, \$ 40$.. subulata Lilacina.

subulata rosea $\ldots \ldots \ldots \ldots \ldots \ldots$

subulata. Deeper red........ 


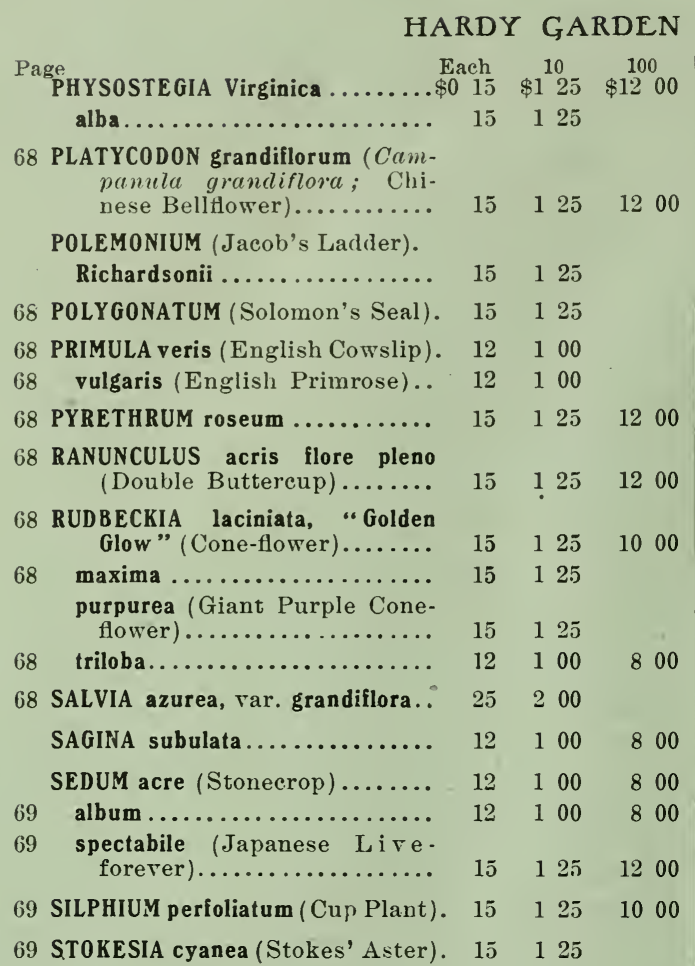

FLOWERS, continued

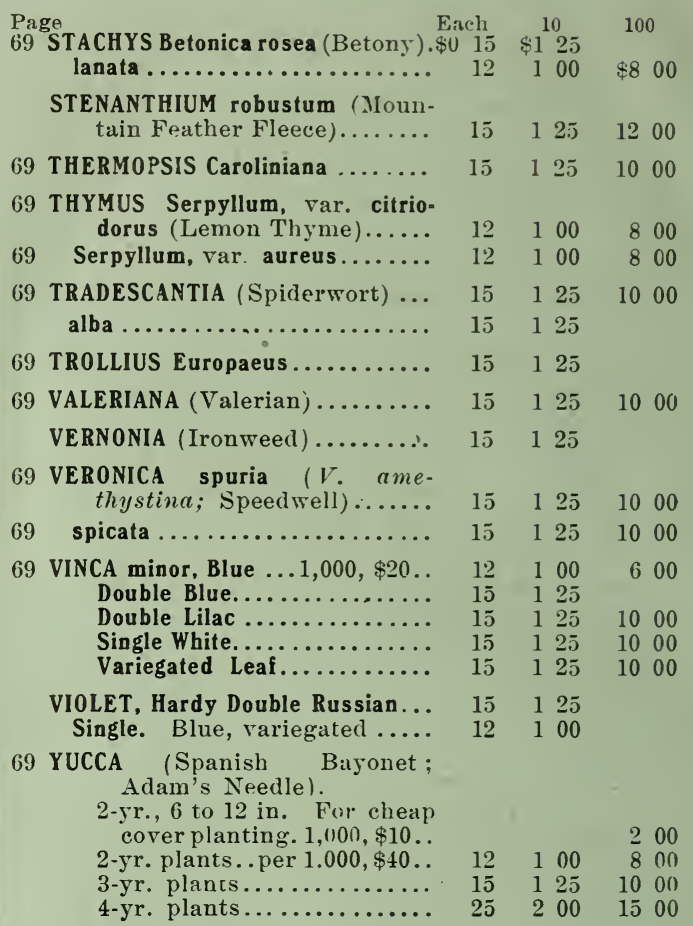

\section{ISAAC HICKS AND SON}

LARGE TREE MOVERS

WESTBURY NURSERIES

Westbury Station, Nassau Co., N. Y.

TELEPHONE, 76 W. WESTBURY 
, 
TRESE FOK LOWTE ISLAWD ISAAC GICKS \& SOX LAREESTRE NOVERS

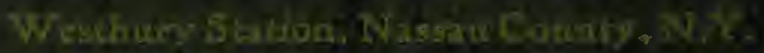

